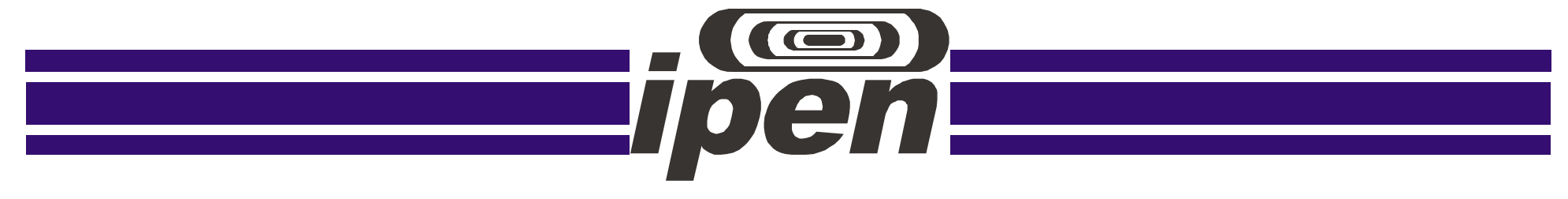

AUTARQUIA ASSOCIADA À UNIVERSIDADE DE SÃO PAULO

Analyses of Planetary Boundary Layer from Remote Sensing Systems

Gregori de Arruda Moreira

Tese apresentada como parte dos
requisitos para obtenção do Grau de
Doutor em Ciências na Área
de Tecnologia Nuclear-Materiais
Orientador:
Prof. Dr. Eduardo Landulfo

Prof. Dr. Lucas Alados Arboledas

São Paulo 


\section{INSTITUTO DE PESQUISAS ENERGÉTICAS E NUCLEARES}

Autarquia associada à Universidade de São Paulo

\section{Analyses of Planetary Boundary Layer from Remote Sensing Systems}

Gregori de Arruda Moreira

Tese apresentada como parte dos
requisitos para obtenção do Grau de
Doutor em Ciências na Área
de Tecnologia Nuclear-Materiais

Orientador:

Prof. Dr. Eduardo Landulfo

Prof. Dr. Lucas Alados Arboledas

\section{Versão Corrigida}

São Paulo

2018 
Dedico este trabalho a todos que participaram direta elou indiretamente no processo de construção. 



\section{Agradecimentos}

Eu agradeço primeiramente a Deus pela inspiração e força para resistir aos duros obstáculos dos processos de aprendizagem. Agradeço aos meus pais, irmãos e a querida Greyse, por terem me aturado durante vários anos.

Agradeço aos meus amigos e orientadores Eduardo Landulfo e Lucas Alados Arboledas, por todo apoio moral, intelectual e paciência durante todo o processo de criação deste trabalho. Sem eles tal projeto jamais seria concluído.

Agradezco a todos mis amigos y compañeros de trabajo: Fábio, Juanlu, Márcia, Jonatan, Antonio, Pablo, Jose, Andres, Hassan, Gloria, Alberto, Roberto, Juan Antonio, Fran y Paco Pepe, por toda la ayuda. En este trabajo hay poco de cada uno de vosotros.

Agradeço ao $\mathrm{CNPq}$ pelo apoio financeiro nos programas ciências sem fronteiras (Chamada 2015) e bolsa de doutorado (Chamada 2017). 

Oro mi má

Oro mi maió

Oro mi maió

Yabado oyeyeo

(Antiga canção Yourbá) 


\section{Summary}

1

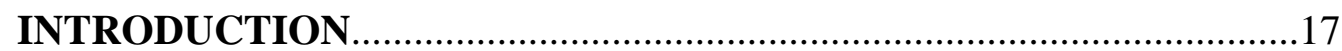

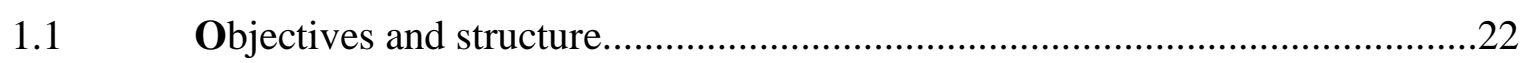

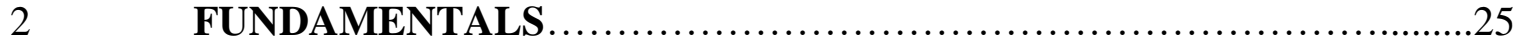

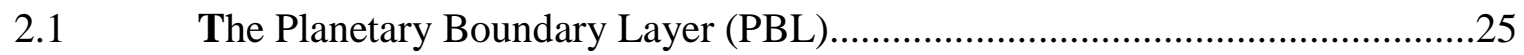

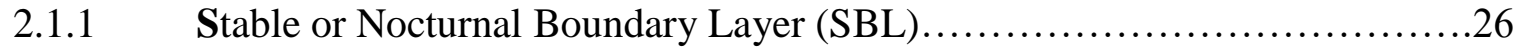

2.1.2 Convective Boundary Layer (CBL) ...................................27

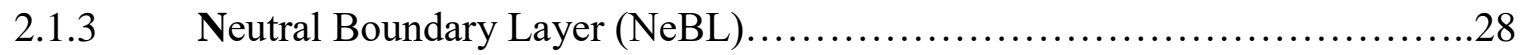

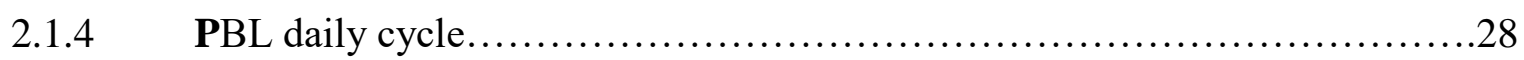

2.1.5 Planetary Boundary Layer Height (PBLH) .............................. 30

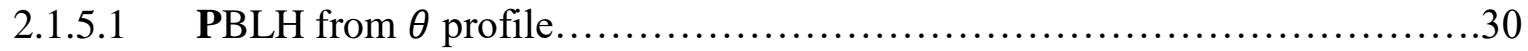

2.1.5.2 PBLH from $w$ profile.............................................. 31

2.1.5.3 PBLH from vertical aerosol concentration.................................. 32

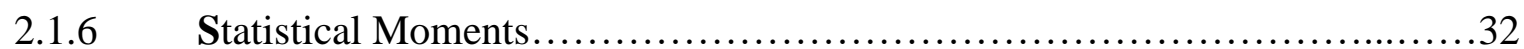

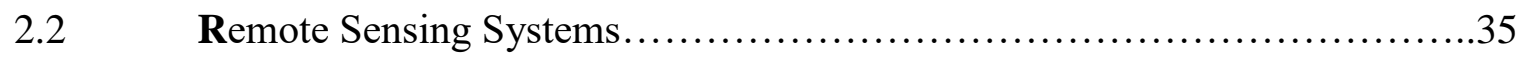

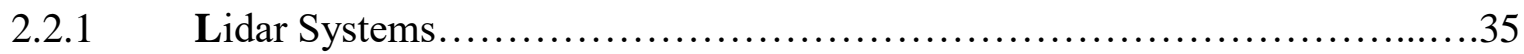

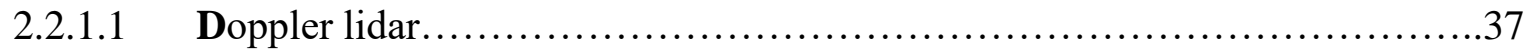

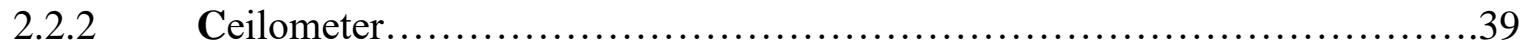

2.2.3 Passive Microwave Radiometer (MWR) .............................. 39

2.2.4 Pyranometer...............................................................

3 EXPERIMENTAL SITE AND INSTRUMENTS .......................42

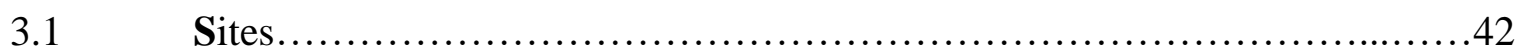

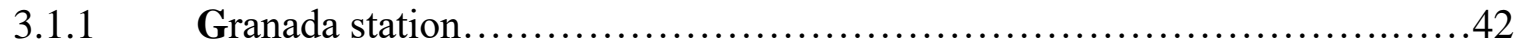

S.1.2 São Paulo station................................................... 44

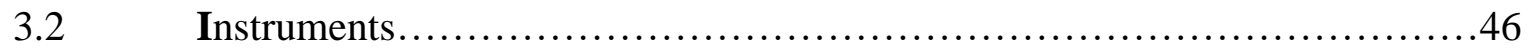

3.2.1 $\quad$ Lidar................................................................. 46

3.2.1.1 Multiwavelength elastic-raman lidar...................................46 


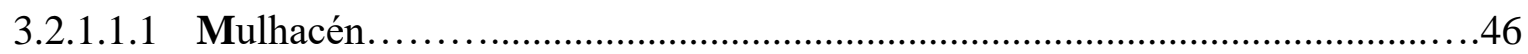

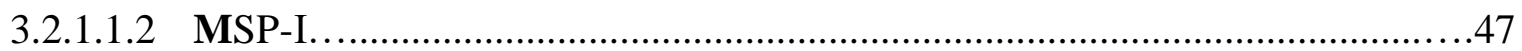

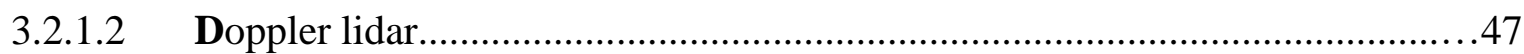

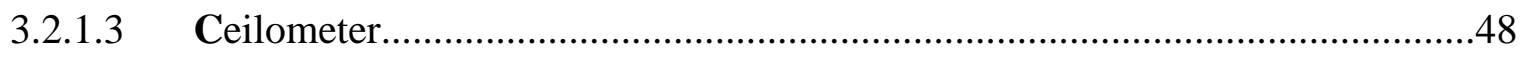

3.2.2 MWR

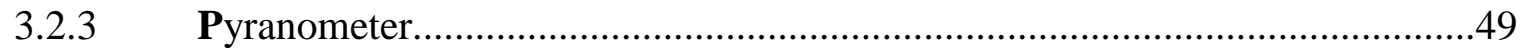

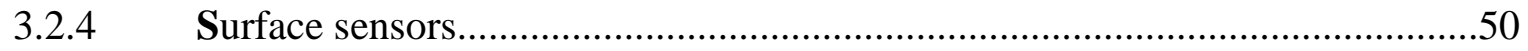

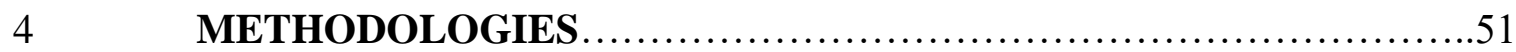

4.1 PBLH Detection.................................................. 51

4.1.1 MWR: MWR Method................................................ 51

4.1.2 Doppler lidar: Variance threshold method................................53

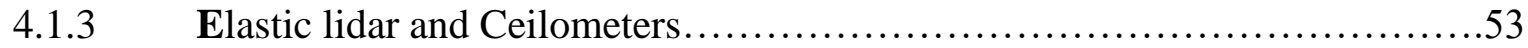

4.1.3.1 Ceilometer: Gradient method.........................................54

4.1.3.2 Elastic lidar: Extended Kalman Filter (EKF) method.......................55

4.2 Lidar turbulence analysis................................................

5 STUDY OF THE PLANETARY BOUNDARY LAYER BY MWR,

ELASTIC LIDAR AND DOPPLER LIDAR ESTIMATIONS ....................63

$5.1 \quad$ Statistical Parameters..................................................63

5.2 MWR and radiosonde PBL intercomparison...........................64

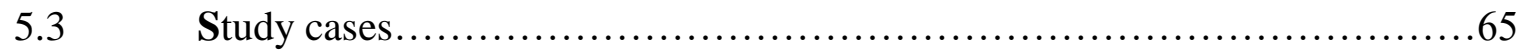

5.3.1 Well-defined PBL case.............................................65

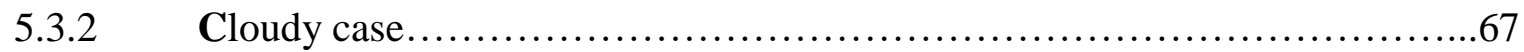

S.3.3 Saharan dust case ...................................................69

$5.4 \quad$ Statistical analysis.................................................. 71

6 STATISTICAL STUDY OF THE PLANETARY BOUNDARY LAYER

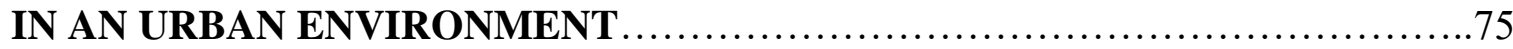

6.1 Variables to long term analysis....................................... 75

6.2 Comparative case studies: $\boldsymbol{P B} \boldsymbol{L} \boldsymbol{H}_{\boldsymbol{M W R}}$ and $\boldsymbol{P B} \boldsymbol{L} \boldsymbol{H}_{\text {ceilometer }} \ldots \ldots \ldots \ldots \ldots . \ldots \ldots$

6.2.1 Case Study I - Sample days.......................................... 76

6.2.2 Case Study II - Saharan Dust......................................... 78

6.3 PBL long term analysis .............................................

6.3.1 Study of the PBL based on MWR .................................... 79

6.3.2 Meteorological variables affecting the PBL............................... 89 
6.3.3 Study of the PBL based on ceilometer: Searching on the Residual Layer......91

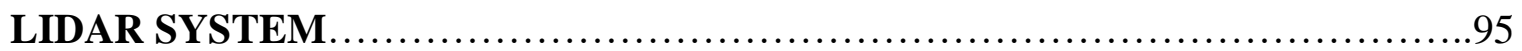

7.1 Wavelength comparison in studies about turbulence.......................95

Case studies............................................................ 102

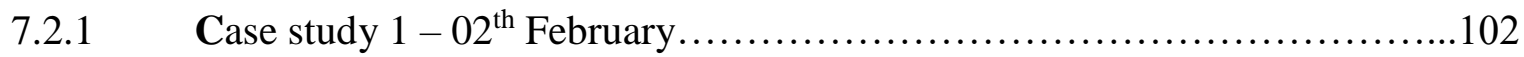

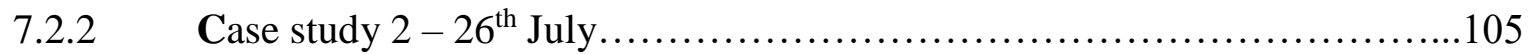

8 ANALYZING THE TURBULENCE IN PBL BY REMOTE SENSING

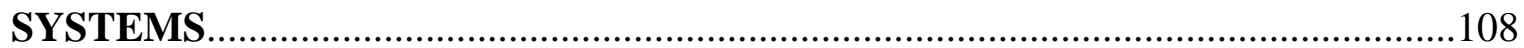

$8.1 \quad$ Error Analysis.......................................................... 108

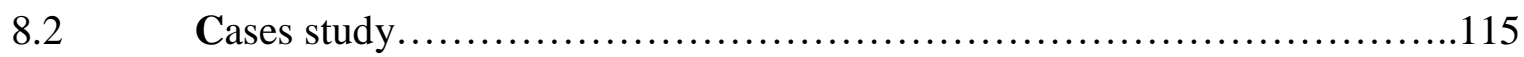

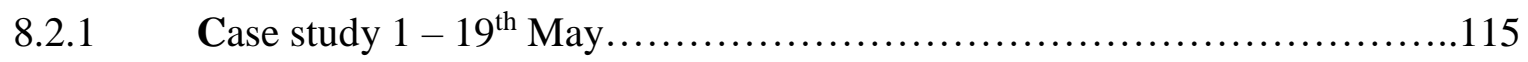

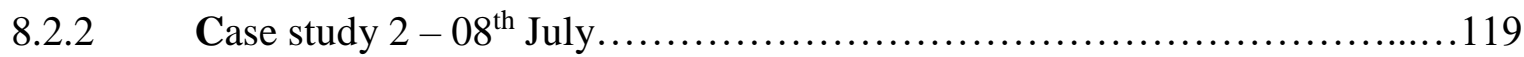

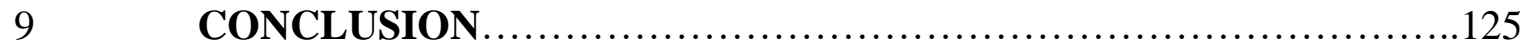

$9.1 \quad$ Sugestions for future work ......................................... 128

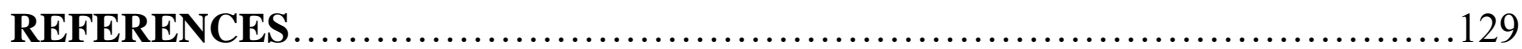




\section{Abstract}

The Planetary Boundary Layer $(P B L)$ is a relevant part of the atmosphere with a variable extension that clearly plays an important role in fields like air quality or weather forecasting. Passive and active remote sensing systems have been widely applied to analyze $P B L$ characteristics. The combination of different remote sensing techniques allows obtaining a complete picture on the PBL dynamic. In this study, we analyze the $P B L$ behavior using four types of remote sensing systems: Microwave Radiometer $(M W R)$, Elastic Lidar $(E L)$, Doppler Lidar $(D L)$ and Ceilometer data. The measurements were performed in two cities Granada (Spain) and São Paulo (Brazil).

Firstly, at Granada, the PBL height $(P B L H)$ obtained from $M W R$ data is validated against $P B L H$ provided by analyzing co-located radiosondes, showing a good agreement. In a second stage, active remote sensing systems were used for deriving the $P B L H$. Thus, Extended Kalman filter is applied to EL data while the vertical wind speed variance method was applied to the $D L$. The derived $P B L H^{\prime} S$ by these approaches are compared to $P B L H$ retrieved by the $M W R$. The results show a good agreement among the retrievals based on active remote sensing in most of the cases, although some discrepancies appear in instances of intense $P B L$ changes (either growth and/or decrease).

Then it is performed the analysis of four and five-year dataset of measurements gathered with a ceilometer and a microwave radiometer, respectively, at Granada. The methodologies applied for the $P B L H$ detection (gradient method for ceilometer and the combination of parcel method and temperature gradient method for microwave radiometer) provided a satisfactory description of the $P B L$ structure in simple cases. In addition, the $P B L$ behavior is characterized by a statistical study of the convective and stable PBLH obtained from microwave radiometer measurements. The analysis of the $P B L H$ statistical study shows some coincidence with other $P B L H$ studies such as daily pattern, and year cycles but also some differences caused by distinct latitudes, topography and climate were found. It was performed as well a combined long-term analysis of Ceilometer retrieved Residual Layer and the Stable and Convective Layer heights determined by microwave radiometer, thus offering a complete picture of the $P B L$ evolution by synergetic combination of remote sensing techniques. This is 
the reason why systems with high temporal and spatial resolution, like lidars, have been increasingly applied in studies about this atmospheric region.

In this work, also was performed, at São Paulo, an analysis on lidar backscattered signal at three wavelengths $(355,532$ and $1064 \mathrm{~nm})$ retrieving the turbulence by the analyses of the high-order moments (variance, skewness and kurtosis) in the backscattered signal. The wavelength of $355 \mathrm{~nm}$ has low applicability in the proposed methodology, due to its low intensity (due to predominance of molecular backscattering) and large presence of noise, while the $532 \mathrm{~nm}$ wavelength showed results similar to those provided by the wavelength of 1064 $\mathrm{nm}$, which was used as reference. Then, it was analyzed two case studies using the wavelengths of 532 and $1064 \mathrm{~nm}$ (in separately). This approach provided information about $P B L$ height, (derived by the variance method (Menut et al., 1999), displacement of aerosol layers (skewness) and level of mixing at several heights (kurtosis). These results show the viability of the proposed methodology when the wavelengths of 532 and $1064 \mathrm{~nm}$ are used for the $P B L$ description by high-order moments of the backscattered distribution.

Furthermore, it is demonstrated how some variables (air temperature, aerosol concentration, vertical wind, relative humidity and net radiation) can influence the $P B L$ dynamic with data from DL, EL and MWR at Granada. The high-order moments of the vertical velocity high frequency distributions derived from $D L$, and EL range corrected signal, were corrected by two methodologies (first lag and $-2 / 3$ correction). The corrected profiles present small differences when compare against the uncorrected profiles, showing low influence of noise and the viability of the proposed methodology. A detailed 2-case studies analysis was carried on, the first case corresponding to a well-defined $P B L$ while the second one corresponds to a situation with presence of an aloft Saharan dust layer and clouds. In both cases the results provided by the different instruments ended up complementing one another, so that the synergistic use of the different systems allowed us a detailed monitoring of the $P B L$.

Keywords: Turbulence, Planetary Boundary Layer, Remote Sensing, lidar. 


\section{Resumo}

A Camada Limite Planetária (PBL - Planetary Boundary Layer) é uma parte relevante da atmosfera com uma extensão variável e que claramente desempenha um papel importante em áreas de estudo, como: a qualidade do ar ou a previsão do tempo. Sistemas de sensoriamento remoto passivo e ativo têm sido amplamente utilizado para analisar as características da PBL. A combinação de diferentes técnicas de sensoriamento remoto permite obter uma imagem completa da dinâmica desta camada. Neste estudo, analisamos o comportamento da PBL utilizando quatro tipos de sistemas de sensoriamento remoto: Radiômetro de Micro-ondas (MWR), Lidar Elástico (EL), Lidar Doppler (DL) e Ceilômetro. As medições foram realizadas em duas cidades, Granada (Espanha) e São Paulo (Brasil).

Primeiramente, em Granada, a altura da PBL (PBLH) obtida a partir dos dados do MWR foi validada pela PBLH gerada pela análise dos dados de radiossondas, mostrando uma boa concordância. Em um segundo estágio, sistemas ativos de sensoriamento remoto foram usados para a obtenção da PBLH. Assim, o método do filtro de Kalman foi aplicado aos dados do EL enquanto o método da variância da velocidade vertical do vento foi aplicado aos dados do DL. As PBLH derivadas dessas abordagens foram comparadas com o PBLH fornecida pelo MWR, sendo que os resultados mostram uma boa concordância na maioria dos casos, embora algumas discrepâncias apareçam nas situações de mudanças intensas da PBL (crescimento e/ou diminuição).

Em seguida, é realizada a análise dos dados das medidas coletadas com um ceilômetro e um radiômetro de micro-ondas durante quatro e cinco anos, respectivamente, em Granada. As metodologias aplicadas para a detecção da PBLH (método de gradiente para o ceilômetro e a combinação do método de parcela e do método de gradiente de temperatura para o radiômetro de micro-ondas) forneceram uma descrição satisfatória da estrutura da PBL em casos simples. Além disso, o comportamento da PBL foi caracterizado por um estudo estatístico das PBLH convectiva e estável, as quais foram obtidas a partir das medidas do radiômetro de micro-ondas. A análise do estudo estatístico realizado para a PBLH mostra algumas coincidências com outros estudos já realizados para a mesma variável, como o padrão diário e os ciclos anuais. Mas também há algumas diferenças, as quais são causadas por latitudes, topografia e clima distintos. 
Foi realizada também uma análise combinada de longo prazo da Camada Residual (gerada pelos dados do Ceilômetro) e da Camada Estável e Convectiva (obtida pelos dados do radiômetro de micro-ondas), oferecendo assim um quadro completo da evolução da PBL por combinação sinérgica de técnicas de sensoriamento remoto. Essa é a razão pela qual sistemas com alta resolução temporal e espacial, como os lidars, têm sido cada vez mais aplicados em estudos sobre essa região atmosférica.

Neste trabalho, também foi realizada, em São Paulo, uma análise do sinal retroespalhado em três comprimentos de onda $(355,532$ e 1064 nm), o qual provê informações da turbulência através da análise dos momentos de alta ordem (variância, assimetria e curtose). O comprimento de onda de $355 \mathrm{~nm}$ apresenta pouca aplicabilidade na metodologia proposta, devido à sua baixa intensidade (por conta da predominância do retroespalhamento molecular) e grande presença de ruído, enquanto o comprimento de onda de $532 \mathrm{~nm}$ apresentou resultados semelhantes aos fornecidos pelo comprimento de onda de $1064 \mathrm{~nm}$, o qual foi usado como referência. Em seguida, foram analisados dois estudos de caso utilizando os comprimentos de onda de 532 e $1064 \mathrm{~nm}$ (em separado). Essa abordagem forneceu informações sobre a altura da PBL (derivada pelo método de variância (Menut et al., 1999), deslocamento de camadas de aerossol (assimetria) e nível de mistura em várias alturas (curtose), mostrando a viabilidade da metodologia proposta, quando os comprimentos de onda de 532 e 1064 nm são usados para a descrição da PBL a partir dos momentos de alta ordem.

Além disso, demonstrou-se, com dados de DL, EL e MWR obtidos em Granada, como algumas variáveis (temperatura do ar, concentração de aerossóis, vento vertical, umidade relativa e radiação líquida) podem influenciar a dinâmica da PBL. Os momentos de alta ordem das distribuições de velocidade vertical derivadas dos dados do DL e o sinal retroespalhado obtido a partir do EL foram corrigidos por duas metodologias (first lag e correção de -2/3). Os perfis corrigidos apresentam pequenas diferenças quando comparados com os perfis não corrigidos, mostrando baixa influência do ruído e a viabilidade da metodologia proposta. Foi realizada uma análise detalhada de dois estudos de casos, o primeiro correspondendo a uma PBL bem definida, enquanto o segundo corresponde a uma situação com a presença de uma camada de nuvens e poeira saariana. Em ambos os casos, os resultados fornecidos pelos diferentes instrumentos acabaram se complementando, de modo que o uso sinérgico dos diferentes sistemas nos permitiu um monitoramento detalhado da PBL.

Palavras Chave: Turbulência, Camada Limite Planetária, Sensoriamento Remoto, lidar. 


\section{List of Figures}

Figure 1.1 - Total annual anthropogenic Green House Gases (GHG) emissions by gases.

Source: IPCC - AR5 ..................................................... 17

Figure 1.2 - Impacts attributed to climate change. Source: IPCC - AR5 ................18

Figure 2.1: Radiative flux at surface - (a) day (b) night. $R_{n}$ (net radiative flux), $F_{H s}$ (sensible heat flux), $F_{E S}$ (latent heat flux), $F_{G S}$ (conduction of heat down into the ground). Source: Adapted from WALLACE et al., 2005........................................26

Figure 2.2: Idealized $\theta$ profile of SBL. Source: Adapted from STULL, 1988..............27

Figure 2.3: Idealized $\theta$ profile of CBL. Source: Adapted from STULL, 1988_..............28

Figure 2.4: Idealized $\theta$ profile of NeBL. Source: Adapted from STULL, 1988.............28

Figure 2.5: Idealized PBL daily cycle. Source: Adapted from STULL, $1988 \ldots \ldots \ldots \ldots \ldots \ldots . . .29$

Figure 2.6: PBLH detected by Parcel Method. Potential Temperature (left) and Temperature

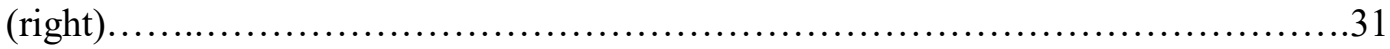

Figure 2.7: PBLH detected by Temperature Gradient Method from SBI and TSL height. Temperature (left), Potential Temperature (center) and Gradient of Potential Temperature

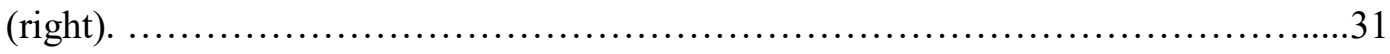

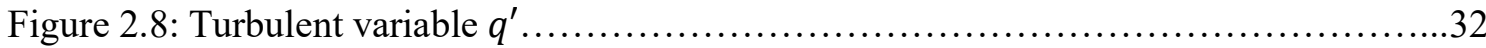

Figure 2.9: Skewness. Source: Own author.....................................33

Figure 2.10: Kurtosis. Source: Own author....................................... 34

Figure 2.11: Representation of a lidar system. Source: Adapted from...................................36

Figure 2.12: Lidar systems classified by its physical process. Yellow stars indicate the lidar

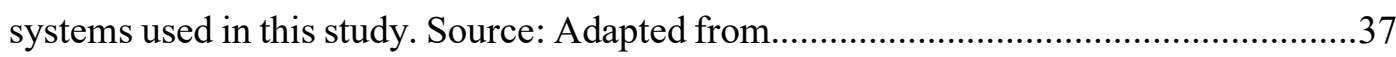

Figure 2.13: Doppler lidar emission and frequency shifting. Source: Own author............38

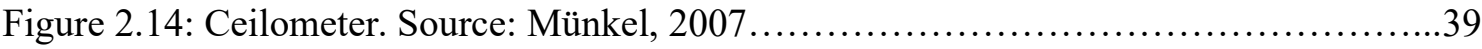


Figure 2.15: Schematic internal structure of a MWR. Source: Adapted from Kunzi et al., 2011 .40

Figure 2.16: Pyranometer. Source: Woodford, 2017 .41

Figure 3.1 - IISTA-CEAMA. Source: Own author. .43

Figure 3.2 - IPEN-CLA. Source: Own author. .44

Figure 3.3 - MULHACÉN. Source: Own author......................................46

Figure 3.4 - MSP-I. Source: Own author..........................................47

Figure 3.5 - Doppler lidar. Source: Own author....................................47

Figure 3.6 - Ceilometer. Source: Own author.......................................48

Figure 3.7 - MWR. Source Own author...........................................49

Figure 3.8 - Pyranometer. Source Own author....................................49

Figure 3.9 - Surface sensors. Source: Own author...................................50

Figure 4.1 - Combination of two methods to detect PBLH based on Temperature Profile.

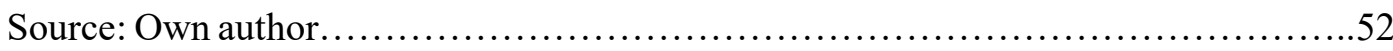

Figure 4.2: Corrections applied on $P(z)$ to obtain $\operatorname{RCS}(z)$. Source: Own author.............54

Figure 4.3- Idealized lidar profile. The pair $R_{1}^{\prime}$ and $R_{2}^{\prime}$ defines the length limit of the observation vector applied in the filter. $R_{1}$ and $R_{2}$ represent the limits of the erf-like PBL transition zone. $R_{b l}$ is the PBLH guest, $\beta_{m o l}$ is the average value of molecular signal, $\beta_{a e r}$ is the signal obtained from aerosol backscattering, $\mathrm{d}$ is a scaling factor to entrainment zone thickness and $A$ is the amplitude of the erf transition. Source: Own author. .56

Figure 4.4 - Procedure to remove the errors of autocovariance functions. $M_{11}(\rightarrow 0)$ - corrected autocovariance function errors; $M_{11}(0)$ - autocovariance function without correction; $\Delta M_{11}(0)$ - error of autocovariance function. Source: Own author

Figure 4.5- Flowchart of data analysis methodology applied to the study of turbulence with Doppler lidar. Source: Own author. .59

Figure 4.6 - Flowchart of data analysis methodology applied to the study of turbulence with elastic lidar. Source: Own author 
Figure 4.7 - Flowchart of data analysis methodology applied to the study of turbulence with elastic lidar. Source: Own author. .62

Figure 5.1 - Temporal evolution of RCS profile and PBLH provided by MWR (pink stars), elastic (green stars) and Doppler lidar (black stars) .66

Figure 5.2 - Temporal evolution of $\triangle P B L H_{\text {Doppler }-M W R}$ (blue bars) and $\triangle P B L H_{\text {Doppler-MWR }}$ (orange bars). .66

Figure 5.3 - Temporal evolution of RCS profile and PBLH provided by MWR (pink stars), elastic (green stars) and Doppler lidar (black stars)....

Figure 5.4 - Temporal evolution of $\triangle P B L H_{\text {Doppler }-M W R}$ (blue bars) and $\triangle P B L H_{\text {Doppler }-M W R}$ (orange bars).

Figure 5.5 - Temporal evolution of RCS profile and PBLH provided by MWR (pink stars), elastic (green stars) and Doppler lidar (black stars)....

Figure 5.6 - Temporal evolution of $\triangle P B L H_{\text {Doppler }-M W R}$ (blue bars) and $\triangle P B L H_{\text {Doppler-MWR }}$ (orange bars)

Figure 5.7 - Average values of PBLH provided by MWR (pink stars), elastic (green stars) and Doppler lidar (black stars) .72

Figure 5.8 - Statistical comparison between the daily patterns of $P B L H_{M W R}$ and $P B L H_{\text {elastic }}$ obtained during all SLOPE-I campaign. Each bin size is equivalent to 30 minutes. $\triangle P B L H_{D o p p l e r-M W R}^{\%}, R M S E, R$ and $D$ represents average percentage difference, root mean square error, correlation index and index of agreement, respectively. .73

Figure 5.9 - Statistical comparison between the daily patterns of $P B L H_{M W R}$ and $P B L H_{\text {elastic }}$ obtained during all SLOPE-I campaign. Each bin size is equivalent to 30 minutes. $\triangle P B L H_{\text {Elastic-MWR }}^{\%}, R M S E, R$ and $D$ represents average percentage difference, root mean square error, correlation index and index of agreement, respectively. .74

Figure 6.1 $-R C S(\lambda=1064 \mathrm{~nm})$ profiles obtained from ceilometer data (A - spring, B - summer, $\mathrm{C}$ - autumn, D - winter). Black and pink stars represent $P B L H_{\text {ceilometer }}$ and $P B L H_{M W R}$, respectively. .77

Figure $6.2-R C S(\lambda=1064 \mathrm{~nm})$ profile obtained from ceilometer data. Black and pink stars represent $P B L H_{\text {ceilometer }}$ and $P B L H_{M W R}$, respectively 78 
Figure 6.3 - Daily $P B L H_{M W R}$ since 2012 until 2016 .80

Figure 6.4 - Daily PBLH $H_{M W R}$ cycle for winter (DJF), spring (MAM), summer (JJA) and autumn (SON) since 2012 until 2016. Whiskers and boxes indicate 10, 25, 75 and 90\% percentiles. The red lines represent the median and the blue stars indicate the mean.....83

Figure 6.5 - $P B L H_{M W R}^{G S p e e d}$ for winter (DJF - dark blue line), spring (MAM - orange line), summer (JJA - red line) and autumn (SON - light blue line) in the period 2012-2016 ...84

Figure 6.6 - $P B L H_{M W R}^{M a x}$ for Winter (DJF), Spring (MAM), Summer (JJA) and Autumn (SON) since 2012 until 2016. Each bin size is equivalent to $100 \mathrm{~m}$. The red line indicates a lognormal distribution. $A_{v}, S_{k}$ and $K_{t}$ represents average, skewness and kurtosis values, respectively .85

Figure 6.7 - $P B L H_{M W R}^{G R a t e}$ for winter (DJF), spring (MAM), summer (JJA) and autumn (SON) since 2012 until 2016. Each bin size is equivalent to $100 \mathrm{~m} / \mathrm{h}$. The red line indicates a lognormal distribution. $A_{v}, S_{k}$ and $K_{t}$ represents average, skewness and kurtosis values, respectively .86

Figure $6.8-P B L H_{M W R}^{G D u r}$ for winter (DJF), spring (MAM), summer (JJA) and autumn (SON) since 2012 until 2016. Each bin has a size of $1 \mathrm{~h}$. The red line indicates a Gaussian distribution. $A_{v}, S_{k}$ and $K_{t}$ represents average, skewness and kurtosis values, respectively

Figure 6.9 - Comparison among average annual daily cycle of $P B L H_{M W R}$ (blue line), $R_{n}$ (orange line), air surface temperature (green line) and surface relative humidity (purple line) for all meteorological seasons from 2012 until 2016 .89

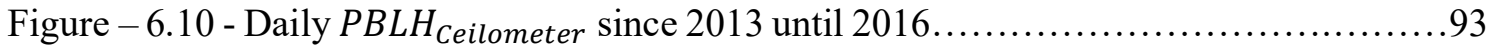

Figure 6.11 $-\triangle P B L H=\left[P B L H_{\text {Ceilometer }}-P B L H_{M W R}(\mathrm{~m})\right]$ or $R L$ depth for winter (DJF), spring (MAM), summer (JJA) and autumn (SON) since 2013 until 2016..................93

Figure 6.12 - Comparison between $P B L H_{M W R}$ and $P B L H_{\text {Ceilometer }} \ldots \ldots \ldots \ldots \ldots \ldots \ldots . \ldots 9$

Figure 7.1 - Autocovariance function of three wavelengths (355, 532 and $1064 \mathrm{~nm})$ at two different heights: 950 (yellow line) and 1175 (green line) m.......................96

Figure 7.2 - Comparison among integral time scale profiles $\left(\boldsymbol{\tau}_{\boldsymbol{R} C \boldsymbol{S}_{I}}\right)$ obtained from three wavelengths: 355 (up), 532 (center) and 1064 (bottom) without corrections (black line), 
with $2 / 3$ corrections (blue line) and first lag correction (green line). The gray line represents the $P B L H_{\text {elastic }}$. The dotted red line corresponds to MSPI acquisition time (2 s). .98

Figure 7.3 - Comparison among skewness profiles $\left(\boldsymbol{S}_{\boldsymbol{R} C \boldsymbol{S}_{\prime}}\right)$ obtained from three wavelengths: 355 (up), 532 (center) and 1064 (bottom) without corrections (black line), with 2/3 corrections (blue line) and first lag correction (green line). The gray line represents the $P B L H_{\text {elastic }}$. The dotted red line corresponds to region where $\boldsymbol{S}_{\boldsymbol{R} C \boldsymbol{S}}$ is zero.... .99

Figure 7.4 - Comparison among kurtosis profiles $\left(\boldsymbol{K}_{\boldsymbol{R} C \boldsymbol{S}_{1}}\right)$ obtained from three wavelengths: 355 (up), 532 (center) and 1064 (bottom) without corrections (black line), with 2/3 corrections (blue line) and first lag correction (green line). The gray line represents the $P B L H_{\text {elastic }}$. The dotted red line corresponds to region where $\boldsymbol{K}_{\boldsymbol{R} C \boldsymbol{S}}$ is three 101

Figure 7.5 - RCS profile and statistical moments $\left(\boldsymbol{q}_{\boldsymbol{R} C \boldsymbol{S}}^{2}\right.$, [pink line], $\boldsymbol{\tau}_{\boldsymbol{R} \boldsymbol{C} \boldsymbol{s}}$, [green line], $\boldsymbol{S}_{\boldsymbol{R} \boldsymbol{C} \boldsymbol{s}}$ [blue line], $\boldsymbol{K}_{\boldsymbol{R} C \boldsymbol{S}}$, [black line]. Gray line represents the $P B L H_{\text {elastic }} \ldots \ldots \ldots \ldots \ldots \ldots . \ldots 103$

Figure 7.6 - RCS profile and statistical moments $\left(\boldsymbol{q}_{\boldsymbol{R} C \boldsymbol{S}}^{2}\right.$, [pink line], $\boldsymbol{\tau}_{\boldsymbol{R} C \boldsymbol{S}}$, [green line], $\boldsymbol{S}_{\boldsymbol{R} \boldsymbol{C} \boldsymbol{S},}$ [blue line], $\boldsymbol{K}_{\boldsymbol{R} \boldsymbol{C} \boldsymbol{s}}$ [ [black line]. Gray line represents the $P B L H_{\text {elastic }} \ldots \ldots \ldots \ldots \ldots \ldots . \ldots 107$

Figure 8.1 - Autocovariance of w' to three different heights.......................... 109

Figure 8.2 - Vertical profile of Integral time scale $\left(\boldsymbol{\tau}_{\boldsymbol{w}^{\prime}}\right)$. Without correction (left), 2/3 correction

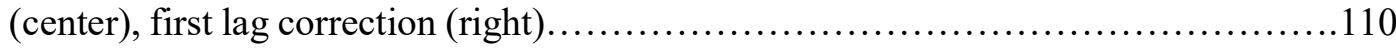

Figure 8.3 - Vertical profile of variance $\left(\boldsymbol{\sigma}_{w}^{2}\right)$. Without correction (left), 2/3 correction (center),

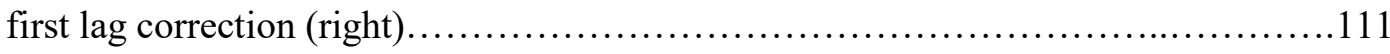

Figure 8.4 - Vertical profile of Skewness. $\left(\boldsymbol{S}_{\boldsymbol{w}}\right)$ Without correction (left), 2/3 correction

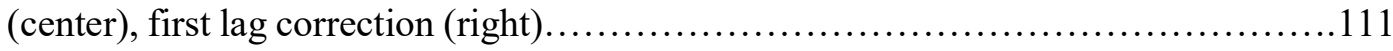

Figure 8.5 - Autocovariance of RCS' to three different heights........................ 112

Figure 8.6 - Vertical profile of Integral time scale $\left(\boldsymbol{\tau}_{\boldsymbol{R} C \boldsymbol{S}^{\prime}}\right)$. Without correction (left), 2/3

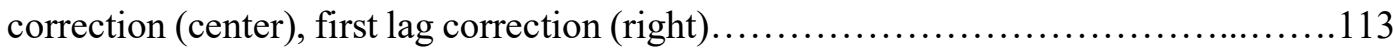

Figure 8.7 - Vertical profile of variance $\left(\boldsymbol{\sigma}_{R C S^{\prime}}^{2}\right)$. Without correction (left), 2/3 correction (center), first lag correction (right) ..................................... 113

Figure 8.8 - Vertical profile of Skewness $\left(\boldsymbol{S}_{\boldsymbol{R} C \boldsymbol{S}_{\prime}}\right)$. Without correction (left), 2/3 correction (center), first lag correction (right). 
Figure 8.9 - Vertical profile of Kurtosis $\left(\boldsymbol{K}_{\boldsymbol{R} C \boldsymbol{S}_{I}}\right)$. Without correction (left), 2/3 correction (center), first lag correction (right) ........................................ 114

Figure 8.10 - A - integral time scale $\left[\boldsymbol{\tau}_{\boldsymbol{w}^{\prime}}\right], \mathrm{B}$ - variance $\left[\boldsymbol{\sigma}_{w^{\prime}}^{2}\right], \mathrm{C}-$ skewness $\left[\boldsymbol{S}_{\boldsymbol{w}^{\prime}}\right], \mathrm{D}-$ net radiation $\left[R_{n}\right], \mathrm{E}-$ Air surface temperature [blue line] and surface relative humidity $[R H$ - orange line]. In A, B and C black lines and white stars represent air temperature and $P B L H_{M W R}$, respectively

Figure 8.11 - RCS Profile 19 May 2016. Pink stars represent $P B L H_{M W R} \ldots \ldots \ldots \ldots \ldots \ldots 118$

Figure 8.12 - Statistical moments obtained from elastic lidar data. From left to right: variance $\left[\boldsymbol{\sigma}_{R C S^{\prime}}^{2}\right]$, integral time scale $\left[\boldsymbol{\tau}_{\boldsymbol{R} C \boldsymbol{S}^{\prime}}\right]$, skewness $\left[\boldsymbol{S}_{\boldsymbol{R} \boldsymbol{C} \boldsymbol{S}^{\prime}}\right]$ and kurtosis $\left[\boldsymbol{K}_{\boldsymbol{R} C \boldsymbol{S}^{\prime}}\right]$ 119

Figure 8.13 - A - integral time scale $\left[\boldsymbol{\tau}_{\boldsymbol{w}^{\prime}}\right], \mathrm{B}-$ variance $\left[\boldsymbol{\sigma}_{w^{\prime}}^{2}\right], \mathrm{C}-$ skewness $\left[\boldsymbol{S}_{\boldsymbol{w}^{\prime}}\right], \mathrm{D}-$ net radiation $\left[R_{n}\right], \mathrm{E}-$ Air surface temperature [blue line] and surface relative humidity $[R H$ - orange line]. In A, B and C black lines and white stars represent air temperature and $P B L H_{M W R}$, respectively. 120

Figure 8.14 - RCS Profile 08 July 2016. Pink stars represent $P B L H_{M W R} \ldots \ldots \ldots \ldots \ldots \ldots \ldots \ldots \ldots \ldots \ldots \ldots$

Figure 8.15 - Statistical moments obtained from elastic lidar data. From left to right: variance $\left[\boldsymbol{\sigma}_{R C S^{\prime}}^{2}\right]$, integral time scale $\left[\boldsymbol{\tau}_{\boldsymbol{R} C \boldsymbol{S}^{\prime}}\right]$, skewness $\left[\boldsymbol{S}_{\boldsymbol{R} C \boldsymbol{S}^{\prime}}\right]$ and kurtosis $\left[\boldsymbol{K}_{\boldsymbol{R} C \boldsymbol{S}^{\prime}}\right] \ldots \ldots \ldots . .123$

Figure 8.16 - Statistical moments obtained from elastic lidar data. From left to right: variance $\left[\boldsymbol{\sigma}_{R C S^{\prime}}^{2}\right]$, integral time scale $\left[\boldsymbol{\tau}_{\boldsymbol{R} C \boldsymbol{S}^{\prime}}\right]$, skewness $\left[\boldsymbol{S}_{\boldsymbol{R} \boldsymbol{C} \boldsymbol{S}^{\prime}}\right]$ and kurtosis $\left[\boldsymbol{K}_{\boldsymbol{R} \boldsymbol{C} \boldsymbol{S}^{\prime}}\right] \ldots \ldots \ldots \ldots 124$ 


\section{List of Abbreviations}

\begin{tabular}{|c|c|}
\hline Abbreviation & Meaning \\
\hline $\boldsymbol{A}$ & Area of telescope cross section \\
\hline$A C F$ & Autocovariance function \\
\hline$A C F_{355}$ & Autocovariance function (Wavelength $355 \mathrm{~nm}$ ) \\
\hline$A C F_{532}$ & Autocovariance function (Wavelength $532 \mathrm{~nm}$ ) \\
\hline$A C F_{1064}$ & Autocovariance function (Wavelength $1064 \mathrm{~nm}$ ) \\
\hline ACTRIS & $\begin{array}{l}\text { European Research Infrastructure for the Observation of Aerosol, Clouds } \\
\text { and Trace Gases }\end{array}$ \\
\hline$A_{v}$ & Average \\
\hline$B G$ & Background Correction \\
\hline $\boldsymbol{c}$ & light speed \\
\hline$C B L$ & Convective Boundary Layer \\
\hline CNR & Carrier-to-noise ratio \\
\hline COP 21 & Conference of the Parties \\
\hline D & Index of agreement \\
\hline$D C$ & Dark Current Correction \\
\hline$D L$ & Doppler lidar \\
\hline$D_{r}$ & number of days with rainfall greater than $1 \mathrm{~mm}$ \\
\hline$D_{s}$ & number of snowy days \\
\hline EARLINET & European Research Lidar Network \\
\hline$E K F$ & Extended Kalman Filter \\
\hline$E L$ & Elastic lidar \\
\hline$E Z$ & Entrainment Zone \\
\hline$f$ & Frequency \\
\hline $\boldsymbol{F A}$ & Free Atmosphere \\
\hline$F_{E s}$ & latent heat flux \\
\hline$F_{G s}$ & conduction of heat down into the ground \\
\hline
\end{tabular}




\begin{tabular}{|c|c|}
\hline$F_{H s}$ & sensible heat flux \\
\hline$G H G$ & Green House Gases \\
\hline$G M$ & Gradient Method \\
\hline$H_{S H}$ & mean number of hours of sunshine \\
\hline IF & Ideal Fit \\
\hline IIST A-CEAMA & Andalusian Institute of Earth System Research \\
\hline $\boldsymbol{K}$ & Kurtosis \\
\hline$K_{R C S}$ & Kurtosis profile $\left(R C S^{\prime}\right)$ \\
\hline$K_{R C S}^{c o r}$ & Corrected Kurtosis profile $\left(R C S^{\prime}\right)$ \\
\hline$K_{R C S}^{u n c}$ & Uncorrected Kurtosis profile $\left(R C S^{\prime}\right)$ \\
\hline$K_{t}$ & Kurtosis normalized \\
\hline$K_{w \prime}$ & Kurtosis profile $\left(w^{\prime}\right)$ \\
\hline LALINET & Latin American Lidar Network \\
\hline$L E A L$ & Laser Environmental Applications Laboratory \\
\hline LES & Large Eddy Simulations \\
\hline LIDAR & Light Detection and Ranging \\
\hline$L N A$ & Low Noise Amplifier \\
\hline$M_{e d} L$ & Mixed Layer \\
\hline$M L$ & Mixing Layer \\
\hline$M W R$ & Microwave Radiometer \\
\hline$N$ & Aerosol number density \\
\hline$N^{\prime}$ & Fluctuation of Aerosol number density \\
\hline$N e B L$ & Neutral Boundary Layer \\
\hline$P(r)$ & signal returned from distance $r$ at time $t$ \\
\hline$P_{0}$ & acquired signal at time $t$ \\
\hline$P B L$ & Planetary Boundary Layer \\
\hline$P B L H$ & Planetary Boundary Layer Height \\
\hline PBLH CBLilometer & $C B L$ detected by ceilometer \\
\hline PBLH Ceilometer & $R L$ detected by ceilometer \\
\hline PBLH $H_{\text {Doppler }}$ & PBLH detected by Doppler lidar \\
\hline PBLH ${ }^{G D u r}$ & $P B L H$ growth duration \\
\hline PBLH ${ }^{\text {GRate }}$ & $P B L H$ growth rate \\
\hline PBLH $H^{\text {GSpeed }}$ & $P B L H$ growth speed \\
\hline$P B L H_{M W R}$ & $P B L H$ detected by MWR \\
\hline
\end{tabular}




\begin{tabular}{|c|c|}
\hline$P B L H_{M W R}^{C B L}$ & $C B L$ detected by $M W R$ \\
\hline$P B L H_{M W R}^{G D u r}$ & $P B L H_{M W R}$ Growth Duration \\
\hline PBLH GRate & $P B L H_{M W R}$ Growth Rate \\
\hline$P B L H_{M W R}^{G S p e e d}$ & $P B L H_{M W R}$ Growth Speed \\
\hline$P B L H_{M W R}^{M a x}$ & $P B L H_{M W R}$ maximum daily value \\
\hline$P B L H_{M W R}^{S B L}$ & $S B L$ detected by $M W R$ \\
\hline$P B L H^{M a x}$ & Maximum daily value of $P B L H$ \\
\hline$P B L H_{\text {ceilometer }}$ & PBLH detected by ceilometer \\
\hline$P B L H_{\text {elastic }}$ & $P B L H$ detected by elastic lidar \\
\hline$P M$ & Parcel Method \\
\hline $\boldsymbol{R}$ & Pearson coefficient of correlation \\
\hline \multicolumn{2}{|l|}{$R_{b l}$} \\
\hline RCS & Range Corrected signal \\
\hline$R C S^{\prime}$ & Fluctuation of Range Corrected signal \\
\hline $\operatorname{RCS}_{1064}^{\prime}$ & Fluctuation of Range corrected signal of wavelength $1064 \mathrm{~nm}$ \\
\hline$R C S_{1064}$ & Range corrected signal of wavelength $1064 \mathrm{~nm}$ \\
\hline $\boldsymbol{R}_{\boldsymbol{f}}$ & Rainfall \\
\hline RH & Surface relative humidity \\
\hline$R L$ & Residual Layer \\
\hline RMSE & Root Mean Square Error \\
\hline $\boldsymbol{R}_{n}$ & Net Radiative Flux \\
\hline$S$ & Skewness \\
\hline$S B I$ & Surface-based temperature inversion \\
\hline$S B L$ & Stable boundary Layer \\
\hline SNR & Signal-to-noise ratio \\
\hline STA & Surface Thermal Amplitude \\
\hline STRAT & Structure of the Atmosphere \\
\hline$S_{R C S}$ & Skewness profile $\left(R C S^{\prime}\right)$ \\
\hline$S_{R C S}^{u n c}$ & Uncorrected Skewness profile $\left(R C S^{\prime}\right)$ \\
\hline$S_{k}$ & Skewness \\
\hline$S_{w^{\prime}}$ & Skewness profile $\left(w^{\prime}\right)$ \\
\hline$T(z)$ & Temperature profile \\
\hline$t_{d}$ & Duration of laser pulse \\
\hline$T G M$ & Temperature Gradient Method \\
\hline
\end{tabular}




\begin{tabular}{|c|l|}
\hline $\boldsymbol{t h}_{\boldsymbol{v a r}}$ & Threshold \\
\hline $\boldsymbol{T} \boldsymbol{K} \boldsymbol{E}$ & Turbulent Kinetic Energy \\
\hline $\boldsymbol{T}_{\boldsymbol{M}}$ & Maximal Temperature \\
\hline $\boldsymbol{T} \boldsymbol{M}$ & Threshold Method \\
\hline $\boldsymbol{T}_{\boldsymbol{m}}$ & Minimal Temperature \\
\hline $\boldsymbol{T S} \boldsymbol{L}$ & Top of Stable Boundary Layer \\
\hline $\boldsymbol{v}$ & Relative speed \\
\hline $\boldsymbol{v}_{\boldsymbol{L O S}}$ & line-of-sight velocity \\
\hline $\boldsymbol{V} \boldsymbol{M}$ & Variance Method \\
\hline $\boldsymbol{v}_{\boldsymbol{r}}$ & radial velocity \\
\hline $\boldsymbol{W} \boldsymbol{C} \boldsymbol{T}$ & Wavelet Covariance Transform \\
\hline $\boldsymbol{w}$ & vertical wind speed \\
\hline $\boldsymbol{w}^{\prime}$ & Fluctuation of vertical wind speed \\
\hline$\overline{\boldsymbol{x}}$ & Average value o variable $x$ \\
\hline
\end{tabular}

\section{List of Greek Symbols}

\begin{tabular}{|c|c|}
\hline Symbols & Definitions \\
\hline$\alpha$ & extinction coefficient \\
\hline $\boldsymbol{\beta}$ & backscatter coefficient \\
\hline $\boldsymbol{\beta}_{\text {aer }}$ & aerosol backscatter coefficient \\
\hline$\beta_{\text {mol }}$ & Molecular backscatter coefficient \\
\hline$\beta_{\text {par }}$ & Particle backscatter coefficient \\
\hline $\boldsymbol{\beta}_{\text {par }}^{\prime}$ & Fluctuation of Particle backscatter coefficient \\
\hline$\Delta \boldsymbol{x}^{\%}$ & Percentage change \\
\hline$\Delta x$ & variation of variable $x$ \\
\hline$\lambda$ & Wavelength \\
\hline$\sigma_{w}^{2}$ & Variance of vertical wind speed \\
\hline$\sigma_{R C S}^{2}$ & Variance profile $\left(R C S^{\prime}\right)$ \\
\hline$\sigma_{w \prime}^{2}$ & Variance profile $\left(w^{\prime}\right)$ \\
\hline$\tau$ & Integral time scale \\
\hline$\tau_{R C S}$ & Integral Time Scale profile $\left(R C S^{\prime}\right)$ \\
\hline$\tau_{R C S}^{c o r}$ & Corrected Integral Time Scale profile $\left(R C S^{\prime}\right)$ \\
\hline
\end{tabular}




\begin{tabular}{|c|l|}
\hline $\boldsymbol{\tau}_{\boldsymbol{R} \boldsymbol{C} \boldsymbol{\prime} \boldsymbol{\prime}}^{\boldsymbol{u n c}}$ & Uncorrected Integral Time Scale profile $\left(R C S^{\prime}\right)$ \\
\hline $\boldsymbol{\tau}_{\boldsymbol{w}}$ & Integral Time Scale profile $\left(w^{\prime}\right)$ \\
\hline $\boldsymbol{\theta}(\mathbf{z})$ & Potential Temperature profile \\
\hline
\end{tabular}




\section{List of Tables}

Table 3.1 - Climatological values of meteorological station Granada airbase $\left(37^{\circ} 8^{\prime} 14^{\prime}\right.$ ' $\mathrm{N}, 3^{\circ}$ $37^{\prime} 53 ” \mathrm{~W}$ ) from the period $1980-2010$. $\mathrm{T}$ (temperature), $\mathrm{T}_{\mathrm{m}}$ (minimal temperature), $\mathrm{T}_{\mathrm{M}}$ (maximum temperature), $\mathrm{R}_{\mathrm{f}}$ (Rainfall), $\mathrm{RH}$ (Relative Humidity), $\mathrm{D}_{\mathrm{R}}$ (number of days with rainfall greater than $1 \mathrm{~mm}$, $\mathrm{D}_{\mathrm{S}}$ (number of snowy days), $\mathrm{H}_{\mathrm{SH}}$ (mean number of hours of sunshine). Source (www.aemet.es). .43

Table 3.2 - Climatological values of meteorological station Mirante de Santana $\left(23^{\circ} 29^{\prime} 46^{\prime}\right.$ ' $\mathrm{S}, 46^{\circ} 37^{\prime} 11^{\prime} \mathrm{W}$ ) from the period 1961 - 2016. $\mathrm{T}$ (temperature), $\mathrm{T}_{\mathrm{m}}$ (minimal temperature), $\mathrm{T}_{\mathrm{M}}$ (maximum temperature), $\mathrm{R}_{\mathrm{f}}$ (Rainfall), $\mathrm{RH}$ (Relative Humidity), $\mathrm{D}_{\mathrm{R}}$ (number of days with rainfall greater than $1 \mathrm{~mm}, \mathrm{D}_{\mathrm{S}}$ (number of snowy days), $\mathrm{H}_{\mathrm{SH}}$ (mean

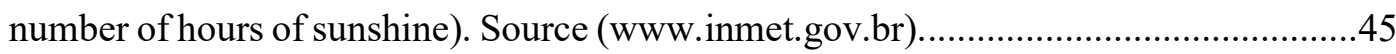

Table 3.3 - Main technical features of lidar/ceilometers systems.........................48

Table 4.1 - Variables applied to statistical analysis (Lenschow et al., 2000).................58

Table 6.1 - MWR Recovery rate................................................... 79

Table 6.2 - Main characteristics of long-term studies campaign......................... 81

Table $6.3-P B L$ characterization of four different places...............................88

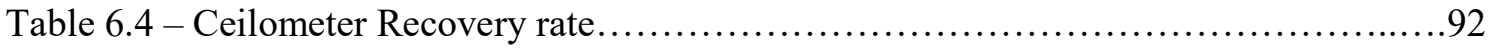




\section{Introduction}

In the last decades, the social preoccupation about air pollution have increased. Cases like as "Great smog of London of 1952" (approximately 12,000 people died) (BELL, 2004) and the "Valley of Death" in Cubatão-Brazil (30,000 tons of pollutants were released per month in the air of the city in the 80 's) have shown to society how harmful this type of pollution can be (COSTA, 2017). Although there are efforts to mitigate the pollutant emission process (e.g. Conference of the Parties - COP 21), the number of anthropogenic emissions have been increased constantly, mainly Green House Gases (GHG), as demonstrated in figure 1.1, where the highest increase of emissions is the $\mathrm{CO}_{2}$ resulting from the burning of fossil fuel and industrial process (IPCC, 2015).

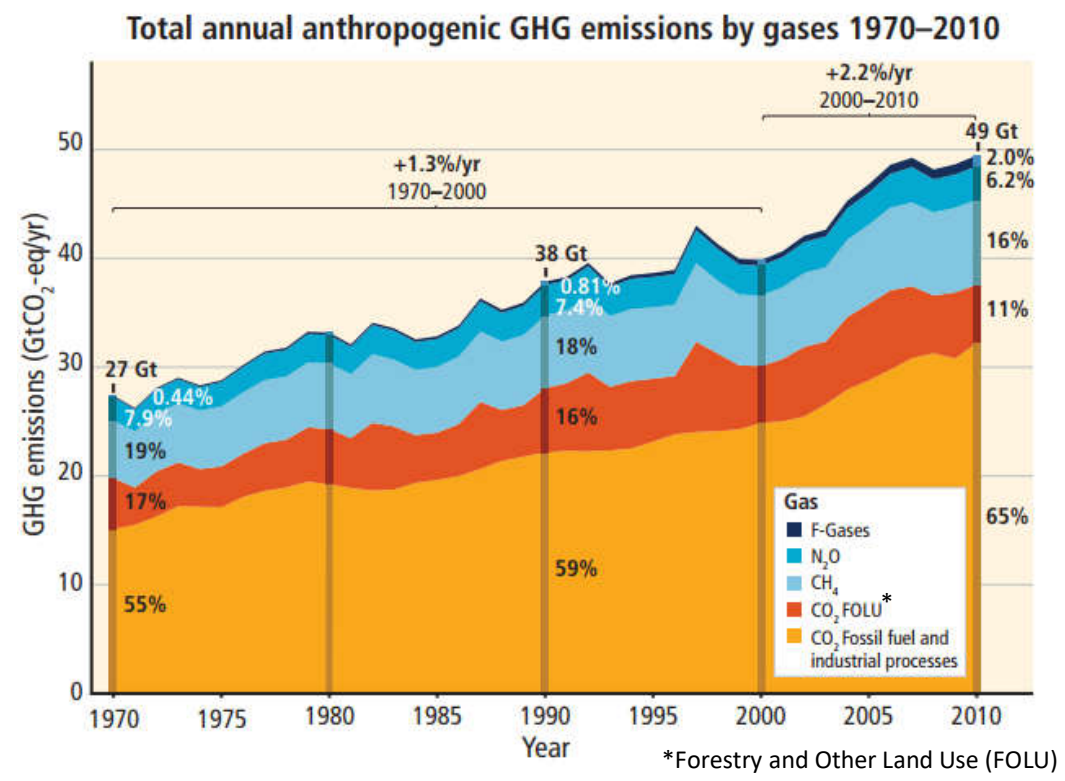

Figure 1.1 - Total annual anthropogenic Green House Gases (GHG) emissions by gases. Source: IPCC - AR5 
Figure 1.2 shows the impacts caused per climate changes, in which GHG emissions play an important role, all over the world. Physical and biological systems are directly affected by them, resulting in noxious influences to human health, mainly in american and european continents. The lowermost region of the troposphere has a crucial role in this process, because, besides to be inhabited, it is the place where the emission of

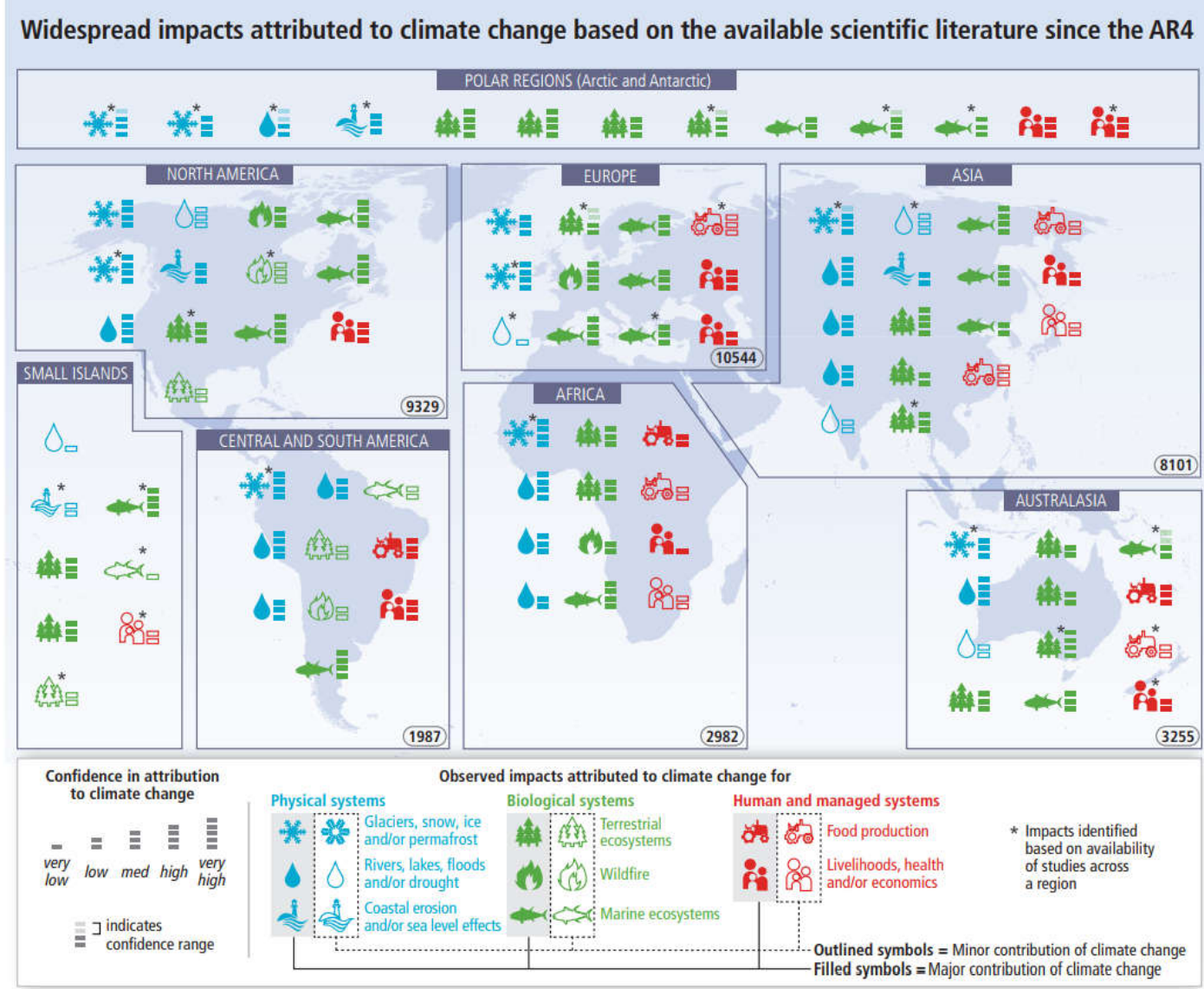

Figure 1.2 - Impacts attributed to climate change. Source: IPCC - AR5

pollutants occurs. Such region also is responsible for dispersion process, which vary with action of certain forcings. This region is denominated Planetary Boundary Layer (PBL) and defined as the "part of the troposphere that is directly or indirectly influenced by the presence of the Earth's surface (ground or sea), and responds to surface forcings with a time scale of hours" (STULL, 1988).

The PBL is characterized by its turbulent behavior and a daily cycle endowed with large variability. The height of this layer (Planetary Boundary Layer Height - PBLH) is an important parameter for a wide set of studies, which include pollutant dispersion, 
weather forecasting, meteorological modeling and air quality (Li et al., 2017). However, this height cannot be measured directly, but due to turbulent vertical process, some atmospheric variables as the potential temperature $(\theta)$, the vertical wind speed $(w)$, the relative humidity $(\mathrm{RH})$ and the aerosols concentration have a characteristic vertical profile that enable PBLH detection (Stull, 1988).

The utilization of radiosonde is the most widespread method in PBLH detection. However, the high variability of PBL during its daily cycle requires systems endowed with high temporal and spatial resolution for continuous monitoring. In this scenario, remote sensing systems arise as important tools in PBL studies. The high temporal and spatial resolution allow remote sensing systems to provide detailed and long-term observational PBLH studies (e.g.He et al., 2006; Granados-Muñoz et al., 2012; Di Giuseppe et al., 2012; Haman et al., 2012; Pal et al., 2013; Coen et al., 2014; Korhonen et. al, 2014; Pal et al., 2015).

In the last two decades, elastic lidar systems have been widely applied in studies about PBLH (Davis et al., 2000; Brooks et al., 2003; Morille et al., 2007; Baars et al., 2008; Pal et al., 2010; De Tomasi et al., 2011; Wang et al., 2012; Granados-Muñoz et al., 2012; Lange et al., 2014; Banks et al., 2016; Bravo-Aranda et al., 2017). These systems detect the

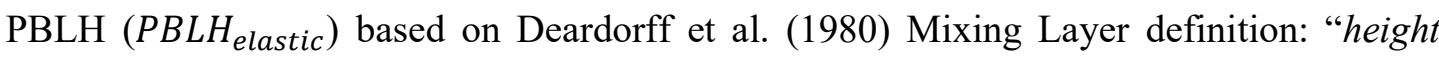
where there are equal areas of clear air below and particulates above", therefore $P B L H_{\text {elastic }}$ "is taken to be the midpoint of the transition region between the areas of higher and lower backscattering". However, it is not easy to find this midpoint in real elastic lidar signals, mainly in complex situations, such as the presence of aerosol multilayers or clouds (Kovalev and Eichinger, 2014). An alternative to solve this problem, it is to use mathematical methods to reduce ambiguities in analyzed signals.

The traditional algorithms applied in $P B L H_{\text {elastic }}$ detection are the Gradient Method (Martucci et al., 2007; Baars et al., 2008; Li et al., 2017), Variance or Centroid Method (Hooper and Eloranta, 1986; Menut et al., 1999; Martucci et al., 2007), Threshold Method (Melfi et al., 1985; Kovalev and Eichinger, 2004), Fit Method (Eresma et al., 2006; Li et al., 2007) and Wavelet Covariance Transform (Davis et al., 2000; Granados-Muñoz et al., 2012; Lopes et al., 2014). However, complex situations, such as presence of aerosol sublayers and clouds, often confuse these methods and $P B L H_{\text {elastic }}$ can be overestimated. Lange et al. (2014), using an algorithm based on Extend Kalman Filter, and Bravo-Aranda 
et al. (2017), utilizing information of depolarization channels, proposed algorithms to deal with these situations. Another difficulty to elastic lidar is the high overlap of some systems, what might prevent a correct detection of PBLH in stable situations, where frequently this variable has the lower heights.

Ceilometers, in the same way of elastic lidars, can be applied in PBLH detection $\left(P B L H_{\text {ceilometer }}\right)$. Although ceilometers and lidars have similar operating principles, ceilometers have some advantages, such as relatively continuous operations and lowmaintenance, eye-safe and comparatively low price, which compensates the disadvantages of lower maximum range and relatively low signal-to-noise ratio (SNR). These facts justify their increasing use in studies related to PBLH (e.g. Eresma et al., 2006; Münkel et al.,2007; Di Giuseppe et al.,2012; Ketterer et al., 2014; Lotteraner et al.,2016; Zhu et al.,2016; Uzan et al.,2016; Avolio et al., 2017; Caicedo et al., 2017).

Doppler lidars also have been used in PBLH detection $\left(P B L H_{\text {Doppler }}\right)$. The algorithms applied in this kind of studies are frequently based on: Mixing Layer definition (carrier-to-noise ratio (CNR) profile (Moreira et. al, 2015)), elastic lidar methods mentioned above using the backscattered signal (Shukla et al, 2014) or turbulence threshold (variance of vertical wind speed $\left(\sigma_{w}^{2}\right)$ (Barlow et al., 2011; Schwenn et al., 2014), low-level jets (Moreira et al., 2015), turbulent energy dissipation rate (O'Connor et al., 2010) and spectrum of horizontal wind component (Marques et al., 2017)). In comparison with elastic lidar, Doppler lidars have a lower full overlap height (less than $100 \mathrm{~m}$ ) what is important to detect the PBLH during early morning as well as under stable situations.

While the remote sensing systems mentioned earlier have its data acquisition affected by rain and/or cloud covers, the Microwave Radiometers (MWR) measurements are not influenced by these factors (Kim et al., 2015). This characteristic allows MWR operates in continuous mode and with high recovery rate. Such characteristic combined with the absence of overlap problems in the near range enables MWR to be applied to estimate the PBLH continuously in stable and unstable atmospheric situations. Based on characteristics of potential temperature profile $(\theta(z))$ in PBL, some authors (Muñoz-Granados et al., 2012; Wang et al., 2012; Coen et al., 2014; Bravo-Aranda et al., 2017) proposed to detect the PBLH $\left(P B L H_{M W R}\right)$ from temperature provided by MWR data. From another point of view, Cimini et al. (2013) estimated $P B L H_{M W R}$ from brightness temperatures, which are obtained directly from MWR. 
The comprehension about turbulent process in the PBL also are important to diverse studies, mainly for atmospheric modeling and pollutant dispersion, so that turbulent mixing can be considered as primary means by which aerosol particles and other scalars are transported vertically in atmosphere. Because turbulent process are treated as nondeterministic, they are characterized and described from their statistical properties (high order statistical moments). When applied to atmospheric studies such properties can provide information about the field of turbulent fluctuation, as well as, a description about mixing process in the PBL (Pal et al., 2010).

Anemometer towers (Kaimal and Gaynor, 1983; van Ulden and Wieringa, 1996) and aircrafts (Lenschow et al., 1980; Williams and Hacker, 1992; Lenschow et al., 1994; Albrecht et al., 1995; Stull et al., 1997; Andrews et al., 2004; Vogelmann et al., 2012) have been widely applied in studies about turbulence in PBL. Nevertheless, the utilization of anemometer towers restricts the analysis to regions near to surface, due to its limited vertical resolution. Although this problem can be solved by aircrafts, they have a short time window limiting the period of analysis. Therefore, due to large variability of PBL along the day, systems with high temporal and spatial resolution are the most recommended for this kind of study.

In this scenario, remote sensing systems also arise as important tool for this kind of study, mainly lidar systems. Another advantage of lidar is the possibility of working with several kind of tracers, like as: vertical wind velocity (Lenschow et al., 2000; Lothon et al., 2006; O’Connor et al., 2010) by Doppler lidar, water vapor (Wulfmeyer, 1999; Kiemle et al., 2007; Wulfmeyer et al., 2010; Turner et al., 2014; Muppa et al., 2015) by Raman lidar or Differential Absorption lidar (DIAL), temperature (Behrendt et al., 2015) by rotational Raman lidar and aerosol (Pal et al., 2010; McNicholas et al., 2015) by elastic lidar or High Spectral Resolution lidar (HSRL). Therefore, a wider range of results can be obtained, especially when different types of systems are applied synergistically, as demonstrated by Engelmann et al. (2008), where from the combination of elastic and Doppler lidar was possible to estimate the vertical particle flux.

In spite of the various applications of remote sensing systems in the atmospheric sciences, there is a small number of long-term studies and several gaps with respect to complex situations (cloud cover, aerosol sublayers, rain, etc), mainly in PBLH detection. 
In most of the cases, the systems have limitations, such as the incomplete overlap, the presence of clouds or rain, or even the limitation of the algorithm that depending on the operational PBLH definition adopted can lead to some restrictions like the part of the day that can be analyzed, consequently preventing a continuous monitoring of PBL. Another important point is the individual utilization of these systems. Although the results obtained are quite satisfactory, a synergistic application of them can generate a greater refinement in the obtained products.

Considering São Paulo and Granada (the two cities where this study was performed), the results obtained from the methodology proposed in this work can provide important information that will assist in the process of comprehension of PBL dynamics. The city of São Paulo has few studies, using remote sensing systems, about the PBL behavior and this will be the first to extract information of turbulent PBL behavior using such systems. In Granada, although there are several studies about PBL, there is still a lack of analysis of the long-term measurements. Otherwise, the observation of turbulent variables using remote sensing systems and the synergistic use of them is an issue that requires study. So in this sense, this work represent a step forward in the remote sensing studies also for Granada. Moreover, the results generated by this work can be used in other studies of same or related area, such as: air quality, dispersion of pollutants, weather modeling, etc.

\subsection{Objectives and structure}

The objective of this thesis is to generate results and methodologies able to assist, qualitatively and quantitatively, in the PBL characterization, as well as, in the description of its behavior, using a combination of different algorithms and remote sensing systems.

From this propose, the following tasks were performed:

- Development and improvement of algorithms for PBLH estimation in simple and complex situations by utilization of remote sensing systems;

- Based on the synergy of remote sensing systems, analyze the dynamics of the PBL from the statistical moments and identification how each one of the tracers used interferes in the processes of evolution of this layer.

The thesis organized as follow: 
Chapter 2 describes the basics concepts about this thesis. Firstly, the PBL and its daily cycle are briefly described. Then, some traditional methods about PBLH detection are presented, as well as, the properties provided by statistical moments. Finally, it is shown the operation principle of remote sensing systems applied in this work.

Chapter 3 details the experimental sites where the measurement campaigns were performed and the technical characteristic of the remote sensing systems utilized.

Chapter 4 presents the methodological aspects. The first subsection is dedicated to description of algorithms used for PBLH detection using: Doppler lidar, elastic lidar, MWR and ceilometer, respectively. In the next subsection are described the algorithms utilized in studies about turbulence.

Chapter 5 describes a study, where using simultaneous and co-located MWR, elastic lidar and Doppler lidar, were performed a comparison among the PBLH estimated from these three different systems, in order to observe how each distinct PBLH definition behave under simple and complex scenarios.

Chapter 6 demonstrates a long-term study performed with ceilometer and MWR. Our analyses has in mind that the PBLH retrievals by these two different techniques are based on the use of different tracers (aerosol and potential temperature vertical profiles). We used this fact to get a synergic understanding on the behavior of these tracers and on their influence on the PBL developing. Furthermore, we interpreted the agreement/disagreement between the techniques on the peculiarities of those tracers.

Chapter 7 presents an study of the PBL turbulence based on the use of Elastic Lidar data acquired with high temporal resolution, $2 \mathrm{~s}$. We include a comparison of the results obtained with three different wavelengths: 355,532 and $1064 \mathrm{~nm}$, in order to identify the viability of applying them in analysis of statistical moments. In addition, two case studies were analyzed to demonstrate how the high order moments can help in the comprehension of the PBL behavior.

Chapter 8 describes a study where three remote sensing systems (Elastic Lidar, Doppler Lidar and MWR) were used synergistically, in order to analyze the PBL behavior and to acquire a better comprehension about how each analyzed variable can influence the PBL dynamics. 
Chapter 9 summarizes the main topics and conclusions of this thesis, and gives some suggestions for the continuity of this study and to accomplishing of future researches 


\title{
2 FUNDAMENTALS
}

\begin{abstract}
This chapter presents the basics concepts about this research, in order to support the results discussed in the following chapters. Then, some topics about the statistical study of turbulence will be discussed. Finally, the operating principles of the equipment used in this research will be described.
\end{abstract}

\subsection{The planetary boundary layer (PBL)}

The lowermost region of troposphere is denominated Planetary Boundary Layer $(P B L)$. This region is defined as " the part of the troposphere that is directly influenced by the presence of the Earth's surface, and responds to surface forcings with a time scale of about an hour or less" (STULL, 1988). The PBL has an important influence in the behavior of atmosphere as a whole, as well as, in several research fields of atmospheric science, such as climate modeling and numerical weather forecasting. This layer has a quite variable thickness in space and time, ranging from tens of meters to few kilometers (GARRATT, 1992).

Variable height and turbulent behavior are fundamental characteristics of PBL. The PBL variability is characterized by daily cycles influenced by variations of variables like air surface temperature, relative humidity, net radiative flux, or atmospheric stability. During the day (figure 2.1-a) the positive net radiative flux $\left(R_{n}\right)$ causes the rising of ground surface temperature and air masses located at low altitudes get warm , favoring convective process and heating the upper regions by the sensible heat flux $\left(F_{H S}\right)$. At night (figure 2.1-b) in absence of solar radiation flux the ground emits more thermal infrared radiation than it receives from the atmosphere, therefore $R_{n}$ becomes negative, leading to the cooling of the surface, reduction of convective activity and inversion in the sign of sensible heat flux $\left(F_{H S}\right)$, latent heat flux $\left(F_{E S}\right)$ and of conduction of heat down into the ground $\left(F_{G S}\right)$ (WALLACE et al., 2005). 


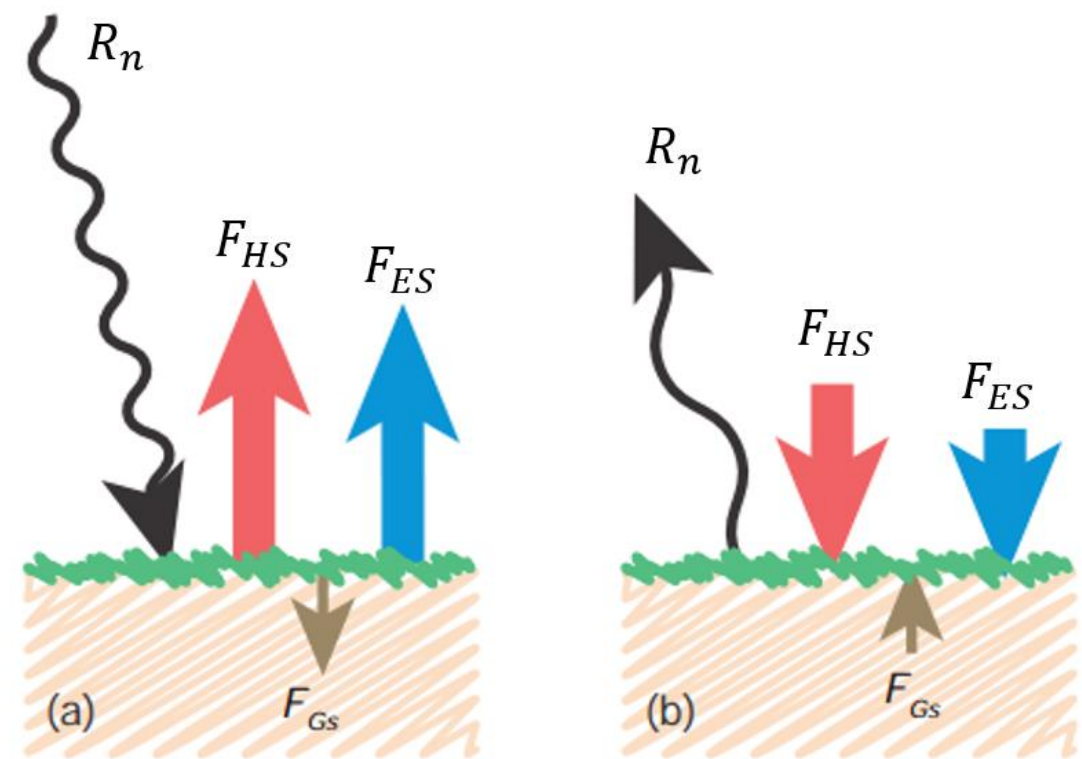

Figure 2.1: Radiative flux at surface - (a) day (b) night. $R_{n}$ (net radiative flux), $F_{H s}$ (sensible heat flux), $F_{E S}$ (latent heat flux), $F_{G S}$ (conduction of heat down into the ground). Source: Adapted from WALLACE et al., 2005.

Therefore, due to its direct contact with Earth surface, the PBL is directly influenced by this one. Such influence consists basically in the exchange of energy and in the existence of a viscous friction, which makes the flux turbulent in this layer and allows to affirm that turbulence in internal part of PBL is directly associated with $F_{H s}$. So, the PBL will have different characteristics according to $F_{H S}$ behavior. So that PBL can be classified as three main types: Stable or Nocturnal Boundary Layer (SBL), Neutral Boundary Layer (NeBL) and Convective Boundary Layer (CBL).

\subsubsection{Stable or Nocturnal Boundary Layer (SBL)}

At night, the radiative cooling, due to longwave emission, causes the reduction of Earth's surface temperature, so that, its temperature is lower than adjacent air layer. Consequently, this layer cools by transferring heat to Earth's surface, developing a stable $\theta$ profile in atmosphere $(\partial \theta / \partial z>0$ - figure 2.2), where the colder air masses are located in the lower part and the warmer layers in the upper region. In this situation when the air parcels move vertically they will be under the action of an acceleration, associated with buoyancy, in the opposite direction of the movement. Then, the turbulence (purely mechanical) is attenuated, so that, the turbulent exchanges between surface and atmosphere have smaller intensity than those observed in daytime period, resulting in the lower heights of SBL when compared to CBL (Stull, 1988). 
In this situation the turbulence generates a negative $F_{H S}$, because the positive temperature fluctuations are related to negative fluctuations of vertical speed and vice versa. Therefore $F_{H S}$ is negative indicating the transfer of heat from the atmosphere to the Earth's surface (figure $2.1 \mathrm{~b}$ ).

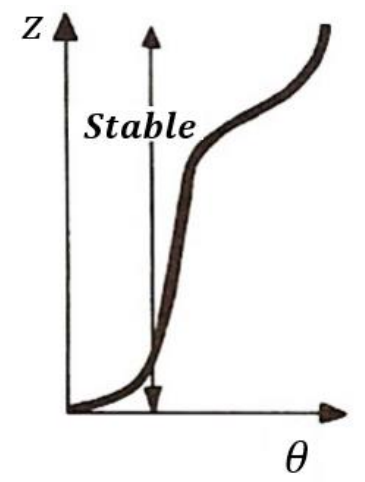

Figure 2.2: Idealized $\theta$ profile of SBL Source: Adapted from STULL, 1988.

\subsubsection{Convective Boundary Layer (CBL)}

Some instants after sunrise the positive value of $R_{n}$ causes the rising of ground surface temperature. Consequently, by conduction process, air masses located at low altitudes get warm and originate a convective process, where heated air masses become less dense and rise in the atmosphere, while the colder ones move in the opposite sense leading to vertical mixing. In this way, an unstable $\theta$ profile $(\partial \theta / \partial z<0$ - figure 2.3) is developed in the region near the surface. Due to buoyancy the air parcels are accelerated in the vertical direction, intensifying the process of thermal convection, as well as, the turbulence in regions close to surface and the energy transfers from ground surface to atmosphere by $F_{H S}$ and $F_{E S}$ (figure 2.1 a). This increase of turbulence causes the CBL ascension (Stull, 1988). CBL also is denominated Mixing Layer (ML), due to a mixing process generated by this turbulent ascending layer. 


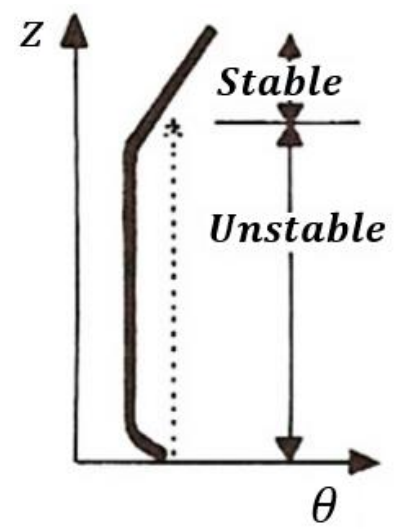

Figure 2.3: Idealized $\theta$ profile of CBL Source: Adapted from STULL, 1988.

\subsubsection{Neutral Boundary Layer (NeBL)}

As mentioned before, the value of heat flux varies between positive and negative according to the time of the day. Therefore, during these transitions there are periods where the heat flux is null or very close to zero, in such cases the PBL is classified as NeBL. Then, in this layer $\theta$ does not change with the height and the ground surface does not act as thermal energy source $(\partial \theta / \partial z=0$ or $\partial \theta / \partial z \cong 0$ - figure 2.4$)$.

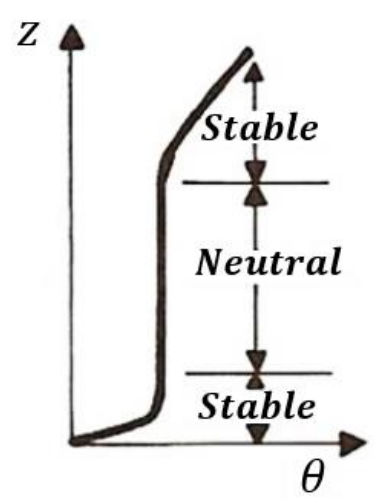

Figure 2.4: Idealized $\theta$ profile of NeBL

Source: Adapted from STULL, 1988.

\subsubsection{PBL daily cycle}

The three types of PBL indicated in the previous subsections constitute a daily cycle that varies according to surface-atmosphere interactions. Figure 2.5 describes this cycle and illustrates others sublayers that acts as divisions and/or transition regions of three stages mentioned before. 
Throughout the lower part of the figure 2.5 there is a continuous layer (red dotted line) called surface layer. This layer has intense vertical gradients of: moisture, wind speed and temperature, mainly during the day.

The CBL (or ML) appears some instants after sunrise and it ascends vertically in accordance with ground heating by solar radiation as described in section 2.1.2. The figure 2.5 illustrates this growth and the variation of $\theta$ profile $(\mathrm{P} 4 \rightarrow \mathrm{P} 5 \rightarrow \mathrm{P} 6 \rightarrow \mathrm{P} 1)$ (STULL, 1988).

In the early hours of the day there is a layer above the ML, which is named Residual Layer (RL) because it has remaining characteristics of the previous day's ML, besides retaining the pollutants that were confined there during the night period. However, the advent of convection during the day causes the expansion of ML and the rupture of RL. (figure 12 - P5 $\rightarrow$ P6) (STULL, 1988).
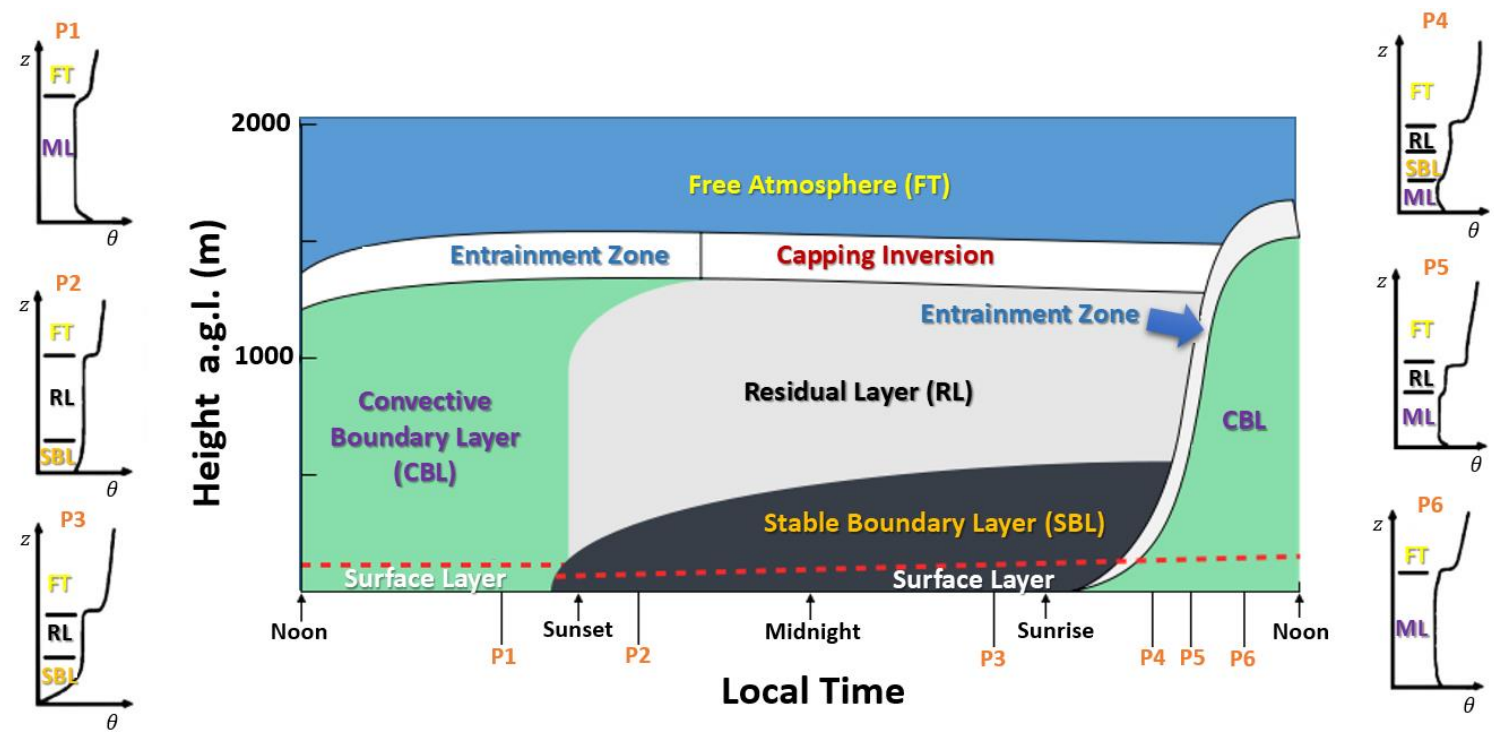

Figure 2.5: Idealized PBL daily cycle. Source: Adapted from STULL, 1988.

At the top of CBL there is a stable layer denominated Entrainment Zone (EZ), which acts as interface between the Free Atmosphere (FA) and the PBL. In this region there is not a strong mixing and the intensity of turbulence decays with the increase of height due to the high stability of this layer. Therefore, EZ works as barrier for the pollutants, keeping them in the ML (STULL, 1988).

Near the sunset, $R_{n}$ decreases considerably and approaches a change of sign, causing the attenuation of convective process. About half an hour before sunset a new RL 
appears and in the following hours, when occurs the inversion of $R_{n}$ signal, the SBL arises, so that it expands along the the night (figure $12-\mathrm{P} 2 \rightarrow \mathrm{P} 3$ ). During the night, the top of PBL is vertically limited by the Capping Inversion, which, like as EZ, acts as interface between the FA and the PBL. This region is characterized by high stability, preventing the output of pollutants from the PBL (WALLACE et al., 2005).

As time passes, the sunrise occurs again and this cycle restarts.

\subsubsection{Planetary Boundary Layer Height (PBLH)}

The height of PBL (Planetary Boundary Layer Height - PBLH) is an important parameter for a wide set of studies, which include pollutant dispersion, weather forecasting, meteorological modeling and air quality (LI et al., 2017). However, this height cannot be measured directly, but due to turbulent vertical process, some atmospheric variables as $\theta$, vertical wind speed $(w)$, and aerosols concentration have a characteristic profile that enable PBLH detection (Stull, 1988).

\subsubsection{PBLH from $\boldsymbol{\theta}$ profile}

Two methods widely applied in PBLH detection from $\theta$ profile are: Parcel Method (PM) and Temperature Gradient Method (GM).

The PM determines the PBLH as the altitude where an air parcel with an ambient temperature $T$ can rise adiabatically from the ground by convection (HOLZWORTH, 1964; COEN et al., 2014). This is equivalent to affirm that PBLH is the altitude $(z)$ where the $\theta(z)$ is equal to surface potential temperature, $\theta\left(z_{0}\right)$. Therefore, this method only can be applied in unstable situations (CBL), as shown in figure 2.6.

The TGM (STULL, 1988; COEN et al., 2014) detects the PBLH in stable situations based on two definitions: the first one relies on surface-based temperature inversion (SBI), and identifies the PBLH as the first height where $T$ decrease as a function of altitude (figure 2.7). The second one, based on the top of Stable Boundary Layer (TSBL), determines the PBLH as the first height where $\theta$ does not change in function of $\mathrm{z}$, in other words, $d \theta / d z=0$ (Fig. 2.7). In principle, this method detects the height where the SBI is situated in the $T$ profile. Then, from this height it is identified the TSBL in the $\theta(z)$ profile. 

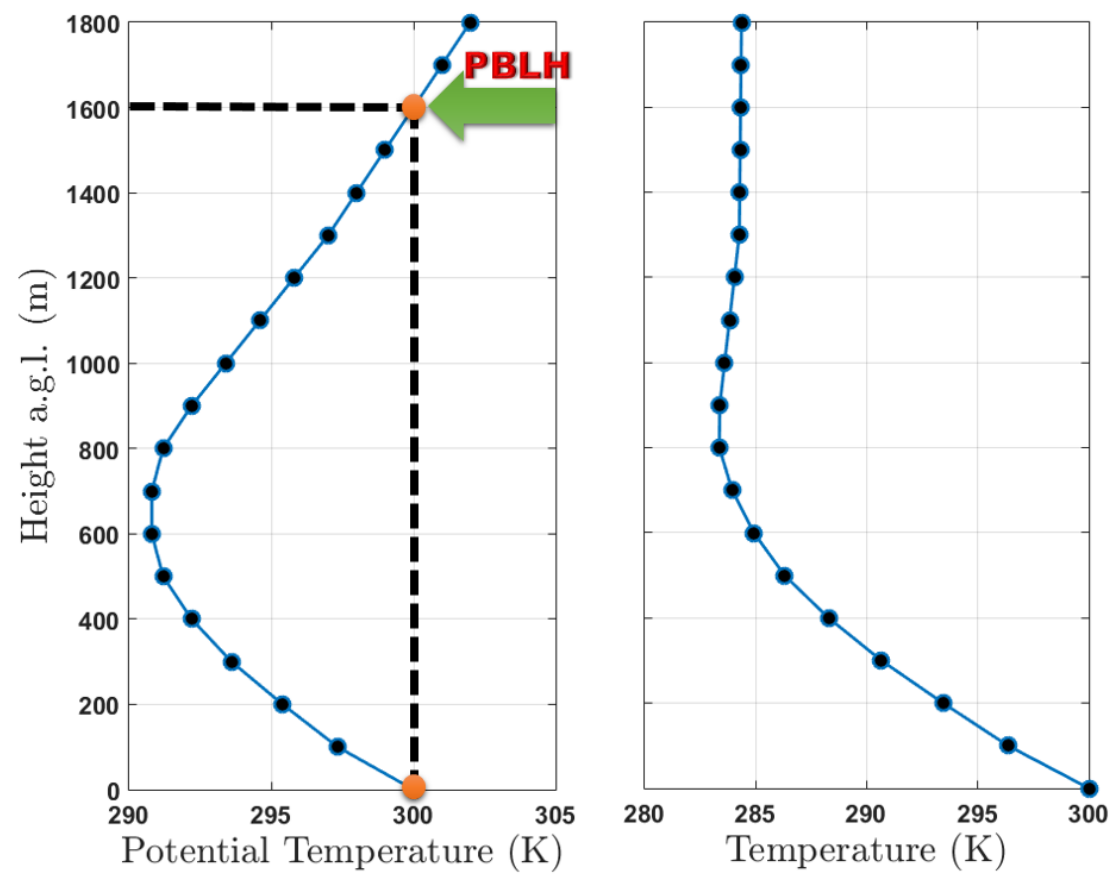

Figure 2.6: PBLH detected by Parcel Method. Potential Temperature (left) and Temperature (right). Source: Own author.
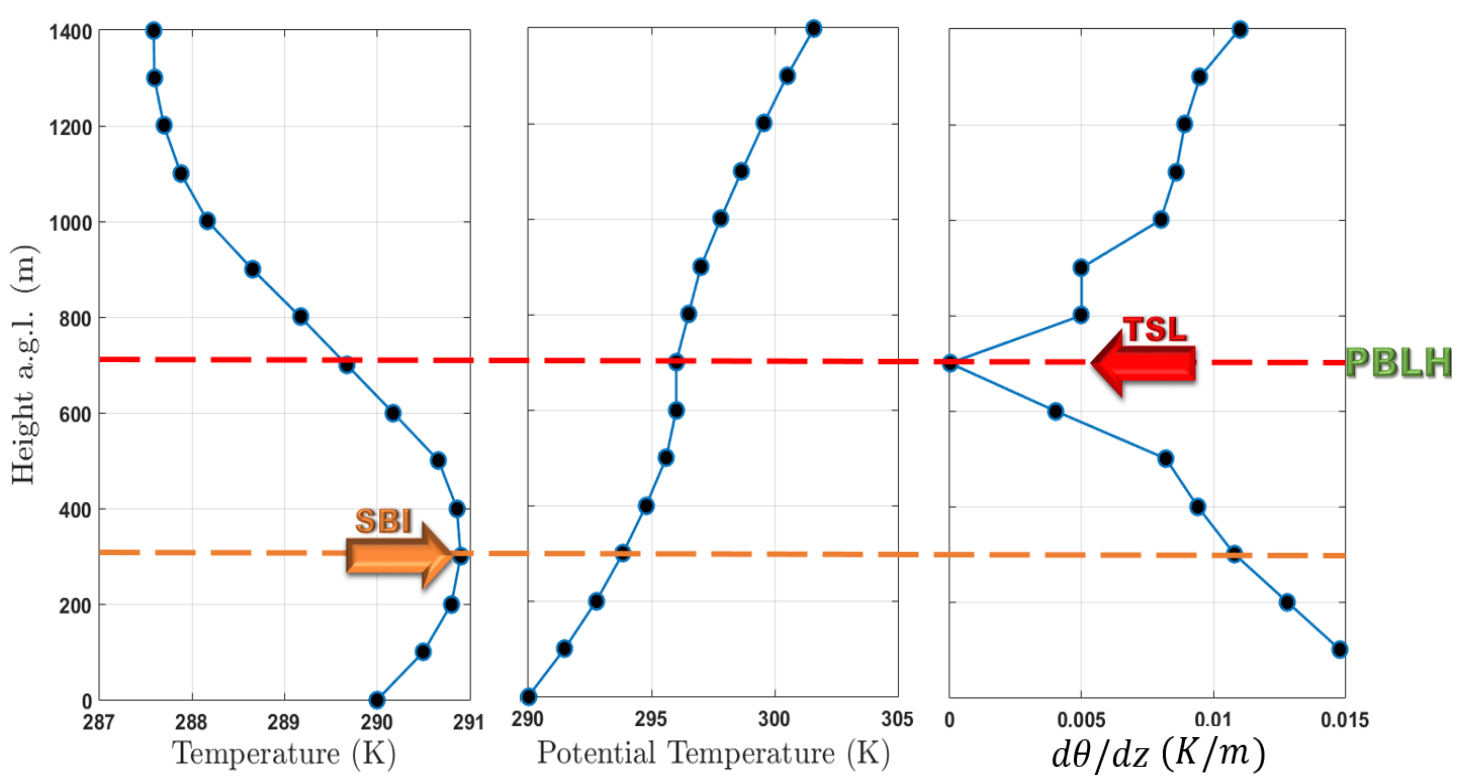

Figure 2.7: PBLH detected by Temperature Gradient Method from SBI and TSL height. Temperature (left), Potential Temperature (center) and Gradient of Potential Temperature (right). Source: Own author.

\subsubsection{PBLH from $\boldsymbol{w}$ profile}

The variance of vertical wind speed $\left(\sigma_{w}{ }^{2}\right)$ is used to estimate the vertical size of plumes growing due to homogeneous turbulent movement. Therefore, this variable is applied as an indicator of mixing layer height. Then, PBLH can be adopted as the first height where 
$\sigma_{w}{ }^{2}$ has a value lower than a predetermined threshold (th) (SCHWEEN et al., 2014). More information about this method will be presented in chapter 4 .

\subsubsection{PBLH from vertical aerosol concentration}

The PBLH can be obtained from vertical aerosol profiles based on the Deadorff's definition of Mixing Layer (ML), that is the "height where there are equal areas of clear air below and particulates above" (DEADORFF et al., 1980). Therefore, the PBLH "is taken to be the midpoint of the transition region between the areas of higher and lower backscattering" generated by the aerosols. Some methods based on this PBLH definition will be described in chapter 4 .

\subsubsection{Statistical Moments}

The turbulent processes are treated as nondeterministic, therefore their statistical properties are used to characterize and describe them. In atmospheric studies, this kind of analysis is applied in order to provide information about the turbulent fluctuation field, besides a description about mixing process in the PBL (PAL et al., 2010).

Considering the existence of a variable $q$ with its values as functions of time (figure 2.8), we can affirm it is composed of a mean value $\bar{q}$ and its fluctuations $q^{\prime}$, as describe by Reynold's decomposition:

$$
\boldsymbol{q}=\overline{\boldsymbol{q}}+\boldsymbol{q}^{\prime} \quad(2.1-\text { Stull, } 1988)
$$

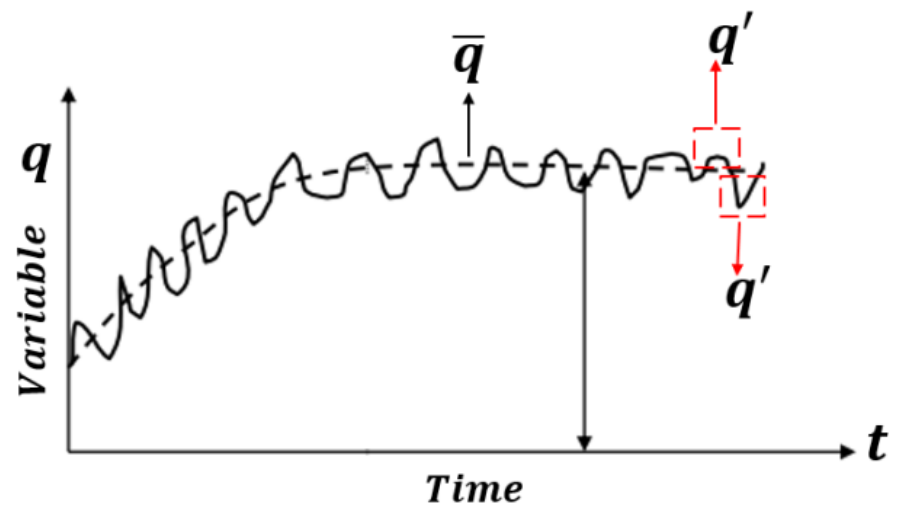

Figure 2.8: Turbulent variable $q^{\prime}$. Source: Own author.

From this concept, the following statistical moments can be found: 
- Variance $\left(\overline{\boldsymbol{q}^{\prime 2}}\right) \rightarrow$ It measures how far a set of data are spread out from their average value.

$$
\overline{q^{\prime 2}}=\frac{1}{T} \sum_{t=1}^{T}\left(q^{\prime}(t)-\bar{q}^{\prime}\right)^{2}
$$

- Skewness $(\boldsymbol{S}) \rightarrow$ It is a measure of the asymmetry of the probability density of random variable $(\boldsymbol{q})$ about its mean. Positive values of skewness indicate that the tail on the upper side of the probability density function $F(q)$ is longer or fatter than the bottom side (figure 2.9).

$$
S=\frac{\overline{q^{\prime 3}}}{\sigma_{q^{\prime}}^{3}}
$$

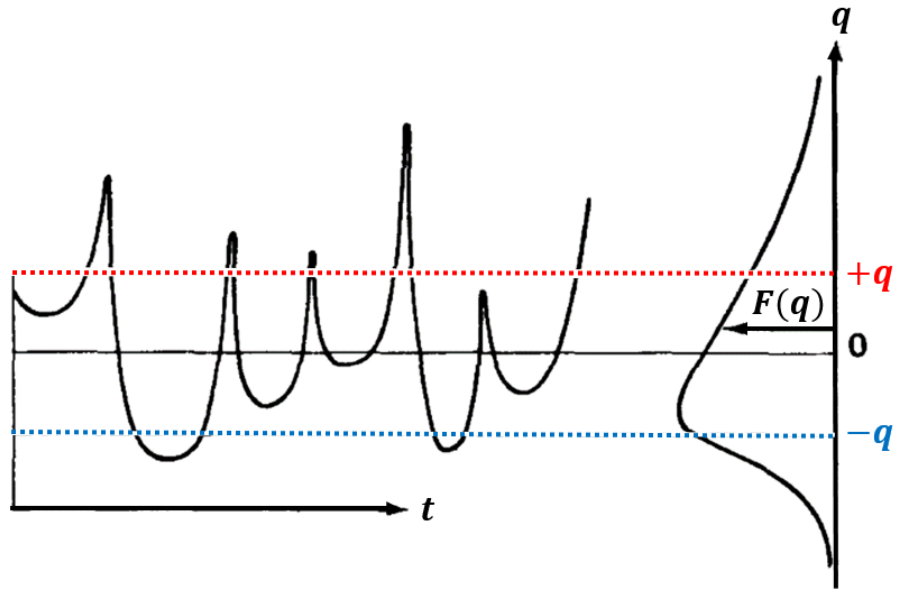

Figure 2.9: Skewness. Source: Own author.

- Kurtosis $(\boldsymbol{K}) \rightarrow$ It is a measure of the "tailedness" of the probability density function of a random variable $(\boldsymbol{q})$. The value of $\boldsymbol{K}$ of a normal distribution is 3, so values of $\boldsymbol{K}<3$ represent a flatness distribution, while $\boldsymbol{K}>3$ indicate a peaked distribution (figure 2.10).

$$
K=\frac{\overline{q^{\prime 4}}}{\sigma_{q^{\prime}}^{4}}
$$



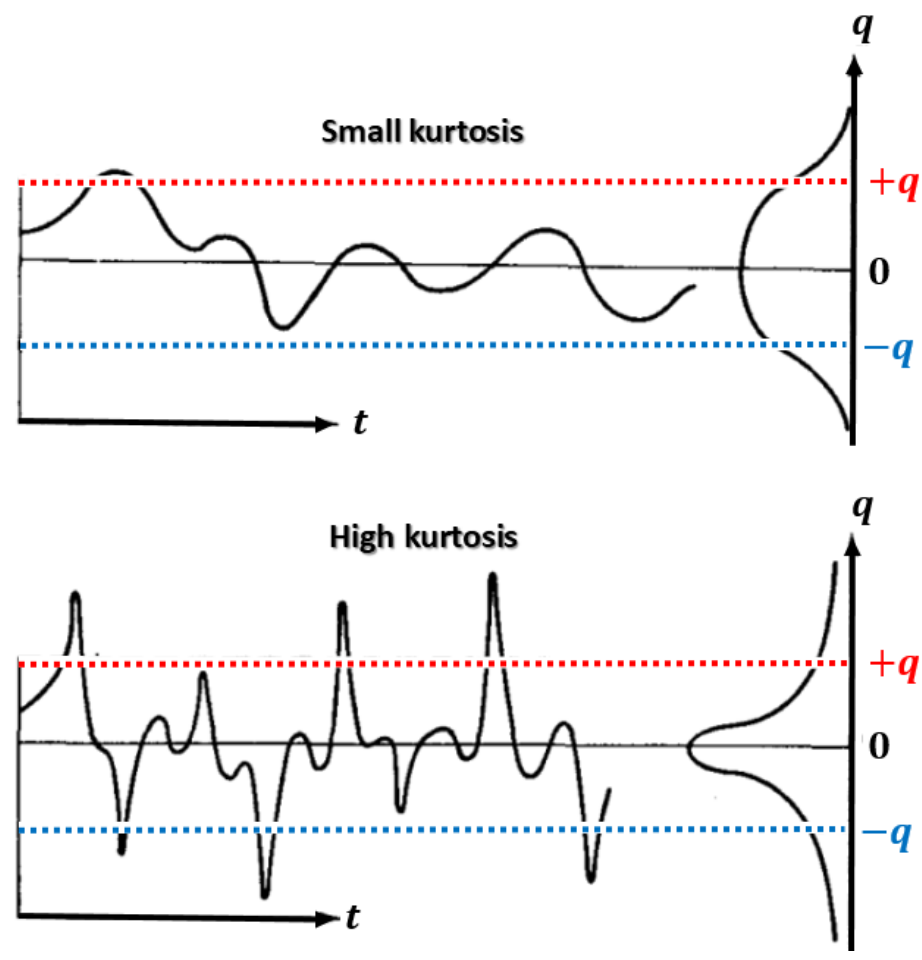

Figure 2.10: Kurtosis. Source: Own author.

The PBL studies mentioned in the subsections above are mainly based on the use of the following equipment: radiosonde (PBLH detection), anemometer towers and aircrafts (studies about turbulence). The utilization of radiosondes are the most widespread method in PBLH detection. However, they are frequently launched only twice per day, so that, due to high variability of PBL during its daily cycle, the continuous monitoring of PBLH evolution is unfeasible. Anemometer towers (Kaimal and Gaynor, 1983; van Ulden and Wieringa, 1996) and aircrafts (Lenschow et al., 1980; Williams and Hacker, 1992; Lenschow et al., 1994; Albrecht et al., 1995; Stull et al., 1997; Andrews et al., 2004; Vogelmann et al., 2012) have been widely applied in studies about turbulence in PBL. Nevertheless, the utilization of anemometer towers restricts the analysis to regions near to surface, due to its limited vertical resolution. Although this problem can be solved by aircrafts, they have a short time window limiting the period of analysis. In this scenario, remote sensing systems arise as important tools for this kind of studies, because their high temporal and spatial resolution enables a continuous PBL monitoring at a wider range of height levels. 


\subsection{Remote Sensing Systems}

Remote sensing "is the science and technology of obtaining information about an object without having the sensor in direct physical contact with the object" (NOAA). In the modern remote sensing the most common interaction used is by radiation (electromagnetic radiation and acoustic waves), so that, radiation properties are modified by object during the interaction, therefore, information about object can be obtained from the analysis of these variations.

These systems can be classified as passive or active. The passive systems respond to external stimuli, in the other words, the sensing is performed by the utilization of naturally occurring radiation, such as sunlight or nightglow. The active systems use selfgenerated radiation sources, as laser-beam, microwave, acoustic wave, radio wave, etc.

In the next subsections will be described some remote sensing systems widely applied in studies about PBL.

\subsubsection{Lidar Systems}

LIDAR is the acronym of LIght Detection And Ranging, a remote sensing technique based on same physical principles of radar, but instead of radio waves a pulsed beam of light is emitted towards the atmosphere.

In general, the operation of the lidar system occurs as follows: A laser (1) emits a beam of light with intensity $F$, which propagates through the atmosphere and it is attenuated throughout the path. Because at each height reached, a fraction of the emitted beam is scattered by atmospheric particles and molecules. The scatter can be elastic (the scattered light has the same wavelength of the light emitted by the laser) or inelastic (the wavelength of the scattered light is different of that one emitted by the laser). 


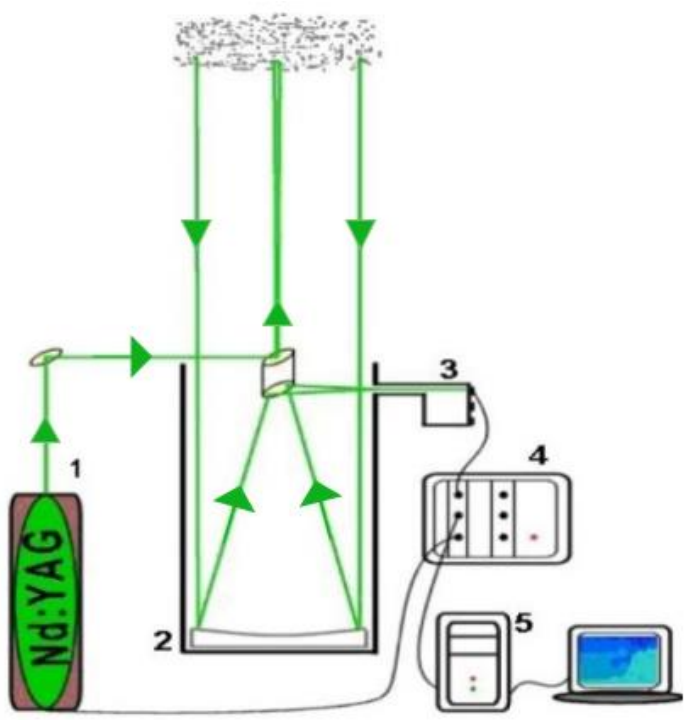

Figure 2.11: Representation of a lidar system. Source: Adapted from Lopes, 2014.

Only a small portion of scattered beam return to detection lidar system, so that, this backscattered beam is collected by a set of refractive and reflective optics instruments (Telescope -2), which are responsible for collecting and focusing the backscattered light on the photodetector. Due to the light of laser to be practically monochromatic, narrowband filters are applied in order to reduce some interferences, like as: light from other sources, mainly the Sun.

After being captured, the beam is transferred to a fast response detector, a photomultiplier or solid state detector (3), in which it is generated an electric signal that has an intensity, at any instant, proportional to the received optical power. Then this signal is sent to a detection system (4), which adds the signal and guarantees the data acquisition sending them to computer.

The lidar signal can be write mathematically, considering elastic scattering, from the following expression:

$$
P(r)=P_{0} \frac{c \tau}{2} A \frac{\beta(r)}{r^{2}} e^{-2 \int_{0}^{r} \sigma\left(r^{\prime} d r^{\prime}\right)}
$$

where:

- $P(r)$ is the signal [W] returned from distance $r$ at time $t$;

- $r$ is the distance $[\mathrm{m}]$ of the volume investigated in the atmosphere;

- $P_{0}$ is the acquired signal $[\mathrm{W}]$ at time $t$; 
- $c$ is the light speed $[\mathrm{m} / \mathrm{s}]$;

- $\tau$ is the duration of laser pulse [ns];

- $A$ is the area $\left[\mathrm{m}^{2}\right]$ of telescope cross section;

- $\beta(r)$ is the backscatter coefficient $\left[(\mathrm{km} \cdot \mathrm{sr})^{-1}\right]$ at distance $r$;

- $\sigma(r)$ is the extinction coefficient $\left[(\mathrm{km})^{-1}\right]$ at distance $r$;

Figure 2.12 demonstrates a classification of some lidar systems by its physical process. In this work, the studies were performed using Doppler and Elastic lidar.

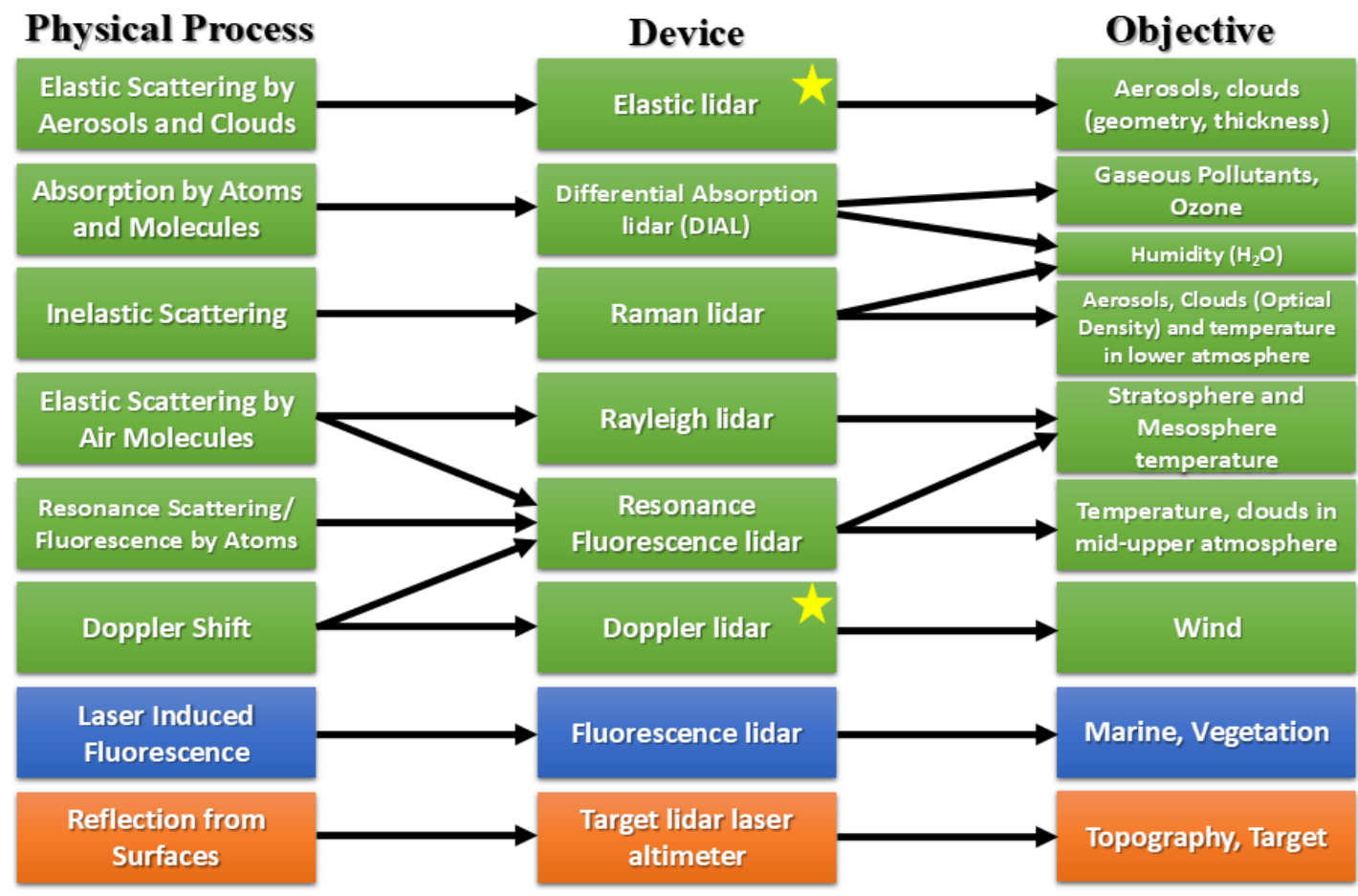

Figure 2.12: Lidar systems classified by its physical process. Yellow stars indicate the lidar systems used in this study. Source: Own author

\subsubsection{Doppler lidar}

This kind of lidar system transmits light from a laser with a wavelength in the near infrared band (around $1.5 \mu \mathrm{m}$ ). It detects Doppler shift in the backscattered light from the small aerosols suspends and moving with the air aloft. Then the wind speed can be estimated from the detection of this shift (Weitkamp, 2005).

In the optical Doppler effect there is not distinction between the case of moving transmitter/receiver or both. Therefore, considering some aerosols with a relative speed $v$ along the line of sight and illuminated by a emitted light with the wavelength $\lambda_{0}$, at frequency $f_{0}$, the apparent frequency of the emitted light on the aerosols particles $(f)$ can be write as: 


$$
f=f_{0}\left(1+\frac{v}{c}\right)
$$

where $c$ is the light speed. However, the light is backscattered, at frequency $f$, but due to the movement of particle during scattering, $f$ is detected by the lidar receiver as being shifted to frequency (figure 2.13):

$$
f=f_{0}+\Delta f=f_{0}\left(1+\frac{2 v}{c}\right)
$$

The signal of speed is obtained from the following concept: if the particle movement is toward the lidar and leading to a positive frequency shift, so the particles velocity, wind velocity, line-of-sight velocity $\left(v_{L O S}\right)$ or radial velocity $\left(v_{r}\right)$, as is more commonly denominated, is classified as positive. In the reverse situation $v_{r}$ is considered as negative.

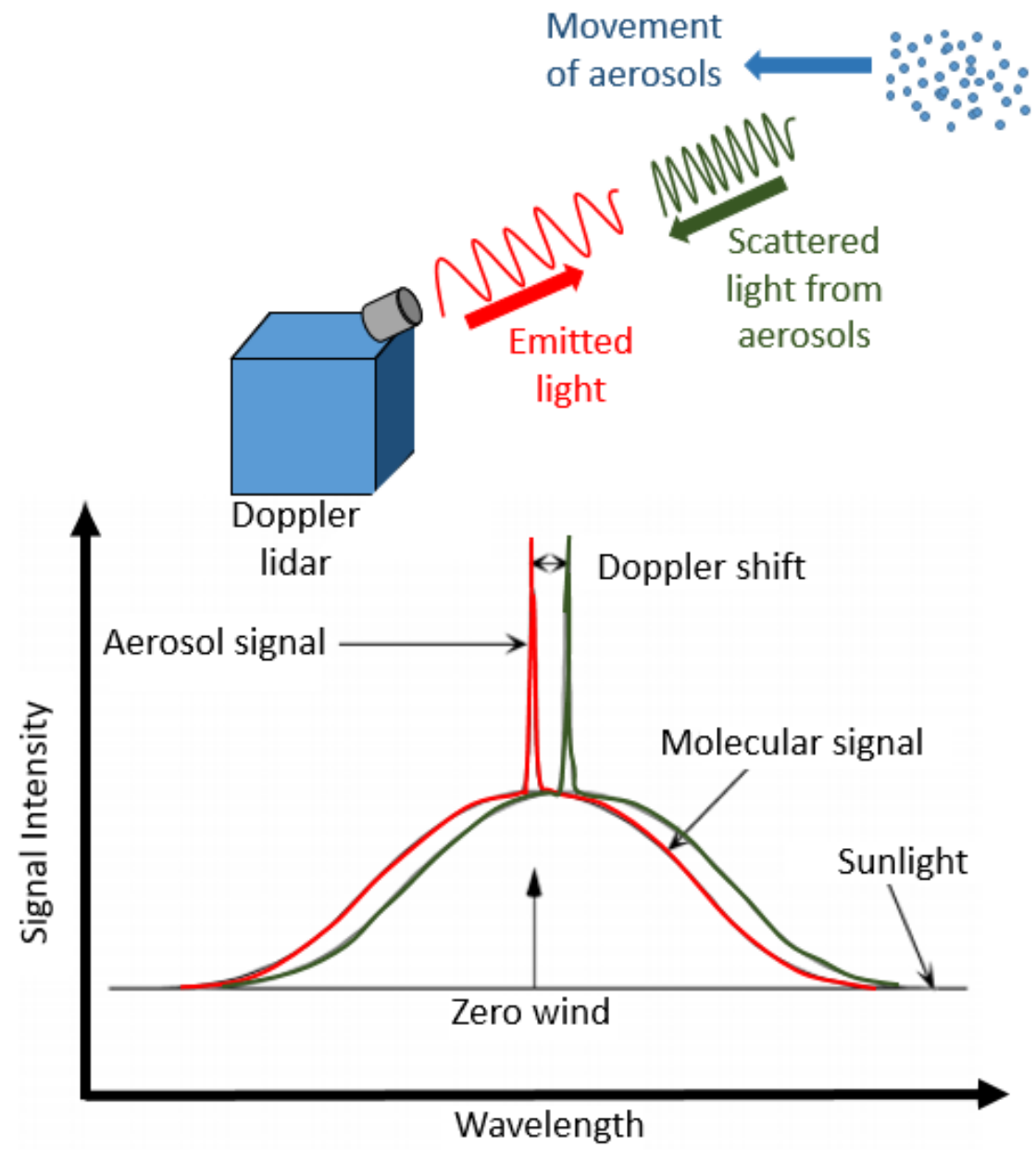

Figure 2.13: Doppler lidar emission and frequency shifting. Source: Own author. 


\subsubsection{Ceilometer}

Ceilometers work similarly to elastic lidar system, so that the equation 2.4 also can be applied to this kind of system. The main disadvantages are its smaller range, noisier signal while its advantages are the capability of operating continuously and to be fully automated. This instrument is widely used by aviation control entities, being often applied in the detection of cloud base and ML height. Figure 2.14 demonstrates a simplified diagram of a ceilometer, where are presents the elements $1-4$ of figure 2.11 .

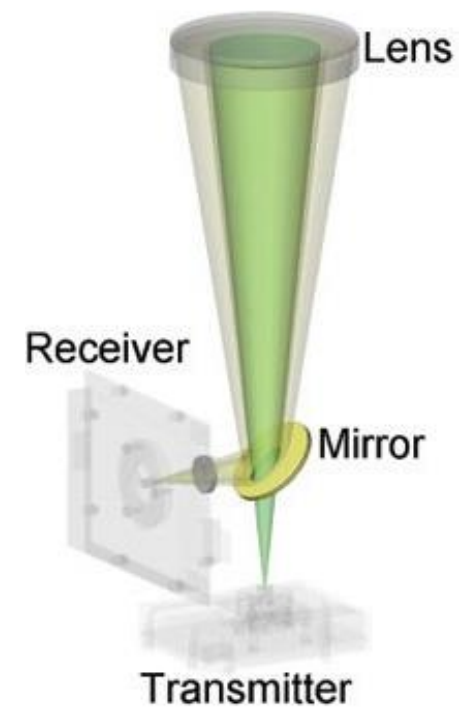

Figure 2.14: Ceilometer. Source: Münkel, 2007.

\subsubsection{Passive Microwave Radiometer (MWR)}

The passive MWR measures electromagnetic radiation (brightness temperature) at frequency of microwave emitted by atmospheric gases. In atmospheric studies this equipment is often applied in detection of humidity and temperature profiles (Skou, et al., 2006).

Several atmospheric gases have rotational lines in the microwave range, from their specific emission features it is possible to derive information about their abundance and vertical profile. For example, applying inversion algorithms, the vertical humidity and temperature profiles can be obtained from the water vapor emission around the band of $22.235 \mathrm{GHz}$ and from the oxygen emission around the complex band $60 \mathrm{GHz}$, respectively, so that the emission at any height is proportional to value of the abundance of the corresponding gas (Skou, et al., 2006). 
Figure 2.15 shows a block diagram of a MWR, which consists of an antenna system, microwave radio-frequency components (front-end) and a back-end for signal processing at intermediate frequencies. Because the atmospheric signal can be very weak it is common the utilization of amplifiers.

Firstly, the antenna receives the thermal emission from the target, so that MWR spatial resolution is given by the refraction limited beam width of the antenna. The calibration unit plays a fundamental role minimizing unavoidable gains drifts and fluctuations. Then signal is downconverted to the intermediate frequency by a stable local oscillator signal. So, it is amplified by a Low Noise Amplifier (LNA) and band pass filtering. Thus, the real time spectral analyzer is used for solving the line shape of the emission line. Finally the data display, storage and processing provide the sought parameter.

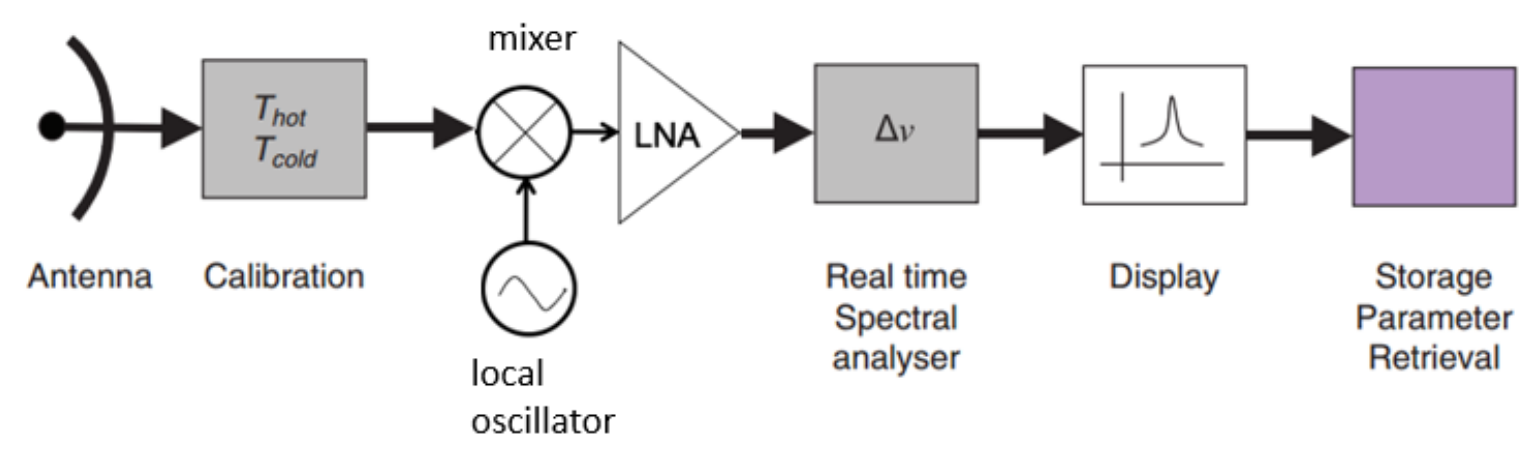

Figure 2.15: Schematic internal structure of a MWR. Source: Adapted from Kunzi et al., 2011.

\subsubsection{Pyranometer}

Pyranometers measure hemispherical solar radiance within a 180-degree field of view.

This system consists basically of a thermopile sensor beneath a glass dome. The thermopile absorbs all the solar radiation and generates a small, proportional output voltage (Woodford, 2017).

Figure 2.16 demonstrates a representation of a pyranometer:

1- Outer dome made from a hemisphere of optical-quality glass;

2- Inner dome made from a smaller hemisphere of optical glass; 
3- Black carbon disk: It is illuminated by the Sun and absorbs a broad range of wavelengths of solar radiation. It also acts as the sensing element;

4- Second control disk: It is not illuminated by the Sun and acts as a comparison and compensating element;

5- Thermopile temperature sensor: It compare the temperature rise of the two disks (3 and 4);

6- Output lead;

7- Silica gel cartridge;

8- Adjustable screw legs;

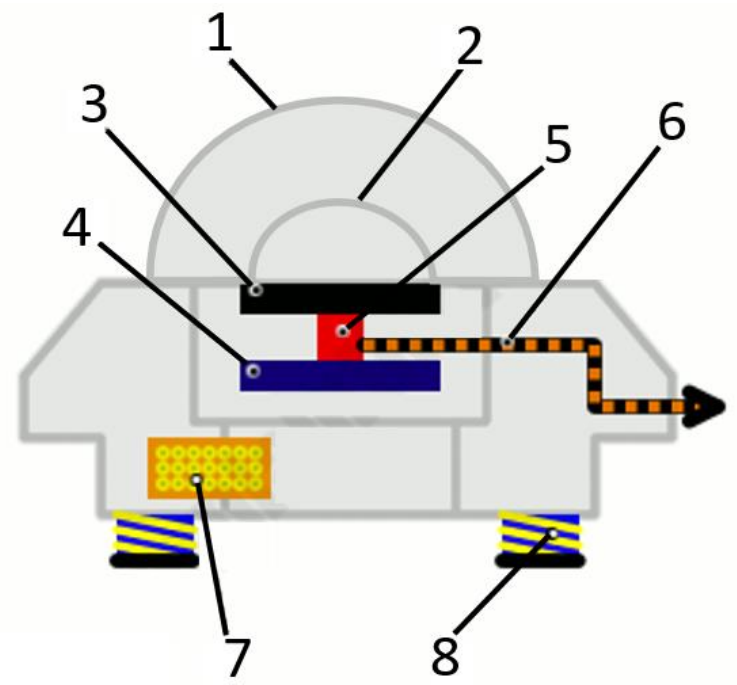

Figure 2.16: Pyranometer. Source: Woodford, 2017. 


\title{
3 Experimental site and Instruments
}

\begin{abstract}
This chapter presents the two sites where the studies were performed: Granada (Spain) and São Paulo (Brazil), as well as, the technical specifications of passive and active remote sensing systems, and other instruments used in measurement campaigns.
\end{abstract}

\subsection{Sites}

The two places where the studies presented in this thesis have been developed have distinct climatological and topographic characteristics. So that the observational study of these regions offers an opportunity for understanding better the differences and similarities of the PBL in distinct regions.

\subsubsection{Granada station}

The measurement campaigns performed in Spain were carried out at the Andalusian Institute of Earth System Research (IISTA-CEAMA). This station is part of EARLINET (Pappalardo et al, 2014) since 2004 and at present is an active station of ACTRIS (http://actris2.nilu.no/).

This station is located at the city of Granada, a medium sized non-industrialized city in the Southeastern Spain (Granada, $37.16^{\circ} \mathrm{N}, 3.61^{\circ} \mathrm{W}, 680 \mathrm{~m}$ a.s.1.) (Figure 3.1), with around 350000 inhabitants (INE, 2017). 


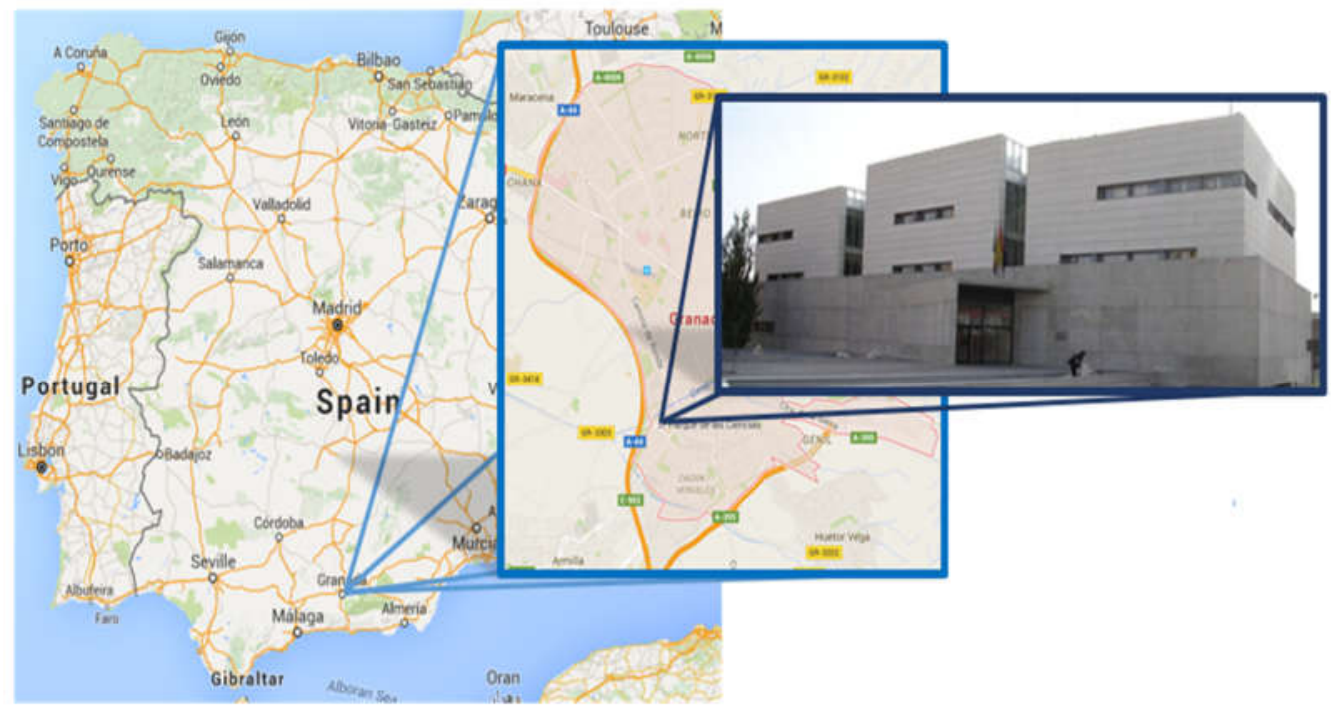

Figure 3.1 - IISTA-CEAMA. Source: Own author

Table 3.1 - Climatological values of meteorological station Granada airbase (37 8' 14' ' N, 3'37'53" W) from the period $1980-2010$. $\mathrm{T}$ (temperature), $\mathrm{T}_{\mathrm{m}}$ (minimal temperature), $\mathrm{T}_{\mathrm{M}}$ (maximum temperature), $\mathrm{R}_{\mathrm{f}}$ (Rainfall), RH (Relative Humidity), $\mathrm{D}_{\mathrm{R}}$ (number of days with rainfall greater than $1 \mathrm{~mm}, \mathrm{D}_{\mathrm{S}}$ (number of snowy days), $\mathrm{H}_{\mathrm{SH}}$ (mean number of hours of sunshine). Source (www.aemet.es)

\begin{tabular}{|c|c|c|c|c|c|c|c|c|}
\hline Months & $\mathrm{T}\left({ }^{\circ} \mathrm{C}\right)$ & $\mathrm{T}_{\mathrm{m}}\left({ }^{\circ} \mathrm{C}\right)$ & $\mathrm{T}_{\mathrm{M}}\left({ }^{\circ} \mathrm{C}\right)$ & $\mathrm{R}_{\mathrm{f}}(\mathrm{mm})$ & $\mathrm{RH}(\%)$ & $\mathrm{D}_{\mathrm{R}}$ (days) & $\mathrm{D}_{\mathrm{S}}$ (days) & $\mathrm{H}_{\mathrm{SH}}(\mathbf{h o u r s})$ \\
\hline January & 7 & 1 & 13 & 41 & 72 & 6 & 1 & 170 \\
February & 8 & 2 & 15 & 33 & 68 & 6 & 1 & 172 \\
March & 11 & 5 & 18 & 35 & 60 & 5 & 0 & 219 \\
April & 13 & 7 & 20 & 37 & 57 & 6 & 0 & 234 \\
May & 17 & 10 & 24 & 30 & 51 & 5 & 0 & 280 \\
June & 22 & 15 & 30 & 11 & 43 & 2 & 0 & 331 \\
July & 26 & 18 & 34 & 2 & 37 & 0 & 0 & 362 \\
August & 25 & 18 & 33 & 3 & 41 & 1 & 0 & 330 \\
September & 22 & 14 & 29 & 23 & 51 & 3 & 0 & 254 \\
October & 16 & 10 & 23 & 38 & 62 & 5 & 0 & 211 \\
November & 11 & 5 & 16 & 50 & 71 & 7 & 0 & 164 \\
December & 8 & 3 & 13 & 50 & 75 & 7 & 0 & 148 \\
\hline Year & 16 & 9 & 22 & 352 & 57 & 52 & 2 & 2881 \\
\hline
\end{tabular}

Granada is surrounded by mountains and dominated by Mediterraneancontinental conditions, which are responsible for large seasonal temperature differences, providing cool winters and hot summers. The most humid period goes from late autumn to early spring. The rest of the year is characterized by rain scarcity. Table 3.1 presents the main climatological variables of Granada obtained between 1980 to 2010 (AEMET, 2017). 
Granada is predominantly affected by aerosol particles coming from Europe and mineral dust particles from the African continent (Lyamani et al., 2006a, b; GuerreroRascado et al., 2011a, .b; Titos et al., 2012; Navas-Guzmán et al., 2013; Valenzuela et al., 2014). Main local sources are road traffic, domestic-heating and biomass burning (mostly in winter time) (Titos et al., 2017). Transported smoke principally from North America, North Africa and the Iberian Peninsula can also affect the study area (Alados-Arboledas et al., 2011; Pereira et al., 2013; Navas-Guzmán et al., 2013; Preißler et al., 2013; Pereira et al., 2014; Ortiz-Amezcua et al., 2014, 2017).

\subsubsection{São Paulo station}

The measurement campaign performed in Brazil was carried out at LEAL (Laser Environmental Applications Laboratory). This station is part of LALINET (AntuñaMerrero, 2017) since 2001.

This research center is located at IPEN/CNEN (Institute of Research and Nuclear Energy) in São Paulo (23 33' S, 46 38' W, $760 \mathrm{~m}$ asl) (Figure 3.2), the largest metropolis in South America, with a population of around 12000000 inhabitants (IBGE, 2017).

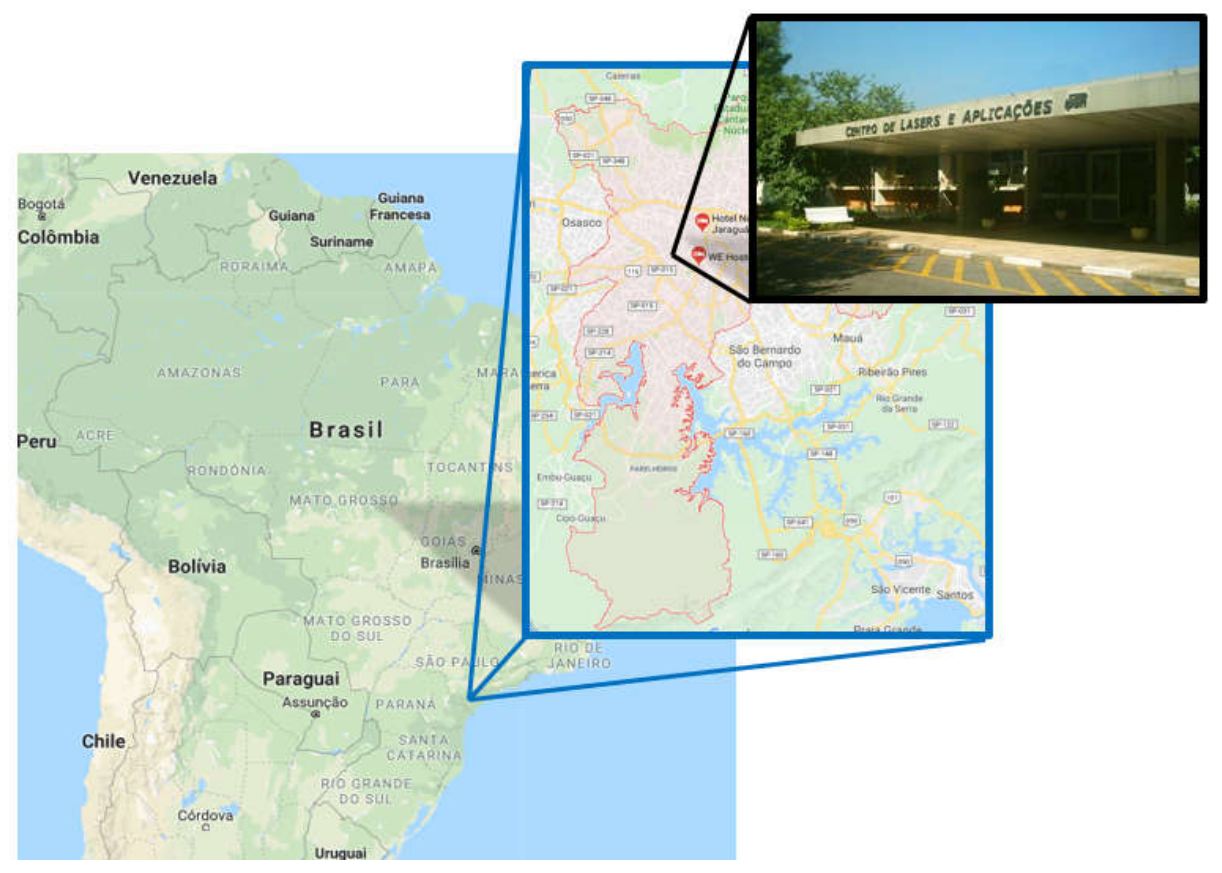

Figure 3.2 - IPEN-CLA. Source: Own author 
Table 3.2 - Climatological values of meteorological station Mirante de Santana (2329' 46' ' S, 46 37' $11^{\circ}$ ' W) from the period 1961 - 2016. $\mathrm{T}$ (temperature), $\mathrm{T}_{\mathrm{m}}$ (minimal temperature), $\mathrm{T}_{\mathrm{M}}$ (maximum temperature), $\mathrm{R}_{\mathrm{f}}$ (Rainfall), RH (Relative Humidity), $\mathrm{D}_{\mathrm{R}}$ (number of days with rainfall greater than $1 \mathrm{~mm}, \mathrm{D}_{\mathrm{S}}$ (number of snowy days), $\mathrm{H}_{\mathrm{SH}}$ (mean number of hours of sunshine). Source (www.inmet.gov.br)

\begin{tabular}{|c|c|c|c|c|c|c|c|c|}
\hline Months & $\mathrm{T}\left({ }^{\circ} \mathrm{C}\right)$ & $\mathrm{T}_{\mathrm{m}}\left({ }^{\circ} \mathrm{C}\right)$ & $\mathrm{T}_{\mathrm{M}}\left({ }^{\circ} \mathrm{C}\right)$ & $\mathrm{R}_{\mathrm{f}}(\mathrm{mm})$ & $\mathrm{RH}(\%)$ & $\mathrm{D}_{\mathrm{R}}$ (days) & $\mathrm{D}_{\mathrm{S}}($ days $)$ & $\mathrm{H}_{\mathrm{SH}}(\mathrm{hours})$ \\
\hline January & 22 & 19 & 27 & 218 & 80 & 15 & 0 & 171 \\
February & 22 & 19 & 28 & 205 & 79 & 14 & 0 & 162 \\
March & 22 & 18 & 27 & 149 & 80 & 11 & 0 & 167 \\
April & 20 & 16 & 25 & 64 & 80 & 7 & 0 & 166 \\
May & 17 & 14 & 23 & 56 & 79 & 6 & 0 & 182 \\
June & 16 & 12 & 22 & 49 & 78 & 4 & 0 & 173 \\
July & 16 & 12 & 22 & 35 & 77 & 4 & 0 & 187 \\
August & 17 & 13 & 23 & 43 & 74 & 4 & 0 & 175 \\
September & 18 & 14 & 24 & 71 & 77 & 7 & 0 & 153 \\
October & 19 & 15 & 25 & 123 & 79 & 10 & 0 & 154 \\
November & 20 & 17 & 26 & 137 & 78 & 11 & 0 & 163 \\
December & 21 & 18 & 26 & 190 & 80 & 14 & 0 & 151 \\
\hline Year & 19 & 16 & 25 & 1340 & 78 & 107 & 0 & 2003 \\
\hline
\end{tabular}

São Paulo is situated on a wide plateau and it is dominated by a humid subtropical climate with relatively well-defined seasons. Winter is mild and sub-dry, and summer is moderately hot and rainy. Spring and autumn are transitions seasons endowed with intermediate features. The proximity to the ocean prevents from intense temperature variations. Table 3.2 demonstrates the main climatological variables of São Paulo obtained between 1961 to 2016 (INMET, 2017).

The air pollution in this city is intense, mainly due to heavy vehicle traffic. In 2011 the high levels of air pollution caused more deaths than traffic accidents (VORMITTAG, 2013). 


\subsection{Instruments}

\subsubsection{Lidar}

3.2.1.1 Multiwavelenght elastic-raman lidar

\subsection{MULHACEN}

The biaxial ground-based multiwavelenght elastic-raman lidar system MULHACEN is situated at IISTA-CEAMA and it is part of the EARLINET (Pappalardo et al, 2014) and SPALINET (Sicard et al, 2009) networks. MULHACEN operates with a pulsed $\mathrm{Nd}$ :YAG laser, frequency doubled and tripled by Potassium Dideuterium Phosphate crystals. It emits at the wavelengths 355, 532 and $1064 \mathrm{~nm}$ with output energies per pulse of 60, 65 and $110 \mathrm{~mJ}$, respectively. It has three elastic channels, which are 355, 532 (s- and p-polarized) and $1064 \mathrm{~nm}$, and three Raman-shifted channels, which are 387 (from $\mathrm{N}_{2}$ ), 408 (from $\mathrm{H}_{2} \mathrm{O}$ ) and 607 (from $\mathrm{N}_{2}$ ) nm. MULHACEN has a nominal spatial resolution of $7.5 \mathrm{~m}$. The overlap is

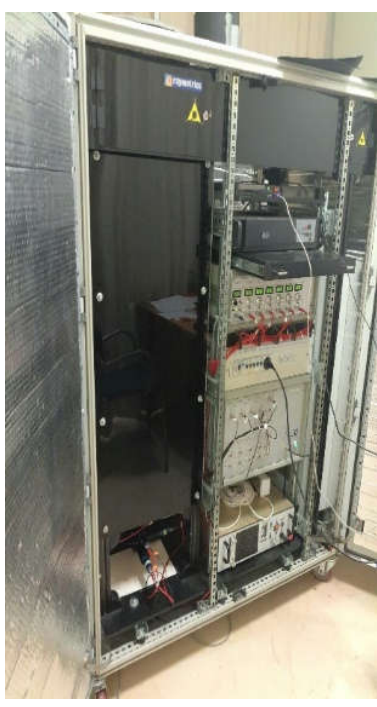

Figure 3.3 - MULHACÉN.

Source: Own author complete at $90 \%$ between 520 and $820 \mathrm{~m}$ agl for all the wavelengths and full overlap is reached around $1220 \mathrm{~m}$ agl (Navas-Guzmán et al., 2011). Further technical details can be found at Guerrero-Rascado et al. (2008, 2009). 


\subsection{MSP-I}

MSP-I is a coaxial ground-based multiwavelenght elastic-raman lidar system. It is situated at LEAL and it is part of the LALINET. This system operates with a pulsed Nd:YAG laser, frequency doubled and tripled by Potassium Dideuterium Phosphate crystals. It emits in the follow wavelengths 355, 532 and 1064. MSP-I operates with three elastic channels: 355, 532 and $1064 \mathrm{~nm}$ and three Raman-shifted

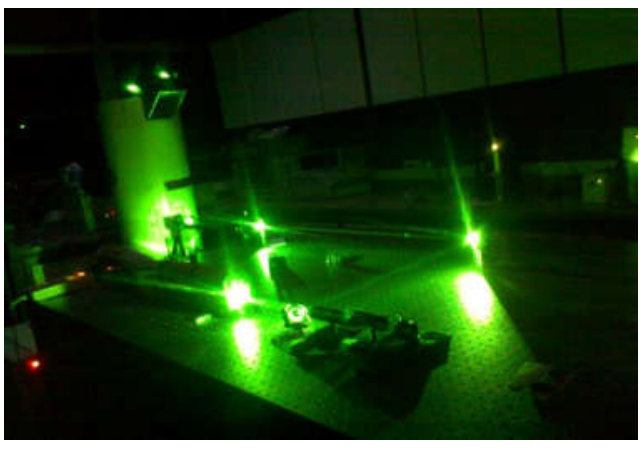

Figure 3.4 - MSP-I. Source:

Own author channels: 387 (from N2), 408 (from H2O) and 607 (from N2) nm. The MSP-I full overlap is reached around $300 \mathrm{~m}$ agl. This system was operated with a temporal and spatial resolution of $2 \mathrm{~s}$ and $7.5 \mathrm{~m}$, respectively.

\subsubsection{Doppler lidar}

The coherent $D L$ (Halo Photonics) model Stream Line is operating in continuous and automatic mode since May 2016. This system uses heterodyne detection to measure the Doppler shift of backscattered light. It operates an eye-safe laser transmitter vertically pointing to zenith emitting at $1.5 \mu \mathrm{m}$ with pulse energy and repetition rate of $100 \mu \mathrm{J}$ and $15 \mathrm{KHz}$, respectively. The DL records the backscattered signal with 300 gates, where the range gate length is $30 \mathrm{~m}$ and its first gate is

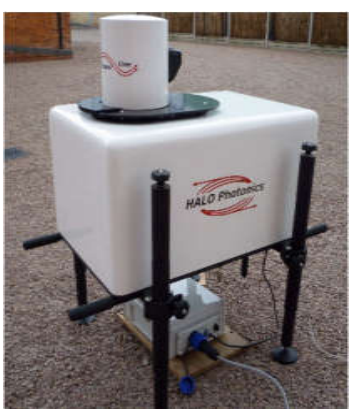

Figure 3.5 - Doppler lidar. Source: Own author located at $60 \mathrm{~m}$. The data acquisition is performed in Stare mode (only the vertical wind speed is measured) with a time resolution of $2 \mathrm{~s}$. 


\subsubsection{Ceilometer}

The ceilometer Jenopitk model CHM15k is operated at the IISTA-CEAMA station. The system is part of the Iberian Ceilometer Network, an initiative of the Atmospheric Physics Group of the University of Granada that coordinates a network of ceilometers (ICENET) combined with Sun-photometers for the characterization of atmospheric aerosol with the objective of obtaining reliable vertically resolved aerosol optical properties in near realtime (Cazorla et al, 2017). It operates with a pulsed Nd:YAG laser emitting at $1064 \mathrm{~nm}$ and a telescope with a field of view of $0.45 \mathrm{mrad}$. The energy per pulse is $8.4 \mu \mathrm{J}$ with a repetition frequency in the range of 5-7 kHz. The laser beam divergence is less than $0.3 \mathrm{mrad}$. The spatial and temporal resolution used are $15 \mathrm{~m}$ and $15 \mathrm{~s}$, respectively (Cazorla et

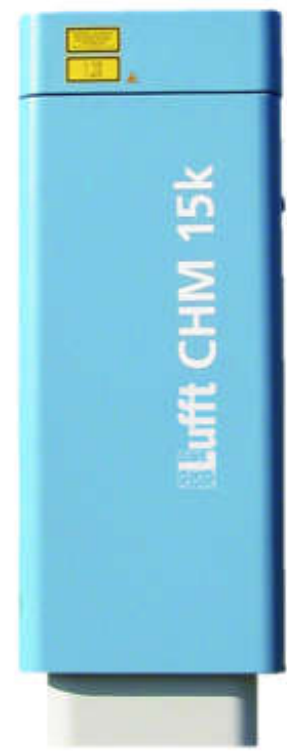

Figure 3.6- Ceilometer. Source: Own author al., 2017). This equipment has been operating continuously since December 2012.

Table 3.3 shows the main technical features of lidar and ceilometers systems utilized in this work.

\begin{tabular}{l|c|c|c|c|}
\hline Instrument & MULHACÉN & MSP-I & Ceilometer & Doppler \\
\cline { 2 - 5 } Localization & Granada & São Paulo & Granada & Granada \\
\hline Pulse laser source & Nd: YAG & Nd: YAG & Nd: YAG & $\begin{array}{c}\text { Eye safe } \\
\text { Class } 1 \mathrm{M}\end{array}$ \\
\hline Wavelength (Pulse & $355(60 \mathrm{~mJ}), 532$ & $355(230 \mathrm{~mJ})$, & $1064 \mathrm{~nm}$ & $1.5 \mu \mathrm{m}$ \\
$(65 \mathrm{~mJ}) \mathrm{and} 1064$ & $532(400 \mathrm{~mJ})$ & $(8.4 \mu \mathrm{J})$ & $(100 \mu \mathrm{J})$ \\
energy) & $(110 \mathrm{~mJ}) \mathrm{nm}$ & $\begin{array}{c}\text { and } 1064 \\
(850 \mathrm{~mJ}) \mathrm{nm}\end{array}$ & \\
\hline Spatial Resolution & $7.5 \mathrm{~m}$ & $7.5 \mathrm{~m}$ & $15 \mathrm{~m}$ & $30 \mathrm{~m}$ \\
\hline Temporal Resolution & $2 \mathrm{~s}$ & $2 \mathrm{~s}$ & $15 \mathrm{~s}$ & $2 \mathrm{~s}$ \\
\hline Full-Overlap & $1220 \mathrm{~m}$ & $300 \mathrm{~m}$ & $885 \mathrm{~m}$ & $60 \mathrm{~m}$ \\
\hline
\end{tabular}

Table 3.3 - Main technical features of lidar/ceilometers systems 


\subsubsection{MWR}

The ground-based passive microwave radiometer (RPG-HATPRO G2, Radiometer Physics GmbH) is situated at IISTA-CEAMA and it is part of the MWRnet [http://cetemps.aquila.infn.it/mwrnet/] (Rose et al., 2005; Caumont et al., 2016). It has been operating in automatic and continuous mode since November 2011. The MWR measures the sky brightness temperature with a radiometric resolution between 0.3 and $0.4 \mathrm{~K}$ root mean square error at $1 \mathrm{~s}$ integration time and uses direct detection receivers within two bands: $22-31 \mathrm{GHz}$ (water vapor - $\mathrm{K}$ band) and 51-58 GHz

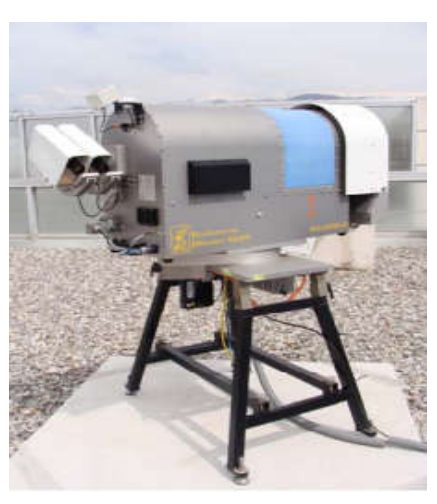

Figure 3.7 - MWR. Source

Own author (oxygen - V band), which are used for deriving relative humidity and temperature profiles, respectively. Relative humidity and temperature profiles from brightness temperature are obtained by inversion algorithms described in Rose et al. (2005). Both profiles have a range resolution varying between 10 and $200 \mathrm{~m}$ in the first $2 \mathrm{~km}$ and varying between 200 and $1000 \mathrm{~km}$ up to $10 \mathrm{~km}$ (Navas-Guzmán et al., 2014).

\subsubsection{Pyranometer}

The pyranometer model CM-11 pyranometer manufactured by Kipp \& Zonen (Delft, The Netherlands) it is situated at IISTA-CEAMA. It has been operating in continuous mode since January 2012, collecting the SW solar irradiance data $(310-3200 \mathrm{~nm})$. The CM-11 pyranometer complies with the specifications for the first-class WMO classification of this instrument (resolution better than \pm 5

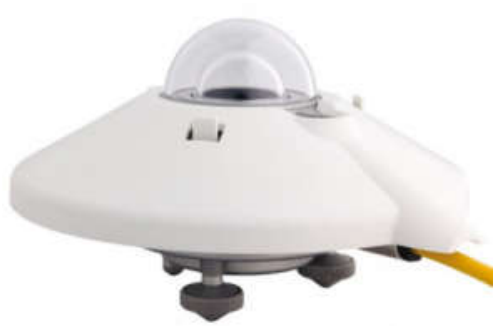

Figure 3.8 - Pyranometer. Source Own author $\mathrm{W} / \mathrm{m}^{2}$ ), and the calibration factor stability has been periodically checked against a reference CM-11 pyranometer. 


\subsubsection{Surface sensors}

The humidity and temperature probe model HMP60 (Vaisala) it is situated at IISTA-CEAMA, co-located with pyranometer mentioned earlier. It has been operating in automatic and continuous mode since November 2011. This system provides the air surface temperature $\left(T_{\text {air }}\right)$ and surface relative humidity $(R H)$ with a temporal resolution of 1 minute. $T_{\text {air }}$ is acquired with an accuracy and precision of

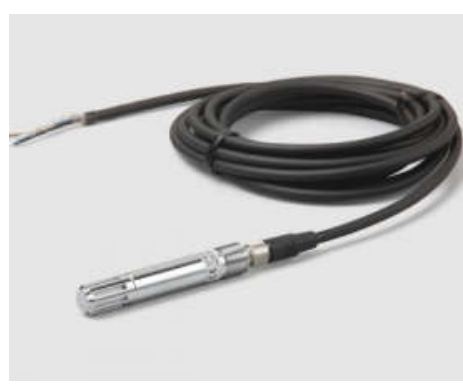

Figure 3.9 - Surface sensors. Source: Own author $0.6^{\circ} \mathrm{C}$ and $0.01^{\circ} \mathrm{C}$, respectively, while $R H$ is detected with an accuracy of $\pm 3 \%$ 


\title{
4 Methodologies
}

\begin{abstract}
This chapter presents the algorithms applied in this thesis, which cover: $P B L H$ detection by MWR, ceilometer, Doppler lidar and elastic lidar and study of turbulence from high-order moments obtained by Doppler lidar and elastic lidar data.
\end{abstract}

\subsection{PBLH Detection}

\subsubsection{MWR: MWR Method}

The algorithm applied to the MWR combines two methodologies that are the parcel method (PM) and temperature gradient method (TGM), in order to detect the $P B L H_{M W R}$ in convective and stable situations, respectively. First of all the potential temperature profile, $\theta(z)$, is derived from the temperature $(T(z))$ profile provided by the MWR, using the following equation:

$$
\theta(z)=T(z)+0.0098 * z \quad(4.1)(\text { Stull, 2011) }
$$

where $z$ is the height above the sea level, and $0.0098 \mathrm{~K} / \mathrm{m}$ is the dry adiabatic temperature gradient. The surface potential temperature $\left[\theta\left(z_{0}\right)\right]$ is obtained from the meteorological station co-located with the MWR. This $\theta(\mathrm{z})$ profile is analyzed in order to label the situation as stable or unstable. Such analysis is made by comparing the surface potential temperature $\left(\theta\left(z_{0}\right)\right)$ with 

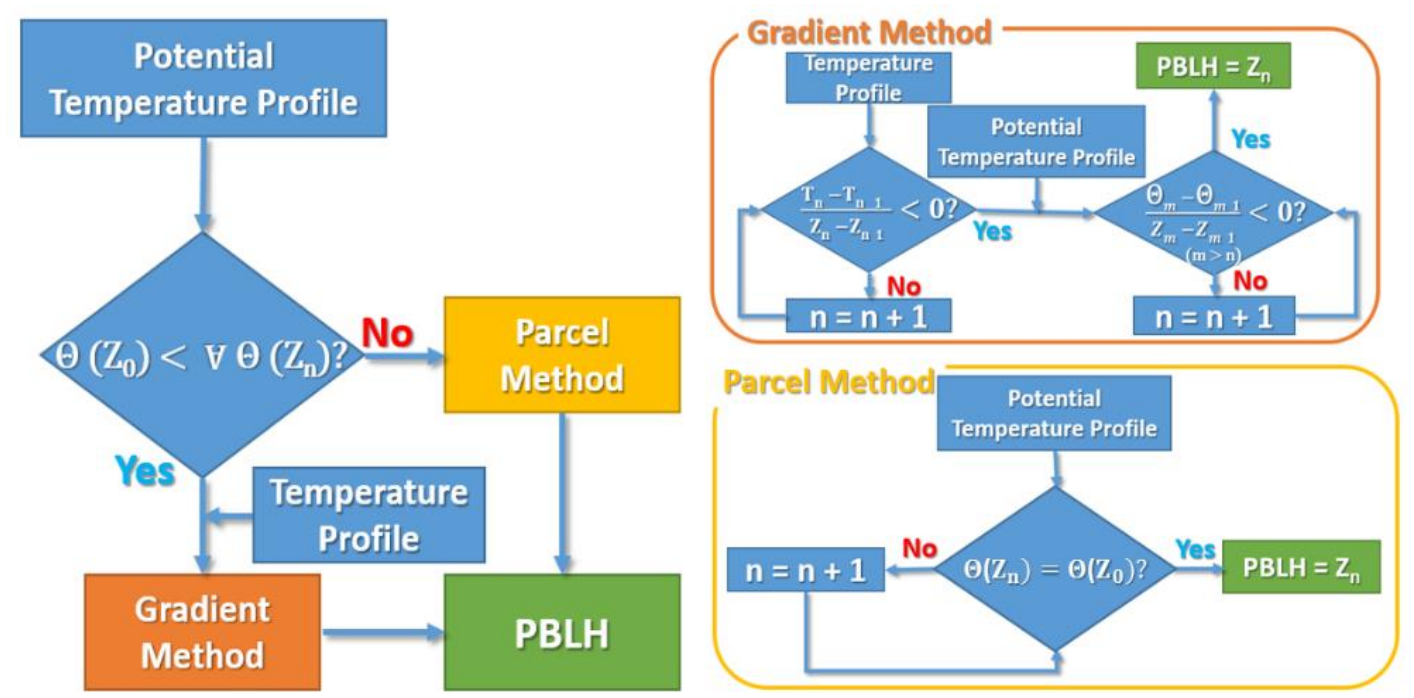

Figure 4.1 - Combination of two methods to detect PBLH based on Temperature Profile. Source: Own author.

all points in the $\theta(z)$ profile below $5 \mathrm{~km}$. If all points presents $\theta(z)$ values larger than $\theta\left(z_{0}\right)$ the situation is considered stable and TGM is applied, otherwise the situation is assumed as unstable and the PM is used instead (Figure 4.1).

The PM determines the $P B L H_{M W R}$ as the altitude where an air parcel with an ambient temperature $T$ can rise adiabatically from the ground by convection (Holzworth, 1964; Coen et al., 2014). This is equivalent to affirm that $P B L H_{M W R}$ is the altitude $(z)$ where the potential temperature $\theta(z)$ is equal to surface potential temperature, $\theta\left(z_{0}\right)$. Therefore, this method only can be applied in unstable situations (CBL).

The TGM (Stull, 1988; Coen et al., 2014) detects the PBLH in stable situations based on two definitions: the first one relies on surface-based temperature inversion (SBI), and identifies the PBLH as the first height where $T$ decrease as a function of altitude. The second one, based on the top of Stable Boundary Layer (TSBL), determines the PBLH as the first height where $\theta$ does not change in function of $\mathrm{z}$, in other words, $d \theta / d z=0$. In principle, this method detects the height where the SBI is situated in the $T$ profile. Then, from this height is identified the TSBL in the $\theta(z)$. Otherwise, the $P B L H_{M W R}$ is labelled as "not identified". 


\subsubsection{Doppler lidar: Variance threshold method}

The variance of vertical wind speed $\left(\sigma_{w}{ }^{2}\right)$ is used to estimate the vertical size of plumes growing due to homogeneous turbulent movement. Therefore, this variable is applied as an indicator of mixing layer height, corresponding to $P B L H_{D o p p l e r}^{S B L}$ in stable cases and $P B L H_{D o p p l e r}^{C B L}$ in unstable cases. $P B L H_{\text {Doppler }}$ is adopted as the first height where $\sigma_{w}{ }^{2}$ has a value lower than a predetermined threshold $\left(t h_{v a r}\right)$. Although different studies use distinct $t h_{v a r}$ values ranging from $t h_{v a r}=0.09 \mathrm{~m}^{2} / \mathrm{s}^{2}$ (Pearson et al.,2010) to $0.16 \mathrm{~m}^{2} / \mathrm{s}^{2}$ (Träumner et. al.,2009; Schween et al., 2014), Schween et al. (2014) demonstrated that a variation of $25 \%$ in $t h_{v a r}$ values causes a deviation around 7\% in PBLH detection. We adopted the threshold value of $0.16 \mathrm{~m}^{2} / \mathrm{s}^{2}$ that is extendedly used, being obtained from the semi-theoretical profile of $\sigma_{w}$ proposed by Lenschow et al. (1980). This value of $t h_{v a r}$ also was confirmed with Doppler lidar measurements and mathematical modelling by Large Eddy Simulations (LES) (Lenschow et al.,2012). In our case $\sigma_{w}^{2}$ is calculated using time intervals of 30 minutes.

\subsubsection{Elastic lidar and Ceilometers}

Before performing the analysis of data provided by elastic lidar/ceilometer $(P(z))$, such data were corrected as described below (figure 4.2):

- Dark Current correction $(D C) \rightarrow$ Firstly, $D C(z)$ is subtracted from raw signal $(P(z))$ in order to reduce the influence of electronical noise.

- Background Correction $(B G) \rightarrow$ Then, $B G$ (radiation provided by external sources, mainly the sun) is removed from the signal to reduce the noise.

- $\mathrm{R}^{2}$ Correction $\rightarrow$ Finally, the signal is corrected by the square of distance $\left(z^{2}\right)$, due its attenuation:

$$
R C S(z)=(P(z)-D C(z)-B G) * z^{2}
$$




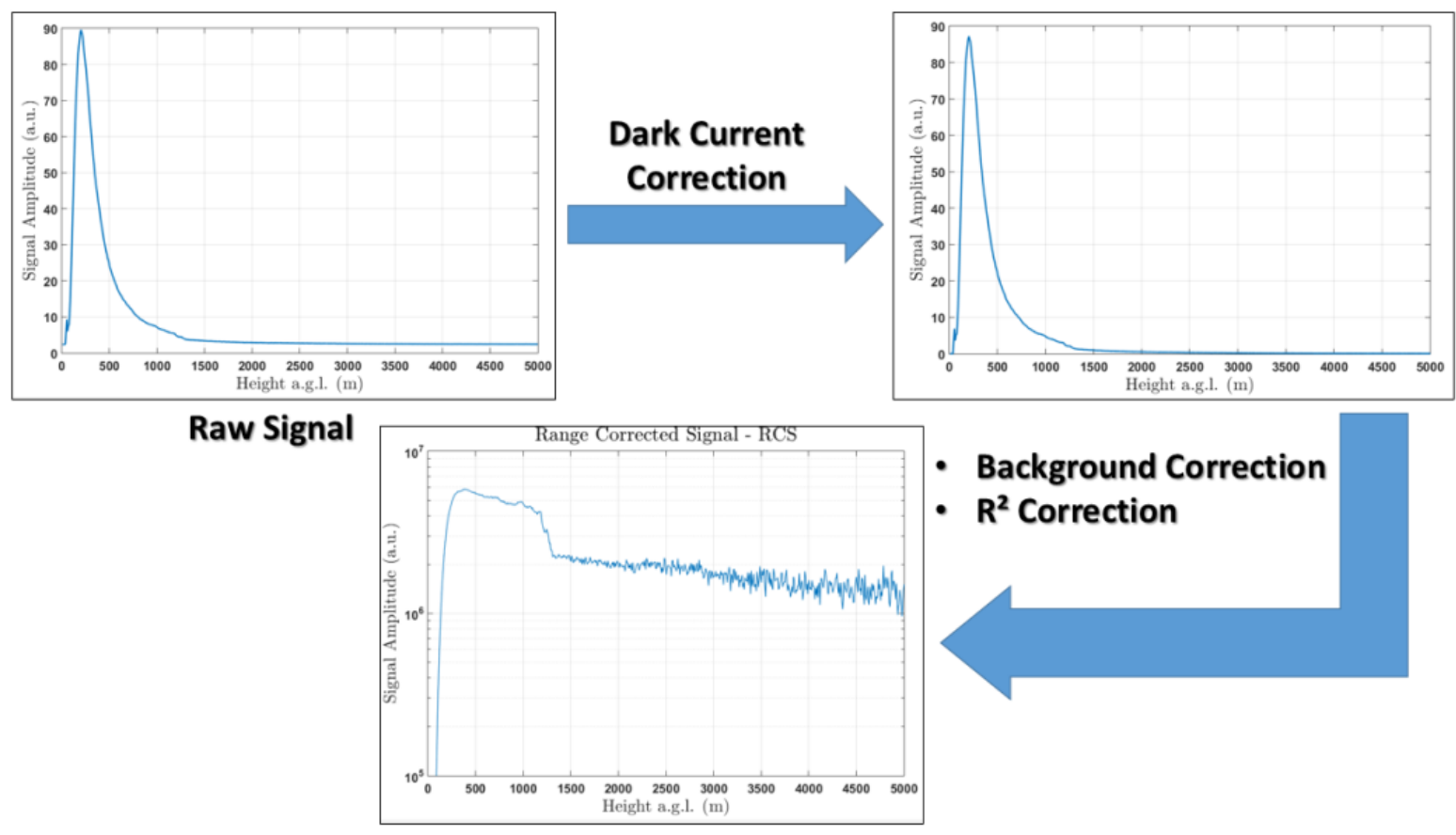

Figure 4.2: Corrections applied on $P(z)$ to obtain $R C S(z)$. Source: Own author.

\subsubsection{Ceilometer: Gradient method}

The ceilometers detect the PBLH using aerosol backscatter as a tracer, in a similar way to lidar systems (Steyn et al., 1999), applying the same algorithms to both instruments. However, the relatively low $S N R$ of ceilometers represents a challenge for accurate $P B L H$ detection, mainly under complex scenarios, such as in the presence of several decoupled aerosol layers (Steyn et al., 1999). The most applied algorithms are: Threshold Method [TM] (Boers and Eloranta, 1986), Variance Method [VM] (Haij et al., 2007), Ideal Fit [IF] (Steyn et al., 1999; Eresmaa et al., 2006; Avolio et al., 2017), Wavelet Covariance Transform [WCT] (Haij et al., 2007; Münkel et al., 2007; Caicedo et al., 2017), Structure of the Atmosphere [STRAT] (Morille et al., 2007). PathfinderTURB (Poltera, 2017) and Gradient Method [GM] (Tsaknakis et al., 2011; Stachlewska et al., 2012; Helmis et al., 2012; Wagner and Schäfer, 2015; Uzan et al., 2016; Caicedo et al., 2017). Nonetheless, it is necessary to note that all methods have advantages and disadvantages identifying the $P B L H$ among the different detected peaks $(P B L H$ candidates). A more detailed comparison among these methods can be found in Eresmaa et al. (2012) and Haeffelin et al. (2012).

In this work the $G M$ is used to $P B L H_{\text {ceilometer }}$ detection, because it does not need a complex selection of specific parameters like as $T M, I F$ or $W C T$, allowing the analysis of the 
4-year time series in an automated way and being able to provide results with good reliability, although it has limitations mainly in complex atmospheric conditions (rainy and/or cloudy days and Saharan dust outbreaks). The GM consists in detecting the minimum of gradient in the $R C S(z)$. Due to a typical reduction of aerosol concentration in the free troposphere $(F T)$ when compared to $P B L$, this transition region (corresponding to $P B L H_{\text {ceilometer }}$ ) is characterized by an abrupt reduction in $R C S(z)$ signal.

$$
P B L H_{\text {ceilometer }}=\min \left(\frac{d R C S(z)}{d z}\right)
$$

GM has some limitations in complex atmospheric conditions. Such situations generate ambiguities in the results, where $P B L H_{\text {ceilometer }}$ might be over or underestimated (Caicedo et al., 2017). Rainy, foggy, and cloudy days typically saturated the $R C S$ above $200 \mathrm{x}$ $10^{-5} \mathrm{sr}^{-1} \mathrm{~km}^{-1}$. Therefore, in the long-term study a threshold analysis is performed over the whole ceilometer data series, cases with attenuated backscatter coefficients above the mentioned threshold are flagged and their profiles removed, as performed by Kamp et al. (2010) and Caicedo et al. (2017). Since Saharan dust outbreaks are frequent in Granada, Bravo-Aranda et al., 2017 give a solution based on depolarization technique to distinguish between different layers (local aerosol and Saharan dust), detecting the $P B L H$. However, the ceilometer used in this work does not have this capability and, therefore, cases of decoupled Saharan dust layers are detected and manually removed.

\subsubsection{Elastic lidar: Extended Kalman Filter (EKF) method}

The Extended Kalman Filter (EKF) method (Lange et al., 2014; Banks et al., 2016) estimates the $P B L H_{\text {elastic }}$ based on an adaptive approach by extended Kalman Filter, which generates a simplified erf-like curve model $h$ (fig. 4.3) from the RCS and four time-adaptive coefficients as follows:

$$
h\left(R ; R_{b l}, a, A, c\right)=\frac{A}{2}\left\{1-\operatorname{erf}\left[\frac{d}{\sqrt{2}}\left(R-R_{b l}\right)\right]\right\}+c
$$


where $R_{b l}$ is an initial guess to $P B L H_{\text {elastic }}, d$ is a scaling factor to entrainment zone thickness, $A$ is the amplitude of the erf transition, and $c$ is the average value of molecular signal (Banks et al. 2016).

The successful use of this method strongly depends on the correct initialization of the EKF state vector that requires a priori statistical covariance information. This is obtained from the state vector noise and a priori error covariance matrices. Further details are given by Lange et al., 2014. In this work the RCS profiles of wavelength $532 \mathrm{~nm}$ are utilized. Such profiles were averaged in order to reduce the noise and provide PBLH estimation with 30 minutes time resolution.

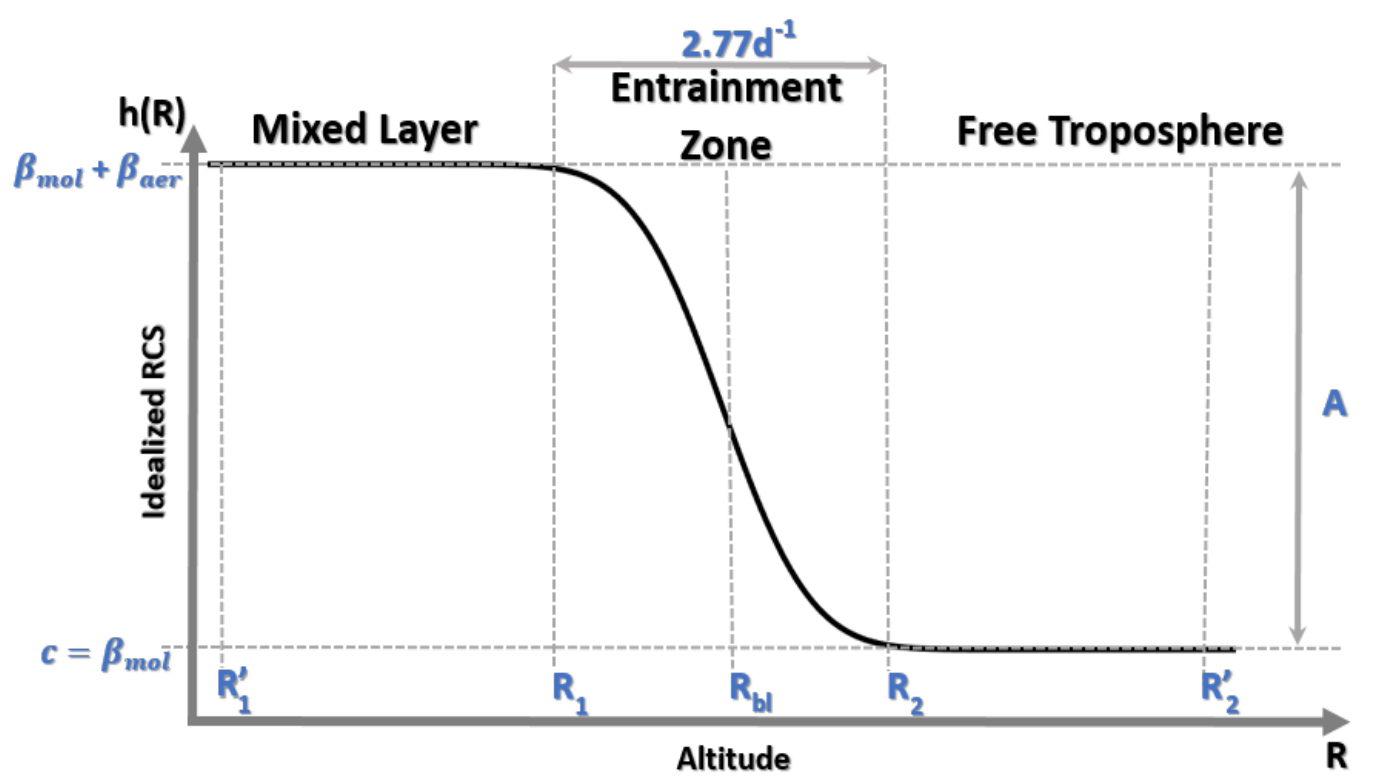

Figure 4.3- Idealized lidar profile. The pair $R_{1}^{\prime}$ and $R_{2}^{\prime}$ defines the length limit of the observation vector applied in the filter. $R_{1}$ and $R_{2}$ represent the limits of the erf-like PBL transition zone. $R_{b l}$ is the PBLH guest, $\beta_{m o l}$ is the average value of molecular signal, $\beta_{a e r}$ is the signal obtained from aerosol backscattering, $\mathrm{d}$ is a scaling factor to entrainment zone thickness and $A$ is the amplitude of the erf transition. Source: Own author.

\subsection{Lidar turbulence analysis}

Both lidar systems, Doppler Lidar and elastic lidar (MULHACÉN and MSP-I), gathered data with a temporal resolution of 2 seconds. Then, the data were averaged in 1-hour packages, from which the mean value was extracted $[\bar{q}(z)]$. Such value was subtracted from each $q(z, t)$ profile, providing the vertical profile of the fluctuation of the measured variable $\left[q^{\prime}(z, t)\right]($ i.e. vertical velocity for the Doppler lidar):

$$
q^{\prime}(z, t)=q(z, t)-\bar{q}(z)
$$


Then, from $q^{\prime}(z, t)$ is possible to obtain the high-order moments (variance $\left(\boldsymbol{\sigma}^{2}\right)$, skewness $(\boldsymbol{S})$ and kurtosis $(\boldsymbol{K})$ ), as demonstrated in the first column of table 4.1. These variables and the integral time scale ( $\boldsymbol{\tau}$ - the time over which the turbulent process are highly correlated to itself) also can be obtained from the following autocovariance function:

$$
M_{i j}=\int_{0}^{t_{f}}\left[q^{\prime}(z, t)\right]^{i}\left[q^{\prime}\left(z, t+t_{f}\right)\right]^{j} d t
$$

However, it is necessary to considerer that acquired data contain instrument noise $(\varepsilon(z))$. Therefore, the equation 3 can be rewritten as:

$$
M_{i j}=\int_{0}^{\tau}[q(z, t)+\varepsilon(z, t)]^{i}[q(z, t+\tau)+\varepsilon(z, t+\tau)]^{j} d t
$$

The autocovariance function of a time series with zero lag results in the sum of the variances of atmospheric variable and the $\varepsilon(z)$. Nevertheless, atmospheric fluctuations are correlated in time, but the $\varepsilon(z)$ is random and uncorrelated with the atmospheric signal, consequently the noise is only associated with lag 0 (fig. 4.4). Based on this concept Lenschow et al. (2000) suggested to obtain the corrected autocovariance function $\left(M_{11}(\rightarrow 0)\right)$ from two methods: first lag correction or $-2 / 3$ law correction. In the first method $M_{11}(\rightarrow 0)$ is obtained directly from the subtraction of lag $0\left(\Delta M_{11}(0)\right)$ of the autocovariance function $\left(M_{11}(0)\right)$. In the second method $M_{11}(\rightarrow 0)$ is generated by the extrapolation of $M_{11}(0)$ at firsts nonzero lags back to lag zero (-2/3 law correction). The extrapolation can be performed using the inertial subrange hypothesis, which is described by the following equation:

$$
M_{11}(\rightarrow 0)=\overline{q^{\prime 2}(z, t)}+C t^{2 / 3} \quad(4.8) \quad(\text { Monin and Yaglom, 1979) }
$$

where $\mathrm{C}$ represents a parameter of turbulent eddy dissipation rate. The high-order moments and $\boldsymbol{\tau}$ corrections and errors are demonstrated in columns 2 and 3, respectively of table 4.1. 


\begin{tabular}{c|c|c|c|}
\hline \multicolumn{2}{|c|}{ Without Correction } & Correction & Error \\
\hline Integral Time Scale $(\tau)$ & $\frac{1}{\overline{q^{\prime 2}}} \int_{0}^{\infty} M_{i j}(t) d t$ & $\frac{1}{\overline{q^{\prime 2}}} \int_{t \rightarrow 0}^{\infty} M_{11}(t) d t$ & $\frac{4 \Delta M_{11}}{M_{11}(\rightarrow 0)}$ \\
\hline Variance $\left(\sigma_{q^{\prime}}^{2}\right)$ & $\frac{1}{T} \sum_{t=1}^{T}(q(t)-\bar{q})^{2}$ & $M_{11}(\rightarrow 0)$ & $q^{2} \cdot \sqrt{\frac{4 \Delta M_{11}}{M_{11}(\rightarrow 0)}}$ \\
\hline Skewness $(S)$ & $\frac{M_{21}(\rightarrow 0)}{M_{11}^{3 / 2}(\rightarrow 0)}$ & $\frac{\Delta M_{21}}{\Delta M_{11}^{3 / 2}}$ \\
\hline Kurtosis $(K)$ & $\frac{q^{3}}{\sigma_{q}^{3}}$ & $\frac{3 M_{22}(\rightarrow 0)-2 M_{31}(\rightarrow 0)-3 \Delta M_{11}^{2}}{q^{4}}$ & $\frac{4 \Delta M_{31}-3 \Delta M_{22}-\Delta M_{11}^{2}}{\Delta M_{11}^{2}}$
\end{tabular}

Table 4.1 - Variables applied to statistical analysis (Lenschow et al., 2000) 


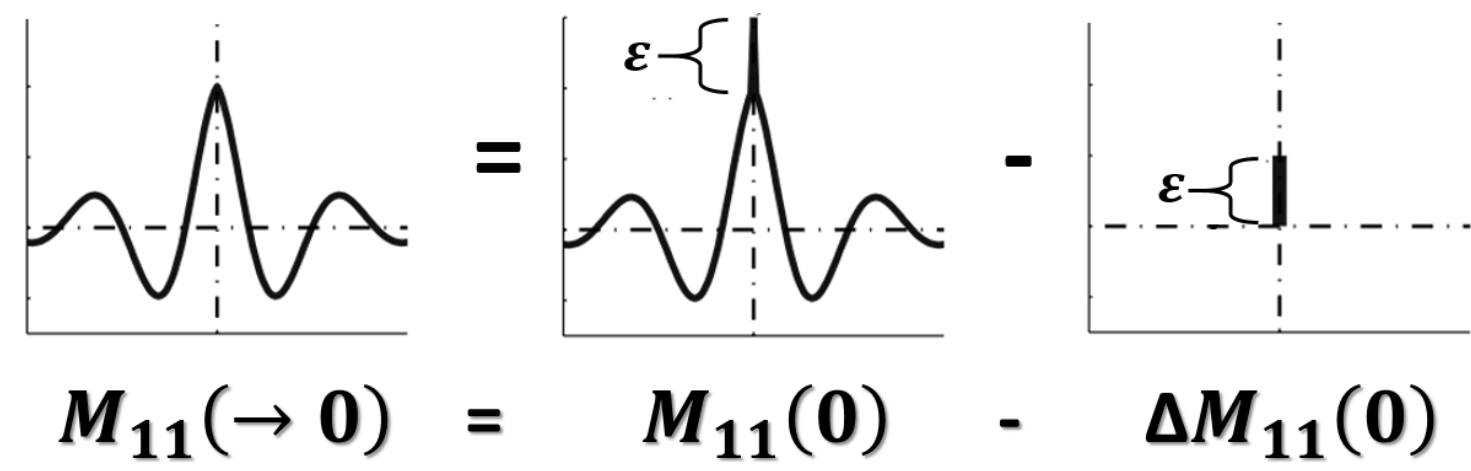

Figure 4.4 - Procedure to remove the errors of autocovariance functions. $M_{11}(\rightarrow 0)-$ corrected autocovariance function errors; $M_{11}(0)$ - autocovariance function without correction; $\Delta M_{11}(0)$ - error of autocovariance function. Source: Own author.

The same procedure of analysis is applied in studies with elastic and Doppler lidar, so that the main difference is about the tracer used by each system, which are the fluctuation of vertical wind speed $\left(w^{\prime}\right)$ to $D L$ and aerosol number density $\left(N^{\prime}\right)$ to $E L . D L$ provides $w(z, t)$ directly, then the procedure described in figure 4.5 can be applied directly. In this study $w(z, t)$ is acquired with a temporal resolution of 2 seconds, then these data are averaged in packages of 1-hour $\overline{w(z)}$, from which are obtained $w^{\prime}(z, t)$ following the procedure described in equation 4.5. So, the two corrections described above are applied separately and finally $\boldsymbol{\tau}$ and high-order moments with and without corrections can be estimated.

On the other hand, the $E L$ does not provide $N(z, t)$ directly. Therefore it is necessary to consider some aspects described by Pal et al. (2010) (ignoring the hygroscopic

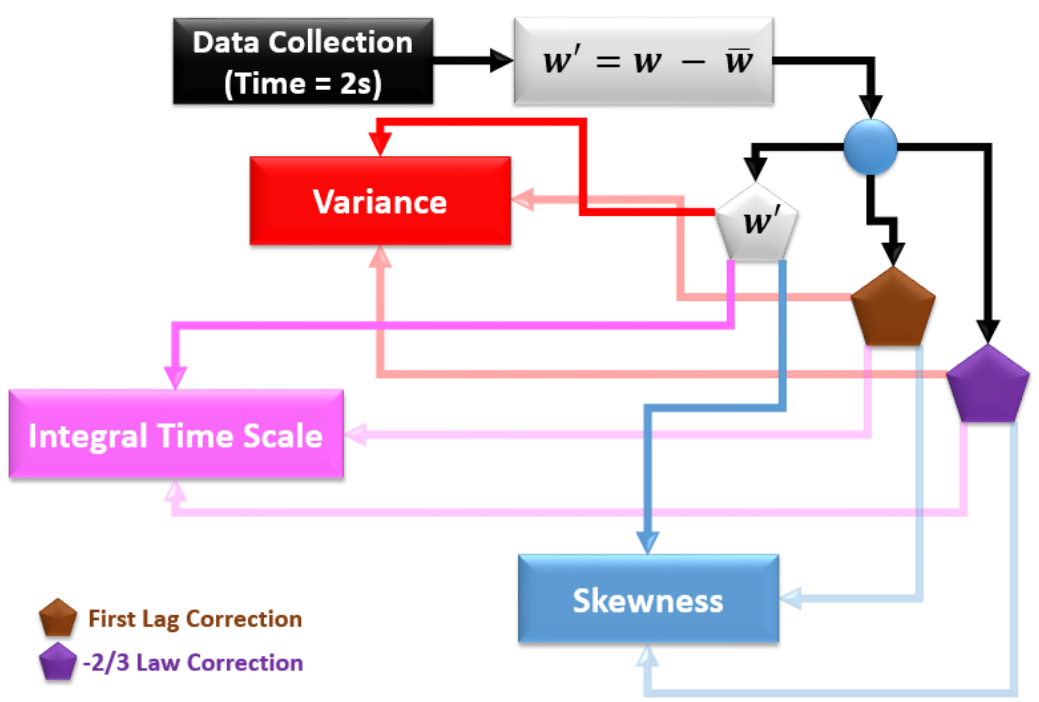

Figure 4.5- Flowchart of data analysis methodology applied to the study of turbulence with Doppler lidar. Source: Own author. 
growth and assuming that the vertical distribution of aerosol type does not changes with time) that allow us to adopt the following relation:

$$
\beta_{\text {par }}(z, t) \approx N(z, t) Y(z) \Rightarrow \beta_{\text {par }}^{\prime}(z, t)=N^{\prime}(z, t)
$$

where: $\beta_{\text {par }}$ and $\beta_{\text {par }}^{\prime}$ represent the particle backscatter coefficient and its fluctuation, respectively, and $Y$ is a constant with time.

Considering the lidar equation:

$$
P_{\lambda}(z)=P_{0} \frac{c t_{d}}{2} A O(z) \frac{\beta_{\lambda}(z)}{z^{2}} e^{-2 \int_{0}^{z} \alpha_{\lambda}\left(z^{\prime} d z^{\prime}\right)}
$$

where: $P_{\lambda}(z)$ is the signal [W] returned from distance $z$ at time $t, z$ is the distance $[\mathrm{m}]$ from the lidar of the volume investigated in the atmosphere, $P_{0}$ is the acquired signal [W] at time $t, c$ is the light speed $[\mathrm{m} / \mathrm{s}], t_{d}$ is the duration of laser pulse [ns], $A$ is the area $\left[\mathrm{m}^{2}\right]$ of telescope cross section, $O(z)$ is the overlap function, $\alpha_{\lambda}(z)$ is the total extinction coefficient (due to atmospheric particles and molecules) $\left[(\mathrm{km})^{-1}\right]$ at distance $z, \beta_{\lambda}(z)$ is the total backscatter coefficient (due to atmospheric particles and molecules) $\left[(\mathrm{km} . \mathrm{sr})^{-1}\right]$ at distance $z$. In the wavelength $1064 \mathrm{~nm}$ the influence of $\alpha_{\lambda}(z)$ provided by aerosol and the Rayleigh scattering due to atmospheric molecules can be assumed as nearly negligible (Paul et al., 2010). So, it is possible to affirm that:

$$
\operatorname{RCS}_{1064}(z)=P(z)_{1064} \cdot z^{2} \cong G \cdot \beta_{1064}(z)
$$

and consequently:

$$
R C S^{\prime}{ }_{1064}(z, t) \cong \beta_{1064}^{\prime}(z, t)=\beta_{\text {par }}^{\prime}(z, t)=N^{\prime}(z, t)
$$

where $R C S_{1064}$ and $R C S^{\prime}{ }_{1064}$ are the range corrected signal and its fluctuation, respectively, $G$ is a constant and the subscribed indexes represents the wavelength. Therefore, in this study the $R C S_{1064}^{\prime}$ is applied in studies about turbulence like $w^{\prime}$, as illustrated in picture 4.6. 


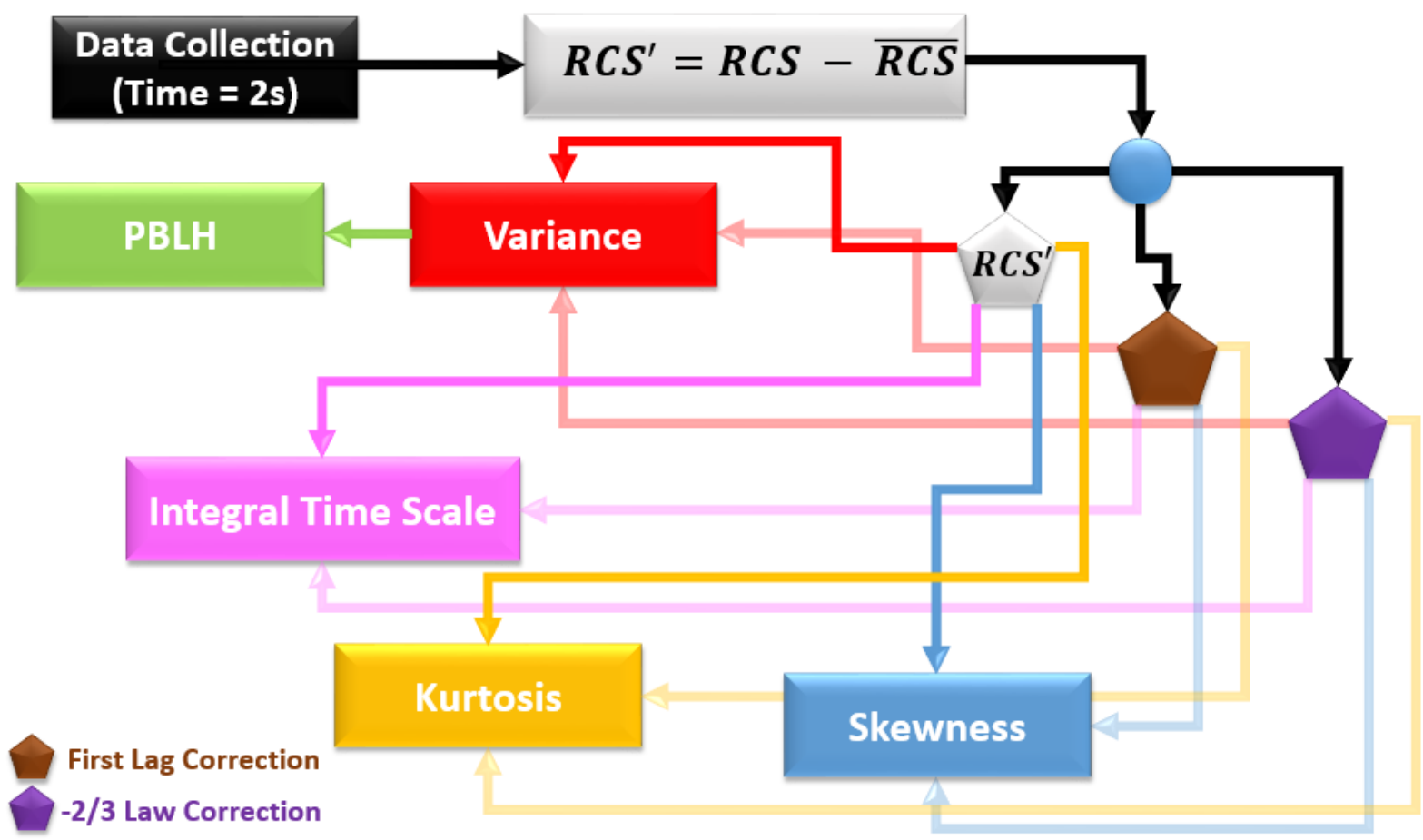

Figure 4.6 - Flowchart of data analysis methodology applied to the study of turbulence with elastic lidar. Source: Own author

Figure 4.7 shows a summary of the devices utilized in this work, as well as the methodology applied to each one and their respective products. 


\section{Device}

\section{Methodology}

Product

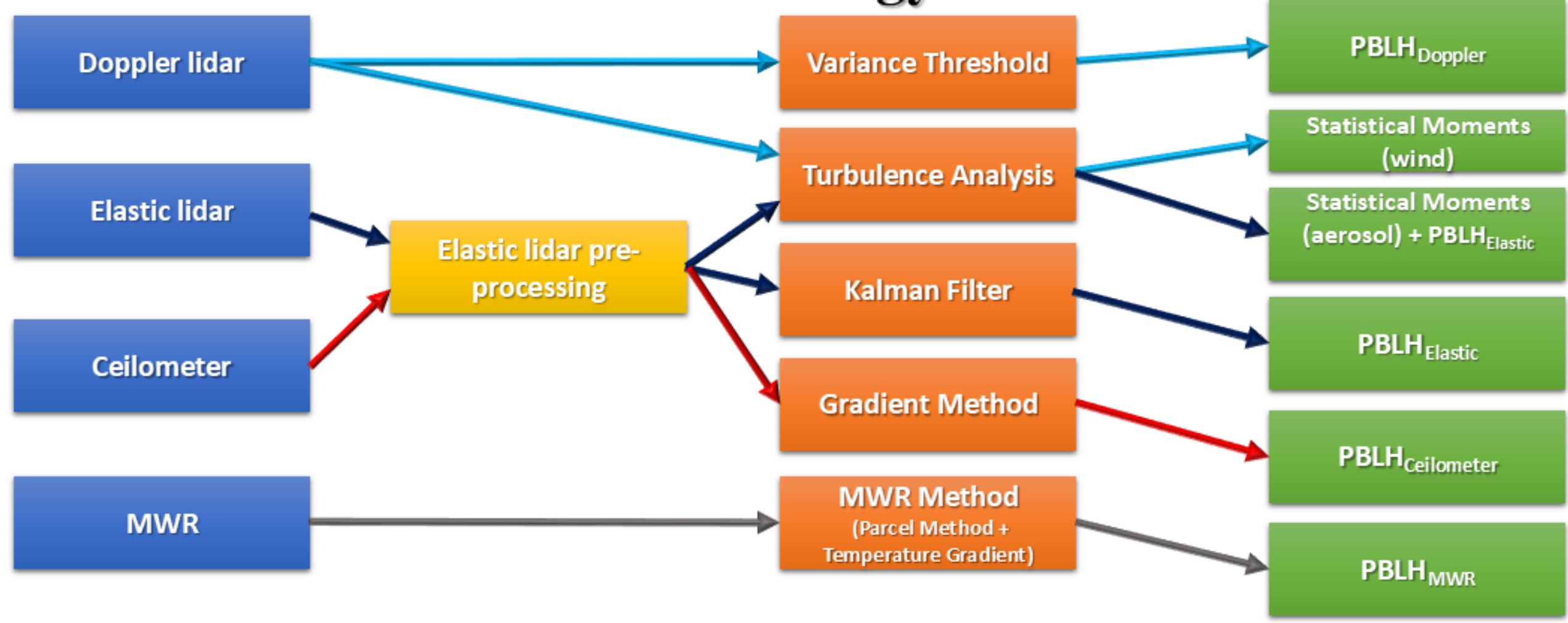

Figure 4.7 - Flowchart of data analysis methodology applied to the study of turbulence with elastic lidar. Source: Own author 


\title{
5 Study of the planetary boundary layer by microwave radiometer, elastic lidar and Doppler lidar estimations
}

\begin{abstract}
In this chapter the $P B L H$ is analyzed using microwave radiometer $(M W R)$, elastic lidar $(E L)$ and Doppler lidar $(D L)$ data. The measurements were performed simultaneously in the framework of SLOPE-I (Sierra Nevada Lidar aerOsol Profiling Experiment) campaign at Granada (Spain) during 90- day period in summer 2016. Firstly, the PBL height (PBLH) obtained from $M W R$ data is validated against $P B L H$ provided by analyzing co-located radiosonde. In a second stage, active remote sensing systems are used for deriving the $P B L H$, which are compared with the $P B L H$ retrieved by the $M W R$.
\end{abstract}

\subsection{Statistical Parameters}

Below are presented the statistical parameter utilized in the comparisons performed in this chapter:

- Pearson coefficient of correlation $(R)$ : It indicates the level (and direction) of correlation performed between two group of data:

$$
R=\frac{\sum_{i=1}^{n}\left(P B L H_{x i}-\overline{P B L H}_{x}\right)\left(P B L H_{M W R i}-\overline{P B L H}_{M W R}\right)}{\sqrt{\sum_{i=1}^{n}\left(P B L H_{x i}-\overline{P B L H}_{x}\right)^{2}} \sqrt{\sum_{i=1}^{n}\left(P B L H_{M W R i}-\overline{P B L H}_{M W R}\right)^{2}}}
$$

- Index of agreement ( $D$ ) (Willmont, 1981): $D$, often applied in comparison of models, presents the level of agreement between a given set of values and the reference values $\left(P B L H_{M W R}\right)$

$$
D=1-\frac{\sum_{i=1}^{n}\left(P B L H_{M W R i}-P B L H_{x i}\right)^{2}}{\sum_{i=1}^{n}\left(\left|P B L H_{x i}-\overline{P B L H}_{M W R}\right|-\left|P B L H_{M W R i}-\overline{P B L H}_{M W R}\right|\right)^{2}}
$$


- Root Mean Square Error (RMSE): Such variable demonstrates how concentrated the data are around the line of the best fit obtained from reference data $\left(P B L H_{M W R}\right)$ :

$$
R M S E=\sqrt{\frac{\sum_{i=1}^{n}\left(P B L H_{M W R i}-P B L H_{x i}\right)^{2}}{n}}
$$

- Percentage change $\left(\triangle P B L H_{x-M W R}^{\%}\right)$ : This variable represents the relative percentage change between $P B L H_{x}$ (provided by $D L$ or $E L$ data) and the reference value $P B L H_{M W R}$ :

$$
\triangle P B L H_{x-M W R}^{\%}=\frac{P B L H_{x}-P B L H_{M W R}}{\left|P B L H_{M W R}\right|}
$$

In all equations demonstrated above $\overline{P B L H}_{M W R}$ represents the average value of $\left(P B L H_{M W R}\right)$, while $P B L H_{x}$ and $\overline{P B L H}_{x}$ represent the $P B L H$ provided by $D L$ or $E L$ and its average value, respectively.

\subsection{MWR and radiosonde PBL intercomparison}

This sub-section presents a statistical comparison of $P B L H$ retrieved from $D L$ or $M W R$ data $\left(P B L H_{M W R}\right)$ and the estimations obtained applying similar methodology (Section 3.1) to the radiosonde profiles ( $P B L H_{\text {Radiosonde }}$ ). $P B L H_{M W R}$ and $P B L H_{\text {Radiosonde }}$ present very similar results with high level of correlations $(R)$ and index of agreement $(D)$ under convective and stable atmospheric conditions $\left(R_{\text {Convective }}=0.96, D_{\text {Convective }}=0.89, R_{\text {Stable }}=0.97, D_{\text {Stable }}\right.$ $=$ 0.98). The percentage difference between $P B L H_{M W R}$ and $P B L H_{\text {Radiosonde }}$ $\left(\triangle P B L H_{M W R-R a d i o s o n d e}\right)$ in convective cases $(-0.6 \%)$ is smaller than the corresponding relative difference observed in stable cases $(8.1 \%)$, when the $M W R$ always overestimate the PBLH derived from the radiosonde. This overestimation probably occurs because of the limited and smaller vertical resolution of $M W R$ in comparison with radiosonde (in the first $350 \mathrm{~m} \theta_{\text {Radiosonde }}(\mathrm{z})$ has around 12 levels, while $\theta_{M W R}(\mathrm{z})$ has 3 levels), what requires further interpolations during the process of $P B L H_{M W R}$ detection. The Root Mean Square Error (RMSE) values observed in both situations are small (190 and $50 \mathrm{~m}$ in convective and stable cases, respectively).The largest value of RMSE occurs under convective conditions 
because of the average value of $P B L H$ obtained in unstable conditions is around $68 \%$ higher than the values in stable conditions.

Based on these results, we can conclude that, although the vertical temperature profile derived from $M W R$ has lower vertical resolution than that derived from the radiosondes, the values of $P B L H_{M W R}$ obtained by the methodology described in section 4.1.1 are equivalents to $P B L H_{\text {Radiosonde }}$, retrieved by an equivalent algorithm applied over the radiosonde temperature profiles.

As mentioned before, the $P B L H$ detection based on radiosonde data is the most accepted methodology for deriving the $C B L$ and $S B L$. Therefore, due to good agreement between $P B L H_{M W R}$ and $P B L H_{\text {Radiosonde }}$, and the high temporal resolution of $M W R, P B L H_{M W R}$ is adopted as standard procedure for deriving the height for the $C B L$ and the $S B L$. In this way a continuous $P B L H$ detection is performed thus providing an insight on the $P B L$ dynamics along the day.

\subsection{Study cases}

As aforementioned, the complexity of the $P B L$ characterization is linked to the complexity of its structure that changes along the day. In this section, we present three case studies in increasing level of complexity to analyze how $M W R, E L$ and $D L$ determine the $P B L$ structure under different situations. The three scenarios are: 1) well-defined $P B L$ (the simplest case); 2) presence of clouds (complicated situation mainly for lidar systems, e.g. Hennemuth and Lammert, 2006), and (iii) Saharan dust outbreak (very complicated and typical situation over the city of Granada, e.g., Bravo-Aranda et al., 2017).

\subsubsection{Well-defined PBL case}

A well-defined $P B L$ case was detected on $19^{\text {th }}$ May 2016 with $M W R$ and $D L$ measuring continuously, and MULHACEN operating from 08:20 until 18:00 UTC. Figure 5.1 shows the temporal evolution of the $E L \mathrm{RCS}$ at $532 \mathrm{~nm}$ and the retrieved $P B L H_{M W R}, P B L H_{\text {Doppler }}$

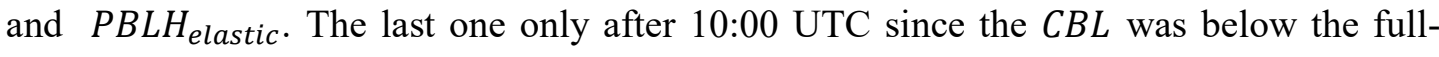
overlap height of MULHACEN, and thus, out of the MULHACEN's range. From 08:20 until 10:00 UTC the $R C S$ temporal evolution suggest the presence of the $R L$ over the $B L$. Also 
there are some aerosol layers over the $C B L$ between 13:00 and 18:00 UTC with altitudes around $2.3 \mathrm{~km}$ a.g.1.

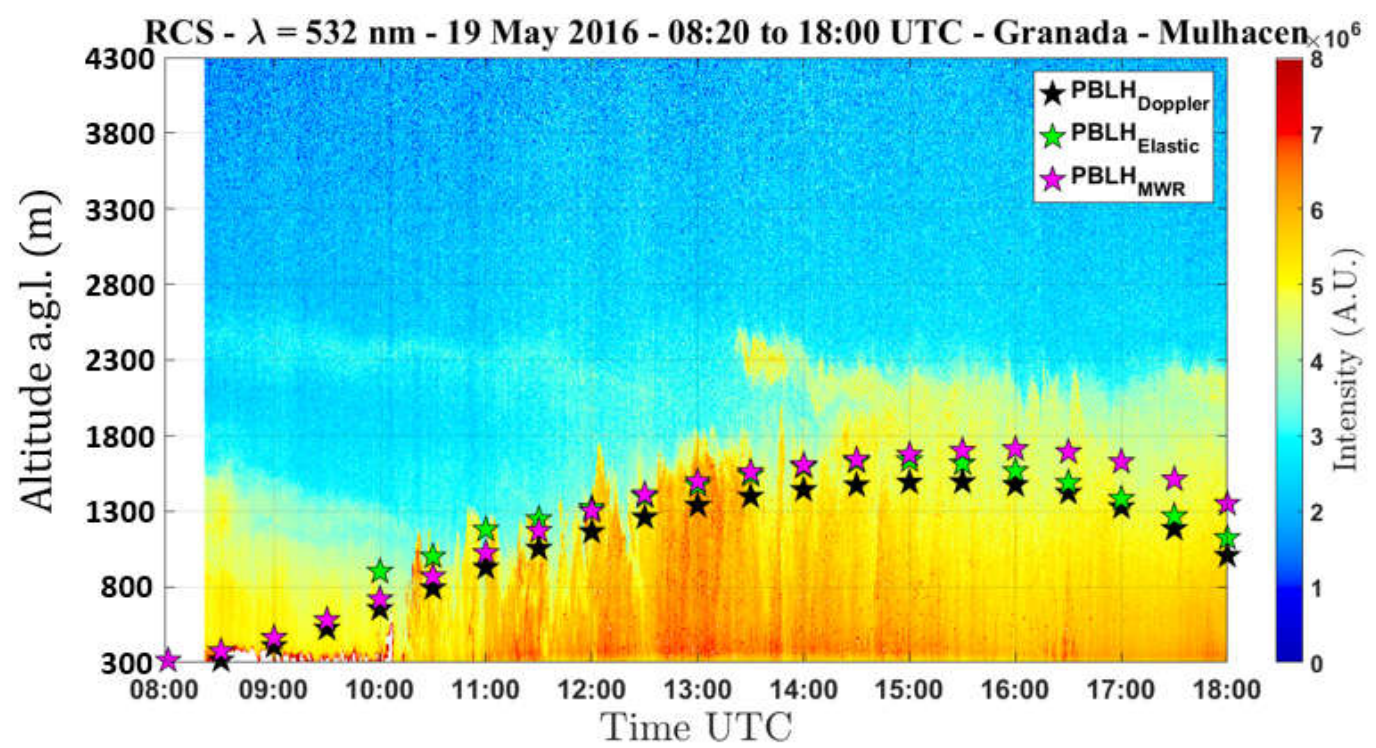

Figure 5.1 - Temporal evolution of RCS profile and PBLH provided by MWR (pink stars), elastic (green stars) and Doppler lidar (black stars)

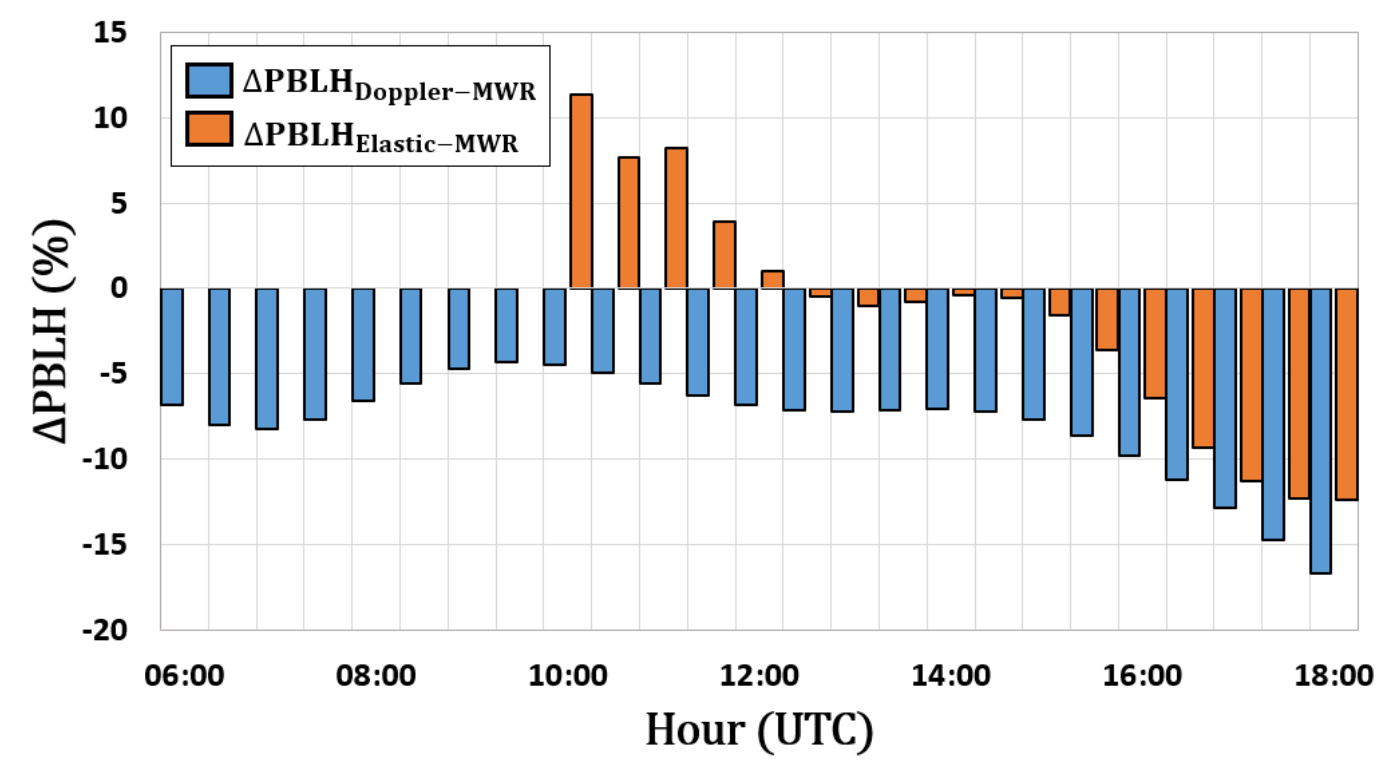

Figure 5.2 - Temporal evolution of $\triangle P B L H_{\text {Doppler-MWR }}$ (blue bars) and $\triangle P B L H_{\text {Doppler-MWR }}$ (orange bars) 
Figure 5.2 presents the temporal evolution of the relative differences in percentage $\triangle P B L H_{\text {Doppler-MWR }}$ (blue bars) and $\triangle P B L H_{\text {Elastic-MWR }}$ (orange bars), evaluated in 30-min intervals. Due to the small height for full overlap of the $D L$, it is feasible perform the comparison between $D L$ and $M W R$ during all the convective period (06:00-18:00 UTC). From the first hours until 15:00 UTC, $\left|\triangle P B L H_{\text {Doppler-MWR }}\right|$ varies between 4 and $8 \%$. The largest values of $\triangle P B L H_{\text {Doppler-MWR }}$ (above 10\%) are observed in the last hours when $P B L$ begins to decrease. This is caused by the different $P B L H$ tracers used in each method. Unlike the moments of intense convection where both algorithms detect the height of $C B L$ $\left(P B L H_{M W R}^{C B L} \sim P B L H_{D o p p l e r}^{C B L}\right)$, when $P B L$ stability is changing the variance threshold method detects the $M L$ height, while $M W R$ method detects the TSBL. Resulting in the higher values of $\triangle P B L H_{\text {Doppler-MWR }}$.

When $C B L$ growths or decrease rather fast (10:00-11:30 UTC and 16:00 - 18:00 UTC), high values of $\left|\triangle P B L H_{\text {elastic-MWR }}\right|$ are observed (between 8 and 15\%). Although, in this period, $E K F$ and $M W R$ methods detect the height of $C B L$, the different tracer used are subject to distinct interferences. While the temperature profile varies directly by thermodynamic phenomena, aerosols are affected by these phenomena and also can be influenced by others like emission rate from the ground and/or inertia, resulting in the differences observed in figure 3. When $C B L$ is fully-developed (between 12:00 and 15:30 UTC) its height does not show great differences among different methods, thus, under these conditions, the different tracers agree in the determination of the PBLH. Therefore the smaller values of $\triangle P B L H_{M W R-e l a s t i c}$ are detected under fully-developed convective columns $(\sim 1 \%)$.

\subsubsection{Cloudy case}

The second study case corresponds to $16^{\text {th }}$ May 2016, where measurements with $M W R$ and $D L$ were continually performed while MULHACEN was operated from 10:36 until 16:30 UTC. This situation is more complex than the one presented in the previous case, due to presence of clouds between 1.8 and $2.8 \mathrm{~km}$ a.g.1. (12:30 to 16:30 UTC -) and lofted aerosol layers between 2.5 and $3.5 \mathrm{~km}$ a.g.1.. Figure 5.3 shows the EL RCS temporal evolution together with $P B L H_{\text {elastic }}, P B L H_{M W R}$, and $P B L H_{\text {Doppler }}$. 


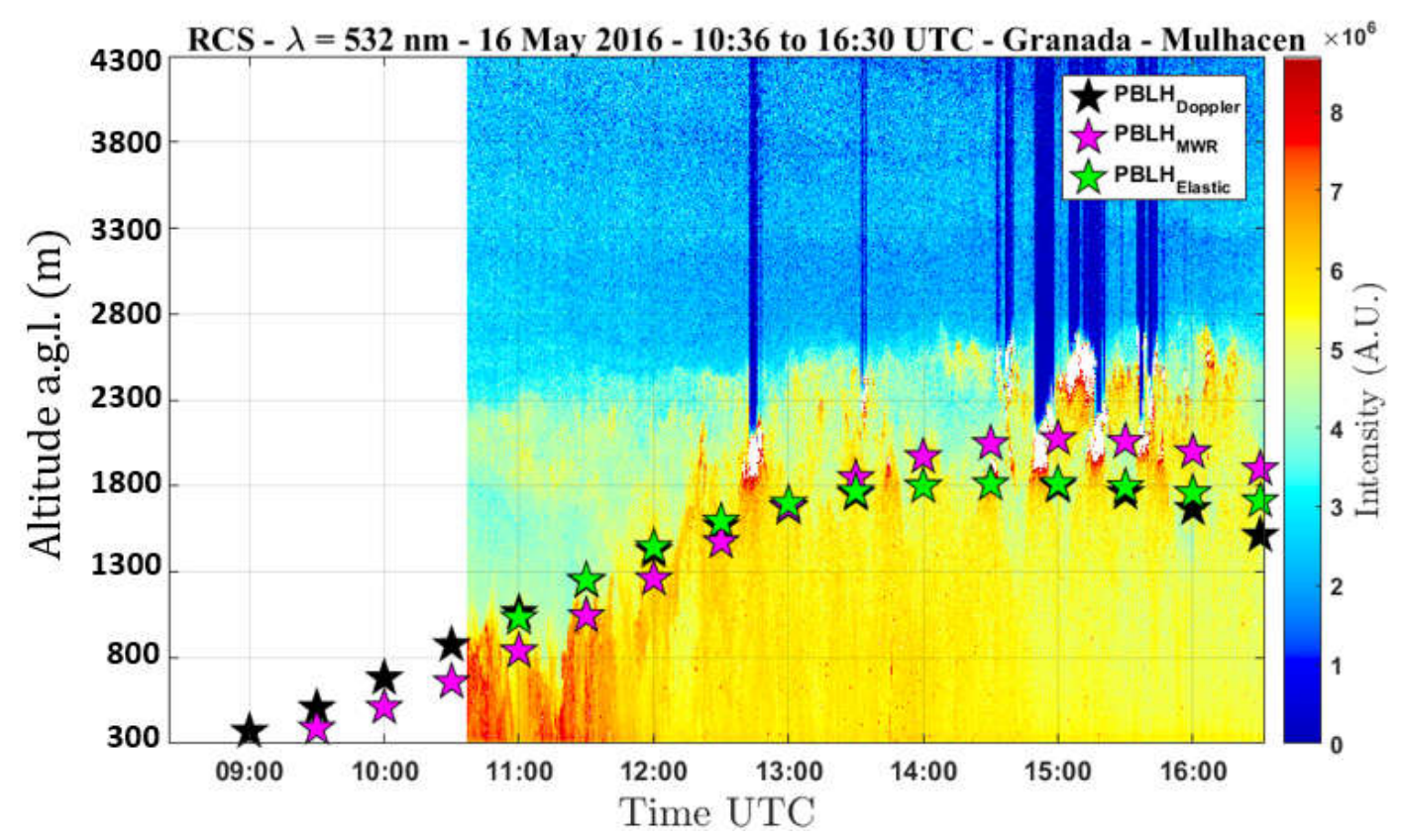

Figure 5.3 - Temporal evolution of RCS profile and PBLH provided by MWR (pink stars), elastic (green stars) and Doppler lidar (black stars)

Figure 5.4 presents the percentage differences of $\triangle P B L H_{\text {elastic-MWR }}$ and $\triangle P B L H_{\text {Doppler-MWR }}$ for the whole period of measurements. The behavior of $\triangle P B L H_{\text {Doppler-MWR }}$ in this case is similar to that observed in the study case I, small and almost constant values when $C B L$ does not varies too much and large values in the periods when there are intense and fast variation of $P B L H$. During the cloudy periods, $\left|\triangle P B L H_{\text {Doppler- }-M W R}\right|$ values increase (around $15 \%$ ), because the $D L$ and $M W R$ methods to detect the $P B L H$ under cloudy conditions establishes the $P B L H$ at the cloud base and at the cloud center, respectively. 


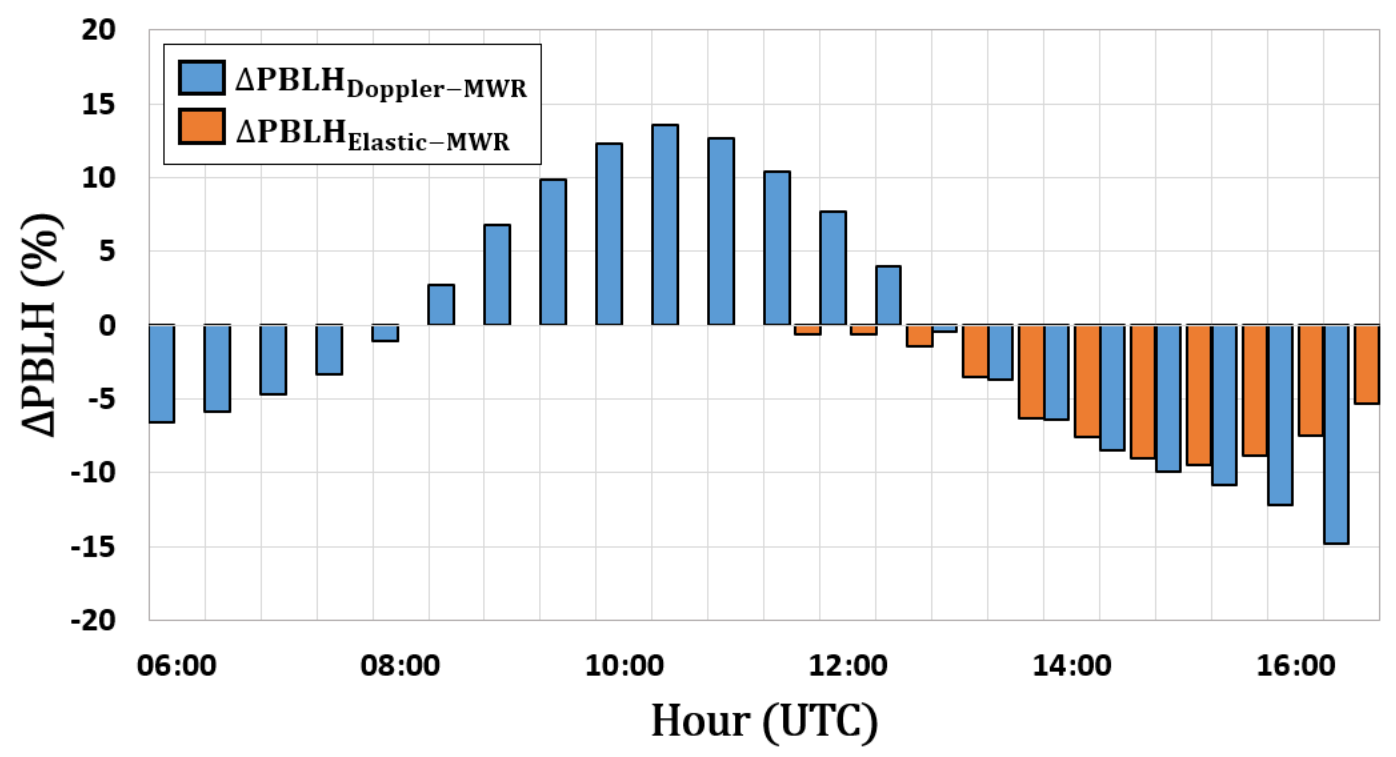

Figure 5.4 - Temporal evolution of $\triangle P B L H_{\text {Doppler-MWR }}$ (blue bars) and $\triangle P B L H_{\text {Doppler }-M W R}$ (orange bars)

In a similar way as $\triangle P B L H_{\text {Doppler }-M W R}, \triangle P B L H_{\text {elastic }-M W R}$ presents a pattern similar to that encountered in the study case I, with values close to $5 \%$ around noon, and values close to $10 \%$ at the moments of high convective activity. High values of $\triangle P B L H_{M W R-e l a s t i c}$ are observed during the cloudy period because, similarly at $D L$ method, $P B L H$ it is established at the cloud base.

\subsubsection{Saharan dust case}

This case illustrates the Saharan dust outbreak over Granada on 22 $2^{\text {th }}$ July 2017 detected by $M W R, D L$ and $E L$ (from 04:47 until 12:32 UTC). Figure 5.5 shows the $E L R C S$ temporal evolution together with $P B L H_{M W R}, P B L H_{\text {Doppler }}$ and $P B L H_{\text {elastic }}$. At the start time of the $E L$ measurement the dust layer is coupled with $R L$. In such cases $P B L H$ detection is very complicated for methods that use the atmospheric aerosol as a tracer, and many of them often overestimate the PBLH. Bravo-Aranda et al. (2017) proposed the utilization of lidar depolarization measurements to distinguish between mineral dust and anthropogenic aerosol layers in order to estimate the height only of the last one and adopt it as PBLH. 


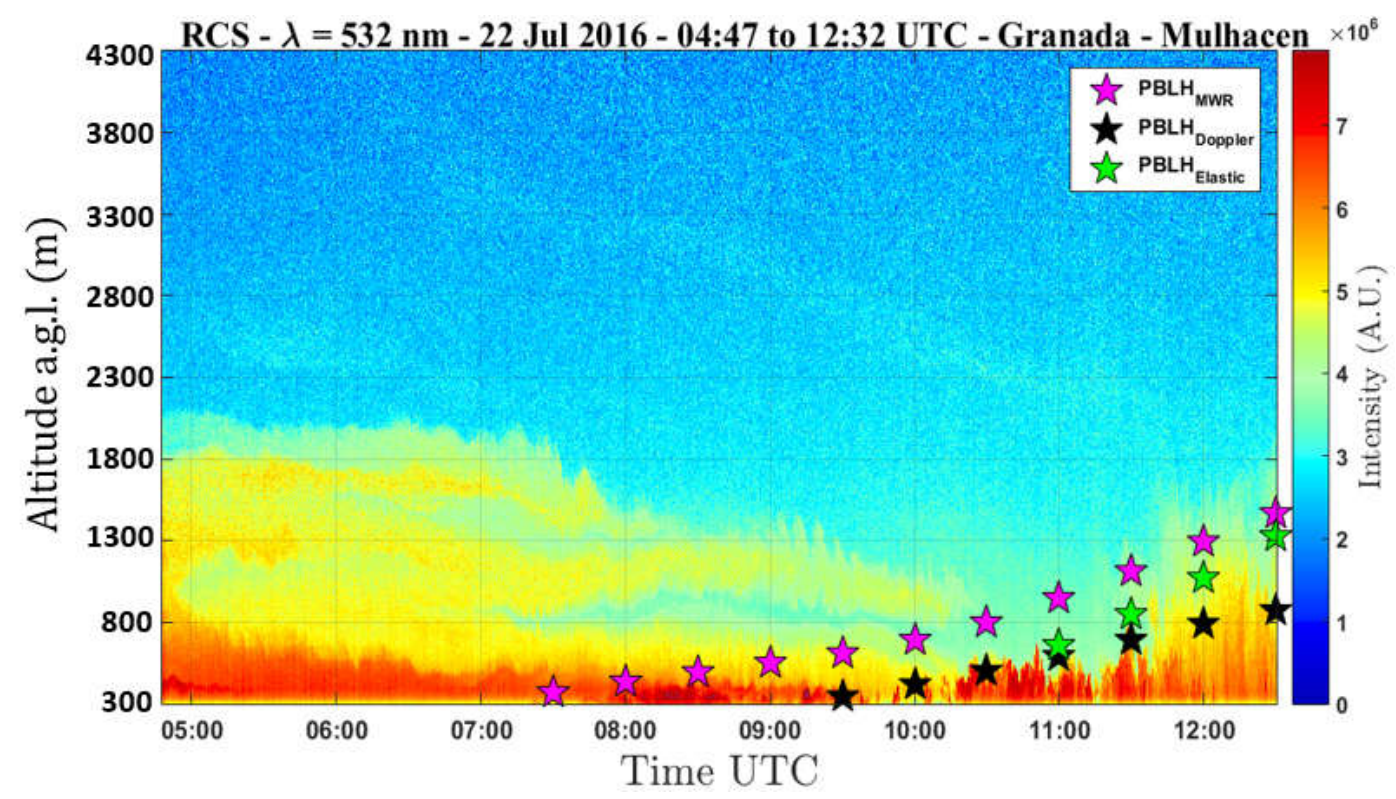

Figure 5.5 - Temporal evolution of RCS profile and PBLH provided by MWR (pink stars), elastic (green stars) and Doppler lidar (black stars)

$P B L H_{\text {Doppler }}$ detection is not affected by presence of dust layer, because it is based on the level of mixing. Although there is a mineral dust layer coupled with other anthropogenic aerosol layers, the level of mixing observed in the first meters of $P B L$ exceeds the threshold selected, therefore $P B L H_{\text {Doppler }}^{C B L}$ is detected at this region. In contrast, the presence of mineral dust layer, due to absorption of infrared radiation, changes the potential temperature profile, so that $P B L H_{M W R}^{C B L}$ is registered in upper layers in comparison with $P B L H_{D o p p l e r}^{C B L}$.

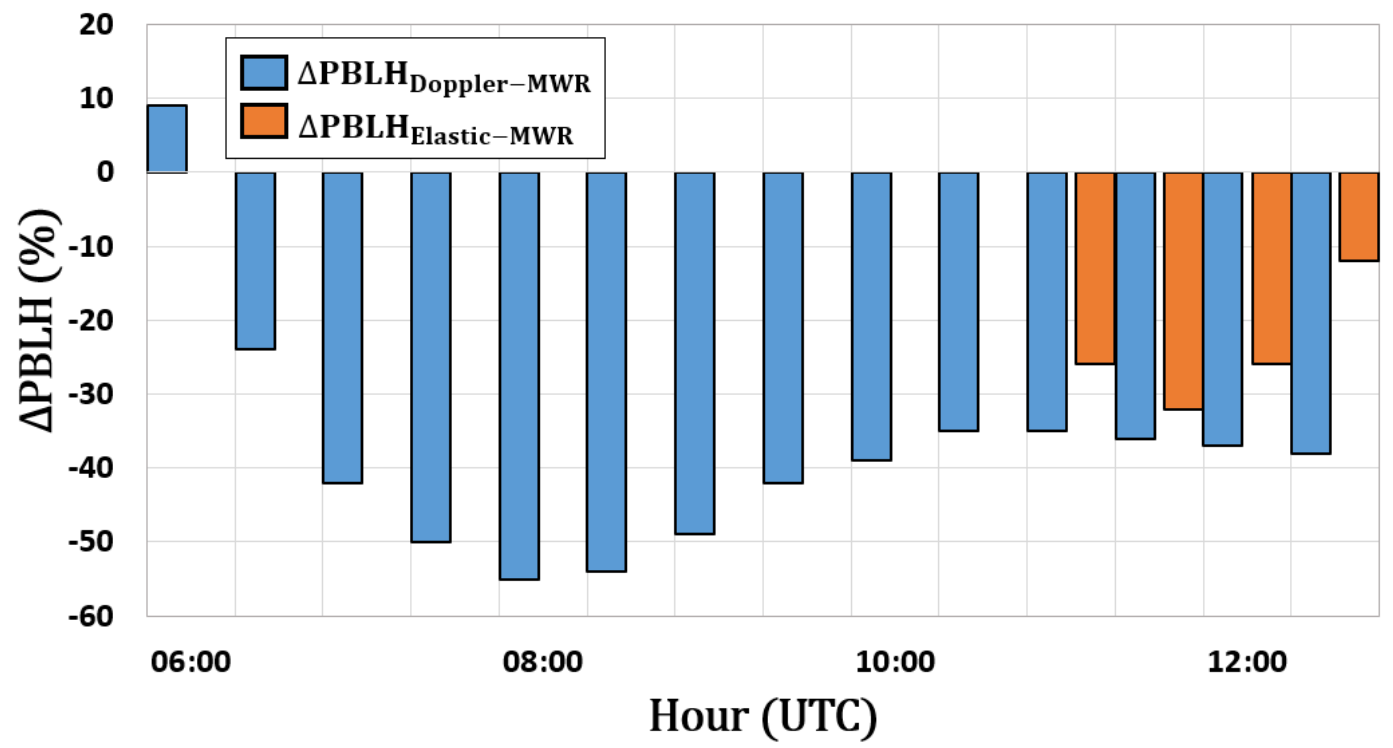

Figure 5.6 - Temporal evolution of $\triangle P B L H_{\text {Doppler }-M W R}$ (blue bars) and $\triangle P B L H_{D o p p l e r-M W R}$ (orange bars) 
These detections of distinct phenomena result in higher values of $\triangle P B L H_{\text {Doppler-MWR }}$ in comparison with the other study cases previously discussed (reaching 60\%). However, the values of $\triangle P B L H_{\text {Doppler }-M W R}$ reduce as the $P B L$ becomes more homogeneous, reaching about $38 \%$ in the last hours of measurement (Fig. 5.6).

During the first hours of this measurement, $P B L H_{\text {elastic }}$ probably would be affected by dust layer due to impossibility of differentiating the coupled layers. At 11:00 UTC the dust layer is displaced (Fig. 5.5) and do not affect the $P B L H_{\text {elastic }}$ detection. Although the fast $P B L$ growth and the existence of different influences acting on the distinct tracers result in high values of $\triangle P B L H_{M W R-e l a s t i c}$ in comparison with other situations (reaching $32 \%$ ). However, these values decrease as the growth rate reduces, reaching $11 \%$ in the last hour of measurements.

\subsection{Statistical analysis}

The statistical study of the comparison of the $P B L H$ retrieved by the three remote sensing methods used during all SLOPE-I campaign is presented in this section. The comparison between $P B L H_{M W R}$ and $P B L H_{\text {Doppler }}$ was performed over 24 hours of all days of campaign. This allows the evaluation of the $D L$ retrieval, $P B L H_{\text {Doppler }}$, both under stable and convective situations. Nevertheless, the comparison between $P B L H_{\text {elastic }}$ and $P B L H_{M W R}$ is not extended for the whole day because, as a result of the relatively large full overlap height of MULHACEN, in the morning and at night the $P B L H_{\text {elastic }}^{R L}$ is detected (Bravo-Aranda, 2017), while $M W R$ method detects the $P B L H_{M W R}^{C B L}$. Therefore, to ensure that both instruments detect the same variable, EKFmethod was applied only when the reference $P B L H_{M W R}$ exceeded 700 meters a.g.1., therefore (between 09:00 and 19:00 UTC) 
In figure 5.7 is demonstrated the comparison among the average daily $P B L H$ values of $M W R$ $\left(\overline{P B L H}_{M W R}\right), D L\left(\overline{P B L H}_{\text {Doppler }}\right)$ and $E L\left(\overline{P B L H}_{\text {Elastic }}\right)$. Both profiles have similar behaviors with differences smaller than $300 \mathrm{~m} . \overline{P B L H}_{\text {Elastic }}$ presents the lowers differences with relation to $\overline{P B L H}_{M W R}$. $\overline{P B L H}_{\text {Doppler }}$ overestimated the reference values along almost the whole profile, however the such values do not exceed the standard deviation of $\overline{P B L H}_{M W R}$.

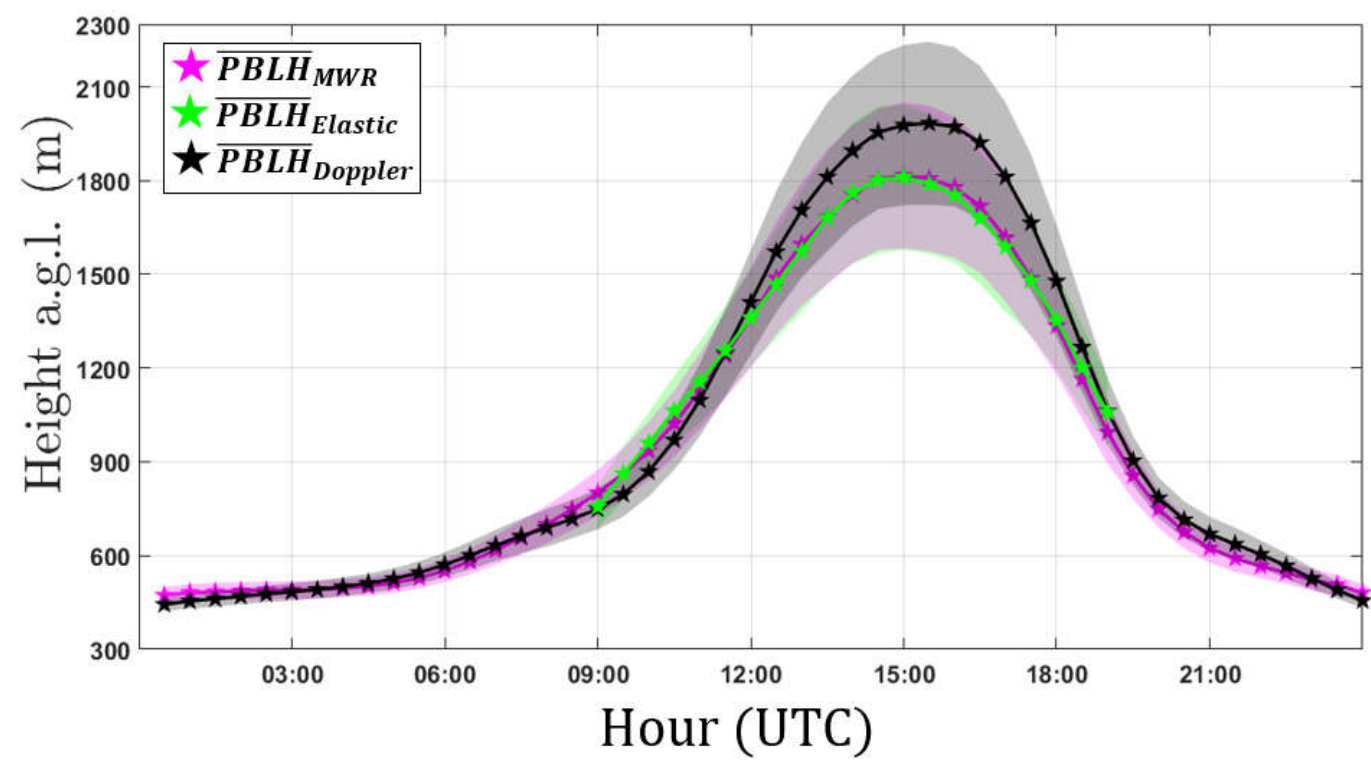

Figure 5.7 - Average values of PBLH provided by MWR (pink stars), elastic (green stars) and Doppler lidar (black stars

Figure 5.8 shows the daily pattern, of the statistics describing the comparison between $P B L H_{M W R}$ and $P B L H_{\text {Doppler }}$, with a temporal resolution of 30 minutes. It is evident that the absolute average value of $\triangle P B L H_{\text {Doppler- } M W R}^{\%}$ does not exceed $20 \%$. The higher values are observed between 21:00 and 22:00 UTC, 00:00 and 01:00 UTC, 08:30 and 10:30 UTC, 16:30 and 18:30 UTC. The last two intervals are characterized by intense $P B L H$ changes, thus being justified in the terms argued in the discussion of the study cases. The lowest differences are concentrated in central region of day and in some moments associated to the SBL (around 3\%). Most of the time $P B L H_{\text {Doppler }}$ overestimates the $P B L H_{M W R}$, however the higher values of average $\triangle P B L H_{D o p p l e r-M W R}^{\%}$ also occur when $P B L H_{M W R}$, is underestimated by and $P B L H_{\text {Doppler. }}$. RMSE has practically constant values during the stable periods (around $100 \mathrm{~m}$ ). The highest values occur between 16:30 and 18:30 UTC (around $450 \mathrm{~m}) . R$ values are larger than 0.70 between $04: 30$ and 16:30 UTC, and the higher values (0.90) are in the central region of day, when $P B L$ is fully-developed. After 16:30 UTC $R$ 
value begins to decrease, reaching their minimum values during the stable period. $D$ values are larger than 0.85 during quite all the period, outside of the period between 22:30 and 00:00 UTC, where $D$ is lower than 0.70 . Similarly to $R$, the higher values of $D(0.99)$ occur often when $P B L$ is fully-developed.
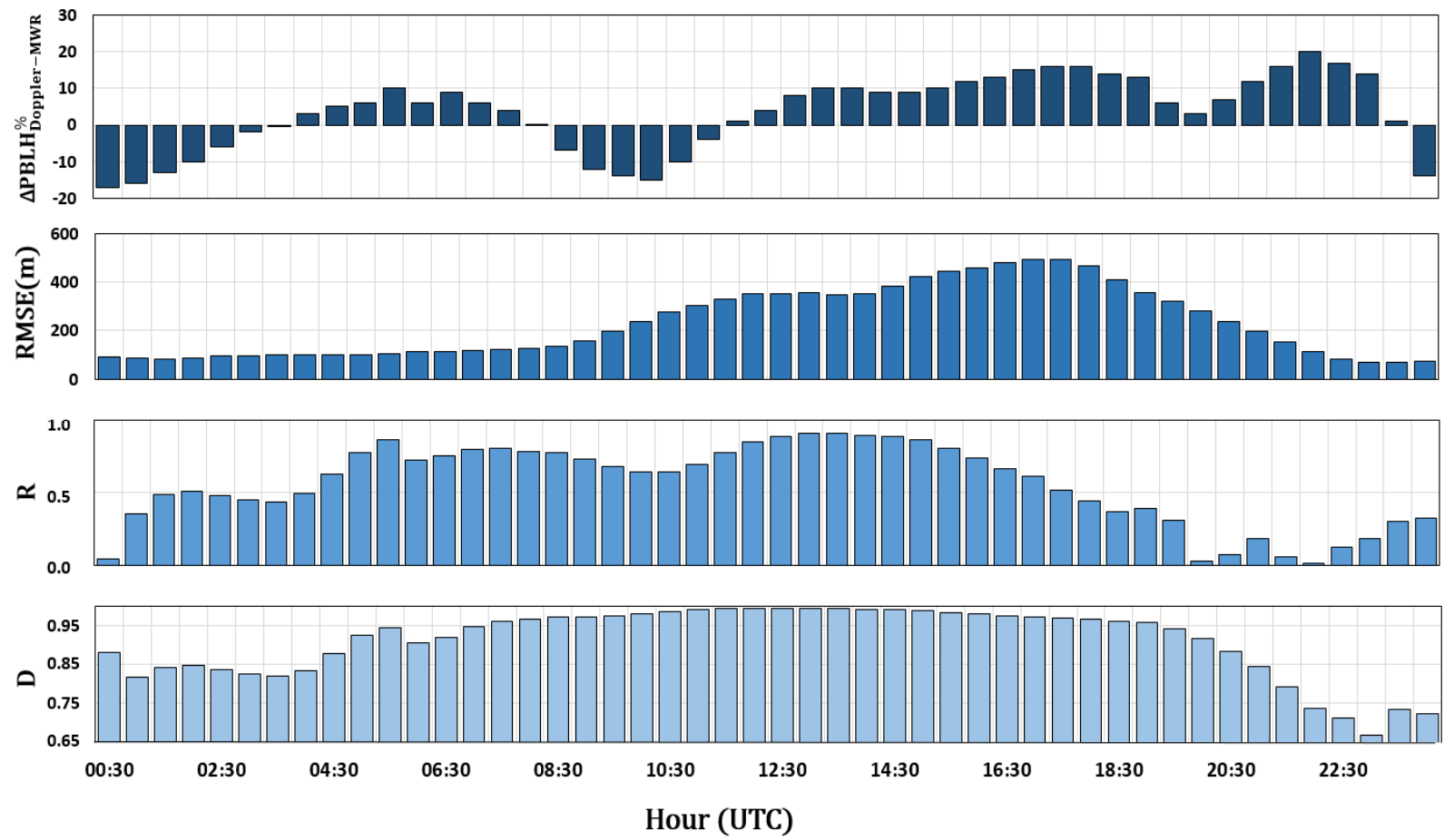

Figure 5.8 - Statistical comparison between the daily patterns of $P B L H_{M W R}$ and $P B L H_{\text {elastic }}$ obtained during all SLOPE-I campaign. Each bin size is equivalent to 30 minutes. $\triangle P B L H_{\text {Doppler-MWR }}^{\%}, R M S E, R$ and $D$ represents average percentage difference, root mean square error, correlation index and index of agreement, respectively.

From the combination of the statistics presented in figure 5.8 it is possible to affirm that $P B L H_{\text {Doppler }}$ has a good agreement with $P B L H_{M W R}$ in $80 \%$ of the daily cycle, so that the lower results are observed between 20:00 and 00:00 UTC. This is due to the different PBLH indicator adopted by each method, because while variance threshold method is based on analysis of turbulence level, $M W R$ method detects the TSBL, so that these events do not occur always at same height, meanly when $P B L$ has vertical movements (in this situation decreasing), as mentioned above.

Figure 5.9 shows the statistics describing the comparison between the daily patterns of $P B L H_{M W R}$ and $P B L H_{\text {elastic }}$. During all SLOPE-I campaign the absolute average value of $\left(\triangle P B L H_{\text {Elastic-MWR }}^{\%}\right)$ does not exceed 15\%. The higher values are detected at 09:00 UTC, between 10:00 and 11:30 UTC, at 17:00 UTC and between 18:30 and 19:00 UTC (around $13 \%$ ), where frequently $P B L H$ has fast changes. For all the period, the $R M S E$ has values 
lower than obtained in the comparison between the retrievals of $P B L H$ by $M W R$ and $D L$. This difference in the results of RMSE probably occurs due to larger vertical resolution of $E L$. Outside the period between 11:30 and 12:00 UTC and at 17:30 UTC, where $R$ values are lower than 0.8 , high correlations are observed, mainly in the beginning of measurement and in the central part of the day. $D$ presents a similar behavior with values lower than 0.85 between 11:30 and 12:00 UTC and at 17:30 UTC and higher values in the central of day, when PBL is fully-developed.

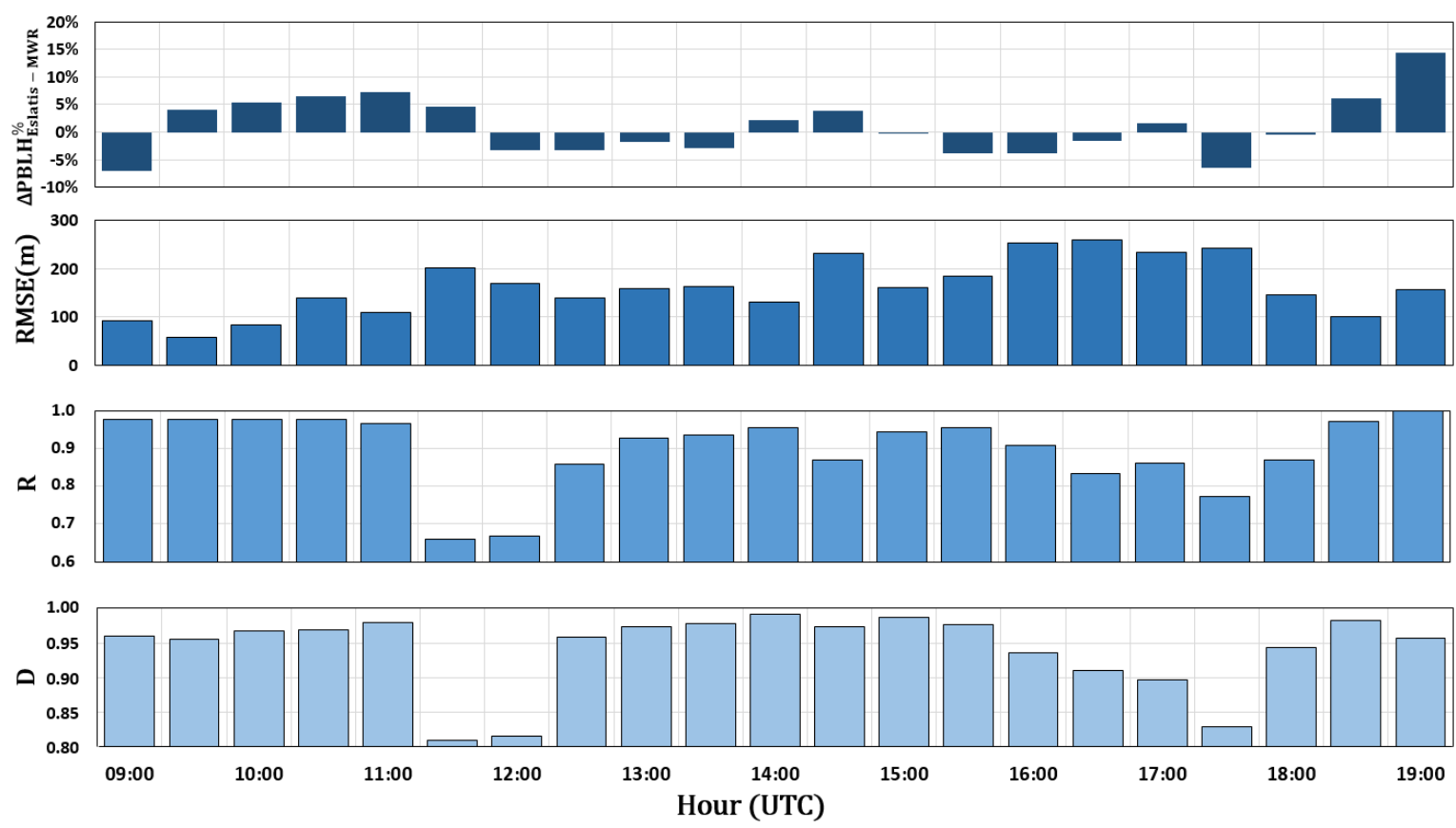

Figure 5.9 - Statistical comparison between the daily patterns of $P B L H_{M W R}$ and $P B L H_{\text {elastic }}$ obtained during all SLOPE-I campaign. Each bin size is equivalent to 30 minutes. $\triangle P B L H_{\text {Elastic-MWR }}^{\%}, R M S E, R$ and $D$ represents average percentage difference, root mean square error, correlation index and index of agreement, respectively.

The joint analysis of these statistical variables reveals a good agreement between $P B L H_{M W R}$ and $P B L H_{\text {elastic }}$ mainly in the central part of day, when $P B L$ is fully developed and low average values of $\triangle P B L H_{M W R-E l a s t i c}^{\%}$ together with high values of $R$ and $D$ are observed. The largest discrepancies are observed in moments of intense increase and/or decrease of $P B L H$, due to great change in $P B L$ affecting in a different way the distinct $P B L H$ tracers used in each method, thus leading to discrepancies in the retrieval of the $P B L H$. 


\title{
6 Statistical study of the Planetary Boundary Layer in an urban environment
}

\begin{abstract}
In this chapter we analyze four- and five-year dataset of measurements gathered with a ceilometer and a microwave radiometer, respectively, in the mid-latitude urban area of Granada (Spain). Firstly, two case studies are analyzed in order to observe the Planetary Boundary Layer $(P B L)$ daily pattern and how the synergy between these systems can provide a description of $P B L$ structure in simple and complex situations. Then, the $P B L$ behavior is characterized by a statistical study of the convective and stable $P B L H$ obtained from microwave radiometer measurements. Such study included the analyses of the following variables: daily $P B L H$ maximum, $P B L H$ growth rate, $P B L H$ growth speed and $P B L H$ growth duration, as well as, its relationship with surface meteorological variables (air temperature, relative humidity and solar global and net irradiances). Finally, it was performed a joint long-term analysis of the Residual Layer provided by ceilometer and the Stable and Convective Layer heights determine by microwave radiometer,
\end{abstract}

\subsection{Variables to long term analysis}

The statistical analysis of the $P B L H$, performed in this chapter, includes histogram, seasonal mean, and the variables described below:

- Maximum of PBLH (PBLH $\left.{ }^{\text {Max }}\right)$ : The $P B L H^{\text {Max }}$ represents the maximum daily value of PBLH.

- PBLH growth rate (PBLH $\left.{ }^{\text {GRate }}\right)$ : The PBLH ${ }^{\text {GRate }}$ measures the intensity of PBLH growth. It is obtained from a slope of a linear fit of the first PBLH detected after sunrise and the last point to reach $90 \%$ of daily PBLH maximum value, like as performed by Baars et al. (2008), Korhonen et al. (2014), Schween et al. (2014) and Pal et al. (2015). 
- PBL growth speed (PBLH $\left.\boldsymbol{H}^{\text {GSpeed }}\right)$ : The $P B L H^{\text {GSpeed }}$ represents the variation of PBLH during a determined time interval:

$$
P B L H^{G S p e e d}=P B L H\left(t_{n}\right)-P B L H\left(t_{n-1}\right)
$$

In this work, the PBLH GSpeed is calculated from the hourly mean difference of PBLH in two consecutive hours.

- PBL growth duration PBL $\boldsymbol{H}^{G D u r}$ : The $P B L H^{G D u r}$ represents the number of hours after sunrise where $P B L H^{G S p e e d}$ is larger than zero, in other words is calculated the interval between the time of beginning of $P B L$ growth and when the $P B L H^{M a x}$ is reached (Pal et al., 2015).

\subsection{Comparative case studies: $P B L H_{M W R}$ and $P B L H_{\text {ceilometer }}$}

\subsubsection{Case Study I - Sample days}

Figure 6.1 shows the 24-h time series of the range-corrected signal and the $P B L H_{M W R}$ (pink stars) and $P B L H_{\text {Ceilometer }}$ (black stars) of four sample days: a) $17^{\text {th }}$ February 2016 ; b) $05^{\text {th }}$ April 2014, c) $20^{\text {th }}$ July 2014 and d) $06^{\text {th }}$ November 2014 as representative days of the four meteorological seasons: winter [December, January and February], spring [March, April and May], summer [June, July and August] and autumn [September, October and November]. These days are selected to show the behavior of the two estimates of the PBLH in different seasons.

During night-time, the $M W R$ measurements mainly show thermal inversions (stable conditions) and thus, the $P B L H_{M W R}^{S B L}$ is detected showing low and almost constant values (Fig. 6.1). However, the GM applied to ceilometer measurements detects the $P B L H_{\text {Ceilometer }}^{R L}$ because the edge of the signal between the $R L$ and the $F T$ is sharper than between the $S B L$ and the $R L$. The independent detection of the $R L$ and the TSBL, due to synergy between ceilometer and $M W R$ measurements, allows us to study its relationship and different temporal evolution during night-time.

As mentioned before, some instants around sunrise the convective process begins originating the $C B L$. Then, $P B L H_{M W R}^{C B L}$ begins to grow fast and continuously becoming closer to 


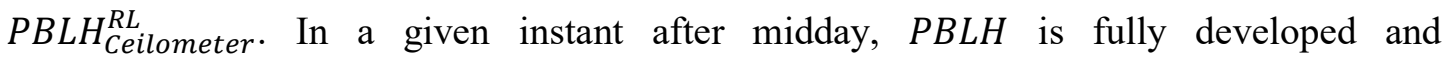
$P B L H_{\text {Ceilometer }}^{C B L}$ is detected, so that such variable and $P B L H_{M W R}^{C B L}$ converge to similar values even if different tracers are used.
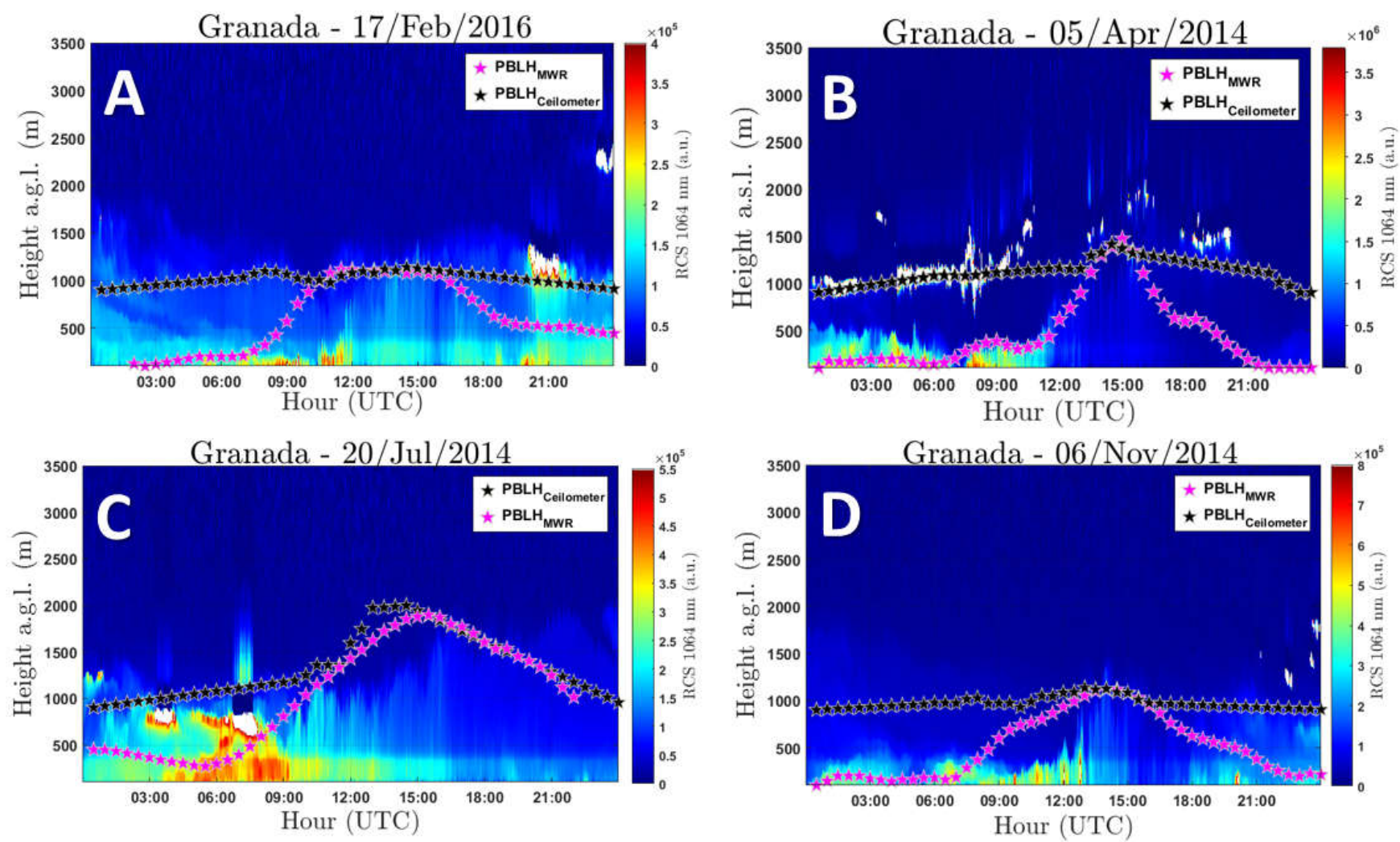

Figure $6.1-R C S(\lambda=1064 \mathrm{~nm})$ profiles obtained from ceilometer data $(\mathrm{A}-$ spring, $\mathrm{B}$ - summer, $\mathrm{C}$ - autumn, $\mathrm{D}-$ winter $)$. Black and pink stars represent $P B L H_{\text {ceilometer }}$ and $P B L H_{M W R}$, respectively.

Around sunset, convective processes gradually decrease and surface cools due to the reduction of the solar irradiance. The surface cooling causes a decrease of temperature of the nearest atmospheric layer by conduction, generating a thermal inversion. In this period, the $M_{e d} L$ becomes two different layers: the $S B L$ (from surface until around the thermal inversion top) and the $R L$ between the top of the $S B L$ and the FT. In this transition, the $G M$ method goes from detecting the $P B L H_{\text {Ceilometer }}^{C B L}$ to detect the $P B L H_{\text {Ceilometer. However, the } M W R}^{R L}$ algorithms depend on the stability in atmosphere. When the stability is changing from unstable to stable, the 'dying' convective cells are detected as rest of $M_{e d} L$ height $\left(P B L H_{M W R}^{C B L}\right)$. After the transition period, the stable method is applied to the $M W R$ measurements to detect the $P B L H_{M W R}^{S B L}$.

This pattern occurs at all seasons (fig. 6.1) with some differences. In summer, the larger positive net radiation balance achieved during daytime causes larger values of $P B L H$ with respect to other seasons, so that, the lower positive net radiation in winter cause an inverse 
effect. Concerning $P B L H_{\text {Ceilometer }}$, it is evident that it presents almost constant values along the day in autumn (case C) and winter (case D), thus suggesting some constancy of the height of the $R L$. The presence of low clouds (cases A and B) difficult the PBLH Ceilometer detection, because the high backscattered signal generates a sharp minimum in gradient profile, which is wrongly interpreted by the algorithm as $P B L H_{\text {Ceilometer }}$.

\subsubsection{Case Study II - Saharan Dust}

An example of dust outbreak is shown in figure 6.2, where the range-corrected signal of the ceilometer shows a dust layer on 20-21 July 2016. The dust layer arrives at 12:00 UTC on $20^{\text {th }}$ July as thin lofted layer at $3000 \mathrm{~m}$ a.g.l., becoming coupled with the $P B L$ at 18:00 UTC of same day at $2000 \mathrm{~m}$ a.g.l. The signal increase between 18:00 UTC on $20^{\text {th }}$ July and 06:00 UTC on $21^{\text {th }}$ July in the region from 1000 to $2500 \mathrm{~m}$ a.g.l. points to an increase of the depth and thick of the dust layer. Then, the episode finishes with the dust entrainment in the $P B L$ between 08:00 UTC and 12:00 UTC on $21^{\text {th }}$ July.

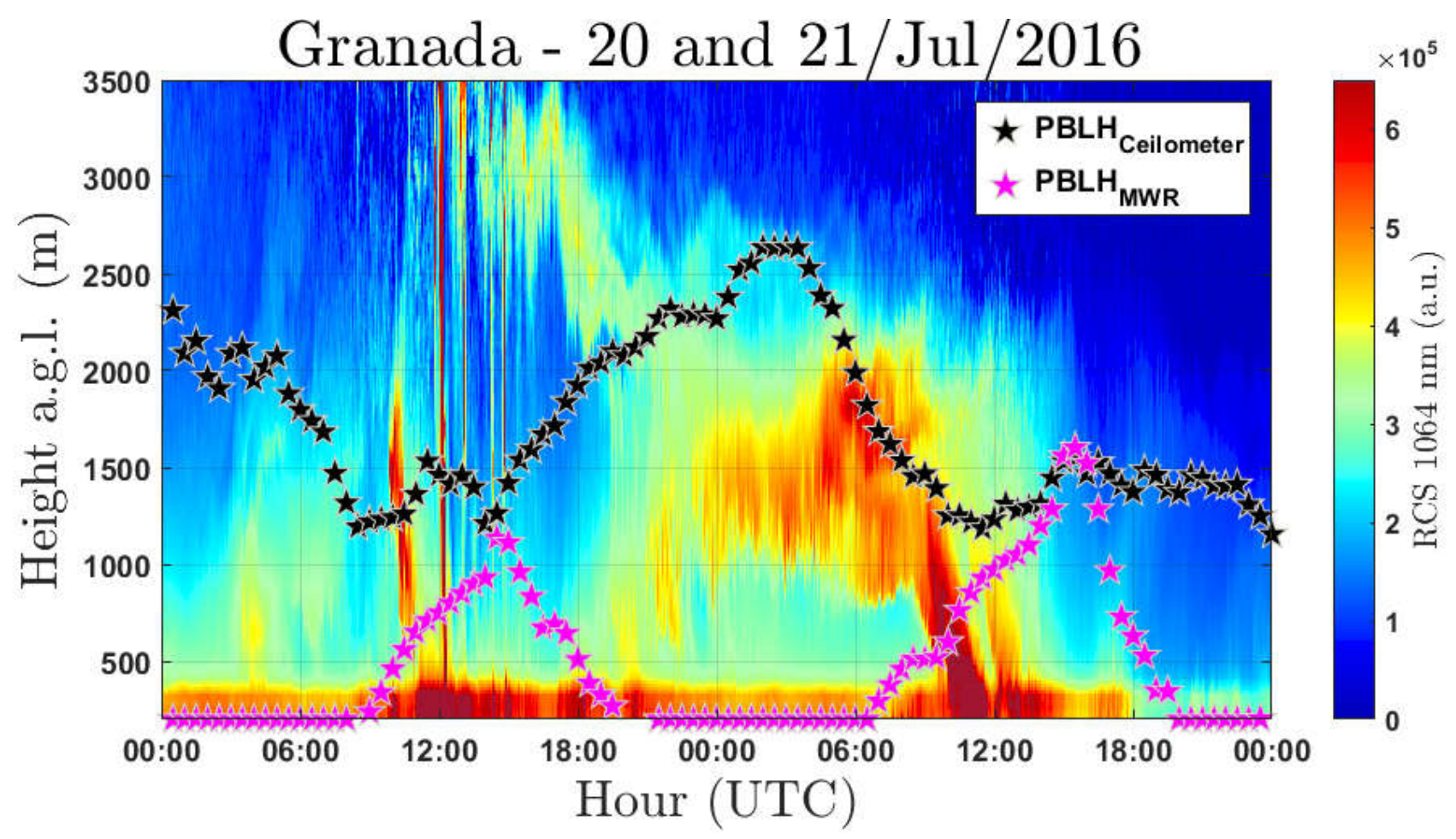

Figure $6.2-\operatorname{RCS}(\lambda=1064 \mathrm{~nm})$ profile obtained from ceilometer data. Black and pink stars represent $P B L H_{\text {ceilometer }}$ and $P B L H_{M W R}$, respectively. 
In the afternoon, when $C B L$ uses to reach its maximum, on 20 and $21 \mathrm{July,} P B L H_{M W R}^{C B L}$ and $P B L H_{\text {Ceilometer }}^{C B L}$ present similar values indicating that the $G M$ works when the dust layer is decoupled of the PBL. However, $P B L H_{\text {Ceilometer }}^{R L}$ is at $2500 \mathrm{~m}$ all along the night from 20 to 21 July since the sharpest vertical decrease of the signal occurs at the top of dust layer instead of the at the top of the $R L$. Therefore, the $G M$ can provide false detection when the dust layer is coupled with the $P B L$.

Although the presence of mineral dust may generate the heating of dust layer, due to the absorption of solar radiation, affecting the vertical temperature profile, the influences were not significant enough in this event and thus the same behavior of $P B L H_{M W R}$ described in section 6.2.1 is observed.

\subsection{PBL long term analysis}

\subsubsection{Study of the PBL based on MWR}

$M W R$ operates continuously, even under rainy and cloudy scenarios, with low interruption periods (which are associated with maintenance, calibration and power outage). With the exception of summer 2015, the maintenance and failures did not affect more than $27 \%$ of data and thus, the MWR measurement covers more than 70\% of the period 2012-2016. Table 6.1 shows the distribution of data recovery rate per season and per year, and the percentage of measurement days.

\begin{tabular}{|l|c|c|c|c|c|}
\hline Year & $\begin{array}{r}2012 \\
\text { Season }\end{array}$ & $\begin{array}{c}2013 \\
(100 \%)\end{array}$ & $\begin{array}{c}2014 \\
(87 \%)\end{array}$ & $\begin{array}{c}2015 \\
(77 \%)\end{array}$ & $\begin{array}{r}2016 \\
(70 \%)\end{array}$ \\
\hline Winter & & & & & \\
\hline Spring & $94 \%$ & $83 \%$ & $86 \%$ & $86 \%$ & $90 \%$ \\
\hline Summer & $83 \%$ & $85 \%$ & $84 \%$ & $88 \%$ & $83 \%$ \\
\hline Autumn & $82 \%$ & $76 \%$ & $77 \%$ & $64 \%$ & $73 \%$ \\
\hline
\end{tabular}

Table 6.1 - MWR Recovery rate

* Measurement Days

The long-term study performed with MWR data at Granada is compared with same kind of study performed at other locations, such as eastern part of the Highveld region (a large 
plateau in South Africa composed by rural area with agriculture, mining and industrial activities) (Korhonen et al., 2017), south of Paris (on the Saclay plateau in a suburban environment surrounded by villages, agricultural fields and some roads) (Pal et al., 2015), Cologne (situated in a flat region and surrounded by some hills at east and west. In addition it is the fourth most populated city in Germany) (Schwenn et al., 2014), and Leipzig (a very populous city situated in a rather flat terrain with some forest parks within its limits and surrounded by a relatively unforested region) (Baars et al., 2008).

Table 6.2 presents some characteristics of each campaign, e.g., localization, instrument and algorithm.

Figure 6.3 shows the average daily evolution of $P B L H_{M W R}$ since 2012 until 2016. The $P B L H_{M W R}$ has low values in winter, maximum values in summer, spring and autumn with intermediate values which is the expected pattern being in agreement with the results showed by Pal et al. (2015) in south of Paris and Korhonen et al. (2014) at Highveld. However, the different latitudes result in distinct average values. For example, the average maximum PBLH value in winter is larger in Highveld $(1480 \mathrm{~m})$ than in Granada and Paris $(1000 \mathrm{~m})$. In summer, Granada and Paris have slightly different average maximum values (around 2 $\mathrm{km}$ in Granada and $1.9 \mathrm{~km}$ in Paris). Therefore, although the seasonal cycle is the same, geographical differences (latitude, ground cover, city size) results in distinct values observed in each season at the different stations.

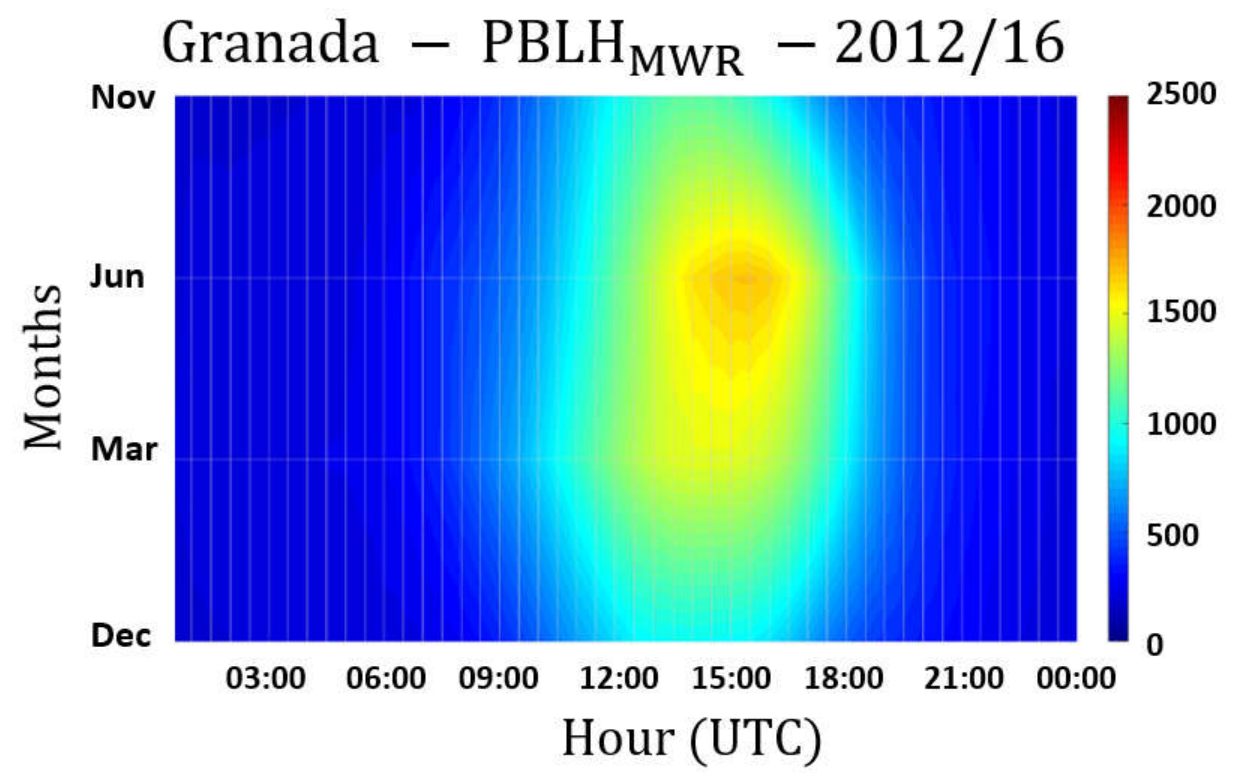

Figure 6.3 - Daily PBLH $H_{M W R}$ since 2012 until 2016. 


\begin{tabular}{|c|c|c|c|c|c|}
\hline Cities & Granada & $\begin{array}{c}\text { Highveld } \\
\text { (Korhonen et al. 2014) }\end{array}$ & $\begin{array}{c}\text { Paris } \\
\text { (Pal et al. 2015) }\end{array}$ & $\begin{array}{c}\text { Colonia } \\
\text { (Schween et al., 2014) }\end{array}$ & $\begin{array}{c}\text { Leipzig } \\
\text { (Baars et al., 2008) }\end{array}$ \\
\hline Localization & $37.16^{\circ} \mathrm{N}, 3.61^{\circ} \mathrm{W}$ & $26^{\circ} 15^{\prime} \mathrm{S}, 29^{\circ} 26^{\prime} \mathrm{E}$ & $48.713^{\circ} \mathrm{N}, 2.208^{\circ} \mathrm{E}$ & $50^{\circ} 54^{\prime} \mathrm{N}, 6^{\circ} 24^{\prime} \mathrm{E}$ & $51.3^{\circ} \mathrm{N}, 12.4^{\circ} \mathrm{E}$ \\
\hline Altitude (m a.s.l.) & 680 & 1745 & 160 & 111 & 113 \\
\hline Instrument & MWR & Polly ${ }^{\mathrm{XT}}$ & $\begin{array}{c}\text { Aerosol lidar and } \\
\text { meteorological station }\end{array}$ & Doppler lidar & Polly \\
\hline Algorithm & PM and TGM & $\begin{array}{l}\text { Wavelet Covariance } \\
\text { Transform }\end{array}$ & STRAT+ & $\begin{array}{l}\text { Variance of vertical wind } \\
\text { speed }\end{array}$ & $\begin{array}{l}\text { Wavelet Covariance } \\
\text { Transform }\end{array}$ \\
\hline
\end{tabular}

Table 6.2 - Main characteristics of long-term studies campaign 
Figure 6.4 shows a deeper statistical analysis using the monthly Whisker boxes for each season of the period 2012-2016. In all seasons, during the sable period, $P B L H$ has a similar behavior with low variability, except in the summer, where the whiskers show larger range of values. Similar behavior was demonstrate by Pal et al. (2015), where, outside of summer, the average $P B L H$ variation in stable situations is around $200 \mathrm{~m}$. During convective period the differences among the seasons are more evident. As confirmed in different works (e.g. Stull, 1988; van der Kamp and McKendry, 2010; Seidel et al., 2012; Pal et al., 2015; Chen et al., 2016), the average value of $P B L H_{M W R}$ is low in winter and reaches its apex in summer. The $P B L H_{M W R}$ in spring is similar to autumn, but with slightly higher average and larger spread of values, as can be seen in the whisker boxes.

The $P B L H$ growth speed $P B L H_{M W R}^{G S p e e d}$ (Fig. 6.5) offers an interesting insight on the $P B L$ behavior where positive values shows the $P B L H$ growth and vice versa. Maxima values of $P B L H_{M W R}^{\text {GSpeed }}$ occur in summer (red line) when the diurnal cycle is wider. This behavior is due to the high incidence of solar radiation on summer which favors the surface heating, generating stronger convective processes. Minima values of $P B L H_{M W R}^{G S p e e d}$ occur also in summer because the PBLH decreases from the largest values of the year $(\sim 2000 \mathrm{~m})$ to the typical value of the $S B L(\sim 500 \mathrm{~m})$. Oppositely, winter (dark blue line) with less solar radiation (low incident angle and few hours of sun) is characterized by smaller absolute values of $P B L H_{M W R}^{G S p e e d}$. Spring (orange line) and autumn (light blue line) present similar intermediate behaviors. It is worthy to note that positive $P B L H_{M W R}^{G S p e e d}$ values starts close to sunrise and last till 14:00 UTC, in this period the mixing process is more intense and $M L$ is expanding. This is a general behavior for all seasons excluding summer, when the growth period last one hour more as a result of the higher incidence of solar radiation during this season. 

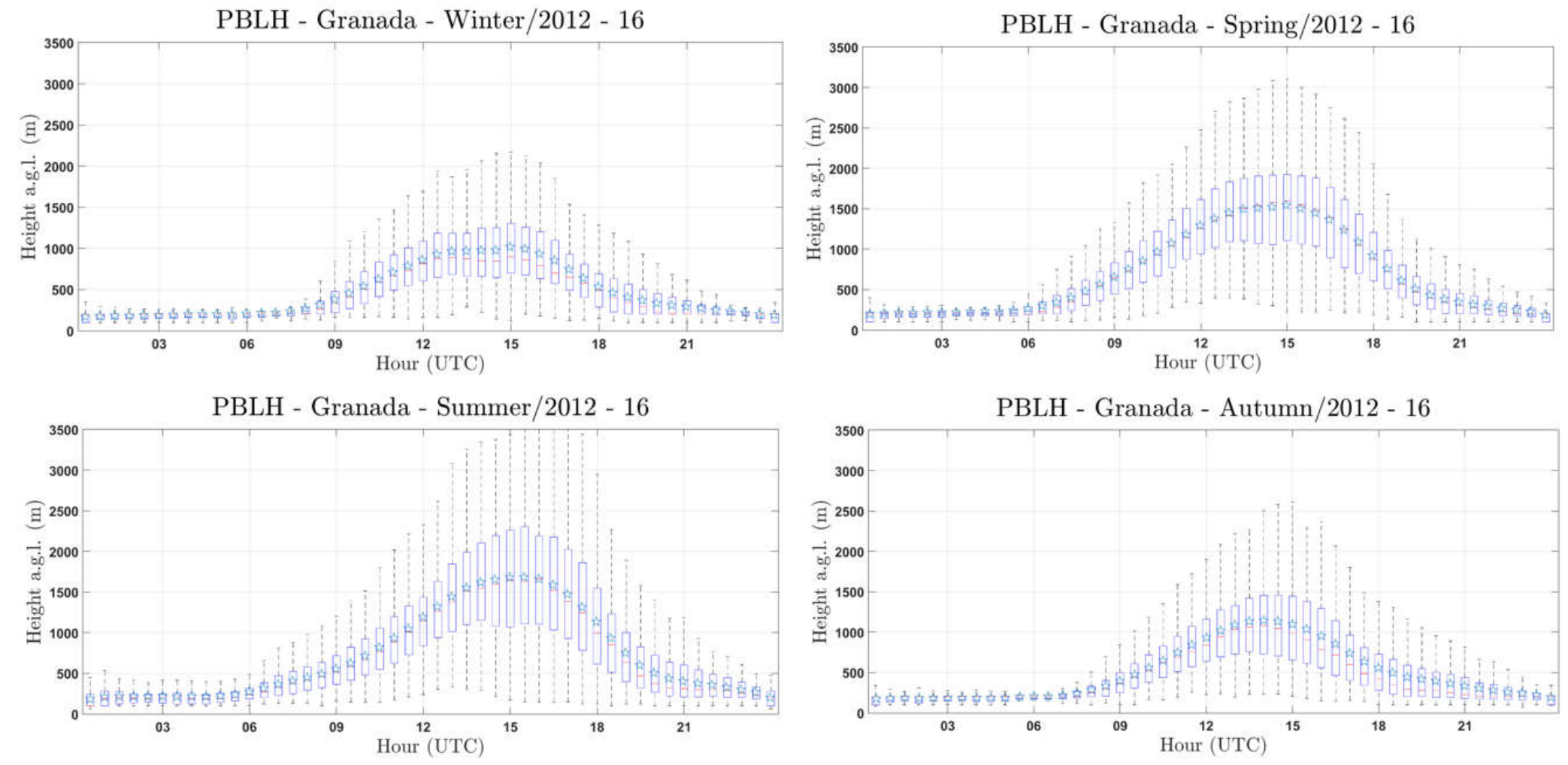

Figure 6.4 - Daily $P B L H_{M W R}$ cycle for winter (DJF), spring (MAM), summer (JJA) and autumn (SON) since 2012 until 2016. Whiskers and boxes indicate $10,25,75$ and $90 \%$ percentiles. The red lines represent the median and the blue stars indicate the mean. 


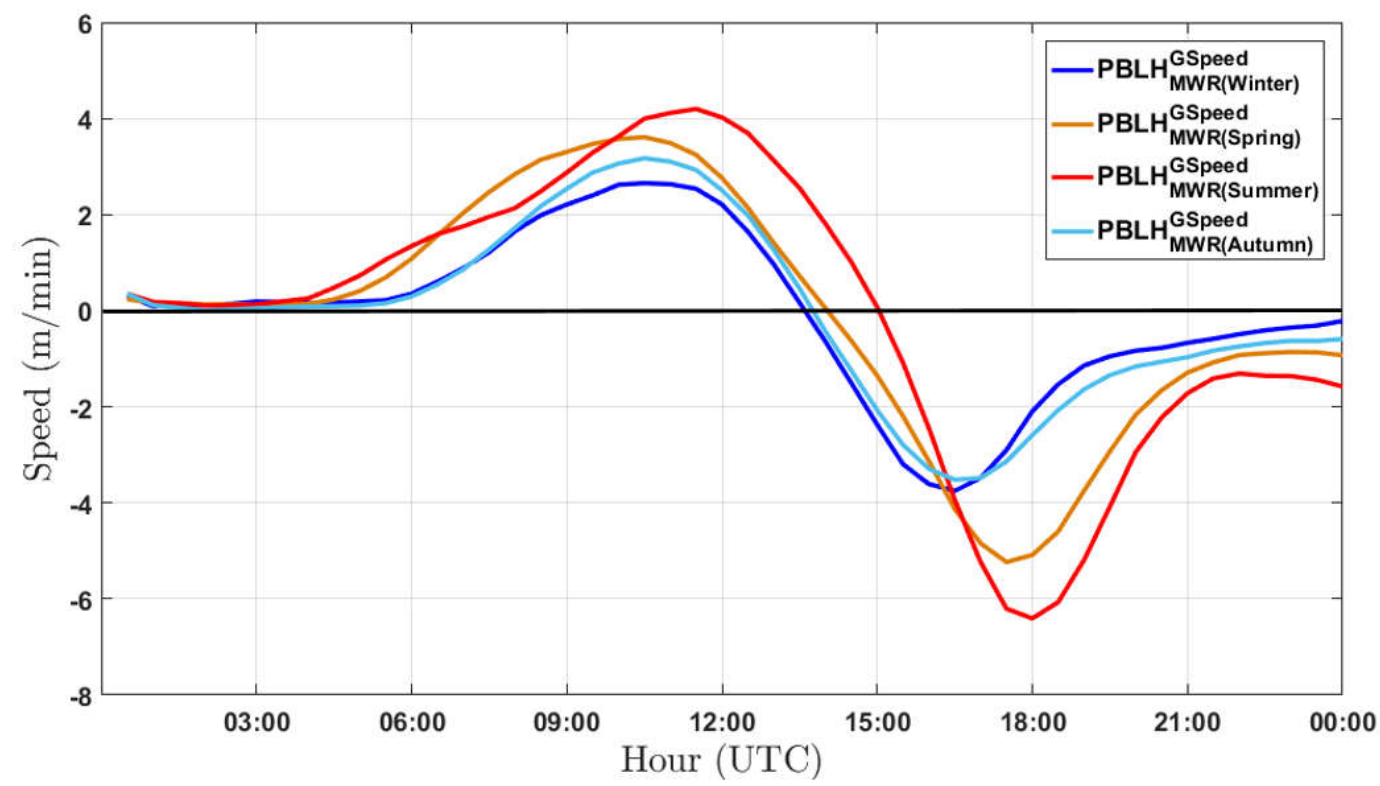

Figure 6.5 - $P B L H_{M W R}^{G S p e e d}$ for winter (DJF - dark blue line), spring (MAM - orange line), summer (JJA - red line) and autumn (SON - light blue line) in the period 2012-2016.

Figure 6.6 shows the $P B L H_{M W R}^{M a x}$ histograms for the four seasons, including the skewness $\left(S_{k}\right)$, the normalized kurtosis $\left(K_{t}\right)$ and the average $\left(A_{v}\right)$ values. Winter and autumn histograms of $P B L H_{M W R}^{M a x}$ have an asymmetric shape $\left(S_{k}^{\text {winter }}=0.8\right.$ and $\left.S_{k}^{\text {autumn }}=0.6\right)$ biased toward small values, with $A_{v}$ of $1000 \pm 350$ and $1300 \pm 600 \mathrm{~m}$, respectively. However, winter histogram present a higher $K_{t}$ value $\left(K_{t}^{\text {winter }}=0.2\right)$ with respect to autumn which presents a more flat distribution $\left(K_{t}^{\text {autumn }}=-0.5\right)$. Spring has an almost symmetric and flat distribution $\left(S_{k}^{\text {spring }}=0.1\right.$ and $\left.K_{t}^{\text {spring }}=-0.6\right)$ with average value of $1600 \pm 500 \mathrm{~m}$. Finally, summer has a flattest distribution $\left(K_{t}^{\text {summer }}=-0.7\right)$ with low asymmetry $\left(S_{k}^{\text {summer }}=0.3\right)$ and high number of cases localized in higher bins and an average value of $1900 \pm 700 \mathrm{~m}$. We found similar seasonal pattern as those determined in other cities like Leipzig (Baars et al., 2008), Cologne (Schween et al., 2014) and Paris (Pal et al., 2015). Nevertheless, the different cities present differences in the average and the range of the variables used in $P B L$ description, thus larger values are obtained at Granada while the lowest ones correspond to Cologne. 

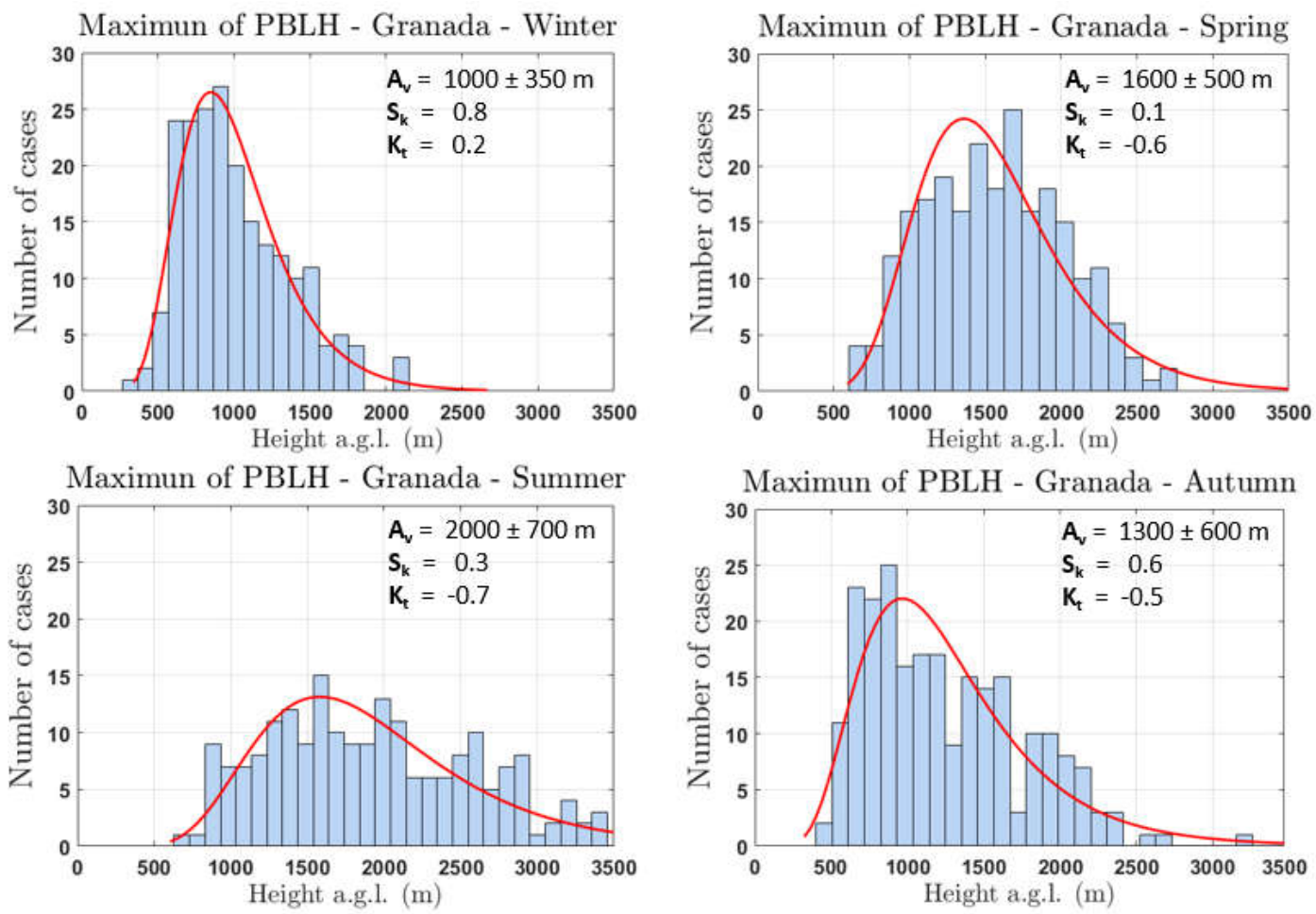

Figure 6.6 - $P B L H_{M W R}^{M a x}$ for Winter (DJF), Spring (MAM), Summer (JJA) and Autumn (SON) since 2012 until 2016. Each bin size is equivalent to $100 \mathrm{~m}$. The red line indicates a lognormal distribution. $A_{v}, S_{k}$ and $K_{t}$ represents average, skewness and kurtosis values, respectively.

The $P B L H_{M W R}^{G R a t e}$ is influenced by the seasonal variability (Fig. 6.7). Winter has the lowest average value $(220 \pm 140 \mathrm{~m} / \mathrm{h})$, as well as a very asymmetric and peaked distribution $\left(S_{k}^{\text {winter }}\right.$ $=3.1$ and $K_{t}^{\text {winter }}=16.2$ ) with values concentrated in smaller bins. Spring and autumn have a considerable difference in their plot shape and average values. Autumn, like winter, presents a small average value $(230 \pm 140 \mathrm{~m} / \mathrm{h})$ and a very asymmetric and peaked distribution $\left(S_{k}^{\text {winter }}=2.9\right.$ and $\left.K_{t}^{\text {winter }}=14.5\right)$ with more frequency of smaller bins. On the other hand, spring, has a high average value $(300 \pm 160 \mathrm{~m} / \mathrm{h})$ and an asymmetric and more flat distribution $\left(S_{k}^{\text {spring }}=2.7\right.$ and $\left.K_{t}^{\text {spring }}=11.6\right)$ concentrated at higher bins. Summer, as expected, has larger average value $(360 \pm 290 \mathrm{~m} / \mathrm{h})$ with a less asymmetric and peaked distribution $\left(S_{k}^{\text {summer }}=2.3\right.$ and $\left.K_{t}^{\text {summer }}=6.0\right)$ with values centered at higher bins, similarly to spring. The same pattern of seasonal variations is observed in Cologne (Schween et al., 2014) and Paris (Pal et al., 2015), however Granada presents greater variability among seasons. Thus, while the difference between average values registered in summer and winter are around 0.8 and $1.0 \mathrm{~km} / \mathrm{h}$ in Cologne and Paris, respectively, this difference in Granada is around $1.8 \mathrm{~km} / \mathrm{h}$. This result can be explained considering the wider range between the 
winter and summer seasonal conditions, as reflected for example in the analysis of the temperature range and explained in Section 6.3.2.
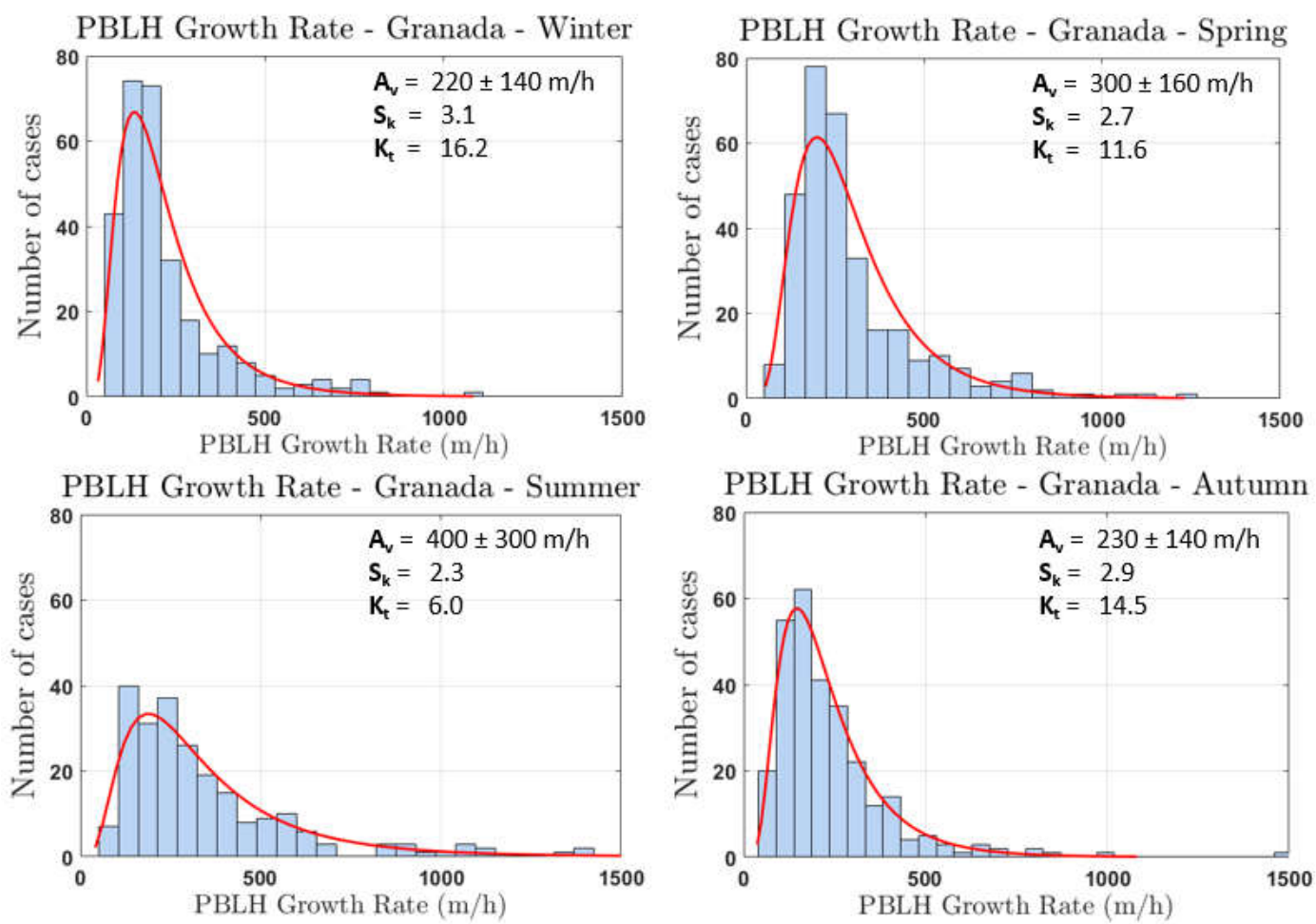

Figure 6.7 - $P B L H_{M W R}^{G R a t e}$ for winter (DJF), spring (MAM), summer (JJA) and autumn (SON) since 2012 until 2016. Each bin size is equivalent to $100 \mathrm{~m} / \mathrm{h}$. The red line indicates a lognormal distribution. $A_{v}, S_{k}$ and $K_{t}$ represents average, skewness and kurtosis values, respectively.

The $P B L H_{M W R}^{G D u r}$ present a clear seasonal pattern (Fig. 6.8). The average value in summer $(6.2 \pm 2.0 \mathrm{~h})$ is larger than average value in winter $(5.4 \pm 1.6 \mathrm{~h})$. This is consequence of earlier sunrise and later sunset in summer, enabling PBL grows during larger time. In winter and autumn, the frequency distribution is more centered on low values, whereas summer and spring has spread distributions with negative skewness $\left(S_{k}^{\text {spring }}=-0.1, K_{t}^{\text {spring }}=-0.6\right.$, $S_{k}^{\text {summer }}=-0.2$ and $\left.K_{t}^{\text {summer }}=-0.8\right)$. Granada, Cologne and Paris present similar seasonal patterns of $P B L H_{M W R}^{G D u r}$, being the difference between summer and winter around $0.9 \mathrm{~h}$ at Granada and 3.6 h at Paris, with Cologne in between. 


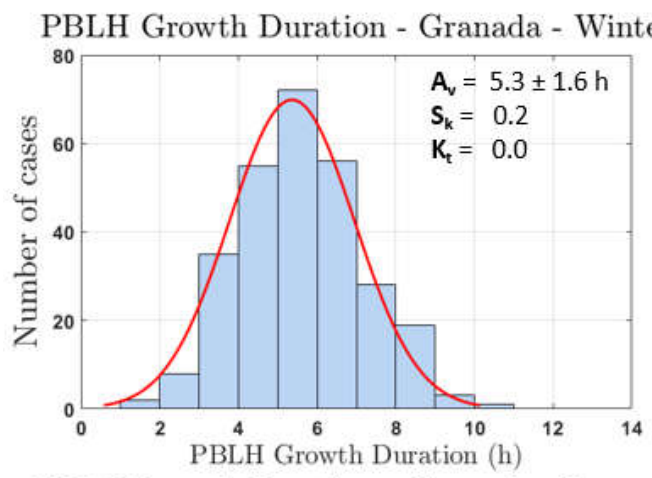

PBLH Growth Duration - Granada - Spring
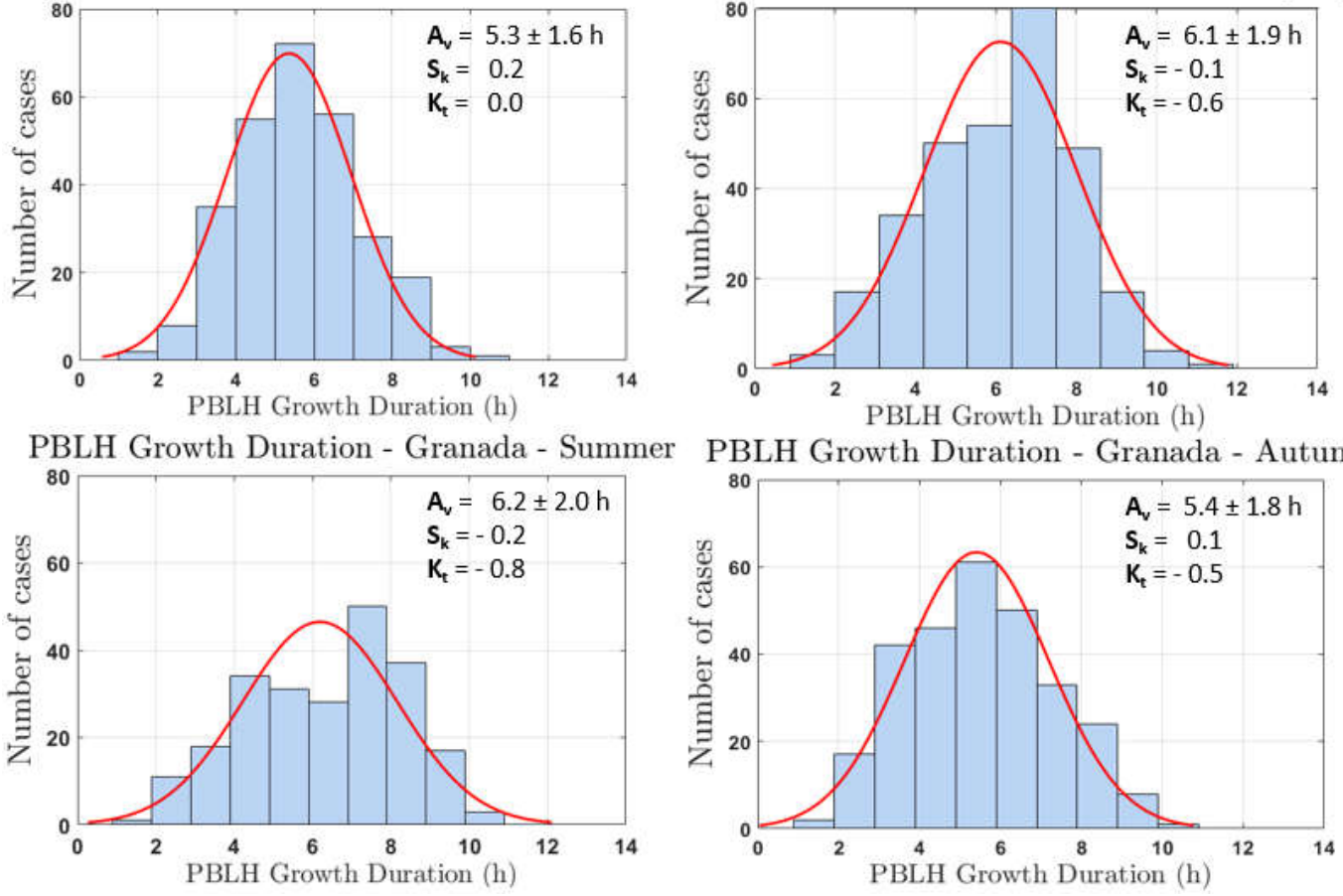

Figure 6.8 - $P B L H_{M W R}^{G D u r}$ for winter (DJF), spring (MAM), summer (JJA) and autumn (SON) since 2012 until 2016. Each bin has a size of $1 \mathrm{~h}$. The red line indicates a Gaussian distribution. $A_{v}, S_{k}$ and $K_{t}$ represents average, skewness and kurtosis values, respectively.

Table 6.3 summarized the comparison among the values of $P B L H_{M W R}^{M a x}, P B L H_{M W R}^{G R a t e}$ and $P B L H_{M W R}^{G D u r}$ obtained at Leipizig (Baars et al. 2008), Cologne (Schween et al. 2014), Paris (Pal et al., 2015) and Granada. It is evident the seasonal pattern of the different variables at all the stations. $P B L H_{M W R}^{M a x}$ presents similar values and ranges at Granada and Paris that are larger than those determined at the other stations with high latitude. Concerning $P B L H_{M W R}^{G R a t e}$, it is clear that Granada presents larger values associated to the larger solar irradiance all around the year. Furthermore the values of Granada also presents a larger seasonal range than the other sites, thus suggesting really dry conditions in summer that favor strong convective processes shortly after sunrise. The combination of larger $P B L H_{M W R}^{M a x}$ and faster $P B L H_{M W R}^{G R a t e}$ at Granada leads $P B L H_{M W R}^{G D u r}$ smaller than those encountered at the other sites. 


\begin{tabular}{|c|c|c|c|c|}
\hline \multirow{2}{*}{ Season } & \multicolumn{4}{|c|}{$\overline{P B L H_{M W R}^{M a x}(k m)}$} \\
\hline & Granada & Paris (Pal et al., 2015) & Colonia (Schween et al.,2014) & Leipzig (Baars et al.,2008) \\
\hline Spring & $1.6 \pm 0.5$ & $1.6 \pm 0.5$ & 1.4 & 1.4 \\
\hline Summer & $2.0 \pm 0.7$ & $1.9 \pm 0.4$ & 1.6 & 1.8 \\
\hline Autumn & $1.3 \pm 0.6$ & $1.4 \pm 0.6$ & 1.0 & 1.2 \\
\hline Winter & $1.0 \pm 0.4$ & $1.0 \pm 0.4$ & 1.1 & 0.8 \\
\hline Season & \multicolumn{4}{|c|}{$P B L H_{M W R}^{G R a t e}(\mathrm{~km} / \mathrm{h})$} \\
\hline Spring & $0.30 \pm 0.20$ & $0.22 \pm 0.14$ & 0.11 & -- \\
\hline Summer & $0.40 \pm 0.30$ & $0.25 \pm 0.14$ & 0.13 & -- \\
\hline Autumn & $0.23 \pm 0.20$ & $0.20 \pm 0.14$ & 0.11 & -- \\
\hline Winter & $0.22 \pm 0.17$ & $0.15 \pm 0.12$ & 0.05 & -- \\
\hline Season & \multicolumn{4}{|c|}{ PBLH ${ }_{M W R}^{\text {GDuration }}(\mathrm{h})$} \\
\hline Spring & $6.1 \pm 1.8$ & $7.2 \pm 2.3$ & 6.6 & -- \\
\hline Summer & $6.2 \pm 1.9$ & $8.1 \pm 2.3$ & 7.0 & -- \\
\hline Autumn & $5.4 \pm 1.7$ & $5.7 \pm 2.3$ & 5.8 & -- \\
\hline Winter & $5.3 \pm 1.5$ & $4.5 \pm 2.1$ & 4.9 & -- \\
\hline
\end{tabular}

Table 6.3 - PBL characterization of four different places 


\subsubsection{Meteorological variables affecting the PBL}

Figure 6.9 shows the average daily pattern for $T_{\text {air }}, R H$ and $R_{n}$ together with the $P B L H_{M W R}$ for all seasons in the period 2012-2016. During summer and spring the $T_{\text {air }}$ rising (triangles) occurs at approximately 06:00 UTC whereas this increase is approximately at 07:30 UTC in winter and autumn. This delay between spring/summer and autumn/winter is due to the changes in the insolation period, the influence of heat conductive fluxes from/to the ground and the dry land with reduced vegetation typical of summer conditions.
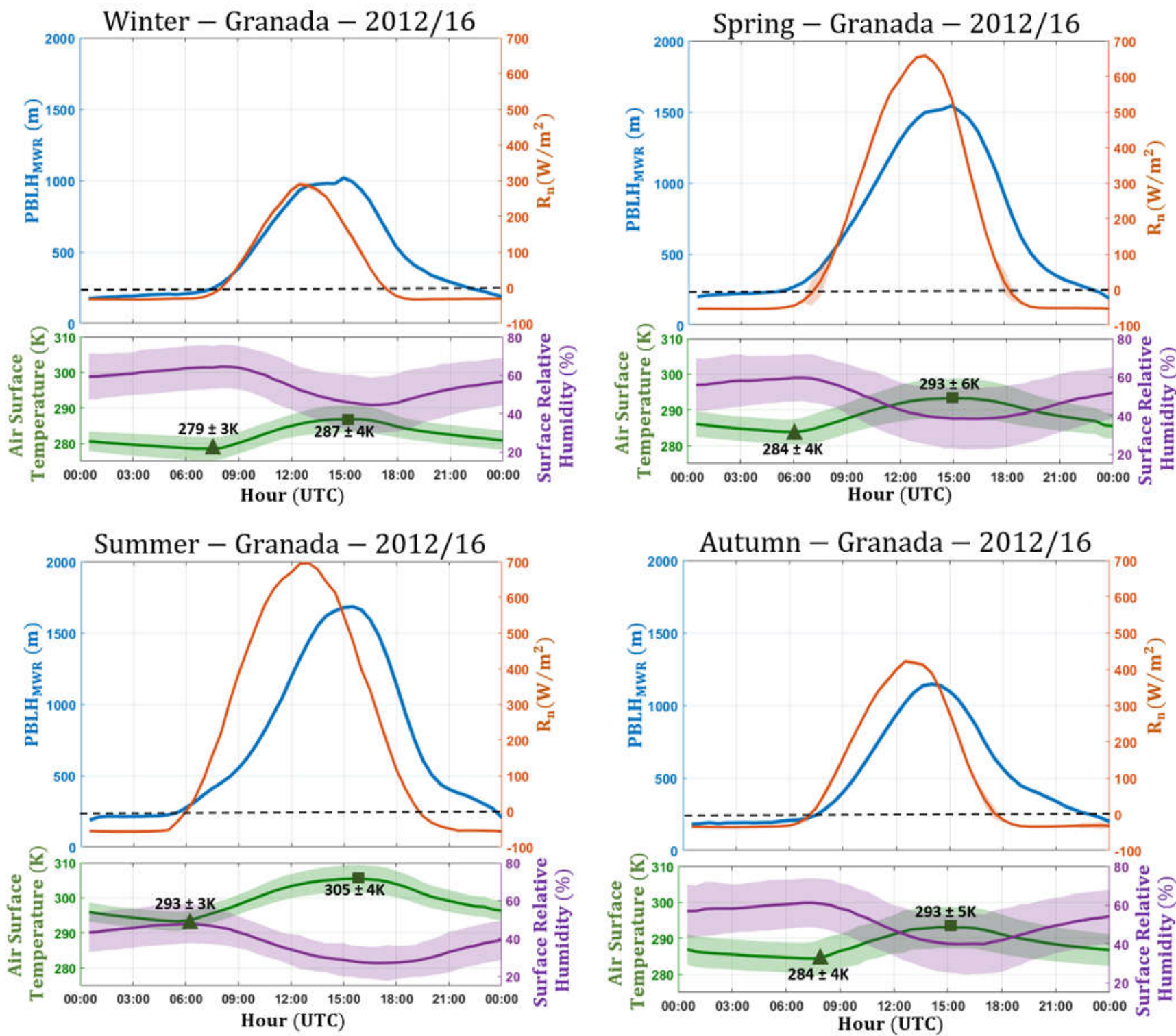

Figure 6.9 - Comparison among average annual daily cycle of $P B L H_{M W R}$ (blue line), $R_{n}$ (orange line), air surface temperature (green line) and surface relative humidity (purple line) for all meteorological seasons from 2012 until 2016. 
Studies performed in other regions such as Paris and Highveld (Pal et al., 2015; Kornohen et al., 2014) reveal similar seasonal patterns for the $T_{\text {air }}$, although both the average air temperature and its interseasonal range are different from site to site due to differences in latitude, climate and ground cover. For example, in Paris the average maximum value obtained in summer and winter of $T_{\text {air }}$ are around 297 and $277 \mathrm{~K}$, respectively, representing an average difference of approximately $20 \mathrm{~K}$ between these seasons. In Highveld, the average maximum values of $T_{\text {air }}$ are around 297 and $290 \mathrm{~K}$, for summer and winter, respectively. While at Granada the maximum average of $T_{\text {air }}$ are $305 \mathrm{~K}$ (summer) and 279 $\mathrm{K}$ (winter) with a difference between them around $26 \mathrm{~K}$, Highveld has a low variability of air surface temperature throughout the seasons, justifying the small difference of Maximum PBLH observed between summer and winter (around $500 \mathrm{~m}$ ), when compared to Paris and Granada, where this variability is approximately 900 and $1000 \mathrm{~m}$, respectively.

The surface thermal amplitude (STA - the difference between the average minimum value of $T_{\text {air }}\left[\overline{T_{a l r}^{m i n}}\right]$ and average maximum value of the same variable $\left.\left[\overline{T_{a l r}^{\max }}\right]\right)$ at Granada is 9, 12,9 , and $8 \mathrm{~K}$ for spring, summer, autumn, and winter, respectively. This seasonal change of STA justifies the pattern of $P B L H_{M W R}^{G R a t e}$ exhibited in table 6.3. As it can be seen, the warmest and coldest seasons have the largest and lowest ST A, respectively. The correlation between the STA and $P B L H_{M W R}^{G R a t e}$ is based on the intensification of convective process caused by the increase of air surface temperature. The opposite situation occurs in Highveld, where low values of $S T A$ are observed $\left(S T A_{\text {summer }}<9 \mathrm{~K}\right)$ and consequently small values of $P B L H^{G R a t e}$ are registered (median value of approximately $0.2 \mathrm{~km} / \mathrm{h}$ ).

The annual cycle of the $R H$ average presents its maximum in winter and its minimum summer (Fig. 6.9). At all seasons, the averages daily values of $R H$ are anti-correlated with $R_{n}, T_{\text {air }}$ and $P B L H_{M W R}$. The minimum of $R H$ occurs close to maximum of $T_{\text {air }}$ and $P B L H_{M W R}^{C B L}$. Therefore the higher values of $R H$ are observed during stable period and the lower one in the central region of day, as expected because $P B L H$ is higher when surface sensible heat fluxes dominate latent heat fluxes, causing an increase in the buoyancy. Similar results also were observed by Pal et al. (2015), however values of $R H$ in Paris are higher than the values in Granada for all seasons, due to higher evapotranspiration and Atlantic influence at Paris.

The lower $T_{a i r}$ and the higher average $R H$ observed in Paris, in comparison with Granada, justify the lower values of $P B L H_{M W R}^{M a x}$ and $P B L H_{M W R}^{G R a t e}$ observed in Paris. Because the low 
values of these surface variables suggest smaller sensible flux in comparison with values observed in Granada.

We have estimated $R_{n}$ from the solar global irradiance using the seasonal model described in Alados et al. (2010) (fig. 6.9). As expected due to the different levels of incidence of solar radiation, the higher values of $R_{n}$ are registered in summer and they decrease continuously until the winter. In all seasons, the higher values are observed in central region of day around 13:00 UTC, close to moment when $P B L H_{M W R}^{C B L}$ is fully developed. There is a clear link between the start of positive $R_{n}$ and the starting time of $P B L H_{M W R}^{C B L}$ growth, as well as, with $P B L H_{M W R}^{G R a t e}$ and $P B L H_{M W R}^{G D u r}$ in all seasons. Positive values of $R_{n}$ heats the ground which at the same time increases the temperature of the adjacent air layer by conduction, and consequently intensifies the convective processes. Therefore, $P B L H_{M W R}^{C B L}$ begins to growth approximately at the same time when $R_{n}$ becomes positive. In the same way, the reduction of $R_{n}$ causes the decrease of $T_{\text {air }}$ and convective process, provoking the fall of $P B L H_{M W R}^{C B L}$. However, this process does not occur immediately having an offset as can be observed in Figure 6.9. This offset may be explained based on the thermal and mechanical inertia of the atmosphere which requires some time to dissipate the convection cells.

The increase of positive values of $R_{n}$ is directly related to $P B L H_{\text {GRate }}$, because the enhancement of $R_{n}$ generates an intensification of convective process, which are responsible for increasing the $P B L H_{M W R}^{C B L}$. The seasonality of $R_{n}$ also is observed in $P B L H_{M W R}^{G R a t e}$, where summer, the season with higher average values of $R_{n}$, has the higher values of $P B L H_{M W R}^{G R a t e}$, as expected.

Negative values of $R_{n}$ correspond to period when the ground emits more longwave irradiance than absorbs solar irradiance, characterizing the cooling of the surface and suppression of the convective activity. Therefore, this period is associated with $S B L$, as shown in figure 6.9. The low variation of the $P B L H_{M W R}^{S B L}$ average is also associated with negative and practically constant values of $R_{n}$. The negatives values of $R_{n}$ also coincide with higher values of $R H$ and lower values of air surface temperature.

\subsubsection{Study of the PBL based on ceilometer: Searching on the Residual Layer}

The ceilometer located at IISTA-CEAMA measured without failures during $96 \%$ of the days from January 2013 until December 2016, showing its automatic operability and low 
maintenance requirements. However, the number of successful $P B L H$ retrievals with the ceilometer (Table 6.4) are lower than those retrieved with the $M W R$ due to influence of atmospheric conditions in aerosol backscatter profiles (Eresma et al., 2006), preventing $P B L H_{\text {Ceilometer }}$ detection in complex situations (rainy, clouds, Saharan dust layers). These cases were flagged and removed as explained in section 4.1.3.1. The lowest retrieval rate is registered in autumn, due to the rain and still the occurrence of Saharan mineral dust outbreaks.

\begin{tabular}{|l|c|c|c|c|}
\hline Year & $\begin{array}{c}2013 \\
(99.7 \%)\end{array}$ & $\begin{array}{c}2014 \\
(100.0 \%)\end{array}$ & $\begin{array}{c}2015 \\
(100.0 \%)\end{array}$ & $\begin{array}{c}2016 \\
(96.2 \%)\end{array}$ \\
\hline Winter & & & & \\
\hline Spring & $96.7 \%$ & $51.1 \%$ & $84.4 \%$ & $67.8 \%$ \\
\hline Summer & $46.7 \%$ & $50.0 \%$ & $50.0 \%$ & $45.6 \%$ \\
\hline Autumn & $34.4 \%$ & $56.7 \%$ & $50.0 \%$ & $32.2 \%$ \\
\hline
\end{tabular}

Table 6.4 - Ceilometer Recovery rate

* Measurement Days

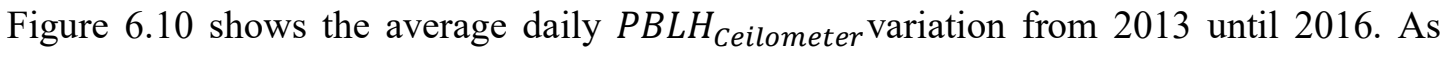
mentioned before, the ceilometer detects the $P B L H_{\text {Ceilometer }}^{R L}$ between sunset and sunrise, often remaining around $1000 \mathrm{~m}$ a.g.l. The GM allows the $P B L H_{\text {Ceilometer }}^{C B L}$ height detection when the $C B L$ is fully developed, reaching the previous-day $R L$ height Thus, the variation observed in this period is large, mainly in summer, when $S T A$ and $R_{n}$ reaches the largest values.

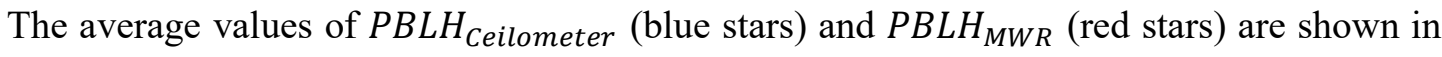
figure 6.11. Only days with these two instruments simultaneously operating are considered. This combination allow us to observe the seasonal behavior of the complex $P B L$ structure composed by $P B L H_{\text {Ceilometer, }}^{R L}, P B L H_{\text {Ceilometer, }}^{C B L} P B L H_{M W R}^{C B L}$ and $P B L H_{M W R}^{S B L}$, so that the presence of these variables is related with the $P B L$ daily cycle presented in previous sections. The same daily pattern described in section 6.2.1 is observed, as well as the seasonality demonstrated in figures 6.3 and 6.10 for $P B L H_{M W R}$ and $P B L H_{\text {Ceilometer, }}$, respectively. 


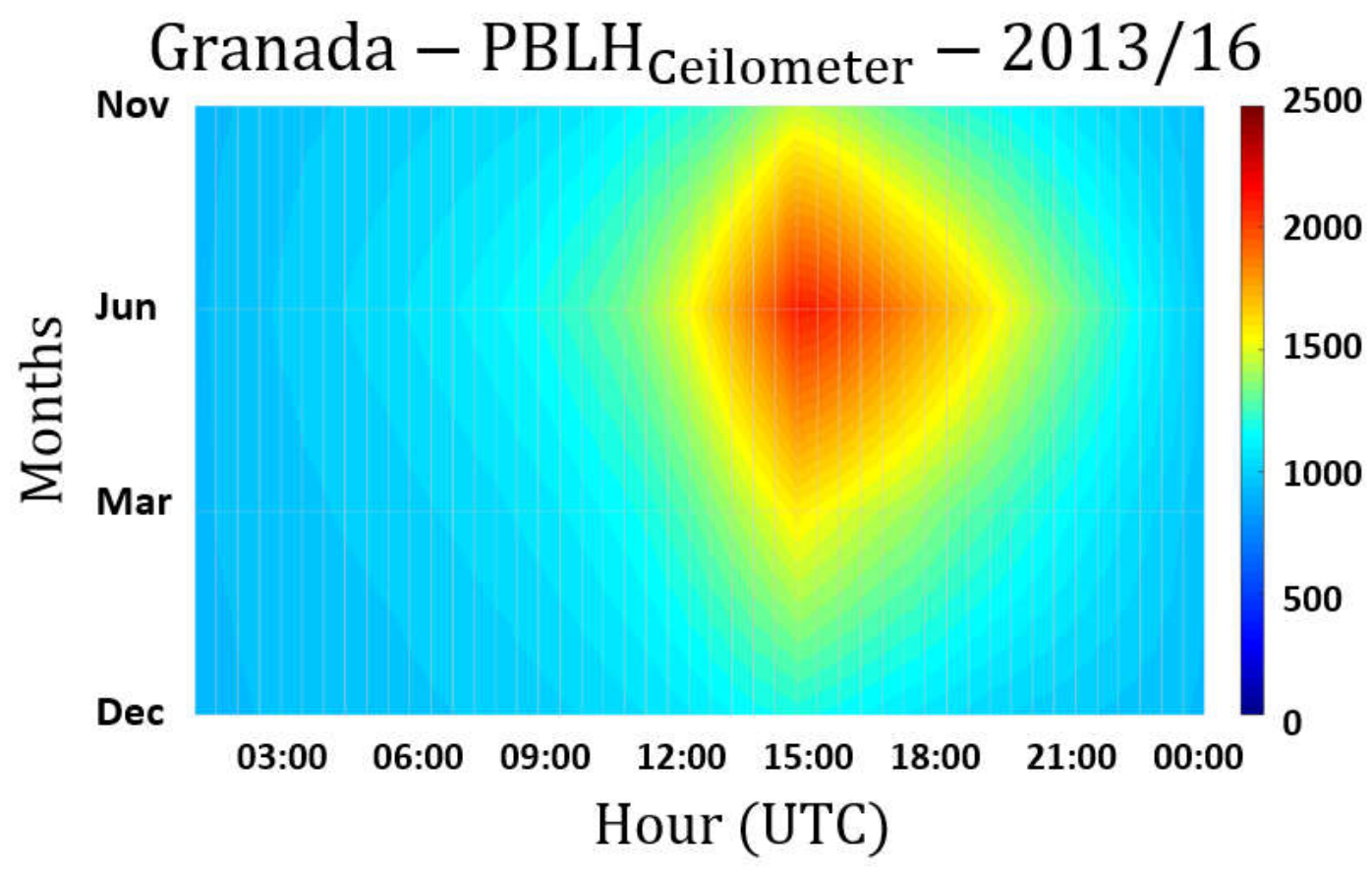

Figure - 6.10 - Daily PBLH Ceilometer since 2013 until 2016.
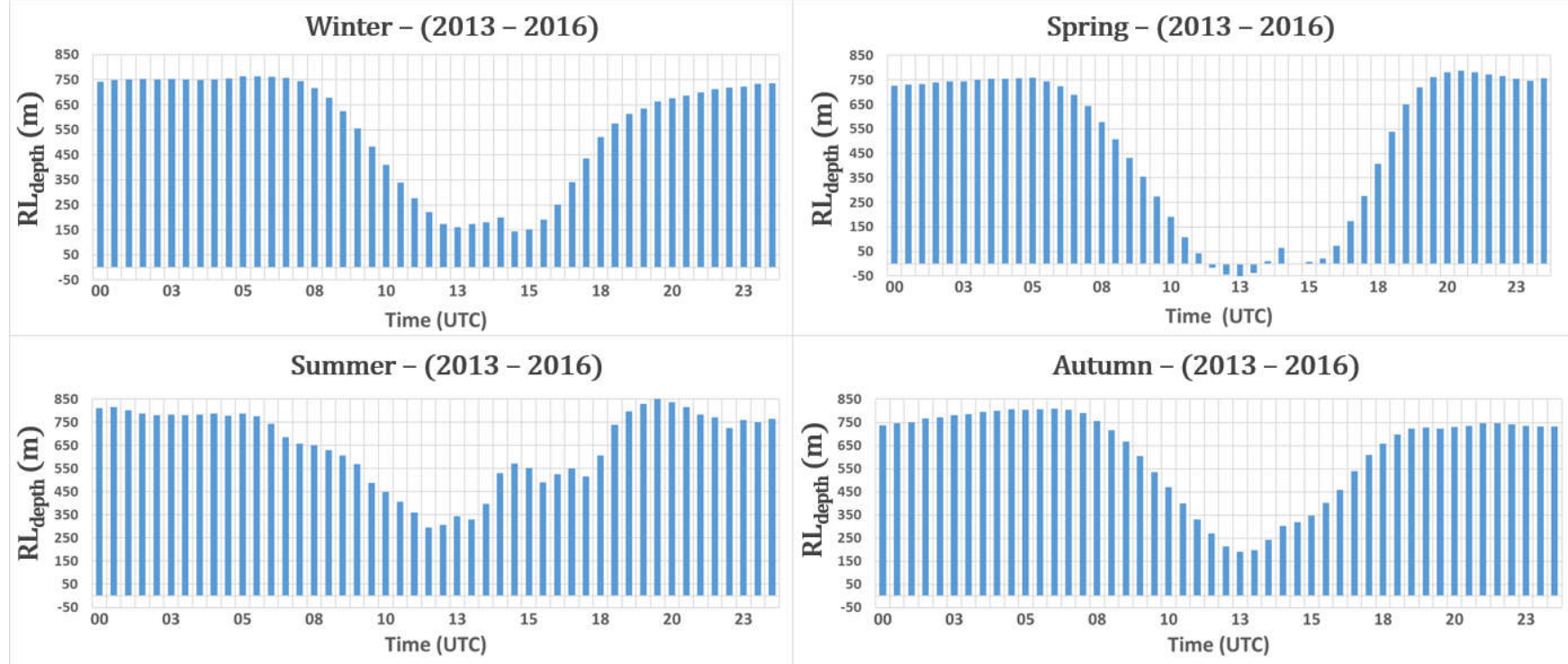

Figure 6.11 $-\triangle P B L H=\left[P B L H_{\text {Ceilometer }}-P B L H_{M W R}(\mathrm{~m})\right]$ or $R L$ depth for winter (DJF), spring (MAM), summer (JJA) and autumn (SON) since 2013 until 2016.

Figure 6.12 shows the average $R L$ depth $\left(\triangle P B L H=P B L H_{\text {Ceilometer }}-P B L H_{M W R}\right)$ for all seasons from 2013 until 2016. During period of $S B L R L$ depth is between 700 and $800 \mathrm{~m}$ for all seasons, however in the course of $C B L$ growth, $R L$ depth decreases reaching the lowest 
values close to the middle of day when $P B L$ is fully developed (between 12 and 15:30 UTC). The lowest $R L$ depth values occur in spring, being that this is the only season where the average value of $P B L H_{M W R}^{C B L}$ is larger than the average value of $P B L H_{\text {Ceilometer }}^{C B L}(\triangle P B L H<$ $0)$. Summer has the largest values of $R L$ depth in convective cases $(250-550 \mathrm{~m})$. The $C B L$ height detected by methods based on temperature vertical profile is usually higher than $C B L$ height obtained from methods based on aerosol vertical profile. The convective cells takes time to growth from the surface up to be fully developed (daily maximum $C B L$ height). However, if the instability is really big, we can have $\triangle P B L H>0$ because the inertia of the convective cell can push up aerosols, breaking the thermal inversion.
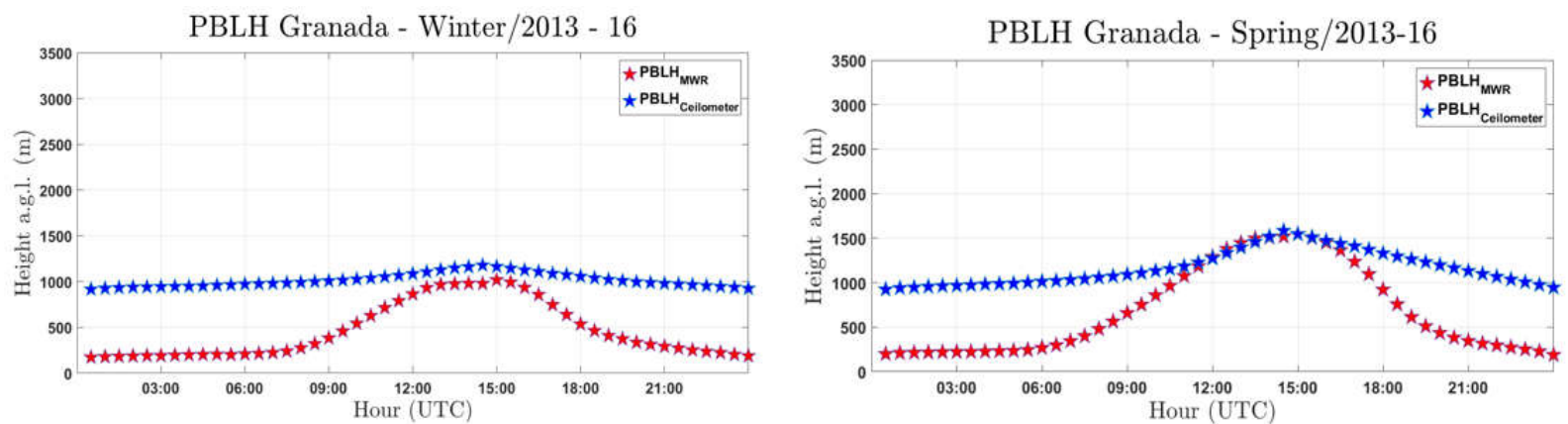

PBLH Granada - Summer/2013 - 16
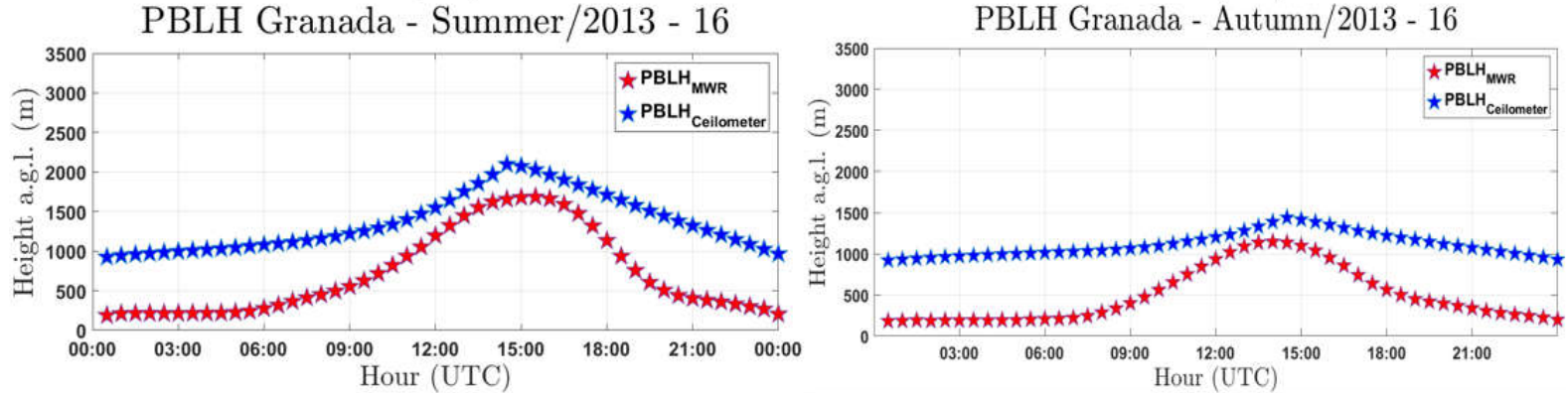

Figure 6.12 - Comparison between $P B L H_{M W R}$ and $P B L H_{\text {Ceilometer }}$ 


\title{
7 Analyzing turbulence in Planetary Boundary Layer from multiwavelenght lidar system
}

\begin{abstract}
In this chapter it is performed an analysis about the utilization of lidar backscattered signal in up to three wavelengths $(355,532$ and $1064 \mathrm{~nm})$ for studying the turbulence by the analyses of the high-order moments (variance, skewness and kurtosis) of the distribution of the backscattered signal. In addition, two study cases are analyzed using the wavelengths of 532 and $1064 \mathrm{~nm}$ (in separated study cases).
\end{abstract}

7.1 Wavelengths comparison in studies about turbulence

Figure 7.1 shows the autocovariance function $(A C F)$ of three wavelengths: 355,532 and 1064 (reference) $\mathrm{nm}$ at two different heights: $950 \mathrm{~m}$ (yellow line) and $1175 \mathrm{~m}$ (green line). As expected $\varepsilon$ increases with height in all analyzed wavelengths due to reduction of aerosol concentrations. In comparison with $A C F_{532}$ and $A C F_{1064}, A C F_{355}$ has the lower intensity (around $90 \%$ smaller) and it is clearly much more affected by the magnitude of $\varepsilon$ that represents $25 \%$ of $A C F_{355}$, while for $A C F_{532}$ and $A C F_{1064}$ the noise represents around $10 \%$ of the corresponding autocovariance. The low values observed in $A C F_{355}$ tend to influence negatively the retrieval of high-order moments and in this way can prevent the observation of some phenomena and/or generate inconsistent results. 

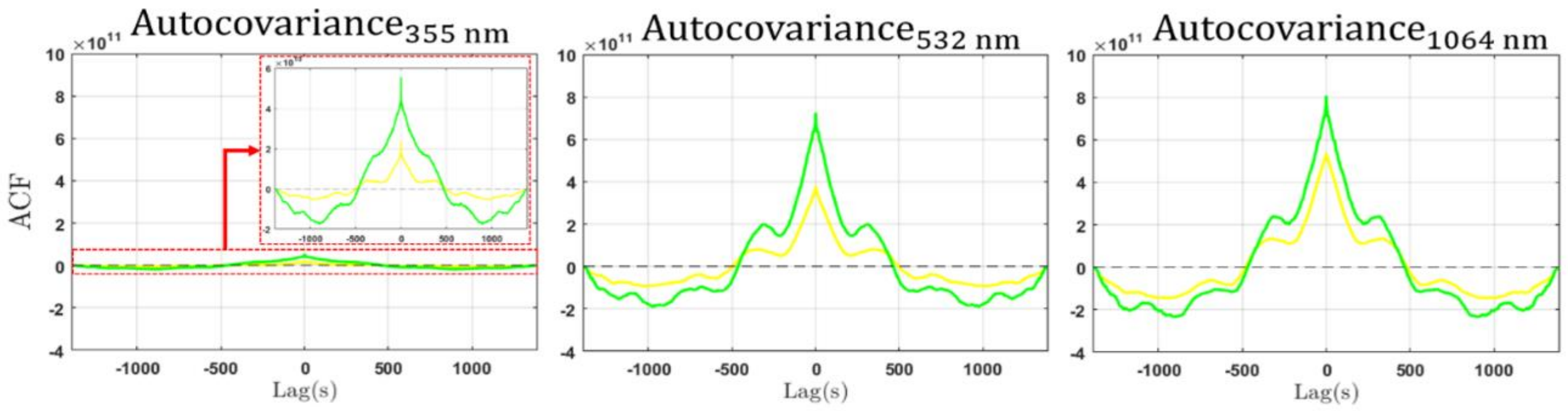

$950 \mathrm{~m}$

$1175 \mathrm{~m}$

Figure 7.1 - Autocovariance function of three wavelengths (355, 532 and $1064 \mathrm{~nm}$ ) at two different heights: 950 (yellow line) and 1175 (green line) m 
The integral time scale vertical profiles $\left(\boldsymbol{\tau}_{\boldsymbol{R} C \boldsymbol{S}_{\prime}}\right)$, with and without corrections ( $\boldsymbol{\tau}_{\boldsymbol{R} C \boldsymbol{C}}^{\boldsymbol{c o r}}$, and $\boldsymbol{\tau}_{\boldsymbol{R} \boldsymbol{C} \boldsymbol{S} \boldsymbol{\prime}}^{\boldsymbol{u n} \boldsymbol{c}}$, respectively), calculated for the three wavelengths are presented in figure 7.2. Comparing the $\boldsymbol{\tau}_{\boldsymbol{R} \boldsymbol{C} \boldsymbol{S} \text {, }}^{\boldsymbol{u n} \boldsymbol{c}}$, profiles, both have values larger than MSP-I time acquisition (red dotted line). However, the largest wavelength has the largest values of $\boldsymbol{\tau}_{\boldsymbol{R} \boldsymbol{C} \boldsymbol{I} \boldsymbol{}}$. In the profiles obtained for the wavelengths of 532 and $1064 \mathrm{~nm}$, the application of the correction of first lag and that of $2 / 3$ do not cause significant changes in comparison with $\boldsymbol{\tau}_{\boldsymbol{R} C \boldsymbol{C}}^{\boldsymbol{u n} \boldsymbol{c}}$, profiles, mainly below the $P B L H_{\text {elastic }}$ (gray line). The $\boldsymbol{\tau}_{\boldsymbol{R} C \boldsymbol{C}}^{\boldsymbol{u n} \boldsymbol{c}}$, at $355 \mathrm{~nm}$ is more affected by the first lag correction and presents larger values and error bars than the other wavelengths. Comparing the amplitude of $\boldsymbol{\tau}_{\boldsymbol{R} C S}$, to all wavelengths, $355 \mathrm{~nm}$ has the lower results. It is consequence of the lower values of $A C F_{355}$. In the same way, the high influence generated by corrections demonstrate the influence of noise in the results obtained from this wavelength.

Figure 7.3 shows the skewness profiles $\left(\boldsymbol{S}_{\boldsymbol{R} C \boldsymbol{S}_{I}}\right)$ for the three wavelengths. Although the skewness profiles without correction $\left(\boldsymbol{S}_{\boldsymbol{R} C \boldsymbol{C} \boldsymbol{S}}^{u n c}\right)$ generated from both wavelengths have the same behavior (negative values below $P B L H_{\text {elastic }}$ and positive values in the first meters above it) indicating the observation of the same phenomenon (positive values represent the aerosol layer updrafts, while the negative ones indicate aerosol layer downdrafts) by both, the intensity of $\boldsymbol{S}_{\boldsymbol{R} C \boldsymbol{S}}$, obtained from $355 \mathrm{~nm}$ has remarkable difference in comparison with the other two wavelengths, so that subtle events cannot be detected. The corrected profiles obtained from 355 $\mathrm{nm}$ present differences mainly close $P B L H_{\text {elastic }}$ region, being highlighted the values and error bars observed in first lag correction profile. The profiles generated from the wavelengths 532 and $1064 \mathrm{~nm}$ are very similar. The main differences are the slightly lower intensity observed in $532 \mathrm{~nm}$ profiles and one region around $1350 \mathrm{~m}$ where $\boldsymbol{S}_{\boldsymbol{R} C \boldsymbol{C} \text {, }}^{\text {unc }}$ of $1064 \mathrm{~nm}$ has negative value and $532 \mathrm{~nm}$ positive one. The corrections in 532 and $1064 \mathrm{~nm}$ do not have significantly impact until approximately $200 \mathrm{~m}$ above $P B L H_{\text {elastic }}$. After this region the error of profiles provided by both wavelengths increase substantially in the size of the error bars, mainly in first lag correction. This demonstrate that low intensity of turbulence above the $P B L H_{\text {elastic }}$, which prevents the use of the proposed methodology in this region. Such limitation also is indicated by intense reductions in $\boldsymbol{\tau}_{\boldsymbol{R} C \boldsymbol{s}}$, values, above $P B L H$, for all wavelengths. 

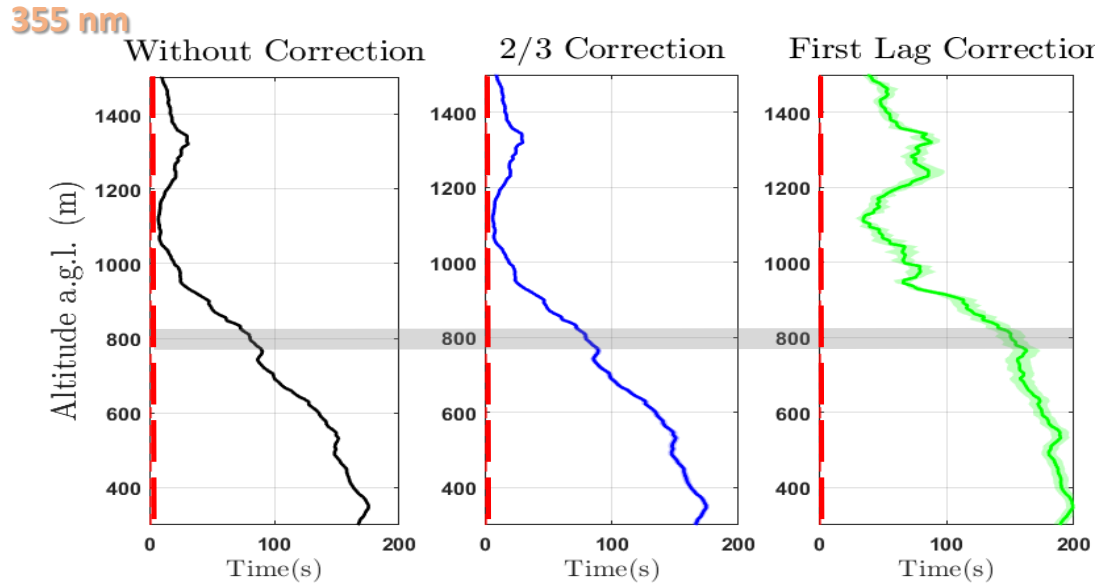

$532 \mathrm{~nm}$
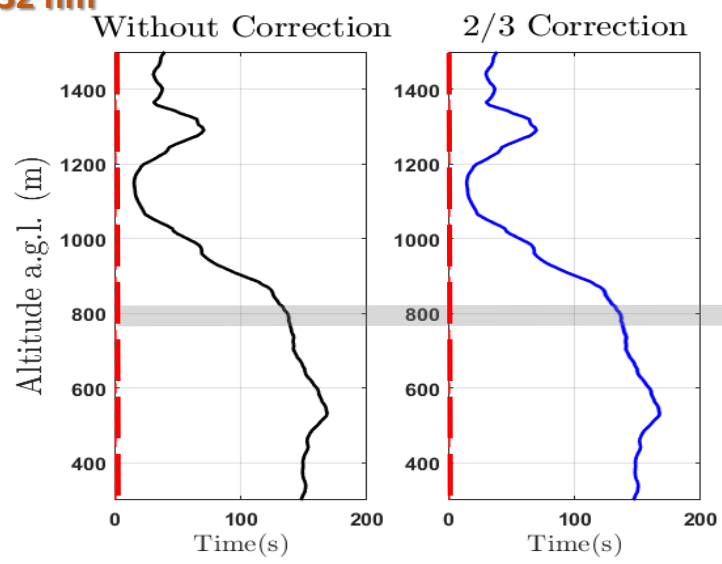

First Lag Correctior

1064 nm
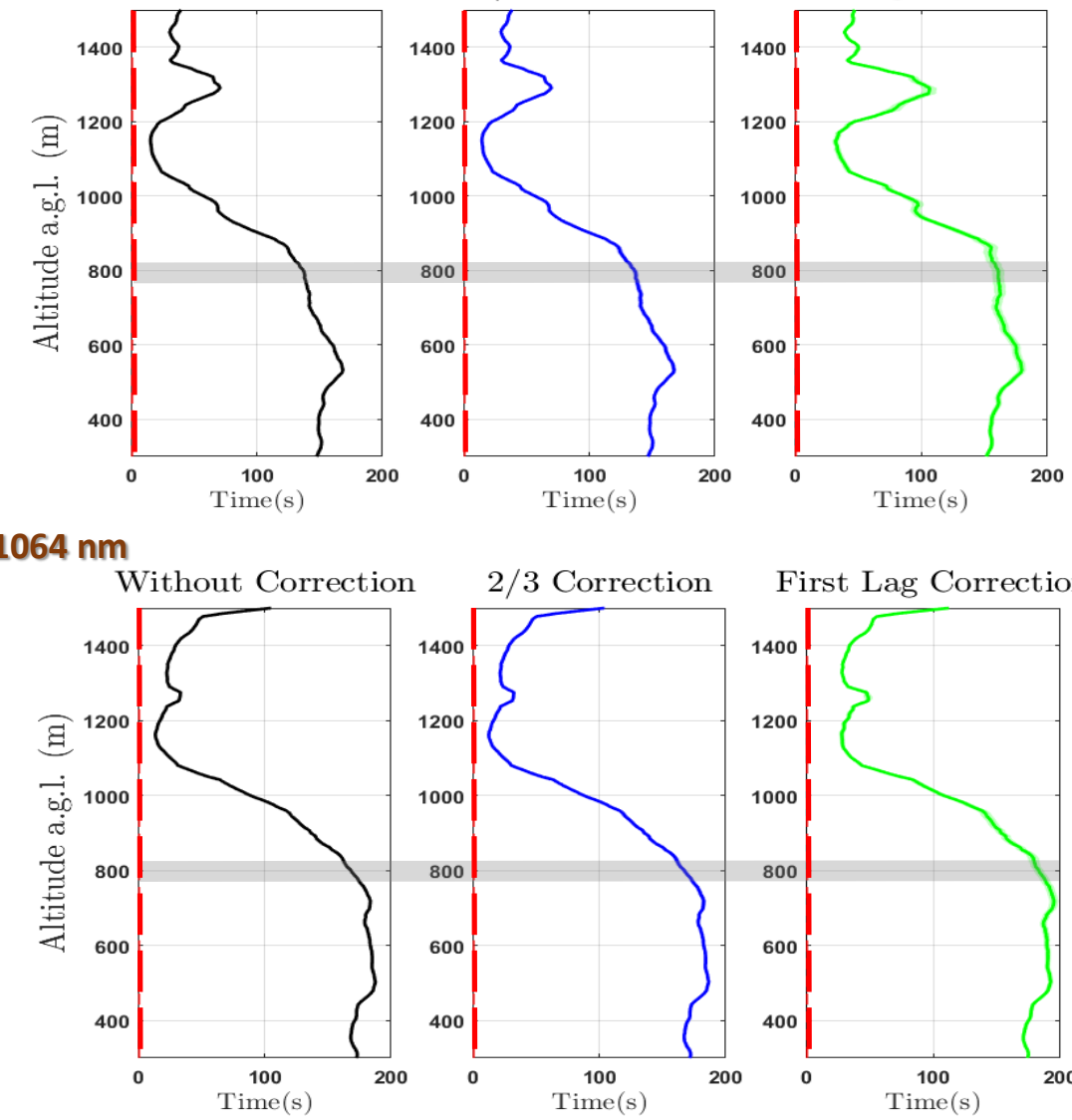

First Lag Correction

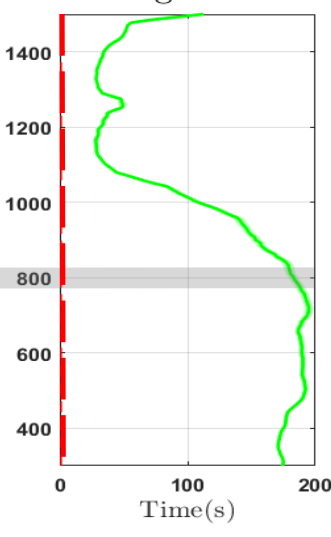

PBLH elastic

Figure 7.2 - Comparison among integral time scale profiles $\left(\boldsymbol{\tau}_{\boldsymbol{R} C \boldsymbol{S}_{\prime}}\right)$ obtained from three wavelengths: 355 (up), 532 (center) and 1064 (bottom) without corrections (black line), with 2/3 corrections (blue line) and first lag correction (green line). The gray line represents the $P B L H_{\text {elastic }}$. The dotted red line corresponds to MSPI acquisition time ( $\left.2 \mathrm{~s}\right)$. 


\section{5 inne}

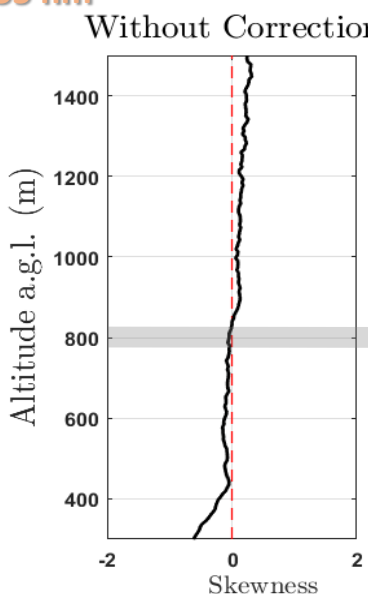

$2 / 3$ Correction

First Lag Correction
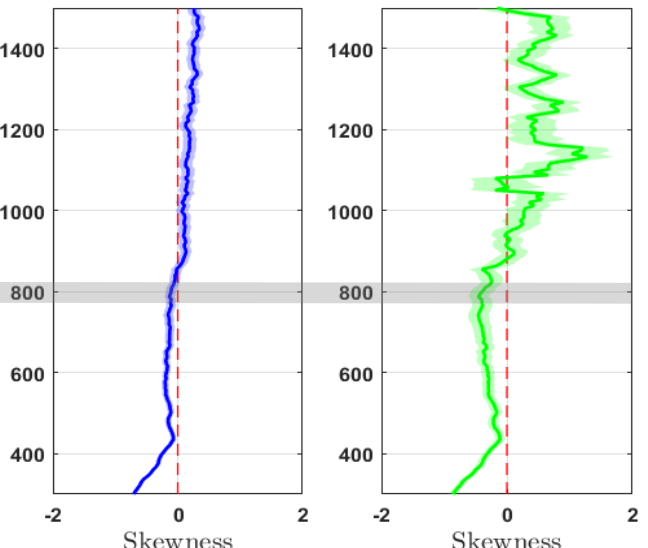

$532 \mathrm{~nm}$

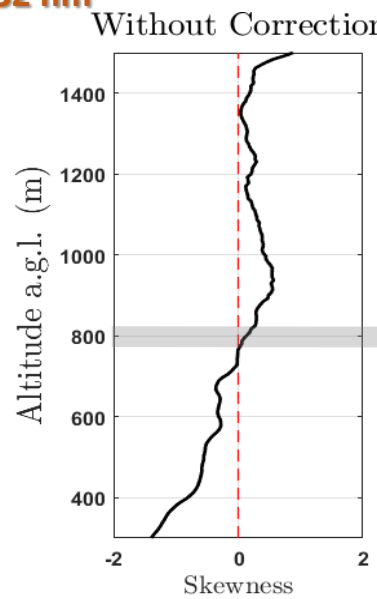

$2 / 3$ Correction

First Lag Correction
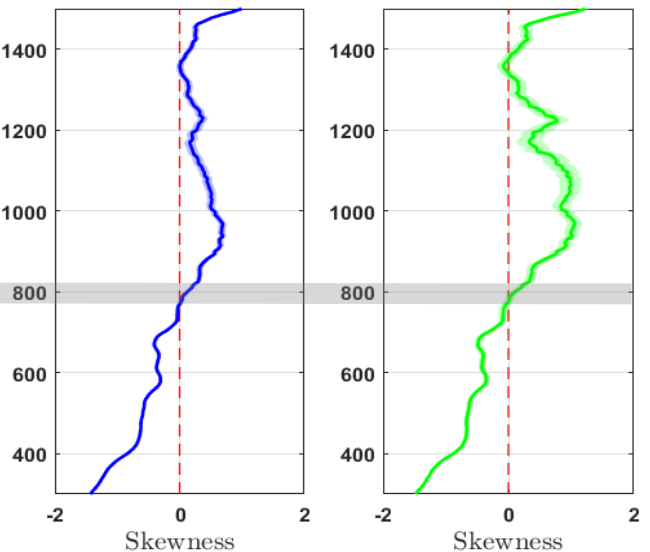

$1064 \mathrm{~nm}$

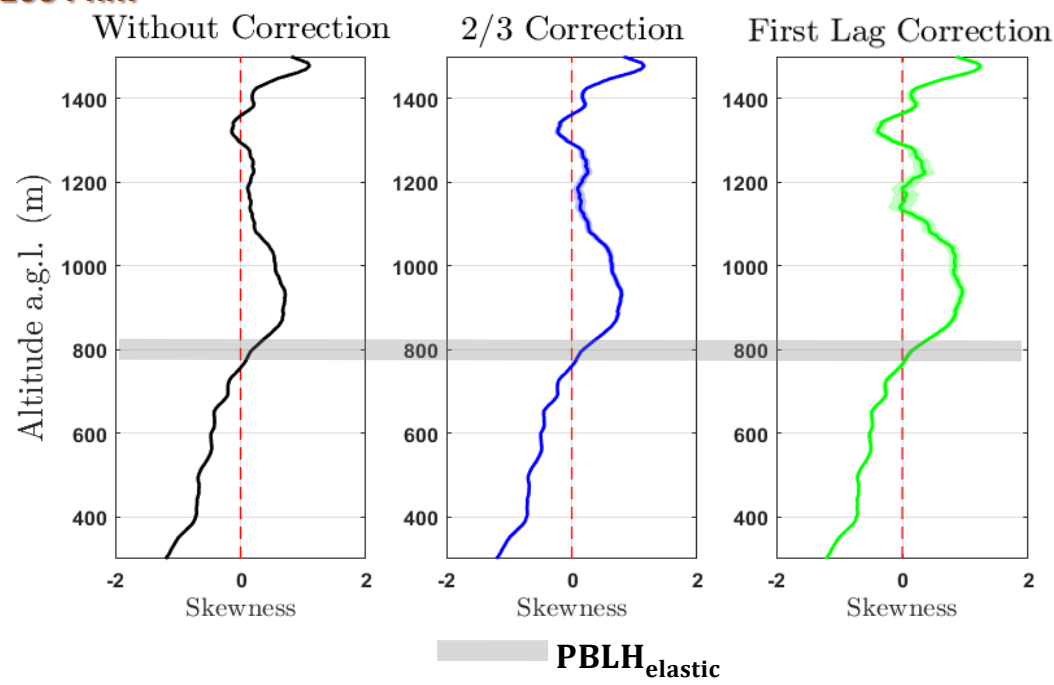

Figure 7.3 - Comparison among skewness profiles $\left(\boldsymbol{S}_{\boldsymbol{R} C \boldsymbol{S}_{I}}\right)$ obtained from three wavelengths: 355 (up), 532 (center) and 1064 (bottom) without corrections (black line), with 2/3 corrections (blue line) and first lag correction (green line). The gray line represents the $P B L H_{\text {elastic }}$. The dotted red line corresponds to region where

The kurtosis profile $\left(\boldsymbol{K}_{\boldsymbol{R} C \boldsymbol{S}_{I}}\right)$ is the most complex moment presented in this study and, consequently in these profiles the differences among the three wavelength is more evident 
(figure 7.4). Comparing the profiles without correction $\left(\boldsymbol{K}_{R C S \prime}^{u n c}\right)$, the values generated for the wavelength $355 \mathrm{~nm}$ has opposite results of $\boldsymbol{K}_{R C S}^{u n c}$, obtained at 532 and $1064 \mathrm{~nm}$. The two corrected $\left(\boldsymbol{K}_{\boldsymbol{R} C \boldsymbol{S}_{\prime}}^{\boldsymbol{c o r}}\right)$ at $355 \mathrm{~nm}$ have considerable differences and error bars, highlighting the impact of the first lag correction, which present larger differences in $P B L H_{\text {elastic }}$ region. The low values of $A C F_{355}$ and the high influence of $\varepsilon$ affects directly the results obtained with the wavelength $355 \mathrm{~nm}$, causing results with low reliability. The $\boldsymbol{K}_{R C S \prime}^{u n c}$, at 532 and $1064 \mathrm{~nm}$ are very similar, although the profile at $1064 \mathrm{~nm}$ has higher intensity, what emphasize some atmospheric features, for example the negative values appearing just below $P B L H_{\text {elastic }}$ and that cannot be detected in $\boldsymbol{K}_{R C S}^{u n c}$ at $532 \mathrm{~nm}$. The $\boldsymbol{K}_{R C S}^{\text {cor }}$, profiles at 532 and $1064 \mathrm{~nm}$ have slighter differences until the first $100 \mathrm{~m}$ above $P B L H_{\text {elastic }}$. At highest altitudes the kurtosis corrected profile at 532 and $1064 \mathrm{~nm}$ present more evident differences and larger error bars, mainly when applying the first lag correction. This restricts our analysis to $P B L H_{\text {elastic }}$ region and demonstrate that the results provided by wavelength $532 \mathrm{~nm}$ has some restrictions in comparison with $1064 \mathrm{~nm}$ results.

From these study of $A C F$ and the associated high-order moments we can observe clear differences among the distinct wavelengths considered. Thus, it is evident that $A C F_{355}$ has lower intensity and it is considerably influenced by presence of noise. This combination of factors generates profiles of the high-order moments where some phenomena cannot be observed or an inverse phenomenon is presented. Otherwise it is evident that at $355 \mathrm{~nm}$ the application of the corrections leads to significant changes. According to the precedent paragraphs this problem increase with the complexity of the high-order moment, with kurtosis results hardly interpretable. On the other hand, inside the $P B L H_{\text {elastic }}$ and in the first meters above it, the analysis of the wavelengths $532 \mathrm{~nm}$ and 1064 present similar behaviors and small changes when the corrections are applied. There are also slight differences between this two wavelengths in terms of intensity, in that way it is evident that some events are more highlighted at $1064 \mathrm{~nm}$ than at $532 \mathrm{~nm}$. 


\section{5 inm}
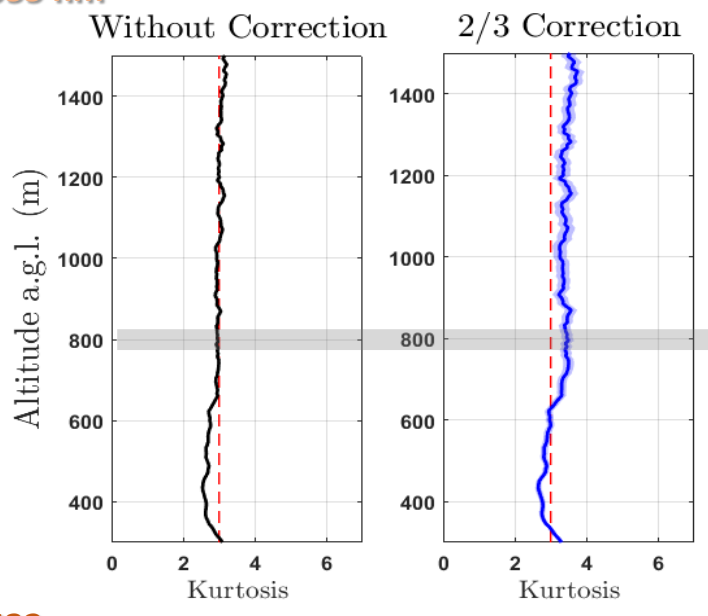

First Lag Correction

$532 \mathrm{~nm}$
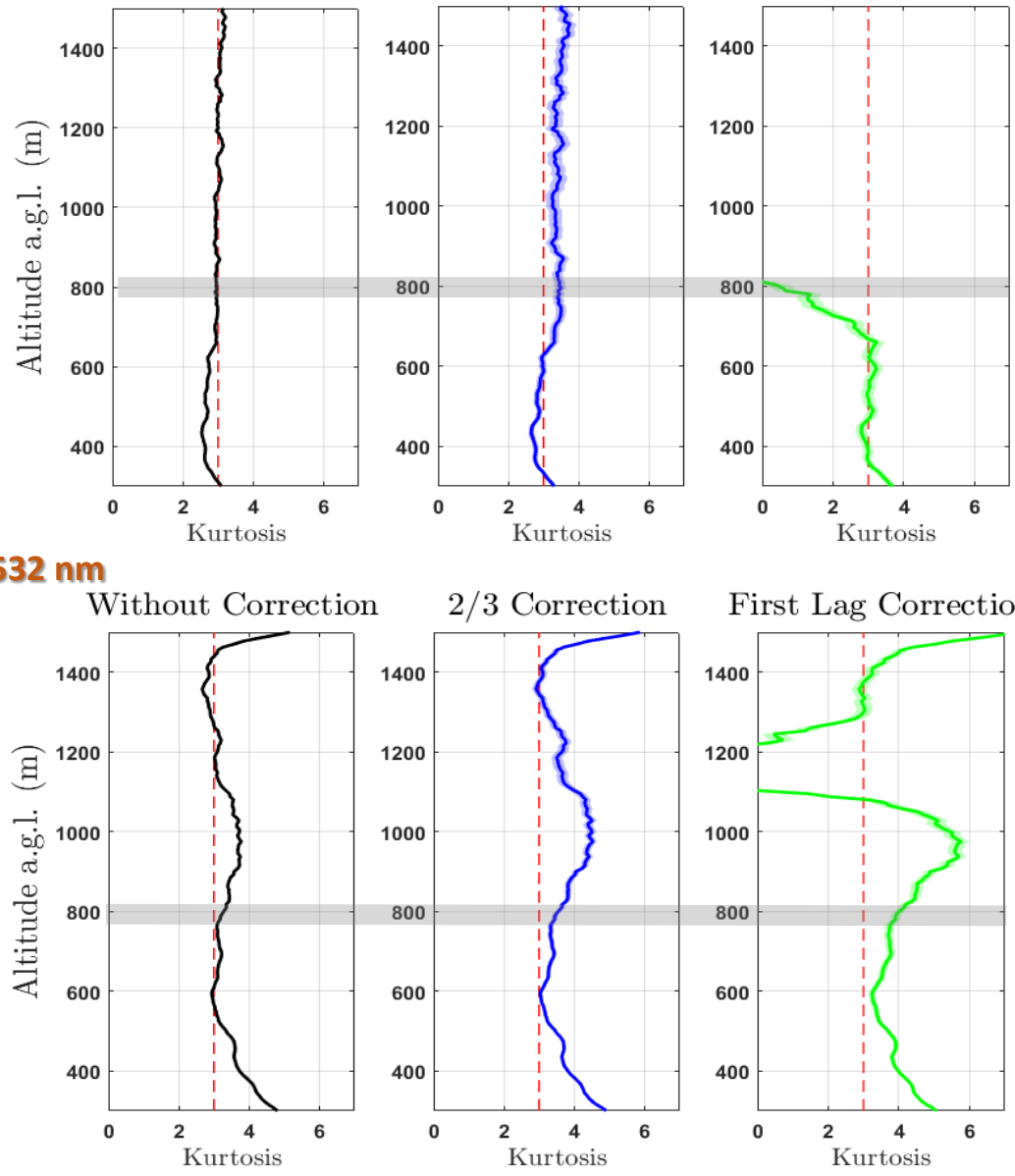

$1064 \mathrm{~nm}$
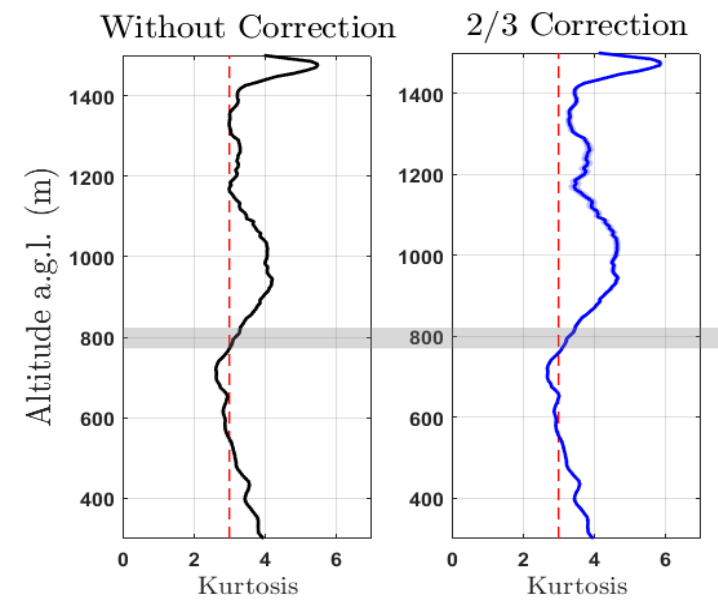

First Lag Correction

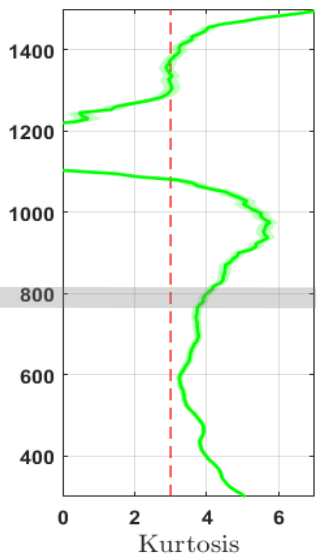

First Lag Correction

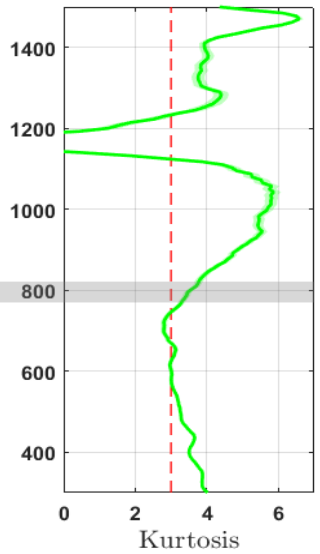

PBLH elastic

Figure 7.4 - Comparison among kurtosis profiles $\left(\boldsymbol{K}_{\boldsymbol{R} \boldsymbol{C} \boldsymbol{S} \boldsymbol{I}}\right)$ obtained from three wavelengths: 355 (up), 532 (center) and 1064 (bottom) without corrections (black line), with 2/3 corrections (blue line) and first lag correction (green line). The gray line represents the $P B L H_{\text {elastic }}$. The dotted red line corresponds to region where $\boldsymbol{K}_{\boldsymbol{R} C \boldsymbol{S}}$, is three. 
This comparison demonstrates that some concepts proposed in equation 4.11 and 4.12 cannot be applied to wavelength $355 \mathrm{~nm}$. Such wavelength is dominated by $\beta_{\text {mole }}$ (unlike $1064 \mathrm{~nm}$, which is dominated by $\beta_{\text {par }}$ ), resulting in low $A C F_{355}$ values and nosier high-order moments, what prevents the use of this wavelength in this kind of study. On the other hand, the wavelength $532 \mathrm{~nm}$, although its $\beta$ is composed by $\beta_{\text {molec }}$ and $\beta_{\text {par }}$, the component molecular is not predominant, so that, the results observed are similar to obtained with wavelength 1064 $\mathrm{nm}$. Even though in the more complex high-order moments the profiles obtained from $532 \mathrm{~nm}$ have lower intensity in comparison to $1064 \mathrm{~nm}$, it does not prevent its use in studies about turbulence from the methodology proposed in this paper.

\subsection{Case Studies}

In this section we analyze three study cases, applying the methodology described in section 4.2, in order to demonstrate how the statistical moments can give us a better comprehension about $P B L H$ behavior. In these cases the wavelengths 532 and $1064 \mathrm{~nm}$ (case I and case II, respectively) were utilized. Although the corrections slightly change the profiles, the first lag correction was applied in all profiles in order to be more restrictive with the results.

\subsubsection{Case Study I - 02 ${ }^{\text {th }}$ February}

In this study case measurements were gathered with the MPS-I system from 10:00 to 14:30 UTC. The wavelength used in the statistical moment analysis is $532 \mathrm{~nm}$. Figure 7.5 shows the RCS profile of the period mentioned above, as well as, the statistical analysis (boxes with dashed lines). From the RCS profile is possible to observe the growth of a well-defined $P B L$. 

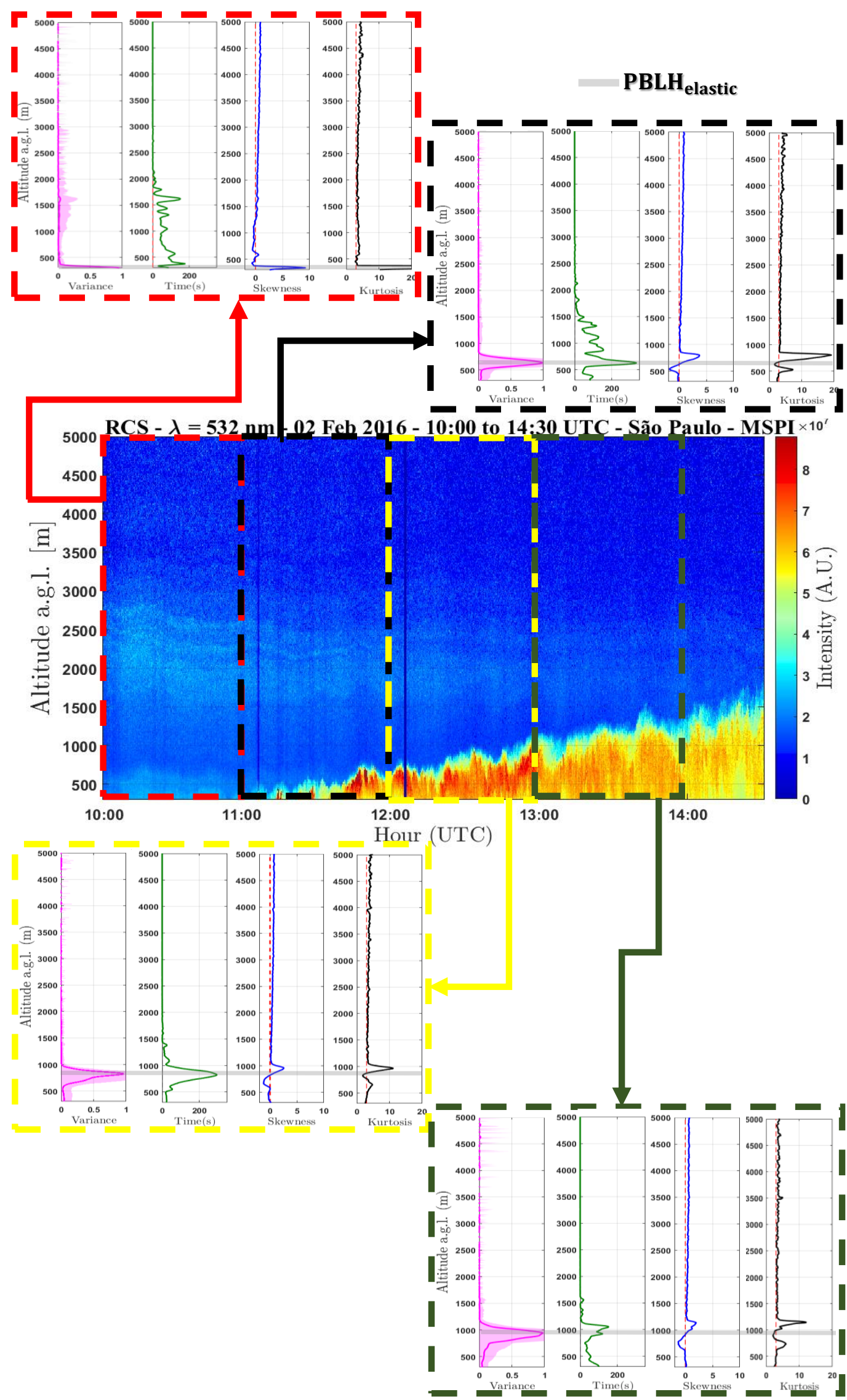

Figure 7.5 - RCS profile and statistical moments $\left(\boldsymbol{\sigma}_{\boldsymbol{R} C \boldsymbol{S}^{\prime}}^{2}\right.$ [pink line], $\boldsymbol{\tau}_{\boldsymbol{R} C \boldsymbol{S}^{\prime}}$ [green line], $\boldsymbol{S}_{\boldsymbol{R} C \boldsymbol{S}^{\prime}}$ [blue line], $\boldsymbol{K}_{\boldsymbol{R} C \boldsymbol{S}}$, [black line]. Gray line represents the $P B L H_{\text {elastic }}$. 
The red dashed box shows the statistical analysis performed between 10:00 and 11:00 UTC. The $\boldsymbol{\sigma}_{\boldsymbol{R} C \boldsymbol{S} \text { ' }}^{2}$ (pink line) has its maximum around $300 \mathrm{~m}\left(P B L H_{\text {elastic }}\right)$ and some small fluctuations above this height evidences the low aerosol concentration. $\boldsymbol{\tau}_{\boldsymbol{R} C \boldsymbol{S}^{\prime}}$ has values higher than MSPI acquisition time (2 s) until around $1600 \mathrm{~m}$, what enable us to study the turbulence throughout this region. The positive values of $\boldsymbol{S}_{\boldsymbol{R} C \boldsymbol{S}}$, under the $P B L H_{\text {elastic }}$ region indicates the presence of aerosol layers updrafts associated to the convective process. The $\boldsymbol{K}_{\boldsymbol{R} C \boldsymbol{S}}$, values larger than 3 under $P B L H_{\text {elastic }}$ evidence the low mixing of this region, associated to a peaked distribution of $R C S^{\prime}$. Above $2000 \mathrm{~m} \boldsymbol{S}_{\boldsymbol{R} C \boldsymbol{S}}$, and $\boldsymbol{K}_{\boldsymbol{R} C \boldsymbol{S}}$, have positive and crescent values, however in this region $\boldsymbol{\tau}_{\boldsymbol{R} C \boldsymbol{S}}$, is equal or below $2 \mathrm{~s}$ (temporal resolution of these time series), then the turbulent eddies cannot be correctly detected and erroneous results can be generated. Therefore the values of $\boldsymbol{S}_{\boldsymbol{R} C \boldsymbol{S}}$, and $\boldsymbol{K}_{\boldsymbol{R} C \boldsymbol{S}}$, cannot be adequately interpreted and this region must be excluded of the turbulence analysis.

In the black dashed box is represented the statistical analysis accomplished between 11:00 and 12:00 UTC. During this period the presence of aerosol is more evident, so that the maximum of $\boldsymbol{\sigma}_{\boldsymbol{R} C \boldsymbol{S}}^{\mathbf{2}}$ demonstrates the ascension of $P B L H_{\text {elastic. }}$. As in the previously analyzed period, $\boldsymbol{\tau}_{\boldsymbol{R} C \boldsymbol{S}}$, has values higher than $2 \mathrm{~s}$ in all the $P B L$ region. $\boldsymbol{S}_{\boldsymbol{R} \boldsymbol{C} \boldsymbol{S}}$, has positive peak just above $P B L H_{\text {elastic }}$, representing the aerosol layers updrafts, and a negative peak just below $P B L H_{\text {elastic }}$ demonstrating the presence of clean air downdrafts from Free Troposphere $(F T)$. This kind of movement with inflexion point of $\boldsymbol{S}_{\boldsymbol{R} C \boldsymbol{S}}$, in $P B L H_{\text {elastic }}$ is characteristic of fast upward growth of the $P B L$, as has been evidenced in other studies like those of Paul et al. (2010) and McNicholas et al. (2014). $\boldsymbol{K}_{\boldsymbol{R} C \boldsymbol{S}}$, has values larger than 3 just below and above $P B L H_{\text {elastic }}$, and values lower than 3 in most of the $P B L$ region, characterizing it as well-mixed region. This behavior is also presented in the studies of Paul et al. (2010) and McNicholas et al. (2014) when they analyze an ascending $P B L$.

The yellow dashed box (statistical analysis performed between 12:00 and 13:00 UTC) presents features similar to those observed in the previous analyzed periods. The growing of $P B L$ can be visualized by maximum of $\boldsymbol{\sigma}_{\boldsymbol{R} C \boldsymbol{s}}^{2}$, which during this period is situated around $800 \mathrm{~m} . \boldsymbol{S}_{\boldsymbol{R} \boldsymbol{C} \boldsymbol{S}}$, and $\boldsymbol{K}_{\boldsymbol{R} \boldsymbol{C} \boldsymbol{S}}$, also maintain the same behavior observed earlier, with $\boldsymbol{S}_{\boldsymbol{R} \boldsymbol{C} \boldsymbol{S}}$ presenting positive and negative peaks just above and below $P B L H_{\text {elastic }}$, respectively. The $\boldsymbol{K}_{\boldsymbol{R} C \boldsymbol{S}}$, profile denotes the existence of a well-mixed region in most of the $P B L$ (values lower than 3) and a peak above the PBLH $H_{\text {elastic }}$. 
In the same way as evidenced in the yellow dashed box, the green dashed box (statistical analysis performed between 13:00 and 14:00 UTC) presents similar features to those evidenced in the previous periods but with a clear increase of the height of most remarkable

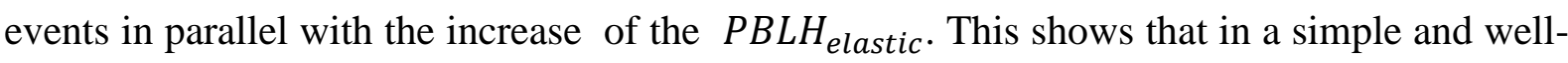
defined $P B L$ structure the growth of the $P B L$ can be followed with the analyses of the lidar backscattered profiles measured at $0.5 \mathrm{~Hz}$.

\subsubsection{Case Study $2-26^{\text {th }}$ July}

In this study case we gathered measurements with the MPS-I system from 13:00 to 19:00 UTC. The wavelength of $1064 \mathrm{~nm}$ was used in statistical moment analysis. Figure 9 shows the RCS profile and the statistical analysis (boxes with dashed lines) during this period. This case also has two distinct moments, in the first two hours there is a shallow $C B L$ covered by a $R L$. Nevertheless, in the final of second hour $C B L$ has a fast increasing and it combines with $R L$ forming a fully-developed $C B L$, which remains constant height from 15:00 to 19:00 UTC.

The red dashed box shows the statistical moments from 13:00 to 14:00 UTC. The $\boldsymbol{\sigma}_{\boldsymbol{R} C \boldsymbol{S}}^{2}$, has the maximum value $\left(P B L H_{\text {elastic }}\right)$ around $500 \mathrm{~m}$ and values close to zero in the rest of profile. Around $1500 \mathrm{~m} \boldsymbol{\sigma}_{\boldsymbol{R} C S}^{2}$, has a small peak, this height is the region where occurs the transition between $R L$ and FT. $\boldsymbol{\tau}_{\boldsymbol{R} C \boldsymbol{S}}$, has values higher than 2 throughout $P B L$ that decreases just above the $P B L H_{\text {elastic }}$. In the region of transition between $R L$ and $F T \boldsymbol{\tau}_{\boldsymbol{R} C \boldsymbol{s}}$, has a peak. The $\boldsymbol{S}_{\boldsymbol{R} C \boldsymbol{S}}$, vertical profile has the similar features to those described in the previous study case, positive and negative peaks just above and below $P B L H_{\text {elastic }}$, respectively. As previously indicated, these features evidence the ascension of aerosol plumes towards the FT and the downdraft of clean air from FT. $\boldsymbol{K}_{\boldsymbol{R} C \boldsymbol{S}}$, also presents a characteristic behavior that denotes the existence of a well-mixed $P B L$. In general, the high-order moments practically did not have variations in the region of $R L$, as expected, due to low convective activity in this region.

In the other three boxes are illustrated the statistical moments from 16:00 to 19:00 UTC, however as suggested by $R C S$ profile observation, $P B L H_{\text {elastic }}$ does not have significant variation. This last fact is also evidenced by the rather constant value of the maximum of $\boldsymbol{\sigma}_{\boldsymbol{R} C \boldsymbol{S}}^{\mathbf{2}}$ during all the study period. Some variations of $\boldsymbol{\sigma}_{\boldsymbol{R} C \boldsymbol{S}}^{2}$, are observed below PBLH $H_{\text {elastic }}$ due to changes in the aerosol distribution along the time. $\boldsymbol{S}_{\boldsymbol{R} C \boldsymbol{S}}$ presents features similar to those observed in the previous analyzed period, however the smaller value of the peaks, in 
comparison with the $\boldsymbol{S}_{\boldsymbol{R} C \boldsymbol{S}}$, profile observed in the first analyzed hour, evidences the low intensity of the movements inside the $P B L$. The small negative and positive peaks observed in the low and middle region of $P B L$ shows the occurrence of updrafts and downdrafts throughout $P B L$, although with intensity smaller than that on observed in $P B L H_{\text {elastic }}$. In a similar way, $\boldsymbol{K}_{\boldsymbol{R} C \boldsymbol{S}}$, presents similar features to those observed during the previous analyzed periods. In the last period (18:00 to 19:00 UTC) all region inside PBL has $\boldsymbol{K}_{\boldsymbol{R} C \boldsymbol{S}}$, lower than 3, demonstrating a well-mixed level. 


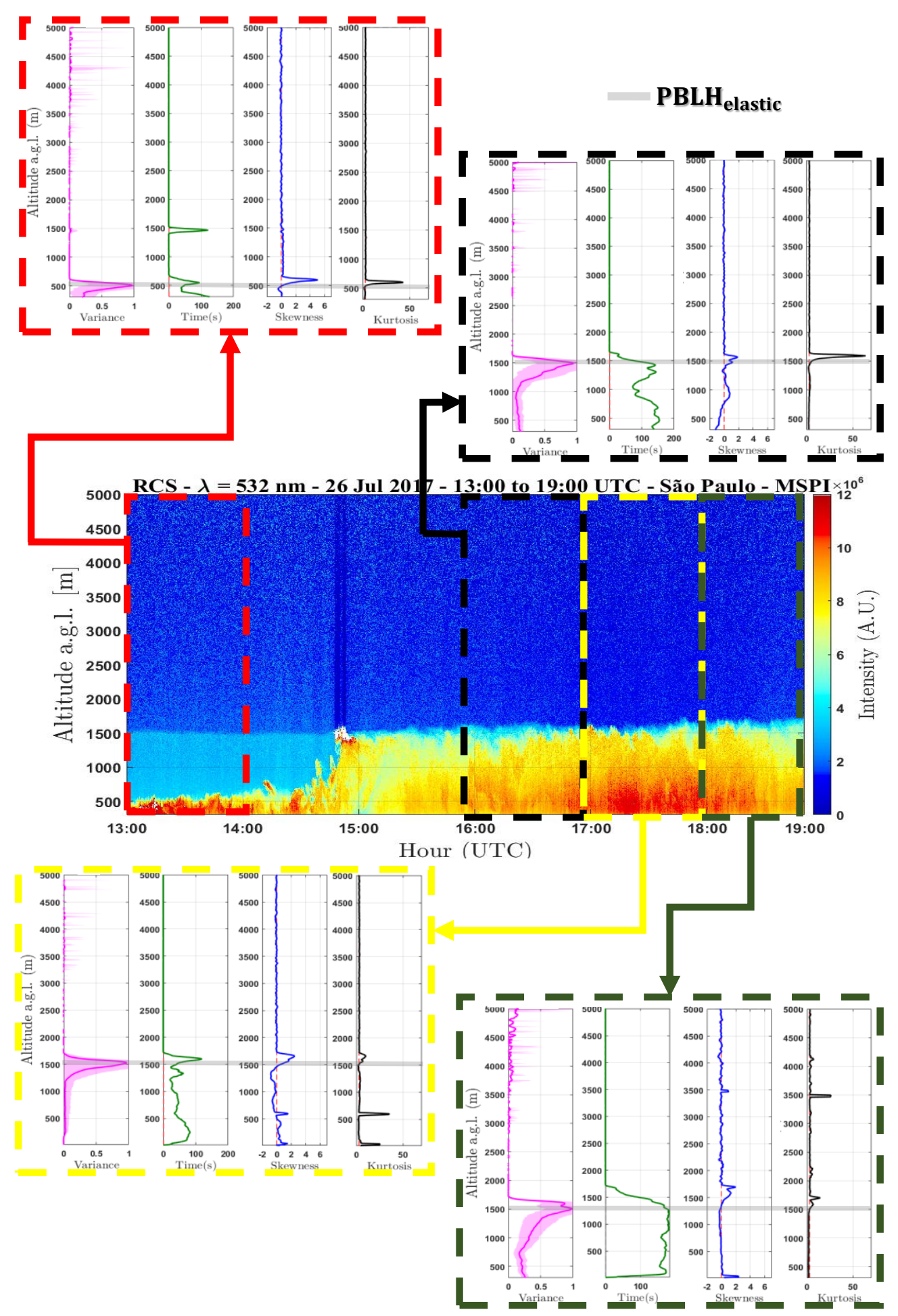

Figure 7.6 - RCS profile and statistical moments $\left(\boldsymbol{\sigma}_{R C S^{\prime}}^{2}\right.$ [pink line], $\boldsymbol{\tau}_{R C S^{\prime}}$ [green line], $\boldsymbol{S}_{\boldsymbol{R} C \boldsymbol{S}^{\prime}}$ [blue line], $\boldsymbol{K}_{\boldsymbol{R} C \boldsymbol{S}}$, [black line]. Gray line represents the $P B L H_{\text {elastic }}$. 


\title{
8 Analyzing the turbulence in the PBL by remote sensing systems
}

\begin{abstract}
In this chapter it is performed the synergetic use of remote sensing systems (microwave radiometer $[M W R]$, Doppler lidar $[D L]$ and elastic lidar $[E L]$ ) to analyze the $P B L$ behavior. Furthermore, it is demonstrated how some variables (air temperature, aerosol, vertical wind, relative humidity and net radiation) can influence the $P B L$ dynamic.
\end{abstract}

\subsection{Error Analysis}

The influence of random error in noisy observations grows rapidly for higher-order moments (i.e., the influence of random noise is much larger for the fourth-order moment than for the third-order moment). Therefore, the first step, in order to ascertain the applied methodology and our data quality, we performed the error treatment of $D L$ data as described in Figure 4.5.

Figure 8.1 illustrate the autocovariance function, generate from $w^{\prime}$, at three different heights. As mentioned before, the lag 0 is contaminated by noise $\varepsilon$, so that impact of the noise $\varepsilon$ increases together with height, mainly above $P B L H_{M W R}(1100 \mathrm{~m}$ a.g.l. in our example). 


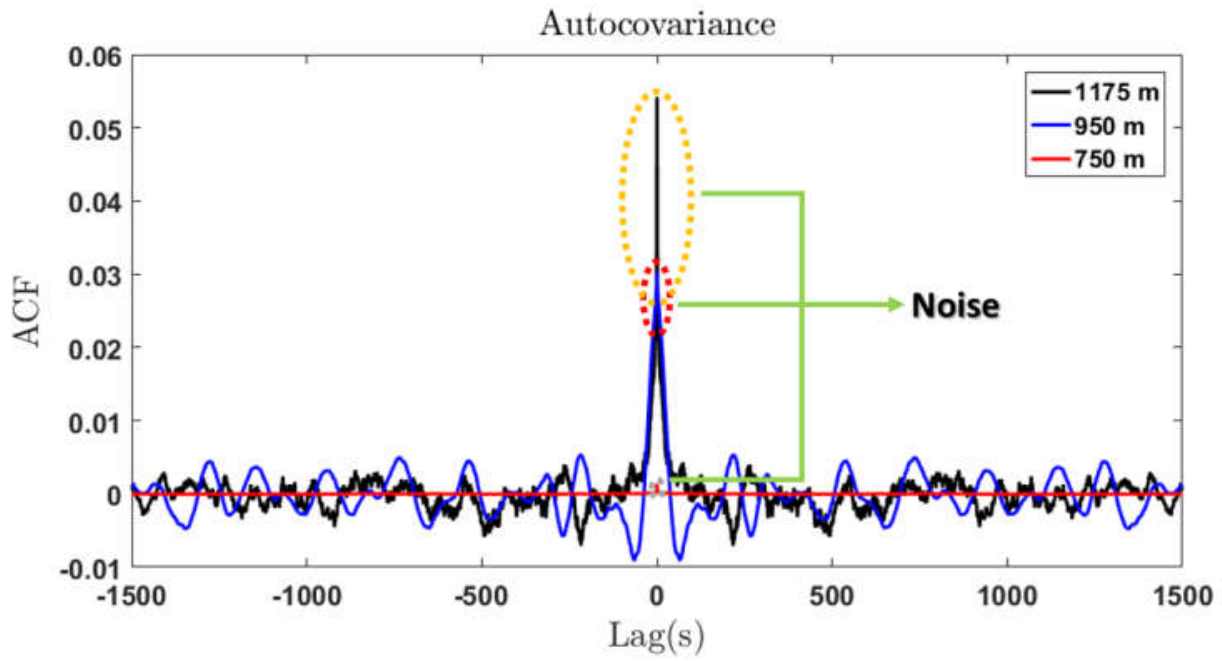

Figure 8.1 - Autocovariance of w' to three different heights

Figure 8.2 illustrates the comparison between integral time scale $\left(\boldsymbol{\tau}_{\boldsymbol{w}}\right)$ without correction and the two corrections cited in section 4.2. Except for the first height, below the $P B L H_{M W R}$ the profiles practically do not have significant difference, as well as small errors bars. Above $P B L H_{M W R}$ the first lag correction presents some difference in relation the other profiles at around $1350 \mathrm{~m}$. 


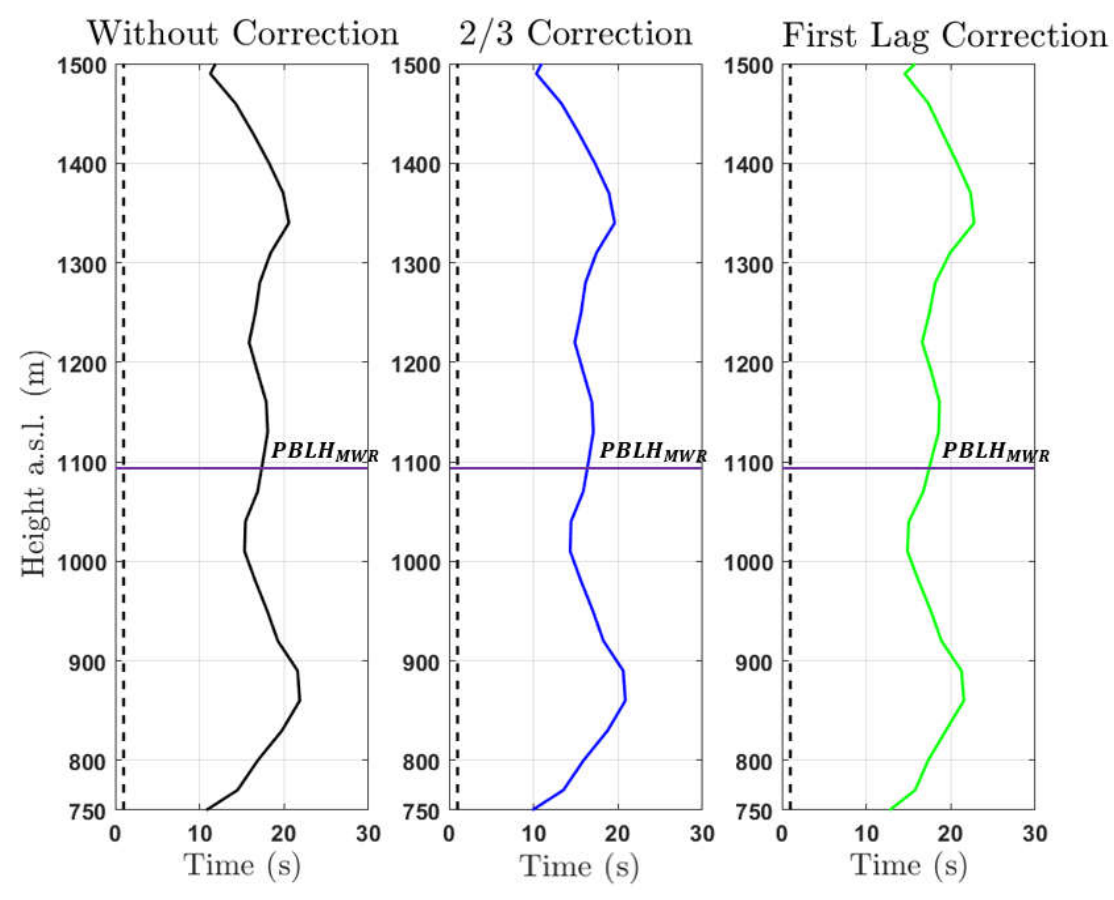

Figure 8.2 - Vertical profile of Integral time scale $\left(\boldsymbol{\tau}_{\boldsymbol{w}^{\prime}}\right)$. Without correction (left), 2/3 correction (center), first lag correction (right).

Figures 8.3 and 8.4 show the comparison of variance $\left(\boldsymbol{\sigma}_{w^{\prime}}^{2}\right)$ and skewness $\left(\boldsymbol{S}_{\boldsymbol{w}^{\prime}}\right)$, respectively, with and without corrections. Under the $P B L H_{M W R}$ the corrected vertical profiles do not present significant differences with the respective corrected profiles. Slight differences are evident above $P B L H_{M W R}$ when the first lag correction is applied. 


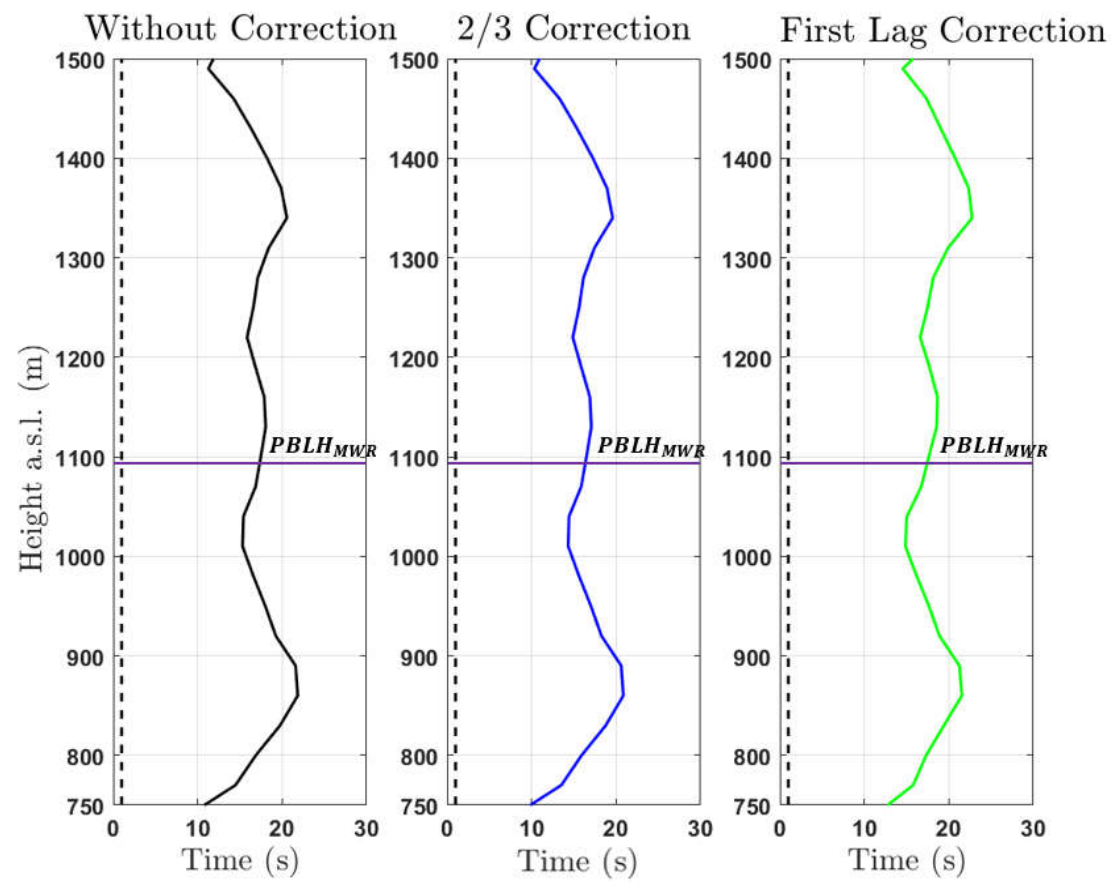

Figure 8.3 - Vertical profile of variance $\left(\boldsymbol{\sigma}_{w \prime}^{2}\right)$. Without correction (left), 2/3 correction (center), first lag correction (right).
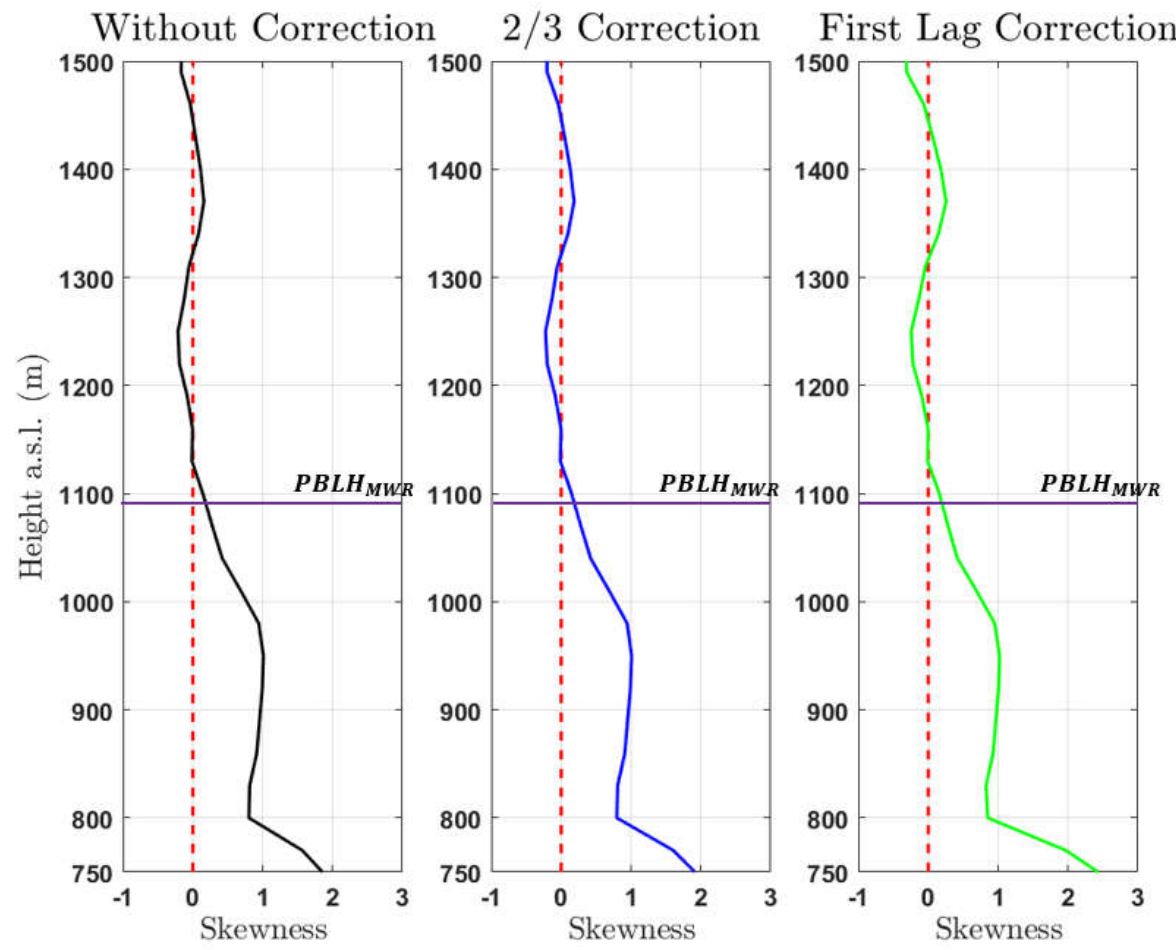

Figure 8.4 - Vertical profile of Skewness. $\left(\boldsymbol{S}_{\boldsymbol{w}^{\prime}}\right)$ Without correction (left), 2/3 correction (center), first lag correction (right). 
For EL we use the same procedure for the correction and error analysis that we apply to the DL data. Figure 8.5 shows the autocovariance function, obtained from $R C S^{\prime}$, at three distinct heights. As expected, the increase of height produces the increase of $\varepsilon$, principally above the $P B L H_{M W R}$.

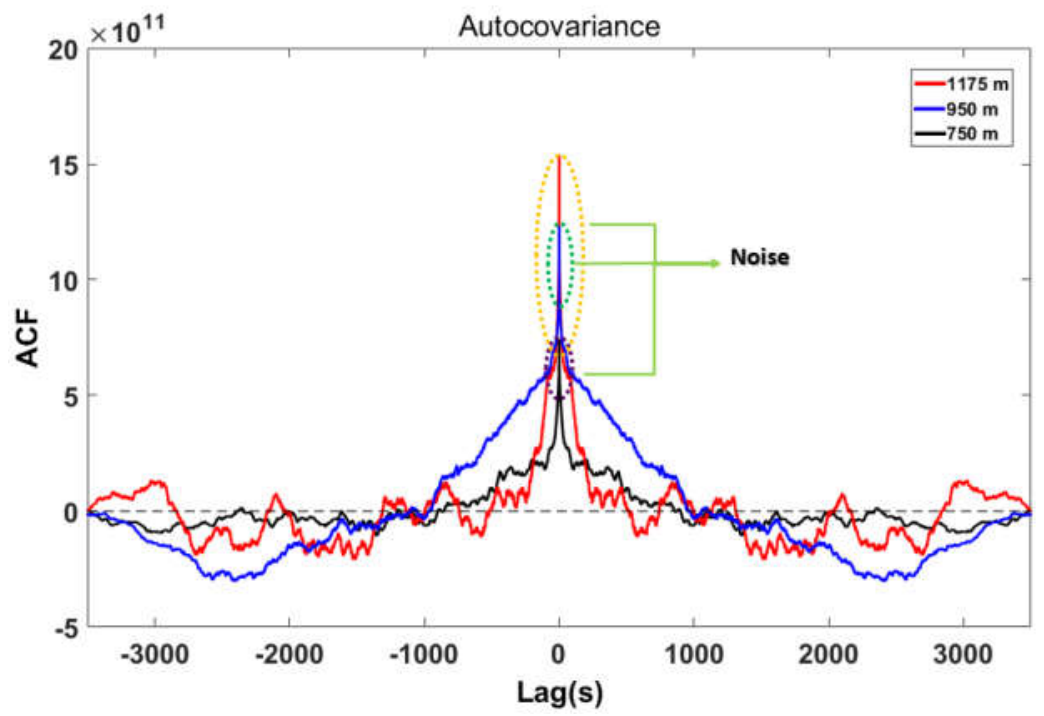

Figure 8.5 - Autocovariance of RCS' to three different heights

Figures 8.6, 8.7, 8.8 and 8.9 show the vertical profiles of $\boldsymbol{\tau}_{\boldsymbol{R} C \boldsymbol{S}^{\prime}}, \boldsymbol{\sigma}_{R C S^{\prime}}^{2}, \boldsymbol{S}_{\boldsymbol{R} C \boldsymbol{S}^{\prime}}$ and kurtosis $\left(\boldsymbol{K}_{\boldsymbol{R} C \boldsymbol{S}_{1}}\right)$, respectively, with and without the corrections described in section 3.2. In general, the corrections do not affect the profiles in a significant way, specially in the region below the $P B L H_{M W R}$. Above the $P B L H_{M W R}$ some small differences are noticed, mainly in the first lag correction. The errors bars associated to each profile also have low values in all cases. When comparing corrected and uncorrected profiles, the largest differences are observed for the profiles of higher order moments, because of error propagation. $\boldsymbol{K}_{\boldsymbol{R} C \boldsymbol{S}}$, profile is the more affected by corrections, so the kurtosis profile after the first lag correction shows the largest difference with uncorrected profile. 

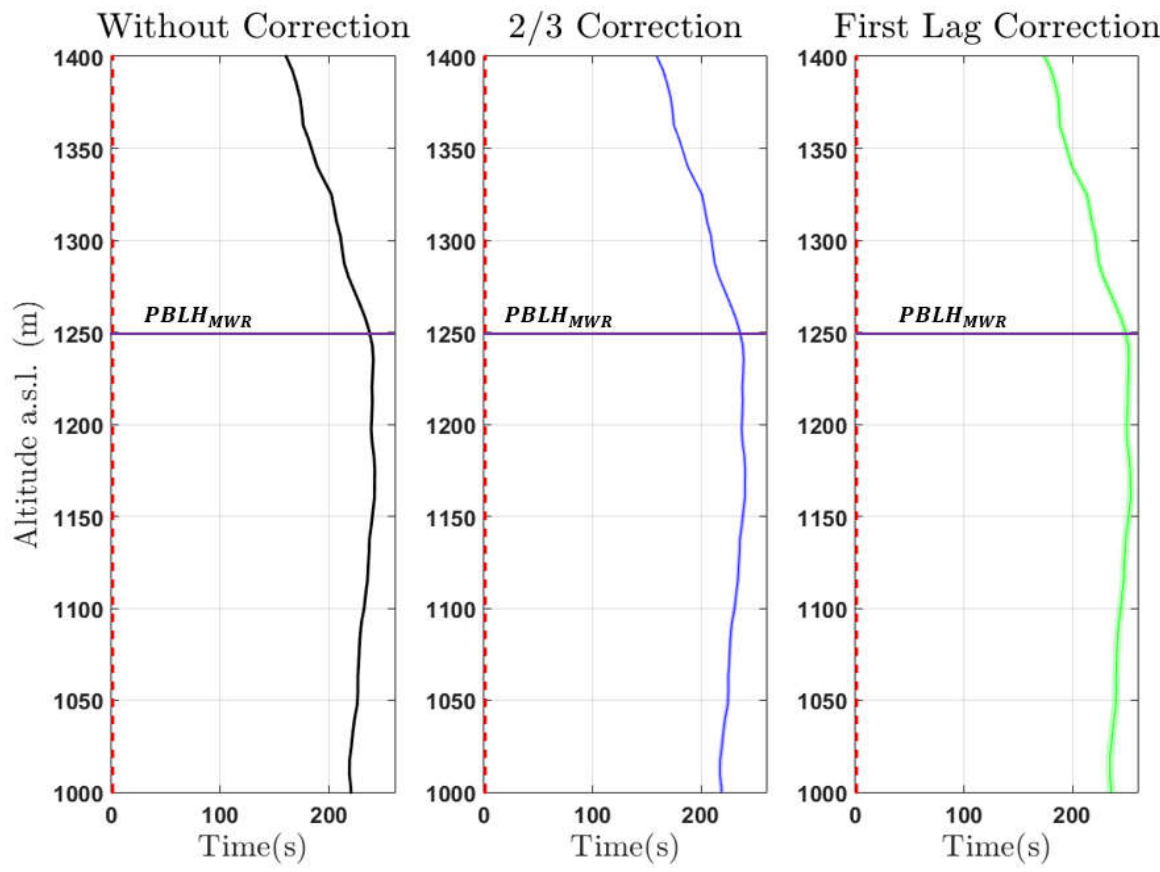

Figure 8.6 - Vertical profile of Integral time scale $\left(\boldsymbol{\tau}_{\boldsymbol{R} C \boldsymbol{S}_{1}}\right)$. Without correction (left), 2/3 correction (center), first lag correction (right).
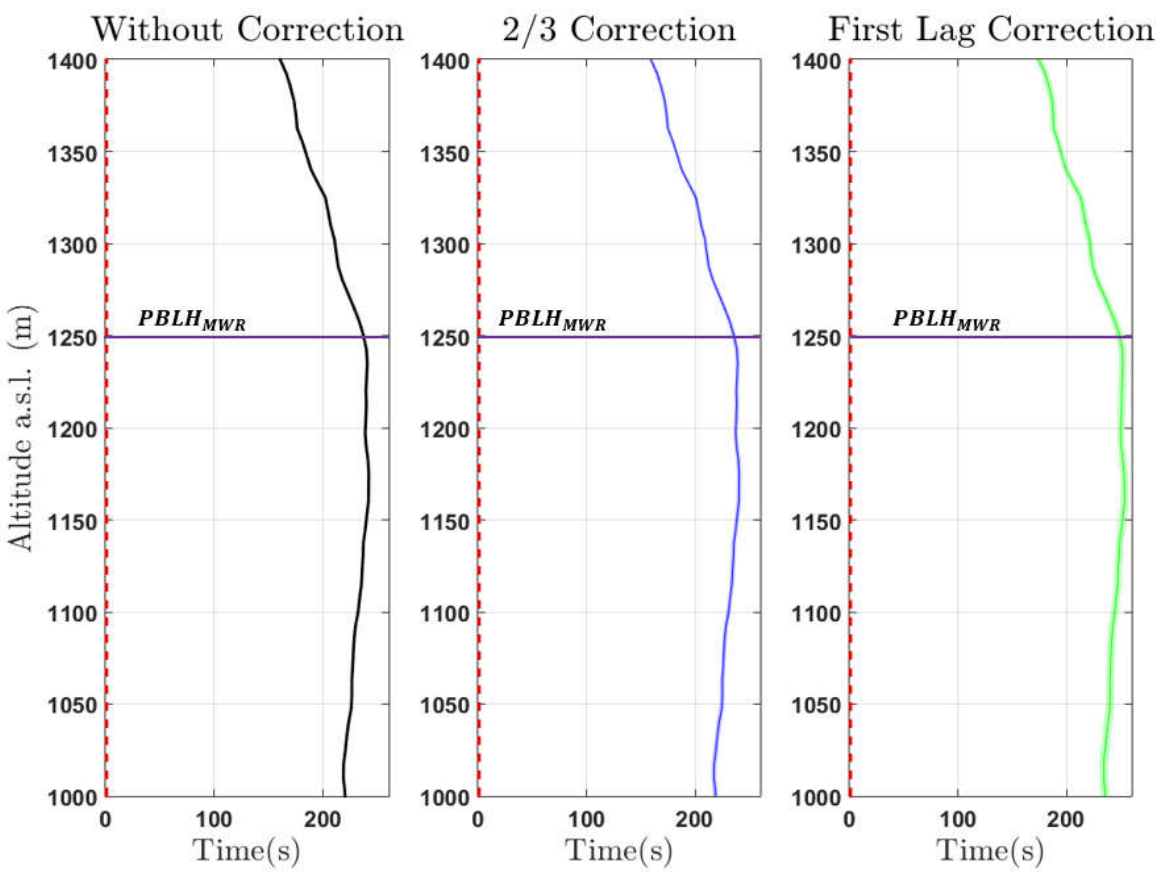

Figure 8.7 - Vertical profile of variance $\left(\boldsymbol{\sigma}_{R C S I}^{2}\right)$. Without correction (left), 2/3 correction (center), first lag correction (right). 

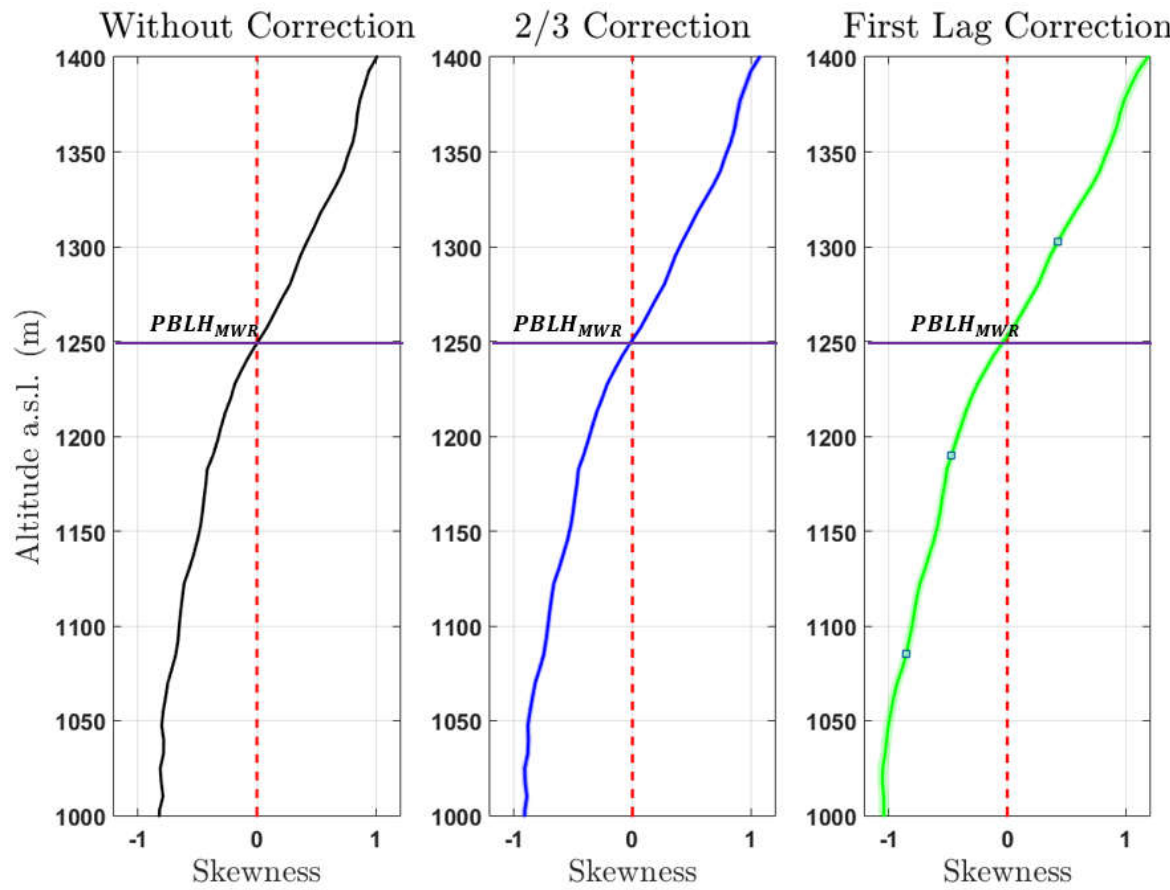

Figure 8.8 - Vertical profile of Skewness $\left(\boldsymbol{S}_{\boldsymbol{R} C \boldsymbol{S}_{I}}\right)$. Without correction (left), 2/3 correction (center), first lag correction (right).
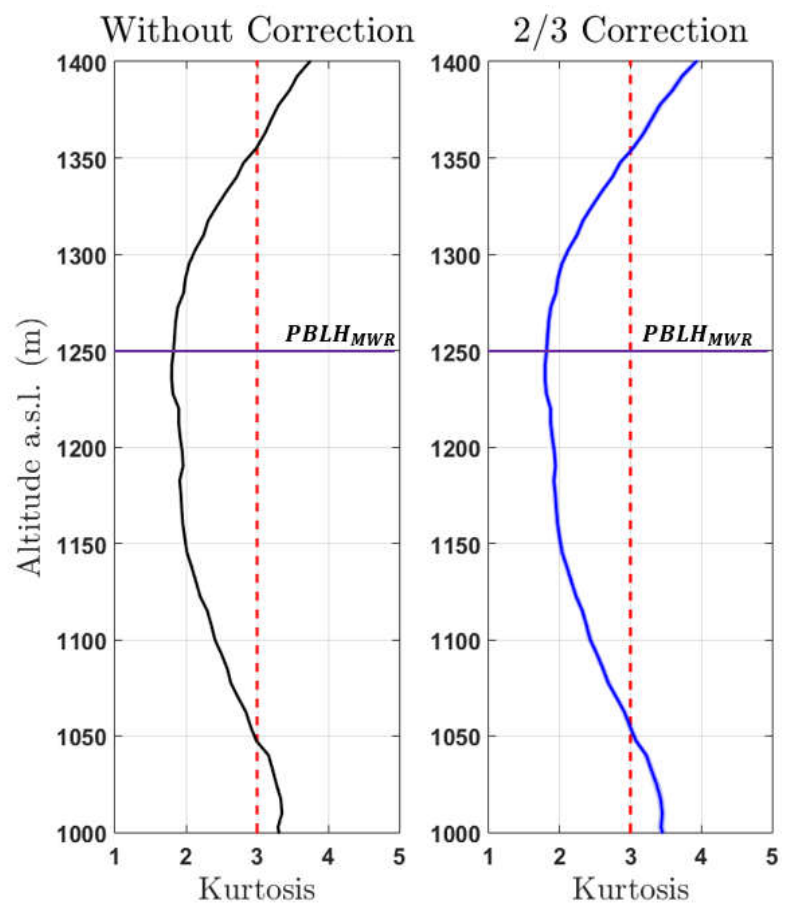

First Lag Correction

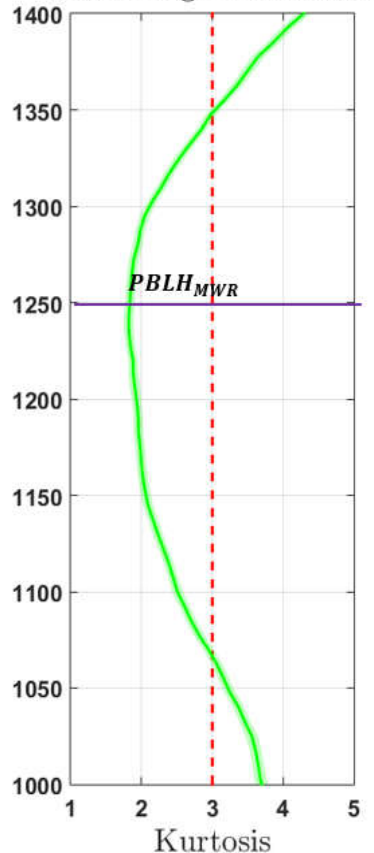

Figure 8.9 - Vertical profile of Kurtosis $\left(\boldsymbol{K}_{\boldsymbol{R} C \boldsymbol{S}_{I}}\right)$. Without correction (left), 2/3 correction (center), first lag correction (right). 
Although the difference observed in the corrected profiles are small, mainly inside the $P B L$, as a general rule the first lag correction will be adopted for all profiles.

\subsection{Cases study}

In this section we present two study cases, in order to show how the synergy of methodologies described in section 3 can provide detailed results about $P B L$ behavior. The first case represents a typical day with well-defined $P B L$. The second case correspond to a more complex situation, where there is presence of clouds and Saharan mineral dust layers.

\subsubsection{Case study 1- $19^{\text {th }}$ May}

In this study case we use measurements gathered with $D L, M W R$ and pyranometer during 24 hours. The $E L$ was operated in supervised mode between 08:20 to 18:00 UTC.

Figure 8.10-A shows the integral time scale obtained from $D L$ data $\left(\boldsymbol{\tau}_{\boldsymbol{w}}\right)$. The gray areas represents the region where $\boldsymbol{\tau}_{\boldsymbol{w}}$, is lower than the acquisition time of $D L$, therefore for this region it is not possible to analyze turbulent process. However, the gray area is located almost entirely above the $P B L H_{M W R}$ (white stars). Thus, the $D L$ acquisition time allows us to observe the turbulence throughout the whole $P B L$. The gray areas have the same meaning in Figures 8.10-B and 8.10-C.

$\boldsymbol{\sigma}_{R C S}^{2}$, has low values during the entire period of $S B L$ (Figure 8.10-B). Nevertheless as air temperature (black lines) begins to increase (around 07:00 UTC), $\boldsymbol{\sigma}_{R C S}^{2}$, increases together, as well as, $P B L H_{M W R} . \boldsymbol{\sigma}_{R C S}^{2}$, reaches its maximum values in the middle of the day, where are we also observe the maximum values of air temperature and $P B L H_{M W R}$. This process is in agreement with the behavior of skewness of $w^{\prime}\left(\boldsymbol{S}_{\boldsymbol{w}^{\prime}}\right)$ shown in Figure 8.10-C. $\boldsymbol{S}_{\boldsymbol{w}}$ is directly associated with the direction of turbulent movements (surface heating or cloud-top cooling). If $\boldsymbol{S}_{\boldsymbol{w}}$, is positive, both $\boldsymbol{\sigma}_{\boldsymbol{w}}^{2}$ and TKE (Turbulent Kinetic Energy) are being transported upwards, consequently the red regions in Figure 8.10-C represents positive values of $\boldsymbol{S}_{\boldsymbol{w}}$, and the blue regions means negative ones. During the stable period, there is predominance of low values of $\boldsymbol{S}_{\boldsymbol{w}}$, nevertheless as air temperature increase, $\boldsymbol{S}_{\boldsymbol{w}}$, values begins to become positive and increase with the ascent of the $P B L H_{M W R}$. The $P B L H_{M W R}$ ascension follows the high 
convection regions. Around 18:00 UTC, air temperature begins to decrease, causing the reduction of $\boldsymbol{S}_{w^{\prime}}$ and consequently of $P B L H_{M W R}$.

Figure 8.10-D shows the values of $R_{n}$ that are estimated from solar global irradiance values using the seasonal model described in Alados et al. (2003). The negative values of $R_{n}$ are concentrated in the stable region. Around 06:00 UTC $R_{n}$ value begins to increase and reach its maximum in the middle of the day. Comparing Figures 8.10-C and D, we can observe a similarity among the behavior of $S_{w}, R_{n}$ and air temperature, because these variable increase and decrease together, as expected. The increase of $R_{n}$ causes the increase of air temperature generating the intensification of convective process $\left(\boldsymbol{S}_{w^{\prime}}\right)$ and consequently the rising of the $P B L H_{M W R} . R_{n}$ begins to decrease some time before the other variables, but the intense reduction of air temperature and decrease of $\boldsymbol{S}_{\boldsymbol{w}}$ and $P B L H_{M W R}$ occurs when $R_{n}$ becomes negative again.

Figure 8.10-E presents the values of air surface temperature and surface relative humidity $(R H)$. Air surface temperature is directly related with $R_{n}$ and $\boldsymbol{S}_{\boldsymbol{w}}$, values. On the other hand $R H$ is inversely correlated with temperature and thus with the rest of variables, in fact $P B L H_{M W R}$ is higher when surface sensible heat fluxes dominate latent heat fluxes and lead to increase buoyancy, what occurs in the middle of the day. 


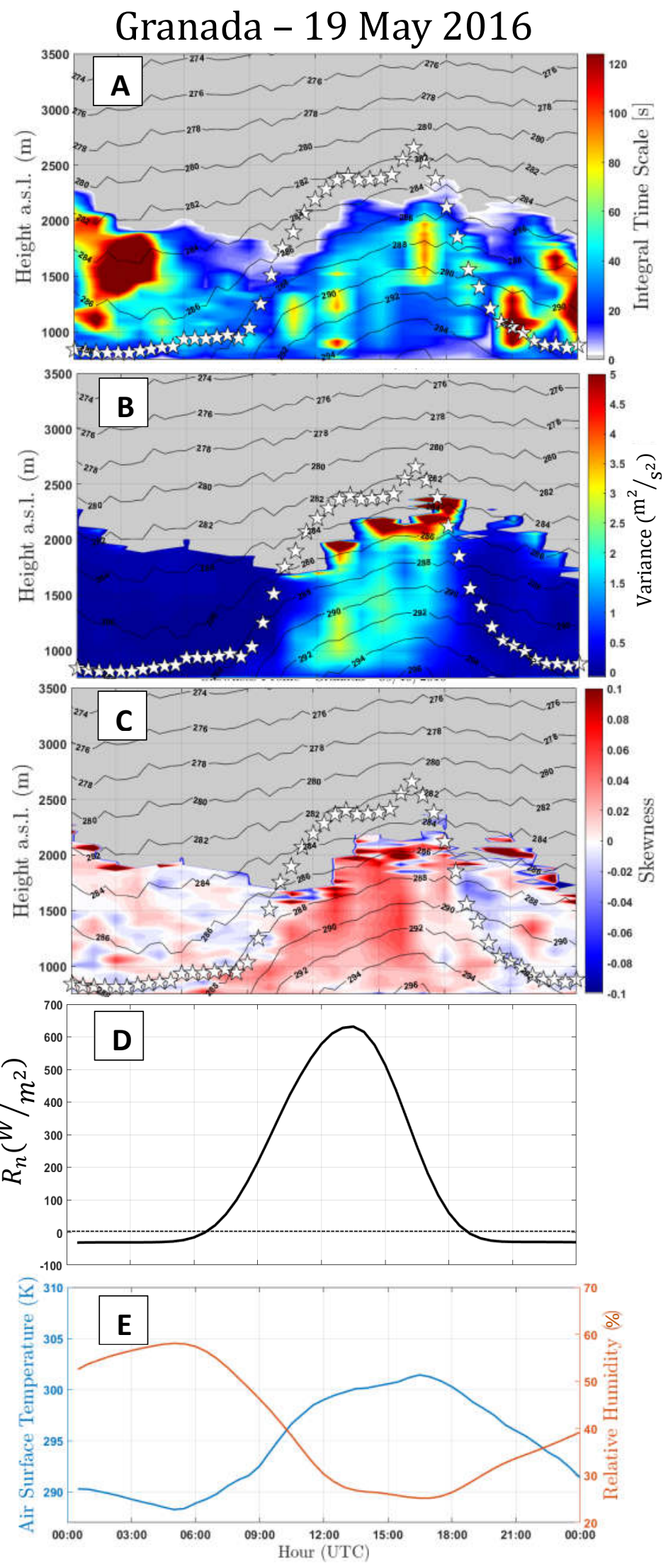

Figure $8.10-\mathrm{A}$ - integral time scale $\left[\boldsymbol{\tau}_{\boldsymbol{w}^{\prime}}\right], \mathrm{B}$ - variance $\left[\boldsymbol{\sigma}_{w^{\prime}}^{2}\right], \mathrm{C}-$ skewness $\left[\boldsymbol{S}_{\boldsymbol{w}^{\prime}}\right], \mathrm{D}$ - net radiation $\left[R_{n}\right], \mathrm{E}$ - Air surface temperature [blue line] and surface relative humidity $[R H-$ orange line]. In $\mathrm{A}, \mathrm{B}$ and $\mathrm{C}$ black lines and white stars represent air temperature and $P B L H_{M W R}$, respectively. 
Figure 8.11 shows the RCS profile obtained from 08:00 to 18:00 UTC and the welldefined $P B L H_{M W R}$ (pink stars). At the beginning of the measurement period (08:20 to 10:00 UTC) it is possible to observe the presence of a thin residual layer, and later from 13:00 to 18:00 UTC it is evident a lofted aerosol layer. Figure 15 presents the statistical moments generated from $R C S^{\prime}$, which were obtained from 13:00 and 14:00 UTC. The maximum for the variance of $R C S$ can be used as indicator of PBLH (PBLH Elastic $_{\text {) }}$ (Moreira et al., 2015), so the red line in all graphics represent the $P B L H_{\text {Elastic }}$ and the blue one the $P B L H_{M W R}$.

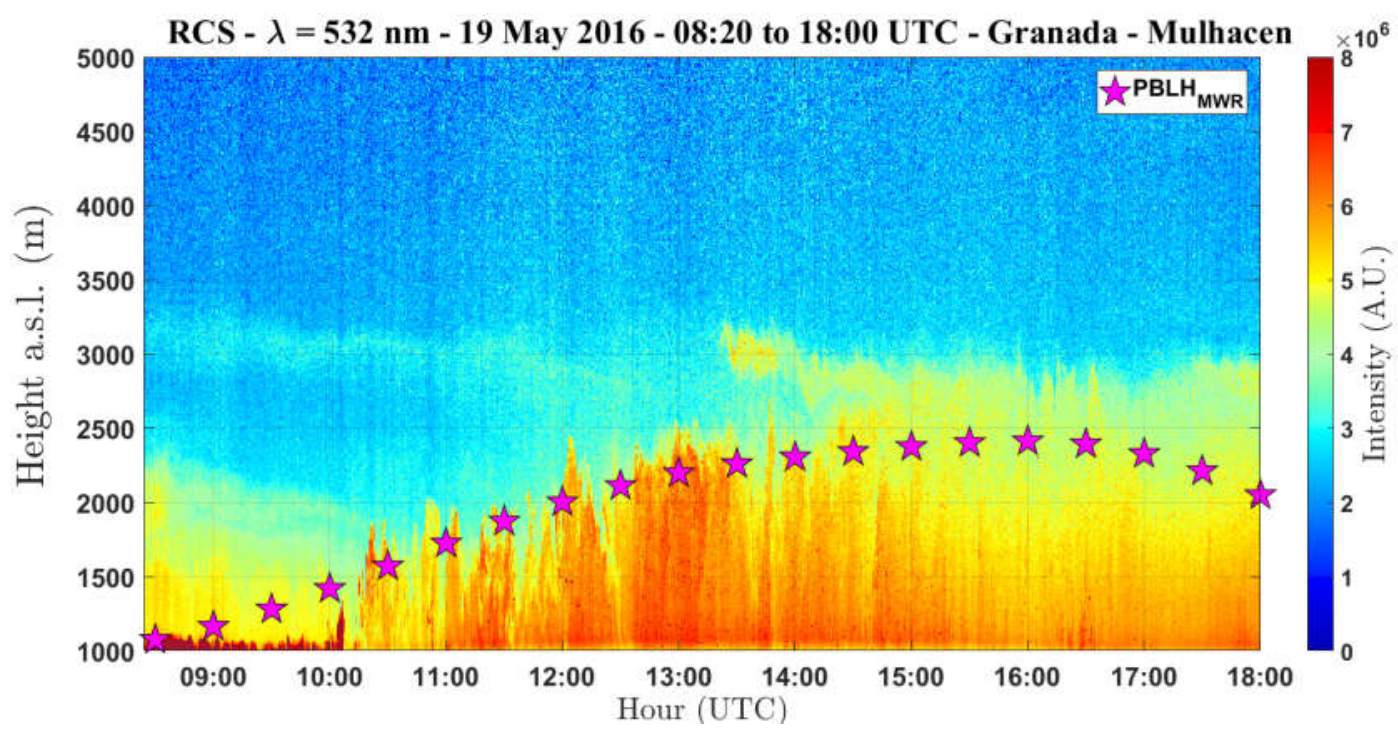

Figure 8.11 - RCS Profile 19 May 2016. Pink stars represent $P B L H_{M W R}$

Due to well-defined $P B L, P B L H_{\text {Elastic }}$ and $P B L H_{M W R}$ do not have significant differences. $\boldsymbol{\sigma}_{R C S}^{2}$, has small values below the $P B L H$. Above $P B L H_{\text {Elastic }}$ the values of $\boldsymbol{\sigma}_{R C S}^{2}$ decrease slowly due to location of the lofted aerosol around $2500 \mathrm{~m}$. However above this aerosol layer the value of $\boldsymbol{\sigma}_{R C S}^{2}$, is reduced to zero, indicating the extreme decreasing in aerosol concentration in the free troposphere. The integral time scale obtained from RCS' $\left(\boldsymbol{\tau}_{\boldsymbol{R} C S^{\prime}}\right)$ has values higher than MULHACEN time acquisition throughout the CBL, evidencing the feasibility for studying turbulence using this elastic lidar configuration. The skewness values obtained from RCS' $\left(\boldsymbol{S}_{\boldsymbol{R} C \boldsymbol{S}^{\prime}}\right)$ give us information about aerosol movement. The positive values of $\boldsymbol{S}_{\boldsymbol{R} C \boldsymbol{S}}$, observed in the lowest part of profile and above the $P B L H_{\text {Elastic }}$ represents the updrafts aerosol layers. The negative values of $\boldsymbol{S}_{\boldsymbol{R} C \boldsymbol{S}}$, indicates the region with low aerosol concentration due to clean air coming from Free Troposphere $(F T)$. This movement of ascension of aerosol layers and descent of clean air with zero value of $\boldsymbol{S}_{\boldsymbol{R} C \boldsymbol{S}}$, is characteristic of growing PBL and also was detected by Pal et al. (2010) and McNicholas et al. (2014). The kurtosis of RCS' 
$\left(\boldsymbol{K}_{\boldsymbol{R} C \boldsymbol{S}_{\prime}}\right)$ determines the level of mixing at different heights. There are values of $\boldsymbol{K}_{\boldsymbol{R} \boldsymbol{C} \boldsymbol{S},}$ larger than 3 in the lowest part of profile and around $2500 \mathrm{~m}$, showing a peaked distribution in this regions. On other hand values of $\boldsymbol{K}_{\boldsymbol{R} C \boldsymbol{S}}$, lower than 3 are observed close the $P B L H_{\text {Elastic }}$, therefore this region has a well-mixed CBL regime. Pal et al. (2010) and McNicholas et al. (2014) also detected this feature in the region nearby the PBLH.

The results provided by $D L$, pyranometer and $M W R$ data agree with the results observed in Figure 8.12. In the same way the analysis of high order moments of $R C S^{\prime}$ fully agree with the information in Figure 8.10. Thus, the large values of $\boldsymbol{S}_{\boldsymbol{R} C \boldsymbol{S}}$, and $\boldsymbol{K}_{\boldsymbol{R} C \boldsymbol{S}}$, detected around $2500 \mathrm{~m}$ a.g.l, where we can see a lofted aerosol layer, suggest the ascent of an aerosol layer and presence of a peaked distribution, respectively.

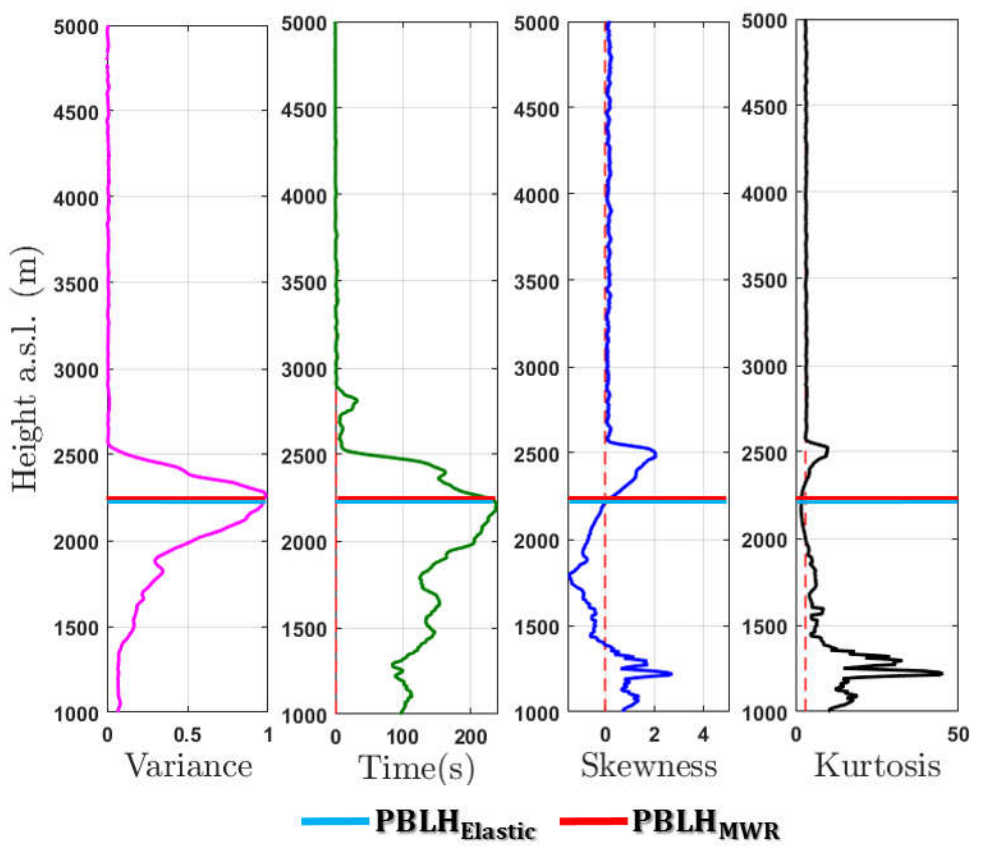

Figure 8.12 - Statistical moments obtained from elastic lidar data. From left to right: variance $\left[\boldsymbol{\sigma}_{R C S^{\prime}}^{2}\right]$, integral time scale $\left[\boldsymbol{\tau}_{\boldsymbol{R} C \boldsymbol{S}^{\prime}}\right]$, skewness $\left[\boldsymbol{S}_{\boldsymbol{R} C \boldsymbol{S}^{\prime}}\right]$ and kurtosis $\left[\boldsymbol{K}_{\boldsymbol{R} \boldsymbol{C} \boldsymbol{S}^{\prime}}\right]$.

\subsubsection{Study Case $2-0^{\text {th }}$ July}

In this study case measurements with $D L, M W R$ and pyranometer expand during 24 hours, while $E L$ data are collected from 09:00 to 16:00 UTC. 


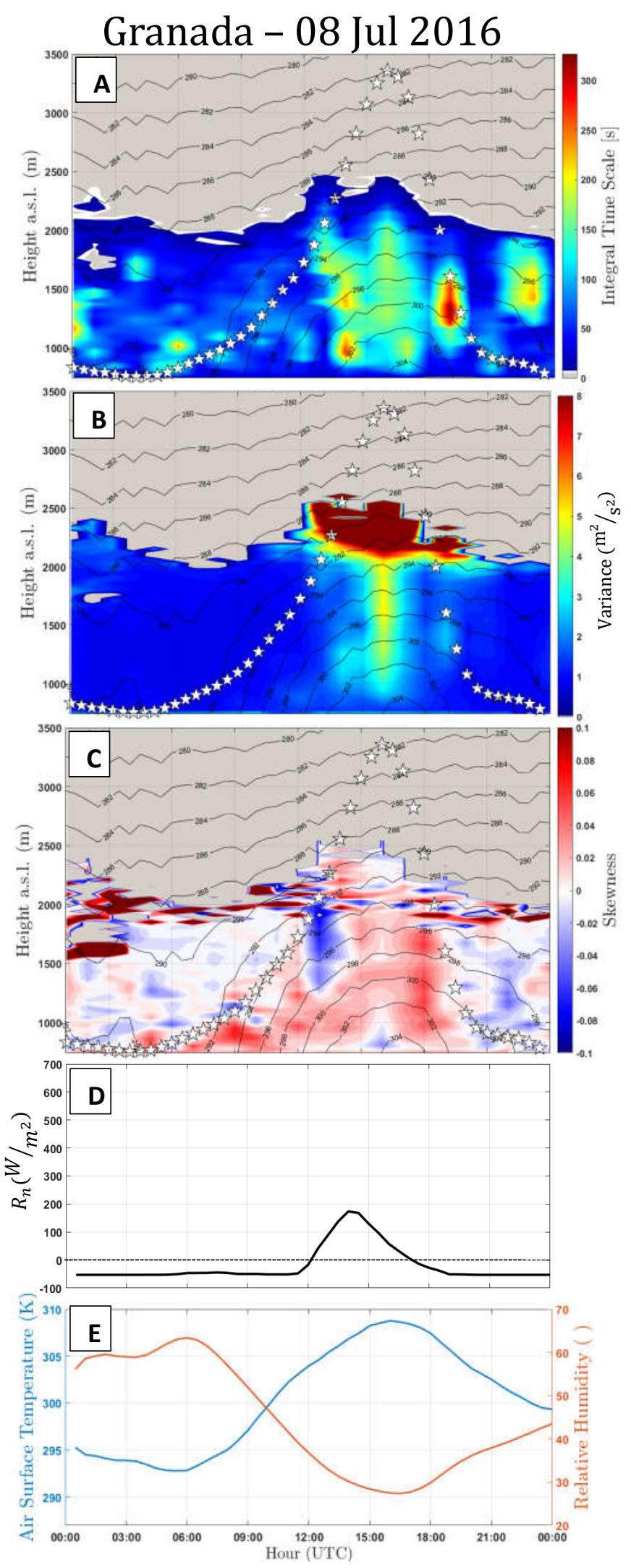

Figure 8.13 - A - integral time scale $\left[\boldsymbol{\tau}_{\boldsymbol{w}^{\prime}}\right], \mathrm{B}$ - variance $\left[\boldsymbol{\sigma}_{w^{\prime}}^{2}\right], \mathrm{C}-$ skewness $\left[\boldsymbol{S}_{\boldsymbol{w}^{\prime}}\right], \mathrm{D}-$ net radiation $\left[R_{n}\right], \mathrm{E}-$ Air surface temperature [blue line] and surface relative humidity $[R H-$ orange line]. In $\mathrm{A}, \mathrm{B}$ and $\mathrm{C}$ black lines and white stars represent air temperature and $P B L H_{M W R}$, respectively. 
Figure 8.13-A shows $\boldsymbol{\tau}_{\boldsymbol{w} /}$, where the gray area has the same meaning mentioned earlier. Outside the period 13:00 to 17:00 UTC, the grey area is situated completely above the $P B L H_{M W R}$ (white stars), thus $D L$ time acquisition is enough to perform studies about turbulence in this case.

$\boldsymbol{\sigma}_{w}^{2}$ has values close to zero during all the stable period (Figure 8.13-B). However, when air temperature (black lines) and $P B L H_{M W R}$ begins to increase (around 06:00 UTC), $\boldsymbol{\sigma}_{w}^{2}$ also increases and reaches its maximum in the middle of the day. In the late afternoon, as air temperature and $P B L H_{M W R}$ decrease, the values of $\boldsymbol{\sigma}_{w}^{2}$, decrease gradually, until reach the minimum value associated to the SBL. Figure 8.13-C shows the profiles of $\boldsymbol{S}_{\boldsymbol{w}}$. In the same way of the previous study case, the behavior of $\boldsymbol{S}_{\boldsymbol{w}}$ is directly related to the air temperature pattern (increasing and decreasing together) and causing the growth and reduction of $P B L H_{M W R}$. The main features of this case are: the low values of $\boldsymbol{S}_{\boldsymbol{w}}$, the slow increase and ascension of positive $\boldsymbol{S}_{\boldsymbol{w}}$, values and the predominance of negative $\boldsymbol{S}_{\boldsymbol{w}}$, values from 12:00 to 13:00 UTC. The first two features are likely due to the presence of the intense Saharan dust layer (Figure 8.14), which reduce the passage of solar irradiance, and consequently the absorption of solar irradiance at the surface, generating weak convective process. From Figure 8.14 we can observe the presence of clouds from 12:00 to 14:00 UTC. This justify the intense negative values of $\boldsymbol{S}_{\boldsymbol{w}}$, observed in this period, because, as mentioned before, $\boldsymbol{S}_{\boldsymbol{w}}$ is directly associated with direction of turbulent movements that during this period is associated to cloudtop cooling, due to the presence of clouds (Asmann, 2010).

The influence of Saharan dust layer can also be evidenced on the $R_{n}$ pattern (Figure 8.13-D), which maintain negative values until 12:00 UTC and reach a low maximum value (around $200 \mathrm{~W} / \mathrm{m}^{2}$ ). Air surface temperature and $R H$ (Figure 8.13-E) present the same correlation and anti-correlation (respectively) observed in the earlier study case, where the maximum of air surface temperature and the minimum of $R H$ are detected in coincidence with the maximum daily value of $P B L H_{M W R}$.

As mentioned before, Figure 8.14 shows the RCS profile obtained from 09:00 to 16:00 UTC in a complex situation, with presence of decoupled dust layer from 09:00 and 12:00 and clouds from 11:00 to 16:00 UTC. The pink stars represents $P B L H_{M W R}$. 


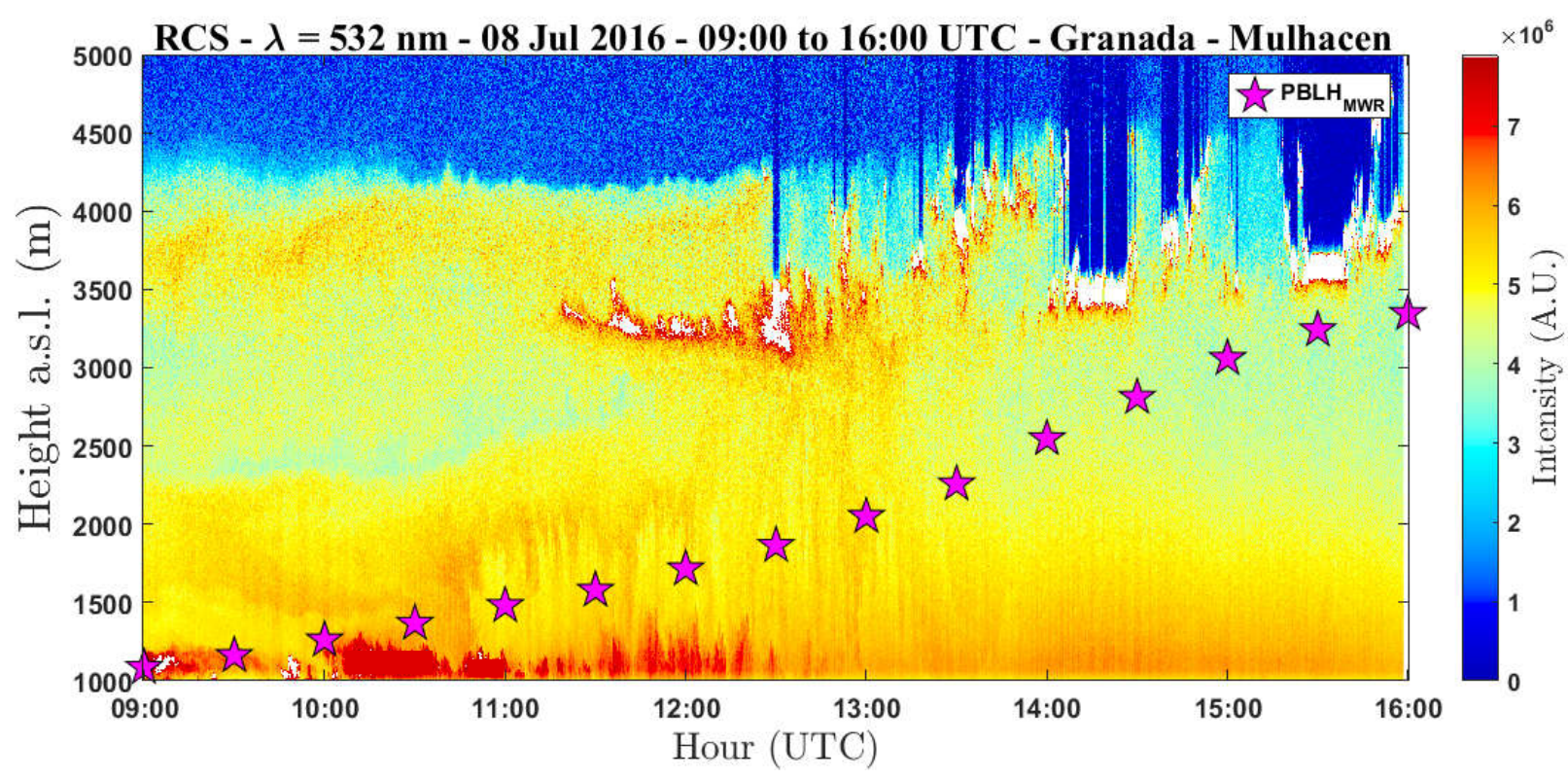

Figure 8.14 - RCS Profile 08 July 2016. Pink stars represent $P B L H_{M W R}$.

Figure 8.15 illustrates the statistical moments of $R C S^{\prime}$ obtained from 11:00 to 12:00 UTC. The $\boldsymbol{\sigma}_{R C S}^{2}$, profile presents several peaks due to the presence of distinct aerosol sublayers. The first peak is coincident with the value of $P B L H_{M W R}$. The value of $P B L H_{\text {elastic }}$, is coincident with the base of the dust layer. This difficulty to detect the $P B L H$ in presence of several aerosol layers is inherent to the variance method (Kovalev and Eichinger, 2004). The values of $\boldsymbol{\tau}_{\boldsymbol{R}} \boldsymbol{C S}$, are higher than MULHACEN acquisition time all a long the $P B L$, evidencing the feasibility of MULHACEN time acquisition for studying the turbulence of $P B L$ in this case. The $\boldsymbol{S}_{\boldsymbol{R} C \boldsymbol{S}}$, profile has several positive values, due to the large number of aerosol sublayers that are present. The characteristic inflection point of $\boldsymbol{S}_{\boldsymbol{R} C \boldsymbol{S}}$, is observed in coincidence with the $P B L H_{M W R}$, that confirming the agreement between this point and the PBLH. $\boldsymbol{K}_{\boldsymbol{R} C \boldsymbol{S}}$, has predominantly values lower than 3 below $2500 \mathrm{~m}$, thus shown how this region is well mixed as can see in Figure 8.15. Values of $\boldsymbol{K}_{\boldsymbol{R} \boldsymbol{C} \boldsymbol{S}}$, larger than 3 are observed in the highest part of profile, where the dust layer is located. 

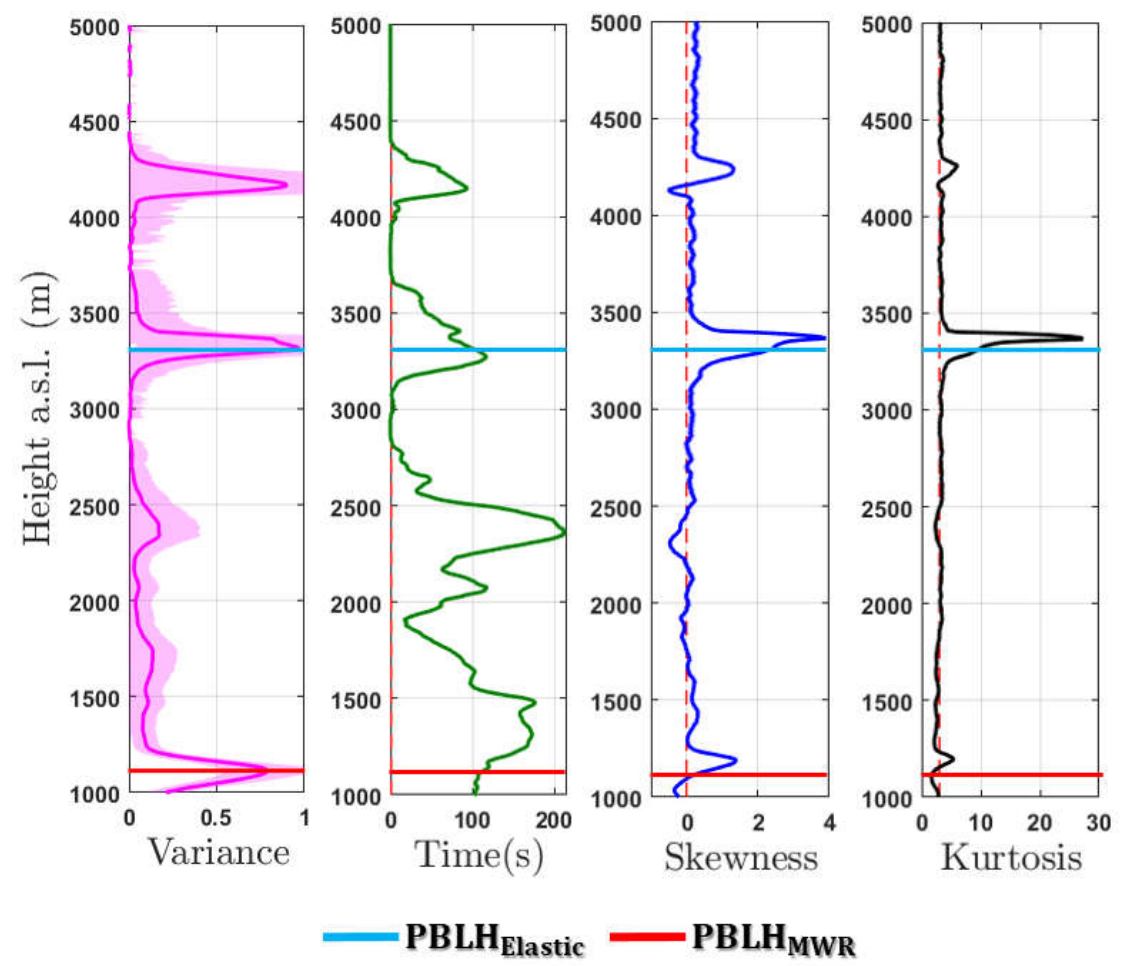

Figure 8.15 - Statistical moments obtained from elastic lidar data. From left to right: variance $\left[\boldsymbol{\sigma}_{R C S^{\prime}}^{2}\right]$, integral time scale $\left[\boldsymbol{\tau}_{\boldsymbol{R} C \boldsymbol{S}^{\prime}}\right]$, skewness $\left[\boldsymbol{S}_{\boldsymbol{R} C \boldsymbol{S}^{\prime}}\right]$ and kurtosis $\left[\boldsymbol{K}_{\boldsymbol{R} C \boldsymbol{S}^{\prime}}\right]$.

Figure 8.16 shows the $R C S^{\prime}$ high-order moments obtained from 12:00 and 13:00 in presence of cloud cover. The method based on maximum of $\boldsymbol{\sigma}_{R C S}^{2}$ locates the PBLH Elastic at the cloud base, due to the high variance of $R C S^{\prime}$ generated by the clouds. $\boldsymbol{\tau}_{\boldsymbol{R}} \boldsymbol{C S}$, provides values larger than MULHACEN time acquisition, therefore this configuration enable us to study turbulence by $E L$ analyses. $\boldsymbol{S}_{\boldsymbol{R} C \boldsymbol{S}}$, has few peaks, due to the mixing between $C B L$ and dust layer, generating a more homogenous layer. The higher values of $\boldsymbol{S}_{\boldsymbol{R} C \boldsymbol{S}}$, are observed in regions where there are clouds, and the negative ones (between 3500 and $4000 \mathrm{~m}$ ) occur due to presence of air from $F T$ between two aerosol layers (Figure 8.14). The inflection point of $\boldsymbol{S}_{\boldsymbol{R} C \boldsymbol{C}}$, profile is observed in $P B L H_{M W R}$ region. $\boldsymbol{K}_{\boldsymbol{R} C \boldsymbol{S}}$, profile has low values in most of the $P B L$, demonstrating the high level of mixing during this period, where dust layer and $P B L$ are combined. The higher values of $\boldsymbol{K}_{\boldsymbol{R} C \boldsymbol{S}}$, are observed in the region of clouds. 

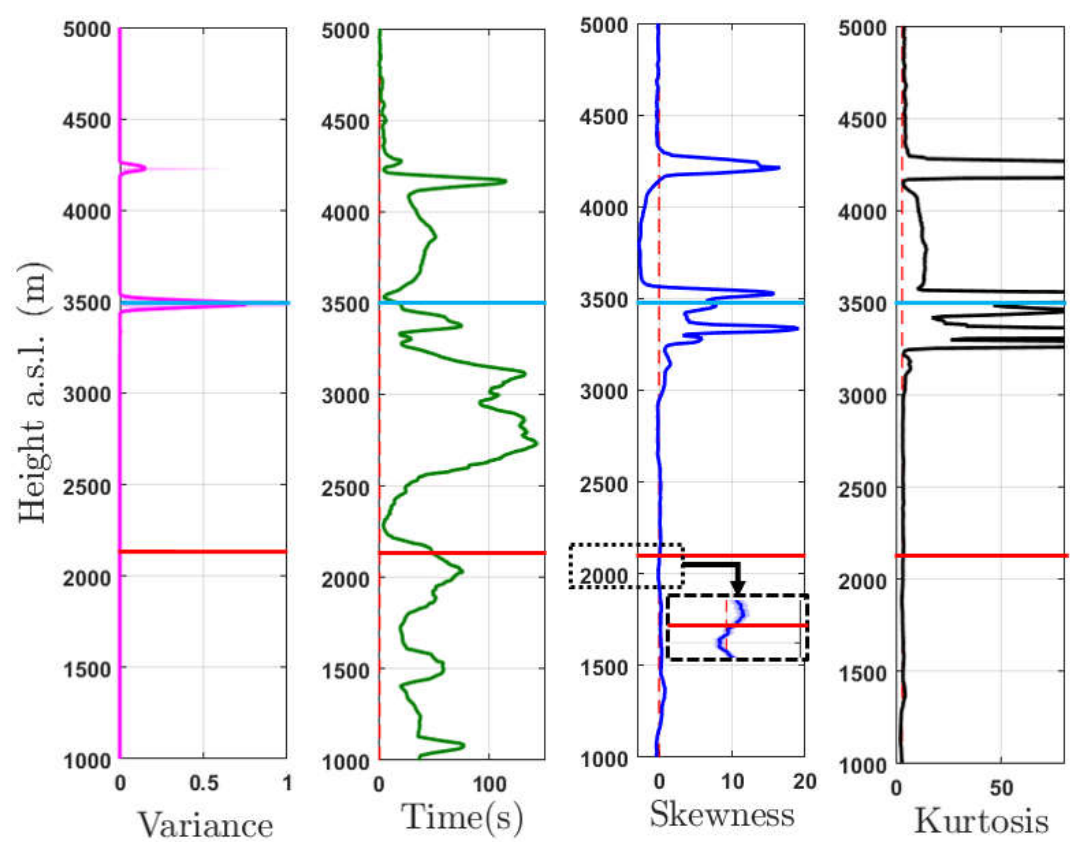

PBLH $_{\text {Elastic }}$

- PBLH $_{\text {MWR }}$

Figure 8.16 - Statistical moments obtained from elastic lidar data. From left to right: variance $\left[\boldsymbol{\sigma}_{R C S^{\prime}}^{2}\right]$, integral time scale $\left[\boldsymbol{\tau}_{\boldsymbol{R} C \boldsymbol{S}^{\prime}}\right]$, skewness $\left[\boldsymbol{S}_{\boldsymbol{R} \boldsymbol{C} \boldsymbol{S}^{\prime}}\right]$ and kurtosis $\left[\boldsymbol{K}_{\boldsymbol{R} C \boldsymbol{S}^{\prime}}\right]$. 


\section{Conclusion}

In this thesis was performed a study about the $P B L$ using remote sensing systems. Such study can be divided in four parts: validation of instruments, long-term studies, validation of methodology and wavelengths in analyses of turbulence, deep analyses of turbulence.

In the first study, the $P B L H_{M W R}$ is validated by $P B L H_{\text {Radiosonde }}$ from the methodology describe in section 4.1. The $P B L H$ provided by both instruments are equivalent in stable and convective situations, with high level of correlations and index of agreement $\left(R_{\text {Convective }}=0.96, D_{\text {Convective }}=0.89, R_{\text {Stable }}=0.97, D_{\text {Stable }}=0.98\right)$ and low values of $\triangle P B L H_{M W R-R a d i o s o n d e}(-0.6$ and $8.1 \%$ for convective and stable cases, respectively). This agreement between the data allowed us to use the $P B L H_{M W R}$ as the reference method, for the rest of the study. Then, three study cases are analyzed in detail in order to investigate the behavior of $P B L H_{\text {Doppler }}, P B L H_{\text {elastic }}$ and $P B L H_{M W R}$. In situations where $P B L$ is well defined and the growth rate is not so intense, all methods present small percentage differences $(\triangle P B L H$ smaller than 5\%). However, under scenarios where $P B L$ grows rapidly, there are presence of clouds and/or dust layers, the values of $\triangle P B L H$ increase (differences around $60 \%$ for $D L$ and $35 \%$ for $E L$, with respect to the $M W R$ estimations). Such differences are originated by the distinct influence suffered by each tracer (inertia, gravitation, etc.), as well as, $P B L H$ definition (case with presence of clouds). In addition, a statistical analysis was performed The comparison between $P B L H_{M W R}$ and $P B L H_{\text {Doppler }}$ is performed over the whole $24 \mathrm{~h}$ day period, while PBLH $H_{\text {elastic }}$ and PBLH $H_{M W R}$ were compared between 09:00 UTC and 19:00 UTC, due to the shortcomings associated to the rather large height for full overlap of the MULHACEN lidar system. From these comparison we can conclude that when $P B L$ is full-developed both lidar systems have good results, although $R M S E_{\text {elastic }}<R M S E_{\text {Doppler }}$ likely as a result of the best vertical resolution of the MULHACEN lidar in comparison with the $D L$. During the periods of intense $P B L H$ increasing and/or reduction $P B L H_{\text {Doppler }}$ has correlations ( $D$ always larger than $0.85)$ better than $P B L H_{\text {elastic }}$. In stable cases $P B L H_{\text {Doppler }}$ has more reliable values only from 00:30 UTC. 
In the second part is shown a study about $P B L H$ obtained from ceilometer $\left(P B L H_{\text {Ceilometer }}\right)$ and $M W R\left(P B L H_{M W R}\right)$ measurements. $P B L H_{\text {Ceilometer }}$ was obtained by the $G M$ (Sec. 3.1.2), which detects the top of aerosol layer $\left(P B L H_{\text {Ceilometer }}^{C B L}\right.$ if $P B L$ is fully

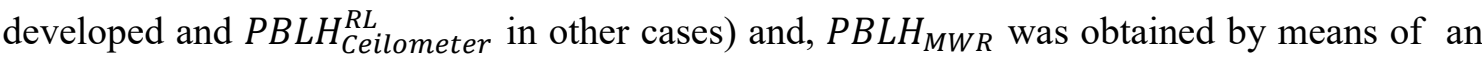
algorithm that combines $P M$ and $T G M$, allowing to differentiate between $S B L\left(P B L H_{M W R}^{S B L}\right)$ and $C B L\left(P B L H_{M W R}^{C B L}\right)$ cases (Sec. 3.1.1). The long-term analyses allowed us to provide a statistical study of the $P B L$ height at Granada which together with other studies at Paris, Highveld, and Cologne, increases the general knowledge on the $P B L$ pattern in Europe at different latitudes. The surface meteorological variables involved in the thermodynamic processes are correlated with the $P B L H$, demonstrating that the correct interpretation of the processes which drives the $P B L$ behavior. Only the $R L$ height is not affected by the seasonality of meteorological variables, being its value practically constant (around $1000 \mathrm{~m}$ a.g.1.) through the year. In this regard, we have shown how the combination of the $P B L H_{M W R}$ and $P B L H_{\text {Ceilometer during stable }}$ conditions allowed the retrieval of the $R L$ depth $\left(P B L H_{\text {ceilometer }}^{R L} P B L H_{M W R}^{S B L}\right)$, opening the door to further investigations about the air quality due to the potential entrainment of the ' $R L$ aerosol load' in the next ' $C B L$ aerosol load'.

This study has demonstrated the feasibility of long-term $P B L H$ analysis using ceilometer and $M W R$, enabling the characterization of this variable and a better comprehension about its behavior, complex structure and how seasonality, geographical differences and surface variables can influence it. In the future we will intend to extend this study to other regions and synergistically aggregate other remote sensing systems.

Then, in order to compare the applicability of different wavelengths in studies about turbulence, it was performed a comparison among three wavelengths: 355, 532 and $1064 \mathrm{~nm}$ using the methodology described in section 3.2. The wavelength $1064 \mathrm{~nm}$ was used as reference due to predominance of $\beta_{\text {par }}$ in its $\beta$. Our study indicates that $A C F_{532}$ and $A C F_{1064}$ shown a similar behavior with approximately the same values of intensity and error. On the other hand, $A C F_{355}$ presents an intensity $90 \%$ smaller than $A C F_{1064}$ and an error around $25 \%$. In the analysis of high-order moments this difference also is remarkable, because while the wavelengths 532 and $1064 \mathrm{~nm}$ have similar results with low influence of corrections, inside $P B L$ region, the wavelength $355 \mathrm{~nm}$ has results with lower intensity, so that the quality of result decreases as complexity of statistical moment increases. The correction also generated a great impact in the profiles at $355 \mathrm{~nm}$, mainly the first lag correction, demonstrating the high 
influence of $\varepsilon$ in the signal. Then, due to combination of this factor with high influence of noise, the wavelength $355 \mathrm{~nm}$ was not applied in turbulence studies described in this paper.

Two case studies were performed in order to demonstrate how this methodology can provide detailed information about $P B L$ behavior. The analyses were carried out for 532 and $1064 \mathrm{~nm}$, respectively. In both cases, the obtained values of $\boldsymbol{\tau}_{\boldsymbol{R} C \boldsymbol{S}_{\prime}}$, inside the $P B L$ region, were larger than MSP-I acquisition time, demonstrating the viability of the system setup for the study of turbulence. From $\boldsymbol{\sigma}_{\boldsymbol{R} C \boldsymbol{S}}^{2}$, it was possible to detect the $P B L H_{\text {elastic }}$, using the maximum value of each profile. $\boldsymbol{S}_{\boldsymbol{R} C \boldsymbol{S}}$, provided information about the dynamic of aerosol layers (updrafts and downdrafts are observed from positive and negative values of $\boldsymbol{S}_{\boldsymbol{R} C \boldsymbol{S}_{\prime}}$, respectively). From $\boldsymbol{K}_{\boldsymbol{R} C \boldsymbol{S}}$, was possible to identify the level of mixing, so that $P B L$ region was often characterized by a well-mixed regime. The results obtained show the viability of the proposed methodology and its applicability to wavelength $532 \mathrm{~nm}$, due to the similarity with results derived at 1064 nm.

Finally, it is performed a study about the turbulence in the Planetary Boundary Layer using three different types of remote sensing systems $(M W R, D L$ and $E L)$. Firstly as held an error analysis in order to validate the quality of methodology applied. The small changes in the profiles after the corrections, specially inside the $P B L$ region, evidence the feasibility of the applied methodology for monitoring the turbulence in the $P B L$. Nevertheless, to be cautious all profiles were corrected by first lag correction, which was more restrictive during the comparison. Then two case studies were performed. In the first one, a well-defined $P B L$ is presented. The values of $\boldsymbol{\tau}_{w^{\prime}}$, in $P B L$ region, are larger than $D L$ acquisition time, demonstrating the feasibility of applying this treatment of $D L$ data in turbulence studies. $\boldsymbol{\sigma}_{w}^{2}$ and $\boldsymbol{S}_{\boldsymbol{w}}$ showed a good agreement with the behavior of the air temperature, $R_{n}$ and $P B L H_{M W R}$, which increase and decrease together. The air surface temperature and $R H$ also showed a good agreement with profiles of other variables, reaching its maximum (air surface temperature) and minimum $(R H)$ close to moment of the daily maximum of $P B L H_{M W R}$ and some instants after the daily maximum of $R_{n}$. The analysis of statistical moments by $E L$ lidar data showed a good agreement with results provided by DL data, enabling us to observe the position $\left(\boldsymbol{\sigma}_{R C S I}^{2}\right)$ and movement $\left(\boldsymbol{S}_{\boldsymbol{w}^{\prime}}\right)$ of aerosol layers, as well as, the level of mixing $\left(\boldsymbol{K}_{\boldsymbol{w}^{\prime}}\right)$ of each height.

The second study case (sect 4.2.2) illustrated a more complex situation with the presence of Saharan dust layer and some clouds. As in the previous study case, $\boldsymbol{\tau}_{\boldsymbol{w}}$ presents inside the $P B L$ region values larger than the DL acquisition time. $\boldsymbol{\sigma}_{w}^{2}$, and $\boldsymbol{S}_{\boldsymbol{w}}$, showed low 
values and a slow growth along the day as a result of the presence of the Saharan dust layer, that filters the incoming solar irradiance affecting the surface net radiation, $R_{n}$, and through this the $P B L H_{M W R}$ behavior. Under cloudy conditions $\boldsymbol{S}_{\boldsymbol{w}}$, has predominantly negative values, due to cloud-top cooling. The analysis of statistical moments of $E L$ data shown a good agreement with results obtained from $D L$ data and give us more information about the characteristic and dynamic of aerosol dust layer. This study shows the feasibility of the described methodology based on remote sensing systems for studying the turbulence. The synergy provided by the different systems allows for a more detailed comprehension about the $P B L$ and some variables that influence its dynamic.

The set of analysis performed in this thesis demonstrates the feasibility of the remote sensing systems application in study about $P B L$ providing a better comprehension about the dynamic of this layer.

\subsection{Suggestions for future work}

The analyzes performed in this thesis demonstrated the feasibility of synergic use of remote sensing systems, so that the combination of results can provide detailed and complementary information. In the future, the methodologies described in this thesis can be applied in other sites, in order to analyze the $P B L$ behavior and identify the main factors that influence the $P B L$ dynamics in each region. In addition, the combination of results provided by $E L$ and $D L$, from methodology proposed in section 4.2, can be applied in detection of aerosol vertical flux. Such analyses is relevant for several research fields like as: weathercast modelling, dispersion of pollutants, air quality. 


\section{References}

AGENCIA ESTATAL DE METEOROLOGIA (AEMET). Available in: http://www.aemet.es/es/serviciosclimaticos/datosclimatologicos/valoresclimatologicos? $1=551$ 4. Accessed on $30^{\text {th }}$ December 2017.

ALADOS, I., FOYO-MORENO, I., OLMO, F. J., ALADOS-ARBOLEDAS, L. Relationship between net radiation and solar radiation for semi-arid shrub-land. Agricultural and Forest Meteorology, 116, 221-227, 2003.

ALADOS-ARBOLEDAS, L., MÜLlER, D., GUERRERO-RASCADO, J., NAVASGUZMÁN, F., PÉREZ-RAMÍREZ, D., OLMO, F. Optical and microphysical properties of fresh biomass burning aerosol retrieved by Raman lidar, and star-and sun-photometry. Geophysical Research Letters, 38, L01807, doi: 10.1029/2010GL045999, 2011.

ALBRECHT, B. A., BRETHERTON, C. S., JOHNSON, D., SCUBERT, W. H., FRISCH, A. S. The Atlantic stratocumulus transition experiment-ASTEX. Bulletin of the American Meteorological Society, 76, 889-904, 1995.

ANDREWS, E., SHERIDAN, P. J., OGREN, J. A., FERRARE, R. In situ aerosol profiles over the Southern Great Plains cloud and radiation test bed site: 1. Aerosol optical properties. Journal of Geophysical Research, 109, D06208, doi:10.1029/2003JD004025, 2004.

ANTUÑA-MARRERO, J. C., LANDULFO, E., ESTEVAN, R., BARJA, B., ROBOCK, A., WOLFRAM, E., RISTORI, P., CLEMESHA, B., ZARATTI, F., FORNO, R., ARMANDILLO, E., BASTIDAS, A. E., DE FRUTOS BARAJA, A. M., WHITEMAN, D. N., QUEL, E., BARBOSA, H. M. J., LOPES, F., MONTILLA-ROSERO, E., GUERRERO-RASCADO, J. L. LALINET: The First Latin American-born Regional Atmospheric Observational Network.

Bulletin of the American Meteorological Society, 98, 1255-1275, https://doi.org/10.1175/BAMS-D-15-00228.1, 2017. 
AVOLIO, E., FEDERICO, S., MIGLIETTA, M. M., FEUDO, T. LO, CALIDONNA, C. R., SEMPREVIVA, A. M. Sensitivity analysis of WRF model PBL schemes in simulating boundary- layer variables in southern Italy: An experimental campaign. Atmospheric Research, 192, 58-71, 2017.

BAARS, H., ANSMANN, A., ENGELMANN, R., AND ALTHAUSEN, D. Continuous monitoring of the boundary-layer top with lidar. Atmospheric Chemistry and Physics, 8, 72817296, doi:10.5194/acp-8-7281-2008, 2008

BANKS, R. F., BALDASANO, J. M. Impact of WRF model PBL schemes on air quality simulations over Catalonia, Spain. Science of the Total Environment, 572, 98-113, http://doi.org/10.1016/j.scitotenv.2016.07.167, 2016.

BARLOW, J. F., DUNBAR, T. M., NEMITZ, E. G., WOOD, C. R., GALlAGHER, M. W., DAVIES, F., O'CONNOR, E., HARRISON, R. M. Boundary layer dynamics over London, UK, as observed using Doppler lidar during REPARTEE-II. Atmospheric Chemistry and Physics, v. 11, n. 5, p. 2111-2125, 2011.

BEHRENDT, A., WULFMEYER, V., HAMMANN, E., MUPPA, S. K., PAL, S. Profiles of second- to fourth-order moments of turbulent temperature fluctuations in the convective boundary layer : first measurements with rotational Raman lidar. Atmospheric Chemistry and Physics, 15, 5485-5500. https://doi.org/10.5194/acp-15-5485-2015, 2015.

BELL, M. L., DAVIS, D. L., FLETCHER, T. A retrospective assessment of mortality from the London smog episode of 1952: the role of influenza and pollution. Environmental Health Perspectives. 112(1), 6-8, 2004.

BIANCO, L., CIMINI, D., MARZANO, F. S.,WARE, R. Combining microwave radiometer and wind profiler radar measurements for high-resolution atmospheric humidity profiling. Journal of Atmospheric and Oceanic Technology, 22: 949-965, 2005.

BOERS, R. AND ELORANTA, E. W. Lidar Measurements of the Atmospheric Entrainment Zone and the Potential Temperature Jump Across the Top of the Mixed Layer. Boundary-Layer Meteorology, 34, 357-37, 1986.

BRAVO-ARANDA, J. A., MOREIRA, G. DE A., NAVAS-GUZMÁN, F., GRANADOSMUÑOZ, M. J., GUERRERO-RASCADO, J. L., POZO-VÁZQUEZ, D., ARBIZUBARRENA, C. A new methodology for PBL height estimations based on lidar depolarization measurements: analysis and comparison against MWR and WRF model-based results. 
Atmospheric Chemistry and Physics, 17, 6839-6851. https://doi.org/10.5194/acp-17-6839$201,2017$.

BROOKS, I. M. Finding Boundary Layer Top: Application of a Wavelet Covariance Transform to Lidar Backscatter Profiles. Journal of Atmospheric and Oceanic Technology, 20(8), 1092 1105. http://doi.org/10.1175/1520-0426(2003)020<1092:FBLTAO>2.0.CO;2, 2003.

CAICEDO, V., RAPPENGLÜCK, B., LEFER, B., MORRIS, G., TOLEDO, D., DELGADO, R. Comparison of aerosol lidar retrieval methods for boundary layer height detection using ceilometer aerosol backscatter data. Atmospheric Measurement Techniques, 10, 1609-1622. https://doi.org/10.5194/amt-10-1609-2017, 2017.

CAUMONT, O., CIMINI, D., LÖHNERT, U., ALADOS-ARBOLEDAS, L., BLEISCH, R., BUFFA, F., FERRARIO, M.E., HAEFELE, A., HUET, T., MADONNA, F., PACE, G. Assimilation of humidity and temperature observations retrieved from ground-based microwave radiometers into a convective-scale NWP model. Quarterly Journal of the Royal Meteorological Society, 142 (700), pp. 2692-2704, 2016.

CAZORLA, A., CASQUERO-VERA, J. A., ROMÁN, R., GUERRERO-RASCADO, J. L., TOLEDANO, C., CACHORRO, V. E., ORZA, J. A. G., CANCILlO, M. L., SERRANO, A., TITOS, G., PANDOLFI, M., ALASTUEY, A., HANRIEDER, N., AND ALADOSARBOLEDAS, L. Near-real-time processing of a ceilometer network assisted with sunphotometer data: monitoring a dust outbreak over the Iberian Peninsula. Atmospheric Chemistry and Physics, 17, 11861-11876, https://doi.org/10.5194/acp-17-11861-2017, 2017.

CIMINI, D., ANGELIS, F. DE, DUPONT, J.-C., PAL, S., HAEFFELIN, M. Mixing layer height retrievals by multichannel microwave radiometer observations. Atmospheric Measurements Techniques, 6, 2941-2951. http://doi.org/10.5194/amt-6-2941-2013, 2013.

CIMINI, D., NELSON, M., GÜLDNER, J., WARE, R. Forecast indices from ground-based microwave radiometer for operational meteorology. Atmospheric Measurement Techniques, 8, 315-333, https://doi:10.5194/amt-8-315-2015, 2015.

CHEN, X., SKERLAK, B., ROTACH, M. W., AÑEL, J. A., SU, Z., MA, Y., LI, M. Reasons for the extremely high-ranging planetary boundary layer over the western tibetan plateau in winter. American Meteorological Society, https://doi:10.1175/JAS-D-15-0148.1, 2016. 
COEN, M. C., PRAZ, C., HAEFELE, A., RUFFIEUX, D., KAUFMANN, P., CALPINI, B. Determination and climatology of the planetary boundary layer height above the Swiss plateau by in situ and remote sensing measurements as well as by the COSMO-2 model. Atmospheric Chemistry and Physics, 14, 13205-13221. https://doi.org/10.5194/acp-14-13205-2014, 2014.

COMPTON, J. C., DELGADO, R., BERKOFF, T. A., HOFF, R. M. Determination of Planetary Boundary Layer Height on Short Spatial and Temporal Scales: A Demonstration of the Covariance Wavelet Transform in Ground-Based Wind Profiler and Lidar Measurements. Journal of Atmospheric and Oceanic Technology, 30(7), 1566-1575. http://doi.org/10.1175/JTECH-D-12-00116.1, 2013.

CÓRDOBA-JABONERO, C., SORRIBAS, M., GUERRERO-RASCADO, J.L., ADAME, J.A., HERNÁNDEZ, Y., LYAMANI, H., CACHORRO, V., GIL, M., ALADOSARBOLEDAS, L., CUEVAS, E., DE LA MORENA, B. Synergetic monitoring of Saharan dust plumes and potential impact on surface: A case study of dust transport from Canary Islands to Iberian Peninsula. Atmospheric Chemistry and Physics, 11, 7, 3067-3091, 2011.

COSTA, C. Mais de 3 décadas após "Vale da Morte", Cubatão volta a lutar contra alta na poluição. BBC Brasil, 10 $0^{\text {th }}$ March 2017. Available in: http://www.bbc.com/portuguese/brasil39204054. Accessed on: 30 $0^{\text {th }}$ December 2017.

DAVIS, K. J., GAMAGE, N., HAGElBERG, C. R., KIEMle, C., LENSCHOW, D. H., SUlLIVAN, P. P. An Objective Method for Deriving Atmospheric Structure from Airborne Lidar Observations. Journal of Atmospheric and Oceanic Technology, 17(11), 1455-1468, http://doi.org/10.1175/1520-0426(2000)017<1455:AOMFDA>2.0.CO, 2000.

DE TOMASi, F., MiglietTA, M. M., PERRONE, M. R. The Growth of the Planetary Boundary Layer at a Coastal Site: a Case Study. Boundary-Layer Meteorology, 139(3), 521541. http://doi.org/10.1007/s10546-011-9592-6, 2011.

DEARDORFF, J. W., WILLIS, G. E., STOCKTON, B. H. Laboratory studies of the entrainment zone of a convectively mixed layer. Journal of Fluid Mechanichs, 100, 41-64, 1980.

DI GIUSEPPE, F., RICCIO, A., CAPORASO, L., BONAFÉ, G., GOBBI, G. P., ANGELINI, F. Automatic detection of atmospheric boundary layer height using ceilometer backscatter data 
assisted by a boundary layer model. Quarterly Journal of the Royal Meteorological Society, 138, 649-663. https://doi.org/10.1002/qj.964, 2012.

EMEIS, S. Surface-Based Remote Sensing of the Atmospheric Boundary Layer. Springer, 2011.

ENGELMANN, R., WANDINGER, U., ANSMANN, A., MÜLLER, D., ŽEROMSKIS, E., ALTHAUSEN, D., WEHNER, B. Lidar Observations of the Vertical Aerosol Flux in the Planetary Boundary Layer. Journal of Atmospheric and Oceanic Technology, v. 25, n. 8, p. 1296-1306, 2008.

ERESMAA, N., KARPPINEN, A., JOFFRE, S. M., RÄSÄNEN, J., AND TALVITIE, H. Mixing height determination by ceilometer. Atmospheric Chemistry and Physics, 6, 14851493, 2006.

ERESMAA, N., HÄRKÖNEN, J., JOFFRE, S. M., SCHULTZ, D. M., KARPPINEN, A., KUKKONEN, J. A three-step method for estimating the mixing height using ceilometer data from the Helsinki testbed. Journal of Applied Meteorology and Climatology, 51, 2172-2187, 2012.

FLAMANT, C., PELON, J., FLAMANT, P. H., DURAND, P. Lidar determination of the entrainment zone thickness at the top of the unstable marine atmospheric boundary layer. Boundary-Layer Meteorology, 83, 247-284, doi:10.1023/A:1000258318944, 1997.

GARRATT, J. R. The Atmospheric Boundary Layer. Cambridge University Press, 1992.

GRANADOS-MUÑOZ， M. J., NAVAS-GUZMÁN， F., BRAVO-ARANDA， J. A., GUERRERO-RASCADO, J. L., LYAMANI, H., FERNÁNDEZ-GÁLVEZ, J., ALADOSARBOLEDAS, L. Automatic determination of the planetary boundary layer height using lidar: One-year analysis over southeastern Spain. Journal of Geophysical Research, 117(D18), n/an/a. https://doi.org/10.1029/2012JD01752, 2012.

GRANADOS-MUÑOZ M.J, NAVAS-GUZMÁN， F., BRAVO-ARANDA， J. A., GUERRERO-RASCADO, J. L., LYAMANI, H., VALENZUELA, A., TITOS, G., FERNÁNDEZ-GÁLVEZ, J., ALADOS-ARBOLEDAS, L. Hygroscopic growth of atmospheric aerosol particles based on active remote sensing and radiosounding measurements: selected cases in southeastern Spain. Atmospheric Measurement Techniques, 8, 705-718, 2015. 
GRANADOS-MUÑOZ, M.J., BRAVO-ARANDA， J.A., BAUMGARDNER, D., GUERRERO-RASCADO， J.L., PÉREZ-RAMÍREZ， D., NAVAS-GUZMÁN， F., VESELOVSKII, I., LYAMANI, H., VALENZUELA, A., OLMO, F.J., TITOS, G., ANDREY, J., CHAIKOVSKY, A., DUBOVIK, O., GIL-OJEDA, M., ALADOSARBOLEDAS, L. A comparative study of aerosol microphysical properties retrieved from ground-based remote sensing and aircraft in situ measurements during a Saharan dust event. Atmospheric Measurement Techniques, 9, 3, 1113-1133, 2016.

GUERRERO-RASCADO, J. L., RUIZ, B., ALADOS-ARBOLEDAS, L. Multi-spectral Lidar characterization of the vertical structure of Saharan dust aerosol over southern Spain. Atmospheric Environment, 42, 11, 2668-268, 2008a.

GUERRERO-RASCADO, J.L., RUIZ, B., CHOURDAKIS, G., GEORGOUSSIS, G., AND ALADOS-ARBOLEDAS, L. One year of water vapor Raman lidar measurements at the Andalusian Centre for Environmental Studies (CEAMA). International Journal of Remote Sensing, 29, 5437-5453, 2008b.

GUERRERO-RASCADO， J.L., OLMO，F.J., AVILÉS-RODRÍGUEZ， I., NAVASGUZMÁN, F., PÉREZ-RAMÍREZ, D., LYAMANI, H., ALADOS-ARBOLEDAS, L. Extreme Saharan dust event over the southern Iberian Peninsula in September 2007: Active and passive remote sensing from surface and satellite. Atmospheric Chemistry and Physics, 9, 21, 8453-8469, 2009.

GUERRERO-RASCADO, J.L., COSTA, M. J., BORTOLI, D., SILVA, A.M., LYAMANI, H., ALADOS-ARBOLEDAS, L. Infrared lidar overlap function: An experimental determination, Optics Express, Volume 18, Issue 19, 13 , 20350-20359, 2010

GUERRERO-RASCADO, J.L., ADAME, J.A., HERNÁNDEZ, Y., LYAMANI, H., CACHORRO, V., GIL, M., ALADOS-ARBOLEDAS, L., CUEVAS, E., DE LA MORENA, B. Synergetic monitoring of Saharan dust plumes and potential impact on surface: A case study of dust transport from Canary Islands to Iberian Peninsula. Atmospheric Chemistry and Physics, 11, 7, 3067-3091, 2011 a.

GUERRERO-RASCADO, J. L., MÜLLER, D., NAVAS-GUZMÁN, F., PÉREZ-RAMÍREZ, D., ALADOS-ARBOLEDAS, L. First results of aerosol microphysical properties by $3+2$ raman lidar at earlinet granada station. Romanian Reports of Physics, Volume 56, Issue 3-4, $467-475,2011 b$. 
HAEFFELIN, M., ANGELINI, F., MORILLE, Y., MARTUCCI, G., FREY, S., GOBBI, G. P., LOLLI, S., O’DOWD, C. D., SAUVAGE, L., XUEREF- RÉMY, L., WASTINE, B., FEIST, D. G. Evaluation, of mixing- height retrievals from automatic profiling lidars and ceilometers in view of future integrated networks in Europe. Boundary-Layer Meteorology, 143, 49-75, 2012.

HAIJ M, WAUBEN W, KLEIN BALTINK H. Continuous mixing layer height determination using the LD-40 ceilometer: a feasibility study. KNMI scientific report, Royal Netherlands Meteorological Institute. Hennemuth, 2007.

HAMAN, C. L., LEFER, B., MORRIS, G. A. Seasonal variability in the diurnal evolution of the boundary layer in a Near-Coastal: Urban environment. Journal of Atmospheric and Oceanic Technology, 29(5), 697-710. https://doi.org/10.1175/JTECH-D-11-00114.1, 2012.

HE, Q. S., MAO, J. T., CHEN, J. Y., HU, Y. Y. Observational and modeling studies of urban atmospheric boundary-layer height and its evolution mechanisms. Atmospheric Environment, 40(6), 1064-1077. https://doi.org/10.1016/j.atmosenv.2005.11.016, 2006.

HELMIS C. G., SGOUROS, G., TOMBROU, M., SCHÄFER, K., MÜNKEL, C., BOSSIOLI E., DANDOU, A. A comparative study and evaluation of mixing-height estimation based on sodar-RASS, ceilometer data and numerical model simulations. Boundary-Layer Meteorology, 145:507-526, 2012.

HENNEMUTH, B., LAMMERT, A. Determination of the atmospheric boundary layer height from radiosonde and lidar backscatter. Boundary Layer Meteorology, 120, $181-200$. https://doi.org/ 10.1007/s10546-005-9035-3, 2006.

HOLZWORTH, C. G. Estimates of mean maximum mixing depths in the contiguous United States. Monthly Weather Review, 92, 235-242, 1964.

HOOPER, W. P., ELORANTA, E. W. Lidar measurements of wind in the planetary boundary layer: the method, accuracy, and results from joint measurements with radiosonde and kytoon. Journal of Applied Meteorology and Climatology, 25, 990-1001, 1986.

IGAMI, M. P. Z. (Org) ; VIEIRA, M. M. F.(Org.) Guia para a elaboração de teses e dissertações: programa de Pós-graduação Tecnologia Nuclear - IPEN/USP . 3 ed. São Paulo: Instituto de Pesquisas Energéticas e Nucleares, 2017. Disponível em: $<$ https://intranet.ipen.br/portal_por/conteudo/biblioteca/arquivos/NOVO_GUIA_TESES_E DISSERTACOES.pdf $>$ Acesso em: 31/12/2017 
INSTITUTO BRASILEIRO DE GEOGRAFIA E ESTATÍSTICA (IBGE). Available in: https://www.ibge.gov.br/geociencias-novoportal/organizacao-do-territorio/estruturaterritorial/15761-areas-dos-municipios.html?t=destaques $\& \mathrm{c}=3550308 . \quad$ Accessed on $30^{\text {th }}$ December 2017.

INSTITUTO NACIONAL DE ESTADÍSTICA (INE). Available in: http://www.ine.es/dyngs/INEbase/es/categoria.htm?c=Estadistica_P\&cid=1254734710990. Accessed on $30^{\text {th }}$ December 2017.

INSTITUTO NACIONAL DE METEOROLOGIA (INMET). Available in: http://www.inmet.gov.br/portal/index.php? $\mathrm{r}=$ estacoes/estacoesConvencionais. Accessed on $30^{\text {th }}$ December 2017.

IPCC 2015. IPCC Climate Change 2014 - Synthesis Report. Intergovernmental Panel on Climate Change - IPCC. Available in: http://www.ipcc.ch.

KAIMAL, J. C., GAYNOR, J. E. The Boulder Atmospheric Observatory. Journal of Applied Meteorology and Climatology, 22, 863-880, 1983.

KAMP, D. VAN DER, MCKENDRY, I. Diurnal and Seasonal Trends in Convective MixedLayer Heights Estimated from Two Years of Continuous Ceilometer Observations in Vancouver, BC. Boundary-Layer Meteorology, 137(3), 459-475, https://doi.org/10.1007/s10546-010-9535-7, 2010.

KIEMLE, C., BREWER, W. A., EHRET, G., HARDESTY, R. M., FIX, A., SENFF, C., WIRTH, M., POBERAJ, G., LEMONE, M. A. Latent heat flux profiles from collocated airborne water vapor and wind lidars during IHOP 2002. Journal of Atmospheric Oceanic Technology, 24, 627-639, 2007

KIM, D.-K., LEE, D.-I. Atmospheric thickness and vertical structure properties in wintertime precipitation events from microwave radiometer, radiosonde and wind profiler observations. Meteorological Applications, 22(3), 599-609. https://doi.org/10.1002/met.1494, 2015.

KETTERER, C., ZIEGER, P., BUKOWIECKI, N., COLLAUD COEN, M., MAIER, O., RUFFIEUX, D., WEINGARTNER, E. Investigation of the Planetary Boundary Layer in the Swiss Alps Using Remote Sensing and In Situ Measurements. Boundary-Layer Meteorology, 151(2), 317-334. https://doi.org/10.1007/s10546-013-9897-8, 2014. 
KONG, W., YI, F. Convenctive boundary layer evolution from lidar backscatter and its relationship with surface aerosol concentration at a location of a central China megacity. Journal of Geophysiscal Research, 120, 7928-7940. http://doi.org/10.1002/2015JD023248, 2015.

KORHONEN, K., GIANNAKAKI, E., MIELONEN, T., PFÜllER, A., LAAKSO, L., VAKKARI, V., BAARS, H., ENGELMANN, R., BEUKES, J. P., VAN ZYL, P. G., RAMANDH, A., NTSANGWANE, L., JOSIPOVIC, M., TIITTA, P., FOURIE, G., NGWANA, I., CHILOANE, K., KOMPPULA, M. Atmospheric boundary layer top height in South Africa: measurements with lidar and radiosonde compared to three atmospheric models. Atmospheric Chemistry and Physics, 14(8), 4263-4278. https://doi.org/10.5194/acp-14-4263$2014,2014$.

KOVAleV, A. V., EICHINGER, E. W. Elastic Lidar: Theory, Practice and Analysis Methods. Willey Interscience, 2004.

KUNZI, K., BAUER, P., ERESMAA, R., ERIKSSON, P., HEALY, S. B., MUGNAI, A., LIVESEY, N., PRIGENT, C., SMITH, E. A., STEPHENS, G. Microwave absorption, emission and scattering: trace gases and meteorological paremeters. In: BURROWS, J. P., PLATT, U., BORRELL, P. (Ed.). The Remote sensing of Tropospheric Composition from Space. Springer Verlag, Heidelberg, Vol. 1, p.153-230.

LANGE, D., TIANA-ALSINA, J., SAEED, U., TOMÁS, S., ROCADENBOSCH, F. Using a Kalman Filter and Backscatter Lidar Returns. IEEE Transactions on Geoscience and Remote Sensing, 52(8), 4717-4728, 2014.

LENSCHOW, D. H., WYNGAARD, J. C., PENNELL, W. T. Mean Field and Second-Moment Budgets in a Baroclinic, Convective Boundary Layer. Journal of the Atmospheric Sciences, 37, 1313-1326, doi:10.1175/1520-0469(1980)0372.0.CO;2, 1980.

LENSCHOW, D. H., MANN, J., KRISTENSEN, L. How long is long enough when measuring fluxes and other turbulence statistics? Journal of Atmospheric Oceanic Technology, 11, 661673, 1994.

LENSCHOW, D. H., WULFMEYER, V., SENFF, C. Measuring second- through fourth-order moments in noisy data. Journal of Atmospheric Oceanic Technology, 17, 1330-1347, 2000.

LENSCHOW, D., LOTHON, M., MAYOR, S., SULLIVAN, P., CANUT, G. A Comparison of Higher-Order Vertical Velocity Moments in the Convective Boundary Layer from Lidar with 
In Situ Measurements and Large-Eddy Simulation. Boundary-Layer Meteorology, 143, 107123, doi:10.1007/s10546-011-9615-3, 2012.

LI, H., YANG, Y., HU, X.-M., HUANG, Z., WANG, G., ZHANG, B., ZHANG, T. Evaluation of retrieval methods of daytime convective boundary layer height based on lidar data. Journal of Geophysical Research, 1-16, http://doi.org/10.1002/2016JD025620, 2017.

LOPES, F. J. S., MOREIRA, G. A., RODRIGUES, P. F., GUERRERO-RASCADO, J. L., ANDRADE, M. F., LANDULFO, E. Comparison between two algorithms based on different wavelets to obtain the planetary boundary layer height. Proc. SPIE 9246, Lidar Technologies, Techniques, and Measurements for Atmospheric Remote Sensing X, 92460H, doi: 10.1117/12.2067352, 2014.

LOTHON, M., LENSCHOW, D. H., AND MAYOR, S. D. Coherence and scale of vertical velocity in the convective boundary layer from a Doppler lidar. Boundary-Layer Meteorology, 121, 521-536, 2006.

LYAMANI, H., OLMO, F. J., ALCÁNTARA, A., AND ALADOS-ARBOLEDAS, L. Atmospheric aerosols during the 2003 heat wave in southeastern Spain I: Spectral optical depth. Atmospheric Environment, 40, 6453-6464, 2006a.

LYAMANI, H., OLMO, F. J., ALCÁNTARA, A., AND ALADOS-ARBOLEDAS, L. Atmospheric aerosols during the 2003 heat wave in southeastern Spain II: microphysical columnar properties and radiative forcing. Atmospheric Environment, 40, 6465-6476, 2006b. LYAMANI, H., OLMO, F. J., AND ALADOS-ARBOLEDAS, L. Physical and optical properties of aerosols over an urban location in Spain: seasonal and diurnal variability. Atmospheric Chemistry and Physics, 10, 239-254, doi:10.5194/acp-10-239-2010, 2010.

LYAMANI，H., FERNÁNDEZ-GÁLVEZ，J. PÉREZ-RAMÍREZ，D., VALENZUELA, A.,ANTÓN, M., AlADOS, I., TITOS, G., OLMO, F.J., ALADOS-ARBOLEDAS, L. Aerosol properties over two urban sites in South Spain during an extended stagnation episode in winter season. Atmospheric Environment, 62, 424-432, 2012.

MARQUES, M. T. A. Medições de velocidade e direção do vento com LIDAR e SODAR em terrenos complexo para aplicações em energia eólica e impacto ambiental de instalações nucleares. Dissertation (Master Degree). Institute of Research and Nuclear Energy, University of São Paulo, 2017. 
MARTUCCI, G., MATTHEY, R., MITEV, V., RICHNER, H. Comparison between Backscatter Lidar and Radiosonde Measurements of the Diurnal and Nocturnal Stratification in the Lower Troposphere. Journal of Atmospheric and Oceanic Technology, 24(7), 1231-1244. http://doi.org/10.1175/JTECH2036.1, 2007.

MCNICHOLAS, C., TURNER, D. D. Characterizing the convective boundary layer turbulence with a High Spectral Resolution Lidar. Journal of Geophysical Research, 119, 910-927, 2014.

MELFI, S. H., SPINHIRNE J. D., CHOU, S. H., PALM, S. P. Lidar observations of vertically organized convection in the planetary boundary layer over the ocean. Journal of Applied Meteorology and Climatology, 24(8):806-821, 1985.

MENUT, L., FLAMANT, C., PELON, J., FLAMANT, P. H. Urban boundary layer height determination from lidar measurements over the Paris area. Applied Optics, 38, 945-954, 1999. MONIN, A. S., YAGLOM, A. M. Statistical Fluid Mechanics. Vol. 2. MIT Press, 874 pp, 1979.

MOREIRA, G. DE A., MARQUES, M. T. A., NAKAEMA, W., MOREIRA, A. C. DE C. A., LANDULFO, E. Planetary boundary height estimations from Doppler wind lidar measurements, radiosonde and hysplit model comparisom. Óptica Pura y Aplicada, 48, 179183,2015

MORILlE, Y., HAEFFELIN, M., DROBINSKI, P., PELON, J. STRAT: An Automated Algorithm to Retrieve the Vertical Structure of the Atmosphere from Single-Channel Lidar Data. Journal of Atmospheric and Oceanic Technology, 24(5), 761-775. http://doi.org/10.1175/JTECH2008.1, 2007.

MÜNKEL, C., ERESMAA, N., RÄSÄNEN, J., AND KARPPINEN, A. Retrieval of mixing height and dust concentration with lidar ceilometer. Boundary-Layer Meteorology, 124, 117 128, doi:10.1007/s10546-006-9103-3, 2007.

MUPPA, K. S., BEHRENDT, A., SPÄTH, F., WULFMEYER, V., METZENDORF, S., RIEDE, A. Turbulent humidity fluctuations in the convective boundary layer: Cases studies using water vapour differential absorption lidar measurements. Boundary-Layer Meteorology, 158, 43-66, DOI 10.1007/s10546-015-0078-9, 2014. 
NAVAS GUZMÁN, F., GUERRERO RASCADO, J. L., AND ALADOS ARBOLEDAS, L. Retrieval of the lidar overlap function using Raman signals. Óptica Pura y Aplicada, 44, 71$75,2011$.

NAVAS-GUZMÁN， F., BRAVO-ARANDA， J.A., GUERRERO-RASCADO, J.L, GRANADOS-MUÑOZ, M.J, AND ALADOS-ARBOLEDAS, L. Statistical analysis of aerosol optical properties retrieved by Raman lidar over Southeastern Spain. Tellus B, 65, 21234, 2013. NAVAS-GUZMÁN， F., FERNÁNDEZ-GÁlVEZ， J., GRANADOS-MUÑOZ， M.J, GUERRERO-RASCADO, J.L., BRAVO-ARANDA, J.A., AND ALADOS-ARBOLEDAS, L. Tropospheric water vapor and relative humidity profiles from lidar and microwave radiometry. Atmospheric Measurement Techniques, 7, 1201-1211, 2104.

NEPOMUCENO, P. S., PREIßLER, J., GUERRERO-RASCADO, J.L., SILVA, A.M., WAGNER, F. Forest fire smoke layers observed in the free troposphere over Portugal with a multiwavelength Raman lidar: Optical and microphysical properties. Scientific World Journal, Volume 2014, Article number 421838, 2014.

O’CONNOR, E. J., ILLINGWORTH, A. J., BROOKS, I. M., WESTBROOK, C. D., HOGAN, R. J., DAVIES, F., BROOKS, A. B. J. A method for estimating the turbulent kinetic energy dissipation rate from a vertically pointing doppler lidar, and independent evaluation from balloon-borne in situ measurements. Journal of Atmospheric and Oceanic Technology, v. 27, n. 10, p. 1652-1664, 2010.

ORTIZ-AMEZCUA， P., GUERRERO-RASCADO， J. L., GRANADOS-MUÑOZ， M. J., BRAVO-ARANDA, J. A., ALADOS-ARBOLEDAS, L. Characterization of atmospheric aerosols for a long range transport of biomass burning particles from canadian forest fires over the southern iberian peninsula in july 2013. Óptica Pura y Aplicada,47(1), pp. 43-49, 2014.

ORTIZ-AMEZCUA, P., GUERRERO-RASCADO, J. L., GRANADOS-MUÑOZ, M. J., BENAVENT-OLTRA, J. A., BÖCKMANN, C., SAMARAS, S., STACHLEWSKA, I. S., JANICKA, Ł., BAARS, H., BOHLMANN, S., ALADOS-ARBOLEDAS, L. Microphysical characterization of long-range transported biomass burning particles from North America at three EARLINET stations. Atmospheric Chemistry and Physics, 2017.

PAL, S., BEHRENDT, A., WULFMEYER, V. Elastic-backscatter-lidar-based characterization of the convective boundary layer and investigation of related statistics. Annales Geophysicae, 28(3), 825-847. http://doi.org/10.5194/angeo-28-825-2010, 2010. 
PAL, S., HAEFFELIN, M., BATCHVAROVA, E. Exploring a geophysical process-based attribution technique for the determination of the atmospheric boundary layer depth using aerosol lidar and near-surface meteorological measurements. Journal of Geophysical Research, 118(16), 9277-9295. https://doi.org/10.1002/jgrd.50710, 2013.

PAL, S., HAEFFELIN, M. Forcing mechanisms governing diurnal, seasonal, and interannual variability in the boundary layer depths: Five years of continuous lidar observations over a suburban site near Paris. Journal of Geophysical Research, 120, 11,936-11,956, doi:10.1002/2015JD023268, 2015.

PAPALARDO, G., AMODEO, A., APITULEY, A., COMERON, A., FREUDENTHALER, V., LINNÉ, H., ANSMANN, A., BÖSENBERG, J., D'AMICO, G., MATTIS, I., MONA, L., WANDINGER, U., AMIRIDIS, V., ALADOS-ARBOLEDAS, L., NICOLAE, D., AND WIEGNER, M. EARLINET: towards an advanced sustainable European aerosol lidar network. Atmospheric Measurement Techniques, 7, 2389-2409, doi:10.5194/amt-7-2389-2014, 2014.

PREIßLER, J., WAGNER, F., GUERRERO-RASCADO, J. L., SILVA, A. M. Two years of free-tropospheric aerosol layers observed over Portugal by lidar. Journal of Geophysical Research, Volume 118, Issue 9, 16, 3676-3686, 2013.

POLTERA, Y., MARTUCCI, G., COEN, M. C., HERVO, M., EMMENEGGER, L., HENNE, S., BRUNNER, D., HAEFELE, A. PatjfinderTURB: an automatic boundary layer algorithm. Development, validation and application to study the impact on in situ measurements at the Jungfraujoch. Atmospheric Chemistry and Physics, 17, 10051-10070, https://doi.org/10.5194/acp-17-10051-2017, 2017.

ROSE, T., CREEWLL, S., LÖHNERT, U., SIMMER, C. A network suitable microwave radiometer for operational monitoring of cloudy atmosphere. Atmospheric Research, Vol. 75, No. 3, $183-200,2005$.

SEIDEL, D. J., ZHANG, Y., BELJAARS A., GOLAZ J., JACOBSON, A. R., MEDEIROS, B. Climatology of the planetary boundary layer over the continental United States and Europe. Journal of Geophysical Research, Vol. 117, D17106, doi:10.1029/2012JD018143, 2012.

SCHWEEN, J. H., HIRSIKKO, A., LÖHNERT, U., CREWELL, S. Mixing-layer height retrieval with ceilometer and Doppler lidar: from case studies to long-term assessment. Atmospheric Measurement Techniques, 7(11), 3685-3704. https://doi.org/10.5194/amt-73685-201, 2014. 
SICARD, M., MOLERO, F., GUERRERO-RASCADO, J.L., PEDROS, R., EXPOSITO, F.J., CORDOBA-JABONERO, C., BOLARIN, J.M., COMERON, A., ROCADENBOSCH, F., PUJADAS, M., ALADOS-ARBOLEDAS, L., MARTINEZ-LOZANO, J.A., DIAZ, J.P., GIL, M., REQUENA, A., NAVAS-GUZMAN, F., MORENO, J.M. Aerosol lidar intercomparison in the framework of SPALINET: The Spanish lidar network: Methodology and results. IEEE Transactions on Geoscience and Remote Sensing, 47, 10, October 2009, Article number 25, Pages 3547-3559, 2009.

STEYN, D. G., BALDI, M., HOFF, R. M. The detection of mixed layer depth and entrainment zone thickness from lidar backscatter profiles. Journal of Atmospheric and Oceanic Technology, 16, 953-959, 1999.

SKOU, N., VINE, D. M. L., Microwave Radiometer Systems: Design and Analysis, Artech House, $2^{\text {nd }}$ edition, 2006.

STACHLEWSKA, I. S., PIĄDŁOWSKI, M., MIGACZ, S., SZKOP, A., ZIELIŃSKA, A. J., SWACZYNA, P. L. Ceilometer Observations of the Boundary Layer over Warsaw, Poland. Acta Geophysica, Vol. 60, No. 5, 1386-1412, 2012

STULL, R. B. An Introduction to Boundary Layer Meteorology. vol. 13, Kluwer Academic Publishers, the Netherlands, Dordrecht/Boston/London, 1988.

STULL, R. B. Meteorology for Scientists and Engineers. $3^{\text {rd }}$ Edition, Uni. Of British Columbia, 2011.

SUMMA, D., DI GIROLAMO, P., STELITANO, D., CACCIANI, M. Characterization of the planetary boundary layer height and structure by Raman lidar: comparison of different approaches. Atmospheric Measurement Techniques, 6(12), 3515-3525. http://doi.org/10.5194/amt-6-3515-2013, 2013.

TALIANU, C., NICOLAE, D., CIUCIU, J., CIOBANU, M., BABIN, V. Planetary boundary layer height detection from LIDAR measurements. Journal of Optoelectronics and Advanced Materials, 8(1), 243-246, 2006.

TITOS, G., FOYO-MORENO, I., LYAMANI, H., QUEROL, X., ALASTUEY, A., ALADOSARBOLEDAS, L. Optical properties and chemical composition of aerosol particles at an urban location: An estimation of the aerosol mass scattering and absorption efficiencies. Journal of Geophysical Research, 117, D04206, doi:10.1029/2011JD016671, 2012. 
TITOS, G., JEFFERSON, A., SHERIDAN, P. J., ANDREWS, E., LYAMANI, H., ALADOSARBOLEDAS, L., AND OGREN, J. A. Aerosol light-scattering enhancement due to water uptake during the TCAP campaign. Atmospheric Chemistry and Physics, 14, 7031-7043, doi:10.5194/acp-14-7031-7043,2014.

TITOS G., LYAMANI H., PANDOLFI M., ALASTUEY A., ALADOS-ARBOLEDAS L. Identification of fine (PM1) and coarse (PM10-1) sources of particulate matter in an urban environment. Atmospheric Environment, 89, 593-602, 2014.

TITOS, G., CAZORLA, A., ZIEGER, P., ANDREWS, E., LYAMANI, H., GRANADOSMUÑOZ, M. J., OLMO, F. J., ALADOS-ARBOLEDAS, L. Effect of hygroscopic growth on the aerosol light-scattering coefficient: A review of measurements, techniques and error sources. Atmospheric Environment, 141, 494-507, 2016.

TITOS, G., DEL ÁGUILA A., CAZORLA, A., LYAMANI, H., CASQUERO-VERA, J.A., COLOMBI, C., CUCCIA, E., GIANELLE, V., ALASTUEY, A., ALASDOS-ARBOLEDAS, L. Spatial and temporal variability of carbonaceous aerosols: assessing the impact of biomass burning in the urban environment. Science of the Total Environmental, 578: 613-625, [http://hdl.handle.net/10481/47096], 2017.

TSAKNAKIS, G., PAPAYANNIS, A., KOKKALIS, P., AMIRIDIS, V., KAM- BEZIDIS, H. D., MAMOURI, R. E., GEORGOUSSIS, G., AVDIKOS, G. Inter-comparison of lidar and ceilometer retrievals for aerosol and Planetary Boundary Layer profiling over Athens, Greece. Atmospheric Measurement Techniques, 4, 1261-1273, doi:10.5194/amt-4-1261-2011, 2011

TUCKER, S. C., SENFF, C. J., WEICKMANN, A. M., BREWER , W. A., BANTA, R. M., SANDBERG, S. P., LAW, D. C., HARDESTY, R. M. Doppler lidar estimation of mixing height using turbulence, shear, and aerosol profiles. Journal of Atmospheric and Oceanic Technology, 26,673-688, doi:10.1175/2008JTECHA1157.1, 2009

TURNER, D. D., FERRARE, R. A., WULFMEYER, V., SCARINO, A. J. Aircraft evaluation of ground-based Raman lidar water vapor turbulence profiles in convective mixed layers. Journal of Atmospheric and Oceanic Technology, 31, 1078-1088, doi:10.1175/JTECH-D-1300075-1, 2014

UZAN, L., EGERT, S., ALPERT, P. Ceilometer evaluation of the eastern Mediterranean summer boundary layer height - first study of two Israeli sites. Atmospheric Measurement Techniques, 9, 4387-4398, doi:10.5194/amt-9-4387-2016, 2016. 
VAN BAELEN J., AUBAGNAC, J. P., DABAS A. Comparison of near-real time estimates of integrated water vapor derived with GPS, radiosondes, and microwave radiometer. Journal of Atmospheric and Oceanic Technology, 22: 201-210, 2005.

VAN DER KAMP, D., MCKENDRY, I. Diurnal and seasonal trends in convective mixed-layer heights estimated from two years of continuous ceilometer observations in Vancouver, BC. Boundary-Layer Meteorology, 137, 459-475, 2010.

VAN ULDEN, A. P., WIERINGA, J. Atmospheric boundary layer research at Cabauw. Boundary-Layer Meteorology, 78,39-69, 1996.

VALENZUELA, A., OLMO, F.J.AB, LYAMANI, H.AB, GRANADOS-MUÑOZ, M.J.AB, ANTÓN, M.C, GUERRERO-RASCADO, J.L.AB, QUIRANTES, A.A, TOLEDANO, C.D, PEREZ-RAMÍREZ, D.EF, ALADOS-ARBOLEDAS, L. Aerosol transport over the western Mediterranean basin: Evidence of the contribution of fine particles to desert dust plumes over alborán island. Journal of Geophysical Research, 119, 24, 14,028-14,044, 2014.

VOGELMANN, A. M., MCFARQUHAR, G. M., OGREN, J. A., TURNER, D. D., COMSTOCK, J. M., FEINGOLD, G., LONG, C. N., JONSSON, H. H., BUCHOLTZ, A., COLLINS, D. R., DISKIN, G. S., GERBER, H., LAWSON, R. P., WOODS, R. K., ANDREWS, E., YANG, H., CHIU, J. C., HARTSOCK, D., HUBBE, J. M., LO, C., MARSHAK, A., MONROE, J. W., MCFARLANE, S. A., JASON, B. S., TOMLINSON, M., TOTO, T. RACORO extended-term aircraft observations of boundary layer clouds. Bulletin of the American Meteorological Society, 93, 861-878, doi:10.1175/BAMS-D-11$00189.1,2012$.

VORMITTAG, V., RODRIGUES, C. G., MIRANDA, M. J., CAVACALNTE, J. A., COSTA, R. R., CAMARGO, C. A., SALDIVA, P. Avaliação do impacto da poluição atmosférica no estado de São Paulo sob a visão da saúde. Instituto saúde e sustentabilidade, 2013.

WAGNER, P., SCHÄFER, K. Influence of mixing layer height on air pollutant concentrations in an urban street canyon. Urban Climate, 22, 64-79, doi:10.1016/j.uclim.2015.11.001, 2015.

WALLACE, J. M., HOBBS, P., Atmospheric Science: An Introductory Survey. Elsevier, 2005

WANG, Z., CAO, X., ZHANG, L., NOTHOLT, J., ZHOU, B., LIU, R., ZHANG, B. Lidar measurement of planetary boundary layer height and comparison with microwave profiling radiometer observation. Atmospheric Measurement Techniques, 5(8), 1965-1972. http://doi.org/10.5194/amt-5-1965-2012, 2012. 
WILLIAMS, A. G., HACKER, J. M. The composite shape and structure of coherent eddies in the convective boundary layer. Boundary-Layer Meteorology, 61, 213-245, 1992.

WILMONT, C. J. On the validation of models. Physical Geography, 2, 184-194, 1981.

WOODFORD, C. What is a pyranometer and what does it do? ExplaithatStuff!, $20^{\text {th }}$ July 2017. Available in: http://www.explainthatstuff.com/how-pyranometers-work.html. Accessed on 30 ${ }^{\text {th }}$ December 2017.

WULFMEYER, V. Investigation of turbulent processes in the lower troposphere with watervapor DIAL and radar-RASS. Journal of the Atmospheric Sciences, 56, 1055-1076, 1999.

WULFMEYER, V., PAL., S., TURNER, D. D., WAGNER, E. Can water vapour Raman lidar resolve profiles of turbulent variables in the con- vective boundary layer? Boundary- Layer Meteorology, 136, 253-284, doi:10.1007/s10546-010-9494-z, 2010

ZHU, X., TANG, G., HU, B., WANG, L., XIN, J., ZHANG, J., LIU, Z., MUNKEL, C., WANG, Y. Regional pollution and its formation mechanism over North China Plain: A case study with ceilometer observation and model simulations. Journal of Geophysical Research, 121, 14,574-14,588, doi:10.1002/ 2016JD025730, 2016. 


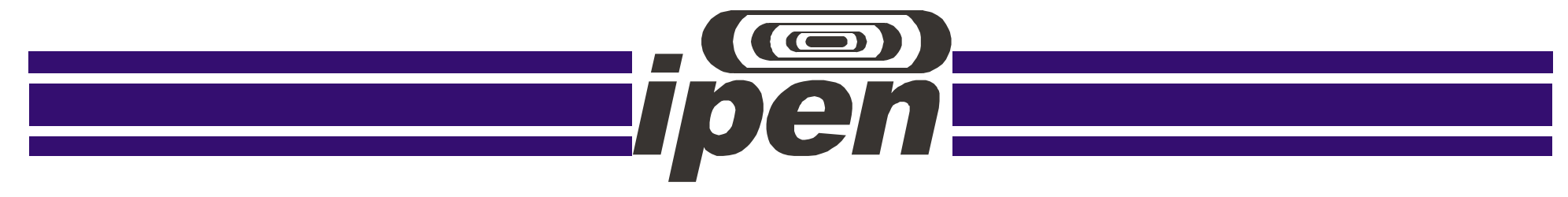

INSTITUTO DE PESQUISAS ENERGÉTICAS E NUCLEARES

Diretoria de Pesquisa, Desenvolvimento e Ensino

Av. Prof. Lineu Prestes, 2242 - Cidade Universitária CEP: 05508-000

Fone/Fax(0XX11) 3133-8908

SÃO PAULO - São Paulo - Brasil

http://www.ipen.br

O IPEN é uma Autaquia vinculada à Secretaria de Desenvolvimento, associada à Universiade de São Paulo e gerida técnica e administrativamente pela Comissão Nacional de Energia Nuclear, órgão do Ministério da Ciência, Tecnologia e Inovação. 